Portland State University

PDXScholar

1990

\title{
The Effectiveness of an Educational Service District's Programs and Services as Perceived by Various Educator Groups
}

Thomas Joseph Rockefeller

Portland State University

Follow this and additional works at: https://pdxscholar.library.pdx.edu/open_access_etds

Part of the Educational Leadership Commons, and the Other Educational Administration and Supervision Commons

Let us know how access to this document benefits you.

\section{Recommended Citation}

Rockefeller, Thomas Joseph, "The Effectiveness of an Educational Service District's Programs and Services as Perceived by Various Educator Groups" (1990). Dissertations and Theses. Paper 1374. https://doi.org/10.15760/etd.1373

This Dissertation is brought to you for free and open access. It has been accepted for inclusion in Dissertations and Theses by an authorized administrator of PDXScholar. Please contact us if we can make this document more accessible: pdxscholar@pdx.edu. 


\title{
THE EFFECTIVENESS OF AN EDUCATIONAL SERVICE DISTRICT'S \\ PROGRAMS AND SERVICES AS PERCEIVED BY \\ VARIOUS EDUCATOR GROUPS
}

\author{
by \\ THOMAS JOSEPH ROCKEFELLER
}

A dissertation submitted in partial fulfillment of the requirements for the degree of

\section{DOCTOR OF EDUCATION \\ in EDUCATIONAL LEADERSHIP: \\ EDUCATIONAL ADMINISTRATION AND SUPERVISION}

Portland State University

(C) 1990 
TO THE OFFICE OF GRADUATE STUDIES:

The members of the Committee approve the dissertation of Thomas Joseph Rockefeller presented June 29, 1990.
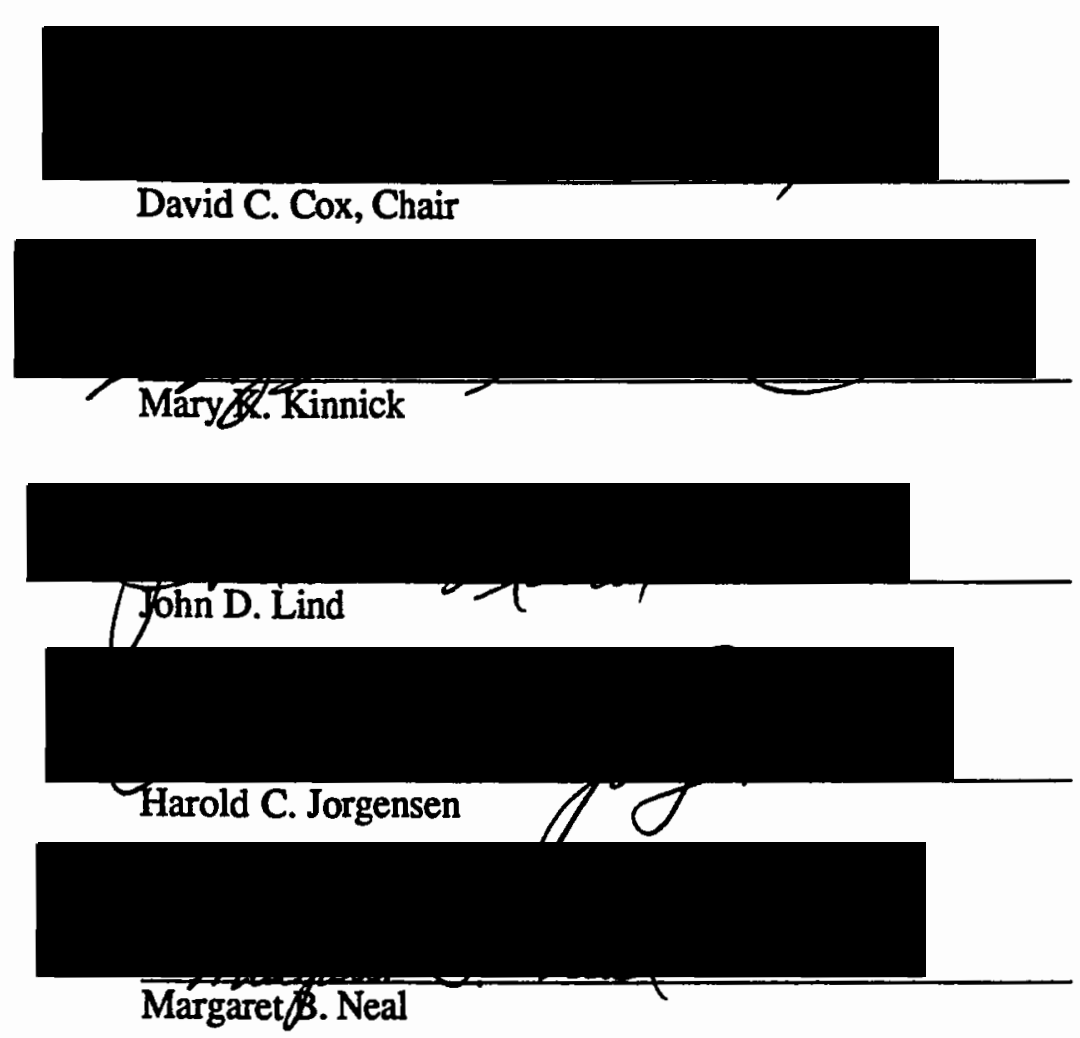

APPROVED:

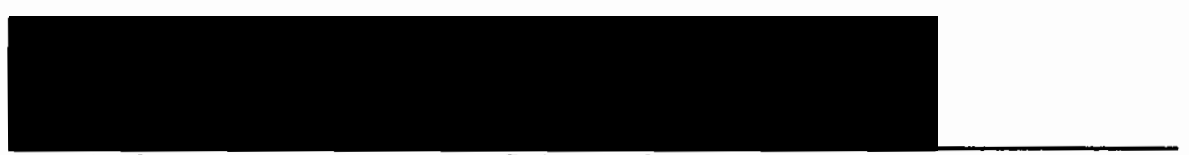

Robert B. Everhart, Dean, School of Education

C. William Savery, Interim Vice Provest for Graduate Studies and Research 
AN ABSTRACT OF THE DISSERTATION OF Thomas Joseph Rockefeller for the Doctor of Education in Educational Administration and Supervision presented June 29, 1990.

Title: The Effectiveness of an Educational Service District's Programs and Services as Perceived by Various Educator Groups.

APPROVED BY THE MEMBERS OF THE DISSERTATION COMMITTEE:
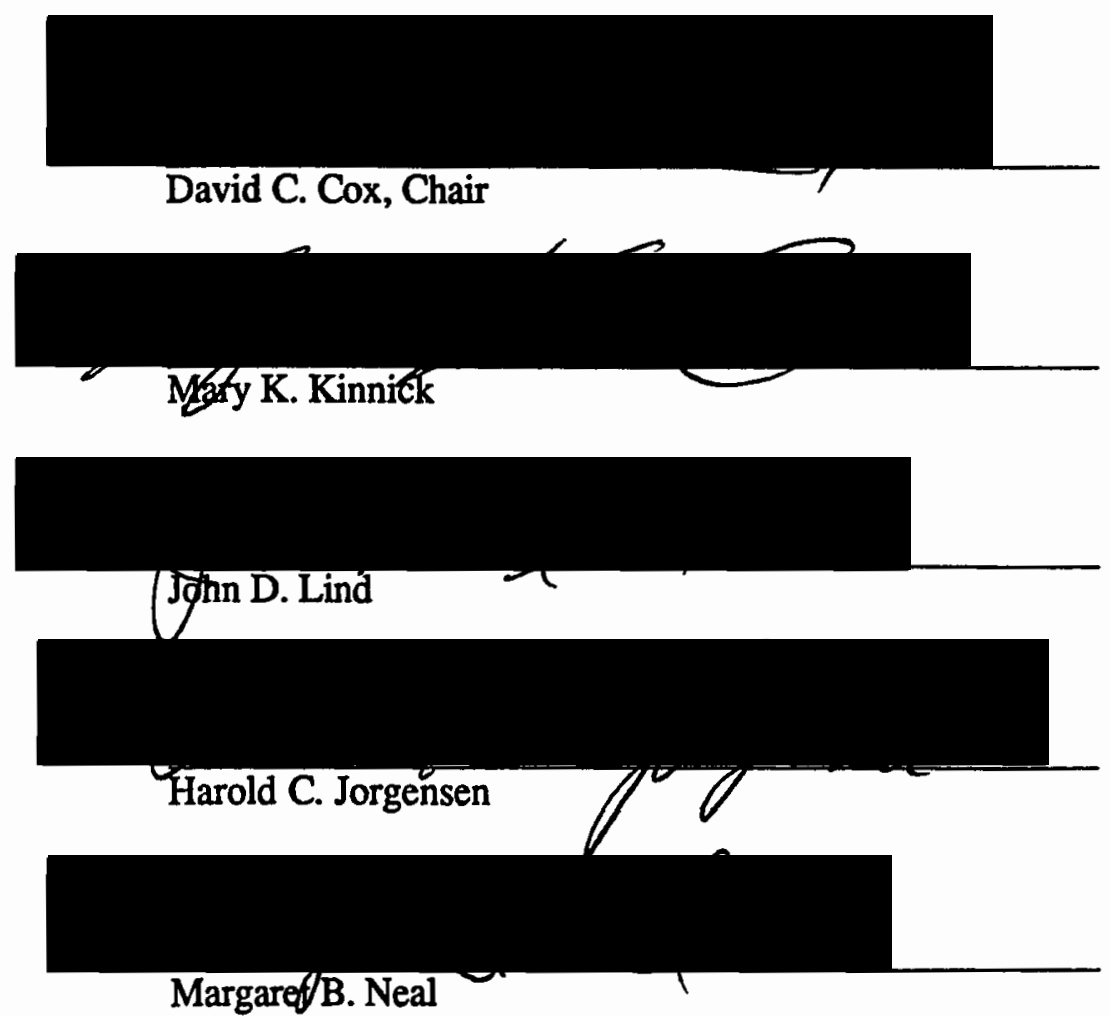

This study examined the effectiveness of an educational service district's programs and services as perceived by various educator groups. The population of the study included certificated public school employees and school board members. 
A sixty-two item survey instrument was used to obtain information from the study population. Of the 1507 survey instruments distributed, 769 instruments were retumed for a response rate of $51 \%$.

Four main research questions were posed: (a) Is Educational Service District 112 perceived as an effective educational component of the Southwest Washington public education system? (b) Are the programs and services provided by Educational Service District 112 perceived as effective by the educational community the regional office is designed to serve? (c) Are Educational Service District 112's services and programs perceived as effective by different characteristic, or demographic, groups? (d) What characteristics, both personal and professional, might influence differences in perceived program effectiveness?

Data were reported in terms of frequency distributions and means and were statistically analyzed using ANOVAs, ANCOVAs, multiple comparisons, and the Chi square test of significance.

The findings show that: (a) Educational Service District 112 is perceived overall as an effective organization. (b) Individual Instructional and Curriculum and Special Services programs and services are perceived as effective. (c) The vast majority of ESD 112's patrons do not have enough knowledge of individual programs and services to rate their effectiveness. (d) When grouping the respondents by different demographic characteristics, all characteristic groupings perceive ESD 112 as effective. (e) When the mean responses of position groups were found to differ significantly, the teacher group always rated ESD 112 as less effective than the group with which they differed, while the board member group always rated ESD 112 as more effective than the group with which they differed. (f) When various county location groups were found to differ significantly, Pacific County always rated ESD 112 as less effective than the group with which they 
differed. (g) Position appears to be the most influential characteristic affecting the patron's effectiveness rating of ESD 112's programs and services. 


\section{ACKNOWLEDGEMENTS}

I would like to extend my gratitude to those people who have been supportive, helpful, and concerned about me while pursuing this degree. I would like to thank the following groups of people:

-Dave Cox-my advisor, committee chairman, and friend, who always steered me the right way, kept me out of trouble, and gave me the right amount of time when I needed it the most.

-Mary Kinnick and John Lind, who were always willing to give a helping hand and good advice when it was needed.

-To Margaret Neal and Hal Jorgensen, for their help and support as committee members and manuscript advisors---especially Margaret's uncanny editing abilities.

-To Melinda Williamson, who appeared to always have the right answers.

-To Gregg and Mary Ford (and the girls) and Geral and Sharron Cox, for showing as much concern for my family as me.

-To Jack and Dorothy Rockefeller and Pat, Lois, John, Tim, Jane, Francis, Becca, and their families. Especially mom-for always saying the other person was in the wrong, that her son had no faults, and that I could achieve.

-To Joe, Becca, and David, my children, for making life worth living and bringing me an undefinable amount of joy and happiness.

-Most of all, to Pera Jo Bauer Rockefeller, my wife, for her all her love and confirmation. Her support and help over the last years have been the key(s) to the completion of this degree. 


\section{TABLE OF CONTENTS}

\section{PAGE}

ACKNOWLEDGEMENTS …................................................ iii

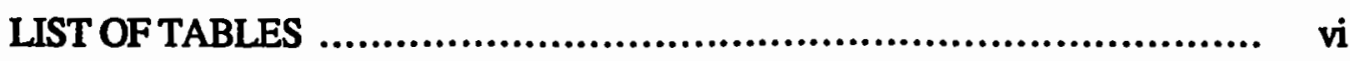

LIST OF FIGURES .......................................................... xvii

\section{CHAPTER}

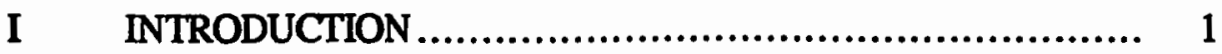

Statement of the Problem .................................. 5

Purpose of the Study ...................................... 6

General Methodology........................................... 9

Basic Assumptions.............................................. 11

Limitations .............................................. 13

Definition of Terms ..................................... 14

Organization of the Study ................................... 18

II REVIEW OF RELATED LITERATURE ......................... 19

Program Evaluation..................................... 21

The Practice of Program Evaluation ....................... $\quad 32$

Perception and Perceiving...................................... 41

Organizational Theory and the Educational Service District........................ 43

Program Evaluation and Educational Service Districts ...... 49

III METHODOLOGY .............................................. 58

Conceptual Framework ................................. 59

Study Population ....................................... 65 
Respondent Overview ..................................... 67

Survey Instrument ...................................... 69

Field Testing............................................. 72

Data Collection ............................................ 73

Data Analysis ............................................. 76

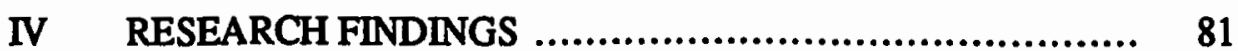

Demographic and General Information

Overview of Respondents.............. 83

General Effectiveness Rating Questions....................... 94

Specific Program and Service Rating Questions ........... 114

Primary Analysis.......................................... 144

Secondary Analysis...................................... 163

Demographic Analysis........................................... 174

V SUMMARY,CONCLUSIONS, AND RECOMMENDATIONS... 183

Summary of Research Findings........................... 185

Conclusions and Implications ........................... 198

Limitations ............................................ 206

Future Research ..................................... 208

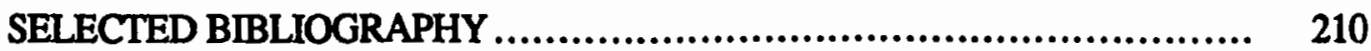

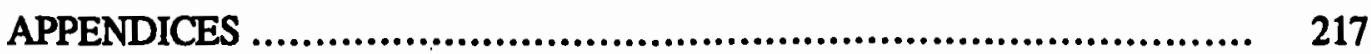

A SURVEY INSTRUMENT ..................................... 217

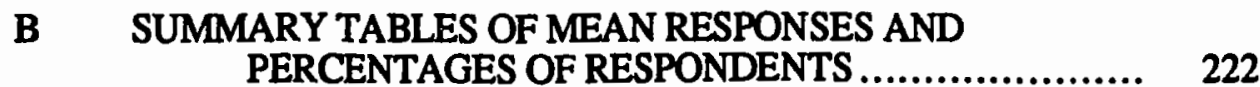

C INDIVIDUAL PROGRAM AND SERVICE DESCRIPTIONS .... 241 


\section{LST OF TABLES}

TABLE

PAGE

I Teacher to Student Ratios for High Schools, Middle Schools, and

Elementary Schools in Districtis with Two-Thousand-And-

One or More Students

II Survey Distribution and Return Rates in Actual Numbers and

Percentages by Aggregate Categories................................. 68

III Respondents Return Rates in Actual Numbers and Percent of

Total Surveys by Occupational Categories ............................. 69

IV Percentage of Respondents According to Five Position Groups

and Three Years of Experience in District Categories ............. 85

V Percentage of Respondents According to Five Position Groups

and Three Years of Experience in the State of Wash-

ington Categories................................................. 86

VI Percentage of Respondents According to Five Position Groups

and Five Different District Size Categories............................. 87

VII Percentage of Respondents According to Five Position Groups

and Six Different County Categories.................................. 89

VIII Percentage of Respondents According to Five Position Groups

and Four Different Degree Level Categories....................... 90

IX Total Group Rating Response Percentages Pertaining to ESD 112

and the Effectiveness of Providing Satisfactory and Relevant

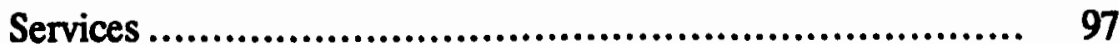


X Total Group Rating Response Percentages Pertaining to ESD 112

and the Effectiveness of Demonstrating Useful Knowledge and

Information

XI Total Group Rating Response Percentages Pertaining to ESD 112 and Effectiveness of Providing Services in a Timely Fashion...... 100

XII Total Group Rating Response Percentages Pertaining to ESD 112 and the Effectiveness of Meeting Needs of Patron Districts

Through Resources and Skills.

XIII Total Group Rating Response Percentages Pertaining to ESD 112 and the Effectiveness of Resources and Skills to Adjust to Individual Needs of Students, Teachers, and Districts

XIV Total Group Rating Response Percentages Pertaining to ESD 112 and the Effectiveness of Interpersonal Skills

XV Total Group Rating Response Percentages Pertaining to ESD 112 and the Effectiveness of Providing Services which Promote Teaching Processes in Classroom

XVI Total Group Rating Response Percentages Pertaining to ESD 112

Having the Skills to Productively Administer Programs and Services

XVII Total Group Rating Response Percentages Pertaining to ESD 112

Providing Useful Evaluations of Student and Personnel Involved in Programs and Services

XVIII Total Group Rating Response Percentages Pertaining to ESD 112 and the Effectiveness of the Organization's Overall Program........ 
XIX Total Group Response Percentages to Overall Knowledge of Specific ESD 112 Programs and Services in the Areas of Instruction and Curriculum and Special Services.......................

XX Total Group Rating Response Percentages Pertaining to ESD 112 and the Effectiveness of the Total Instructional and Curriculum

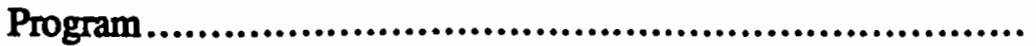

XXI Total Group Rating Response Percentages Pertaining to ESD 112 and the Effectiveness of the Instructional and Curriculum Division's Staff.......................................................

XXII Total Group Rating Response Percentages Pertaining to ESD 112 and the Effectiveness of the Communication Devices Concerning Curriulum and Instructional Programs and Services...................

XXIII Total Group Rating Response Percentages Pertaining to the Effectiveness of ESD 112 as an Information and Resource Center for Instructional and Curriculum Matters .....................

XXIV Total Group Rating Response Percentages Pertaining to ESD 112 and the Effectiveness of Inservices Provided in the Areas of Curriculum and Instruction

XXV Total Group Rating Response Percentages Pertaining to ESD 112 and the Effectiveness of the Services Provided by the Educational Technology Center..................................................

XXVI Total Group Rating Response Percentages Pertaining to ESD 112 and the Effectiveness of the Inservice Grant Committee

XXVII Total Group Rating Response Percentages Pertaining to ESD 112 and the Effectiveness of the Student Teacher Pilot Program......... 
XXVIII Total Group Rating Response Percentages Pertaining to ESD 112 and the Effectiveness of the Teacher Asssitance Program.............

XXIX Total Group Rating Response Percentages Pertaining to ESD 112 and the Effectiveness of the Whole Language Support Group ...... 124

XXX Total Group Rating Response Percentages Pertaining to ESD 112 and the Effectiveness of Student Involved Programs................

XXXI Total Group Rating Response Percentages Pertaining to ESD 112 and the Effectiveness of the Traffic Safety Cooperative.............

XXXII Total Group Rating Response Percentages Pertaining to ESD 112 and the Effectiveness of the Substance-Abuse Programs ........... $\quad 126$

XXXIII Total Group Rating Response Percentages Pertaining to ESD 112 and the Effectiveness of the Project Write Program.....................

XXXIV Total Group Rating Response Percentages Pertaining to ESD 112 and the Effectiveness of the Practioners' Workshops ...............

XXXV Total Group Rating Response Percentages Pertaining to ESD 112 and the Effectiveness of Instructional Media Staff................. 128

XXXVI Total Group Rating Response Percentages Pertaining to ESD 112 and the Effectiveness of Instructional Media Cooperative Services.

XXXVII Total Group Rating Response Percentages Pertaining to ESD 112 and the Effectiveness of the Films and Videos Provided by the Instructional Media Cooperative

XXXVIII Total Group Rating Response Percentages Pertaining to ESD 112 and the Effectiveness of the Total Special Service's Program.......

XXXIX Total Group Rating Response Percentages Pertaining to ESD 112 and the Effectiveness of the Special Services Division's Staff ...... 
XI Total Group Rating Response Percentages Pertaining to ESD 112

and the Effectiveness of Communication Devices Concerning

Special Service's Programs.........................................

XIII Total Group Rating Response Percentages Pertaining to ESD 112

and the Effectiveness of the Special Services Division as a

Resource Center for Special Education Matters

XLII Total Group Rating Response Percentages Pertaining to ESD 112

and the Effectiveness of Inservices Provided by the Special

Services Division

XLIII Total Group Rating Response Percentages Pertaining to ESD 112

and the Effectiveness of the Special Education Program Review

Service.

XIVIV Total Group Rating Response Percentages Pertaining to ESD 112

and the Effectiveness of the Agency and Community Liason

Services

XIV Total Group Rating Response Percentages Pertaining to ESD 112

and the Effectiveness of the Preschool Screening Service ...........

XIVI Total Group Rating Response Percentages Pertaining to ESD 112

and the Effectiveness of the Audiological and Hearing Services....

XLVII Total Group Rating Response Percentages Pertaining to ESD 112

and the Effectiveness of the Regional Early Childhood Coord-

ination Services......................................................

XLVIII Total Group Rating Response Percentages Pertaining to ESD 112

and the Effectiveness of the Seriously Behavior Disabled Program

XIDX Total Group Rating Response Percentages Pertaining to ESD 112

and the Effectiveness of the School Psychological Services 
L Total Group Rating Response Percentages Pertaining to ESD 112 and the Effectiveness of the Communications Disorders Services.. 140

LI Total Group Rating Response Percentages Pertaining to ESD 112 and the Effectiveness of the Motor Therapy Services................. $\quad 140$

LII Total Group Rating Response Percentages Pertaining to ESD 112 and the Effectiveness of the Preschool Handicap Services............

LIII Total Group Rating Response Percentages Pertaining to ESD 112 and the Effectiveness of the SESARA Program................... 142

LIV Total Group Rating Response Percentages Pertaining to ESD 112 and the Effectiveness of the Special Education Direct Services......

LV Total Group Rating Response Percentages Pertaining to ESD 112 and the Effectiveness of the Special Education Direct Instruction Staff.........................................................

LVI A Summary Table of Analysis of Variance Tests Performed on General Effectiveness Rating Questions Fifteen through Twenty-four by Position Groups ................................

LVII Position Group Mean Response Paired Comparisons and Comparison Probability Level on General Effectiveness Questions Fifteen Through Twenty-Four

LVIII A Summary Table of Analysis of Variance Tests Performed on Specific Program and Service Effectiveness Rating Questions Twenty-five through Forty-three by Position Groups...............

LIX Position Group Mean Response Paired Comparisons and Comparison Probability Level on General Effectiveness Questions Twenty-five through Forty-three 
LX A Summary Table of Analysis of Variance Tests Performed on Specific Program and Service Effectiveness Rating Questions Forty-five through Sixty-two by Position Groups................. 152

LXI Position Group Mean Response Paired Comparisons and Comparison Probability Level on General Effectiveness Questions Forty-five through Sixty-two.

LXII A Summary Table of Analysis of Variance Tests Performed on General Effectiveness Rating Questions Fifteen through

Twenty-four by District Size Groups..............................

LXIII District Size Mean Response Paired Comparisons and Comparison Probability Level on General Effectiveness Questions Fifteen Through Twenty-Four.

LXIV A Summary Table of Analysis of Variance Tests Performed on General Effectiveness Rating Questions Fifteen through Twenty-four by County Groups .................................

LXV County Group Mean Response Paired Comparisons and Comparison Probability Level on General Effectiveness Questions Fifteen Through Twenty-Four

LXVI A Summary Table of Analysis of Variance Tests Performed on General Effectiveness Rating Questions Fifteen through Twenty-four by Degree Level Groups

LXVII Degree Level Mean Response Paired Comparisons and Comparison Probability Level on General Effectiveness Questions Fifteen Through Twenty-Four 
LXVIII A Summary Table of Analysis of Covariance Tests Adjusting for the Effects District Size, County Location, and Highest Degree Level Attained on the Position Gategory Mean Responses on the General Effectiveness Questions Fifteen through Twenty-four .....................................................

LXIX Summary Table for Total Respondents by Five Position Groups Regarding Mean Response and Percentage of Group Responding to General Effectiveness Questions Fifteen through Twenty-four

LXX Summary Table for Total Respondents by Five Position Groups Regarding Mean Response and Percentage of Group Responding to Instructional and Curriculum Questions Twenty-six through Forty-three ................................................

LXXI Summary Table for Total Respondents by Five Position Groups Regarding Mean Response and Percentage of Group Responding to Special Services Questions Forty-five through Sixty-two

LXXII Summary Table for Total Respondents by Three Years of Experience in District Groups Regarding Mean Response and Percentage of Group Responding to General Effectiveness Questions Fifteen through Twenty-four

LXXIII Summary Table for Total Respondents by Three Years of Experience in District Groups Regarding Mean Response and Percentage of Group Responding to Instructional and Curriculum Questions Twenty-six through Forty-three.............. 
LXXIV Summary Table for Total Respondents by Three Years of Experience in District Groups Regarding Mean Response and Percentage of Group Responding to Special Services Questions Forty-five through Sixty-two

LXXV Summary Table for Total Respondents by Three Years of Experience in State Groups Regarding Mean Response and Percentage of Group Responding to General Effectiveness

Questions Fifteen through Twenty-four

LXXVI Summary Table for Total Respondents by Three Years of

Experience in State Groups Regarding Mean Response and Percentage of Group Responding to Instructional and Curriculum Questions Twenty-six through Forty-three

LXXVII Summary Table for Total Respondents by Three Years of Experience in State Groups Regarding Mean Response and Percentage of Group Responding to Special Services Questions Forty-five through Sixty-two

LXXVIII Summary Table for Total Respondents by Five District Size Groups Regarding Mean Response and Percentage of Group Responding to General Effectiveness Questions Fifteen through Twenty-four.

LXXIX Summary Table for Total Respondents by Five District Size Groups Regarding Mean Response and Percentage of Group Responding to Instructional and Curriculum Questions Twenty-six through Forty-three 
LXXX Summary Table for Total Respondents by Five District Size

Groups Regarding Mean Response and Percentage of Group

Responding to Special Services Questions Forty-five

through Sixty-two....................................................

LXXXI Summary Table for Total Respondents by Six County

Groups Regarding Mean Response and Percentage of Group

Responding to General Effectiveness Questions Fifteen

through Twenty-four

LXXXII Summary Table for Total Respondents by Six County

Groups Regarding Mean Response and Percentage of Group

Responding to Instructional and Curriculum Questions

Twenty-six through Forty-three.

LXXXIII Summary Table for Total Respondents by Six County

Groups Regarding Mean Response and Percentage of Group

Responding to Special Services Questions Forty-five

through Sixty-two..................................................

LXXXIV Summary Table for Total Respondents by Four Degree Level

Groups Regarding Mean Response and Percentage of Group

Responding to General Effectiveness Questions Fifteen

through Twenty-four

LXXXV Summary Table for Total Respondents by Four Degree Level

Groups Regarding Mean Response and Percentage of Group

Responding to Instructional and Curriculum Questions

Twenty-six through Forty-three. 
LXXXVI Summary Table for Total Respondents by Four Degree Level

Groups Regarding Mean Response and Percentage of Group

Responding to Special Services Questions Forty-five

through Sixty-two.................................................... 240 


\section{LIST OF FIGURES}

FIGURE

PAGE

1. ESD 112 Service Area by Individual School

Districts ..................................................... 4

2. Schooling as an Input-Process-Output System ................... 47

3. The Organization as a Transformation System ..................... 48 


\section{CHAPTER I}

\section{INTRODUCTION}

Not unlike most other states, the State of Washington's citizens, through their elected officials, and professional educators, have struggled to create a public school system which is both effective and efficient in its mission. First, by creating an effective social institution, the State of Washington has provided educational situations and learning environments which address the academic and social needs of students, community, and ultimately the greater society. Second, by creating an efficient service organization, the State of Washington has worked to produce a comparable balance between the human and monetary needs of the schooling system and the will of the people supporting this system. This state schooling system, as with all social or bureaucratic institutions, is based on the notion of creating a progressive process which promotes the customs, values, and beliefs of the host society (Luft, 1984; Mouzelis; 1967). These efforts result in creating a more equitable, sustaining culture with the progression of each new generation.

From the first session of the Washington Territorial Legislature on February 27, 1854 (Dewey, 1909) to present, the public education system in Washington has been in a state of constant change. The majority of changes and developments within the system have occurred in order to bring about a more intensive and well-suited educational program for students.

As a result of these 136 years of progressive change, the educational system in the State of Washington today has developed into a multi-faceted, multi-dimensional entity. A component of this system is the Educational Service District (ESD). 
The purpose of the ESD unit is best described by the following "purpose" statement issued by ESD 112 (1989b.): "The mission of ESDs is to ensure that every child receives equal and appropriate educational programs regardless of his/her residency in large or small districts, rural or urban communities, and socio-economic conditions." The ESD, as a component of the Washington educational system, is delegated to create and implement programs and services in order to give all children in the State an equal educational opportunity.

The Educational Service District's ancestral roots extend to the first session of the Washington Territorial Legislature in 1854 , which resulted in the creation of the "County Superintendent of Schools." This office remained virtually unchanged in legislated responsibilities until the mid-1960s (Ruel, 1986). At this time a rising consensus among educators in the State was to make the county superintendent's office more serviceoriented. These services were to be focused on curricular and instructional needs of local school districts, as well is supportive legislated administrative and operational requirements.

With continued concern and pressure from different educational groups during the late 1950s and 1960s, the Legislature enacted legislation to create "Intermediate School Districts" (ISDs, a layer of bureaucratic educational offices situated between the individual district and the State Superintendent of Public Instruction office) statewide in early 1969 (Ruel, 1986; Rorher, 1988), replacing the County Superintendent of Schools office. After several years of operation, State legislation reduced the numbers of the Intermediate School Districts in the State during 1975. At this time they also renamed these units Educational Service Districts (Ruel 1986; Rohrer, 1987). At present there are nine Educational Service Districts serving the State. From the start of the "County Superintendent of Schools" office to the present "Educational Service District," the emphasis has evolved from a passive office of information gathering and dissemination to the present day service organization 
involved in all phases of public education. This involvement includes a spectrum of business and administrative services at the district-wide level as well as curricular and instructional programs found in the individual classroom.

Of specific interest to this study is one of these nine ESDs: Educational Service District 112. This particular regional education district serves greater southwest Washington. It includes a six-county region and presently serves 30 public school systems and 17 approved private schools (Figure 1.). The region has a public school population of over 64,000 students. ESD 112 now provides 62 different services and programs on a contractual or legislated basis to any or all districts soliciting any or all of its services. These services and programs include business and administrative services, curriculum and instructional programs, and special services such as hearing screening, psychological services, and special education programs.

With Legislation passed in 1981, the ESDs were allowed to provide direct student services to students within their regional jurisdiction. From this legislative action emerged ESDs more diversified in scope and content and having the ability to shift program concentration in relation to needs of those supporting school districts. At the heart of this change were the program and service areas of Instruction and Curriculum and Special Services. Each of the programs and services found in these areas directly affect the classroom learning environment, and ultimately the individual student.

Of particular interest to this study are the Instructional and Curriculum and Special services provided by the Educational Service District 112. As a public educational organization with a relatively brief existence in the State as it is presently structured, the ESD never-the-less has become a predominant component in the overall structure of Southwest Washington's public school system. Presently operating as a service-oriented organization, ESD 112 fills many individual district bureaucratic and administrative voids and also provides an array of educationally-oriented programs. Having grown in human 


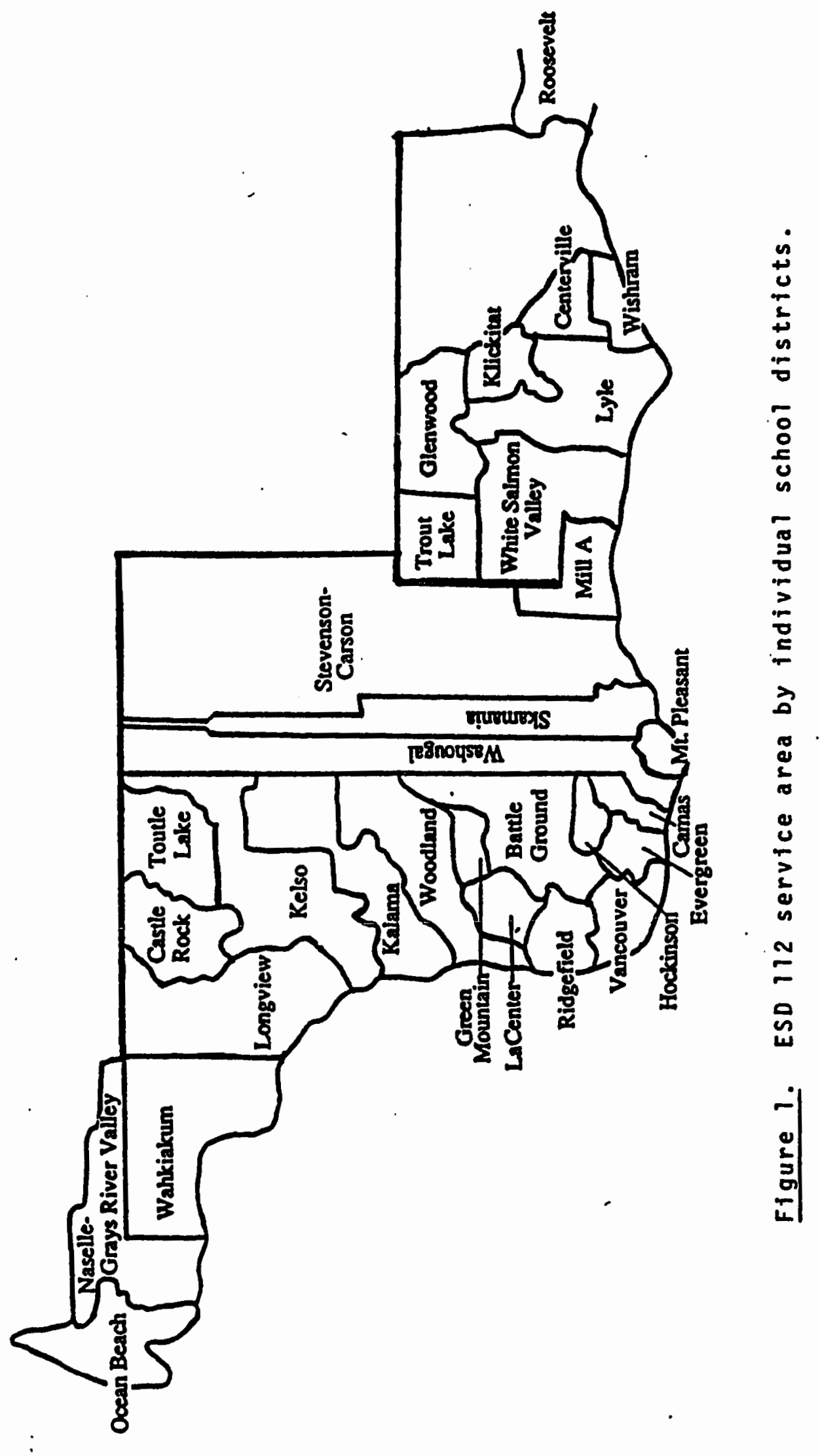


and financial resources as the needs placed upon the ESD by the individual districts within the organization's service area have multiplied, the need for pertinent evaluative information regarding available programs has increased. Unlike the previous "County Superintendent's Office," which interpreted State legislation and kept a census of the county schools, the ISDs (Intermediate School Districts), and eventually the ESDs, were developed with the primary intent of serving the area's schools in the fields of curriculum and instruction (Ruel, 1986).

\section{STATEMENT OF THE PROBLEM}

Two central problems face Educational Service District 112 at this time. First, methodology and instrumentation which specifically deals with the collection of information relating to educational service districts and the effectiveness of their programs and services is unavailable at this time. Second, information pertaining to educational service districts and program and service effectiveness is extremely limited. Due to this lack of information, educational service districts have no common body of knowledge relating to educational service districts from which to draw inferences, make related judgements, or develop formative and summative evaluative strategies.

The quality of the entire educational service district's program is judged in regard to the perception of effectiveness held by the different groups of educational patrons and service users. This is true of any service organization which is as near totally dependent on patron support for its livelihood, as is the educational service district. Grounded information and tried methodology which focus on the specifics of educational service agencies is a prerequisite for productive evaluation and decision making.

At present, educational service districts in the State of Washington depend upon the commitment of funds from individual school districts for the livelihood of a majority of their programs. These include services in areas such as media services, business and 
central office services, instructional support services, special education services, and printings services. A school district may elect to pay for services on a yearly basis through a contractual agreement in order to benefit from the shared resources. The selection of services by the individual school district directly effects the development of the educational service district's budget, and is the major driving force behind what programs will be excluded, included, or developed for future needs. It is evident then, that the ESDs must be responsive in providing effective and efficient services to their clients in order to maintain a progressive and productive organizational life.

Descriptive information which identifies and describes the present state of patron educators' perceptions of educational service district agencies is non-existent at the national level and is limited to a single study at the state level (Ruel, 1986). This lack of local formal research is also true for Educational Service District 112. There has been no formal gathering of information on the perceived effectiveness of ESD 112's programs and services among patrons. There has been no explicit attempt to investigate the differences in the perceptions of effectiveness of programs and services among different groups of professional educators within ESD 112's service area. There has been no effort to investigate the impact various demographic characteristics may have on the perceived effectiveness of ESD 112's programs and services. This lack of information creates a obvious void in understanding the present perceptions of effectiveness that different service patrons hold. This deficit in information could affect the wisdom of future decisions regarding ESD 112's programs and services and the people it most serves.

\section{PURPOSE OF THE STUDY}

The purpose of this study was to investigate the perceptions of effectiveness various patron educator groups have in regard to programs and services offered by one 
educational service district. The end-result of the study was to produce comparative analyses of the perceptions held by these different groups.

This study was an attempt to understand the present status of perceptions in a single educational service district. In a broader perspective the purpose of this study was to lay the groundwork for future research in this field of endeavor. As the human and monetary resources invested in educational service districts in the State of Washington and around the nation increase, the need to understand and be responsive to patrons who are watchful of personal expenditures will also increase. This study attempted to deal with this need. Since this particular vein of investigative research is new, it is intended that the procedures and concepts relied upon in this study will serve to guide future research. This study attempted to reveal potential productive strategies and methodologies for related study in educational service districts at the local, regional, and national levels. Moreover, the study may have produced productive information for ESD 112's decision making process and also revealed trends that may be applicable outside of this single organization.

\section{Background Related To Study Purpose}

The idea for this study originated as a slow coagulation of many different experiences and thoughts the author has gathered during a decade of educational experience and interaction with Educational Service District 112. During this decade of educational experience and interaction with ESD 112, the author had used several of the ESD services, was involved in a few of the ESD regional educational committees, and had become well acquainted with several ESD programs. Also during this time, the author had a number of experiences with a large number of professional educators in this region of the state. These included a wide range of educators serving in different capacities within numerous school districts served by ESD 112 .

First, the author had observed considerable differences in the manner in which different groups of educators feel about different ESD 112 programs and services. 
Second, the author had observed differences in the amount and types of programs different school districts contract from ESD 112. Third, the author had observed substantial differences in the general knowledge of the intended purpose of the educational service district. Last, the author had recognized a lack of knowledge among groups of educators as to the actual programs and services offered by the Educational Service District. From these observations major questions were then materialized: "Is ESD 112 perceived as an effective educational component of the Southwest Washington public education system?"; "Are the programs and services provided by Educational Service District 112 perceived as effective by the educational community this regional office is designed to serve?"; "Are ESD 112's services and programs perceived as effective by different characteristic, or demographic, groups?"; "What characteristics, both personal and professional, might influence differences in perceived program effectiveness?"; and "What evaluative approach or research methodology can be used to identify these perceptions of effectiveness?" It was from these broad questions that the structure and content of this study was derived.

The emphasis of this study was to identify the perceptions of effectiveness that different members (classroom teachers, board members, principals, superintendents, and certified support personnel) of individual school districts have toward the Instructional and Curriculum and Special Services programs provided by ESD 112. This study also focused on stratifications of individual and group characteristics in relation to perceptions of effectiveness. Do they have the same or differing views of how effective these programs and services are? What programs are perceived as effective, and which are ineffective? What demographic characteristics (e.g., age, amount of education, size of district) influence the perceptions of effectiveness held by individuals and groups?

Another purpose of this study was creating the foundation for the possible development of an evaluative instrument which may used in the future by this and other educational service districts in Washington and the nation. An evaluative instrument 
specific to the evaluation of educational service district's programs and services in the State of Washington and nation is needed in order to obtain accurate and productive information.

Above all else, it is hoped that this study will help to better the programs and services offered in this, and possibly other educational service districts in the state and across the nation. By having a better understanding of how their programs and services are perceived by patrons, the educational service districts will be better able to make formative decisions regarding their effectiveness. This should eventually create a better learning environment for the students and educators it is designed to serve.

\section{GENERAL METHODOLOGY}

\section{Instrument and Procedure}

The basic method of study was to gather relevant information on Educational Service District 112 through the use of a survey instrument. The instrument was developed in order to ascertain the views of effectiveness held by educators in the ESD 112 service area. This was accomplished through the development of a survey instrument which obtained information concerning respondents' demographic characteristics as well as their perceptions of program effectiveness.

The construction of the survey instrument involved three steps. First, indicators relating to the concept of educational service district effectiveness were identified. Second, items identifying the programs and services under the divisions of Instructional and Curriculum and Special Services were developed. These items were then divided into two sections (instructional and curriculum section and the special services section) on the survey. These sections were accompanied by a demographic and general information section. The result was a 62 item survey instrument pertaining to the programs and services of ESD 112. 
Study Population

All levels of certified staff members and school board members were surveyed. "Certified staff members" included all persons employed as teachers (including certificated support personnel), principals, assistant principals, superintendents, or other certificated central office personnel. The entire population for the study was located within the ESD 112 service region. The survey was sent to all school board members, all superintendents, all principals and assistant principals, and all central office personnel. The survey was also sent to all teachers and support personnel in districts with two-thousand or fewer students, and a random cluster sample of teachers and support personnel in districts with more than two-thousand students (Ary, 1985; Vockell, 1983). This random cluster sample was obtained by random selection of school units (school buildings) found within districts with more than 2000 students. Once randomly selected, the entire certificated staff of each of these units was surveyed.

The entire survey sample consisted of members of those public school districts found in the ESD 112 service area. The survey sample included: 150 board members, 30 district superintendents, 125 principals, 54 assistant principals, 55 central office personnel, all 747 teachers and certificated support personnel in districts with two-thousand or fewer students, and a random cluster sample of 346 teachers and certificated support personnel from districts with more than 2000 students.

The intent of the survey was to elicit perceptions of program and service effectiveness as provided to patron school districts by Educational Service District 112. More specifically, the survey instrument was designed to indicate differences and similarities of perceived effectiveness among various groups of educators, with an ultimate goal of improving these services. 
Yalidation

Survey items were validated by a panel of certificated educators. Validation of the survey instrument was accomplished by post-survey interviewing a panel of certificated staff members within the ESD 112 service area. Teachers, administrators, and board members were asked to participate in an irformal interview. The questions were read to the those people agreeing to the interview process, and answers were recorded by the researcher on a standard survey form.

The purpose of this process was to validate the survey through reviewing the content and structure of the survey instrument, in regards to how questions were understood by the respondents. Interviews were scheduled and completed after the results of the study were compiled. The general outline and content of the interviewing procedure was regulated by the structure of the survey questionnaire.

\section{Data Treatment}

The findings from this study primarily reported in descriptive form. This was done through reporting the modes, percentages, means, and standard deviations for the total population and different demographic characteristic groups. ANOVAs (analysis of variance), multiple comparisons (Tukey-Kramer), ANCOVAs (analysis of covariance) tests were used to analyze differences in group mean responses according to category grouping, and also to investigate the effect of different demographic characteristics on the respondents' answers. Chi-square tests of significance were used to test differences in the proportions of groups falling into different response categories.

\section{BASIC ASSUMPTIONS}

Several assumptions were made during the development of this research project. Most of these assumptions lend themselves to the implementation of the study, although it 
was assumed each of these factors would have an influence on the actual results gathered to some degree.

These assumptions are:

1. That a questionnaire survey approach, with an anonymous response platform, would allow for honest, straightforward responses to the questions, regardless of an educator's occupational title.

2. That the survey questionnaire would be the most comprehensive approach to gathering data/information, and would be the most appropriate for this situation.

3. That at least half of those educators sampled within the ESD 112 service region would return their questionnaire surveys.

4. That although the study was conducted over a four-week period, no changes would occur to differentially affect respondents' perceptions of ESD 112's effectiveness.

5. That all educators in ESD 112's service region had at least some knowledge of the organization's existence and its organizational purpose in the overall structure of Washington State's educational system.

6. That conducting the study during the first few months of the academic year would be more preferable to the respondents. This was to avoid those pressure periods of the school year, such as conference time and quarter grading periods, which it was felt might effect the respondents' ability, or initiative, to complete and return the survey.

7. That the survey questionnaire approach would be the most feasible in regards to cost. 


\section{LIMITATIONS}

Several factors have been identified as possible limitations of this study dealing with the curriculum, instruction, and special services programs offered by Educational Service District 112.

These limitations are:

1. The generalizability of the findings is limited. These findings are specific only to the respondents and educational environment found in the ESD 112 service region.

2. The perceptual content and context of the individual respondent is limited to the knowledge base held by that individual. This is in regards to the different educational service district services and programs the respondent had been in contact with.

3. Within the context of the previous discussion, the findings of this study only relate to the programs and services in the areas of curriculum, instruction, and special services which are offered by ESD 112.

4. Due to the use of the random sample cluster the results from the sample used in this study may be different from what might be found if the whole population were used, due to sampling error.

5. The survey was limited in scope and size to that which was felt to adequately assess different educators' perceptions of effectiveness. An exhaustive instrument would have been unmanageable to respondents, and likely would have decreased the response rate.

6. That data collected are subject to response errors and errors of estimation, tabulation, and subsequent interpretation.

7. That data collected are based on a "self-reporting" format and are subject to errors and personal biases of the subjects responding to the survey instrument. 


\section{DEFINITION OF TERMS}

\section{Educational Service District}

The Educational Service District is most commonly identified as an "ESD" (and shall be referred to as such during the remainder of this study). The nine educational service districts in the State of Washington act as the middle tier in the state public school system, a level between the local school district and the Superintendent of Public Instruction's Office. Although "intermediate school district" is the most recognized term for describing this bureaucratic level in state public school systems, terms such as "regional service district," "county superintendent," "regional education agency," "cooperative educational service district," "regional service agency," "county school system," and "board of cooperative educational services" (BOCES) are among others which are also used as descriptors (Hughes, 1976; Encyclopedia of Education, 1971).

\section{Proprams and Services}

ESD 112, like other ESDs in the State, organizes itself in a similar structure. Services are organized in divisions generally centered around the areas of administrative services, business services, curriculum and instruction services, and special services. The instructional and curriculum and special services provided by the Educational Service District 112 are organized within the same division of the service organization. Each subdivision carries a specific description of job responsibility and includes services and programs which support an individual unit purpose or mission.

\section{Instructional and Cumriculum Services}

The program cooperatives and individual programs associated with curriculum and instruction are: Student Teacher Pilot, Inservice Grant Committee, Whole Language Support Group, Teacher Assistance Program, Specific Staff Development Projects, Selfstudy Models, and Knowledge Bowl/History Day/Art Show, SLO (student leaming 
objectives) Revisions, Traffic Safety Cooperative, Mount St. Helens Curriculum. Project

Write, Textbook/material Adoption Services, Curricular Challenges, Critical Thinking Skills, Home-Based Education, Highly Capable Program Assistance, Practitioners'

Workshops, and Substance-abuse Programs. Also included in the instructional division of ESD 112 is the Instructional Media Center. The media center consists of the Instructional Materials Cooperative and the Educational Technology Center.

\section{Special Services}

The Special Services division of the ESD 112 provides services relating to observance and understanding of state and federal laws, rules, and regulations. It also acts as the liaison between individual districts and the Superintendent's Office of Public Instruction(SPI). This division's services include: Inservice Training and Program Review, Seriously Behavior Development Program (SBD), Audiology Services, Regional Early Childhood Consultant, and Infant and Preschool Screening/coordination. This division also includes the Special Education Cooperatives. These services include: Itinerant Psychological Services, Communications Disorders Services, Hearing Services, Motor Therapy Services, Preschool Services, Training of Special Education Support Assistants in Rural Areas (SESARA), and the Special Education Direct Instruction Staff Cooperative.

\section{Effectiveness}

For the purposes of this study a definition of "effectiveness" used in an earlier study by Reul (1986) was employed:

Effectiveness implies proven capability based on productiveness in operation, and especially stresses ability to perform well and economically. Inherent in such performance are the absence of waste of time, energy, or material and the demonstration of skillful management of means and technical expertness suggested by the term "know-how" (Ruel, 1986, p. 7). 
Components of the preceding definition were isolated and expanded upon for further clarity of what the concept of "effectiveness" meant in regards to Educational Service District 112. These "indicators" were developed through consultation and discussion with ESD 112 staff and through the literature review (Stephens, Perry and Sanders, 1989). Since it is the perceptions of individuals which are being measured in this study, no attempt to numerically operationalize effectiveness will be made. These indicators were included before the first effectiveness rating section of all survey instruments in this study.

Specific indicators of "effectiveness" included before the rating section of the survey instrument included:

-providing satisfactory and relevant services to patrons. - demonstrating useful knowledge and information. -providing services in a timely fashion.

-having the resources and skills to meet the needs of students, teachers, and districts.

-having the resources and skills to adjust to the individual needs of students, teachers, and districts.

-having the interpersonal skills to work effectively with teachers and administrators in schools.

-providing services which ultimately promote the teaching processes found in the classroom.

-having resources and skills to productively administer programs and services.

-providing useful evaluations of students and personnel involved in programs and services.

\section{Perception}

Perceiving, or to perceive, as it is related to this study, is best defined as: "To come to understand; apprehend with the mind" (Funk and Wagnalls, Standard College Dictionary, 1963, p. 421). This study was more concerned with the results of perceiving than with the act or process of perceiving and was specifically attuned to the insight, knowledge, or intuitive judgement arrived at by the perception process. An understanding of the perceiving process which is supportive of the preceding concept is that of "indirect perception." This concept is based on the notion that our perceived reality is always being 
mediated by feelings, emotions, and past experiences (Michaels and Corello, 1981; Shaw and Bransford, 1977).

\section{Definitions of Occupations}

1. Teacher: A person who holds a Washington State teaching certificate and who is employed by a local public education school district to educate students within the classroom environment.

2. Principal: A person who holds a Washington State administrative certificate and who is employed by a local public education school district to administer the entire functions of an individual school unit.

3. Assistant Principal: A person who holds a Washington State administrative certificate and who is employed by a local public education school district to function as an assistant to the principal in an individual school unit.

4. Superintendent: A person who holds a Washington State superintendency certificate and who is employed by a local public education school district as the executive officer in the operation of the entire school district.

5. Central office personnel: A person who holds a Washington State administrative certificate, superintendency certificate, specialist's certificate (i.e. psychologist, media specialist), or teaching certificate and who is employed by a local public education school district to function under the direction of the superintendent (i.e. assistant superintendent, administrative assistant, director, assistant director).

6. Board member: A person who is elected by the public within a designated local public school district to serve for a designated term, and who is ultimately responsible for the functions and actions of the entire school district.

7. Certificated support personnel: A person who provides instruction as that of the teacher, but not necessarily in the classroom setting. This would include personnel such as math specialists, reading specialists, librarians, and music teachers. 


\section{ORGANIZATION OF THE STUDY}

This study consisted of six stages: (1)problem identification and formulation of intended study, (2) research and review of related literature, (3) construction of survey questionnaire, (4) sampling and field testing of the survey instrument, (5) collection of data, and (6) the analysis and summarization of data and subsequent reporting and interpretation of the findings.

The first chapter has been an introduction to the subject studied. It includes a statement of the problem and the purpose of the study, an outline of the general methodology used, assumptions and limitations relating to the research project, and the definitions of terms used in this study.

Chapter II develops a four-part review of the literature relevant to this study. The first two sections pertain to the subject area of program evaluation, which are supported by a review of the historical, theoretical, and practical aspects of this field of study. The third section of the literature review covers the topic of perception and perceiving. The fourth section includes a brief section on the theoretical assumptions regarding organizational behavior in specific relationship to the Educational Service District. The fifth, and final, section of this chapter reviews literature regarding intermediate school districts and educational service district effectiveness research.

Chapter III details the conceptual framework and research design used in this project for both the developmental and instrument utilization stages and the research methods and analytic procedures utilized.

Chapter IV communicates the findings of the study. These findings are developed through the numeric and statistical analysis of the data collected.

Chapter $V$ is a complete summarization of the research project. It includes discussion of all previous stages of the project and also includes recommendations and the subsequent implications for the practical application of these findings. 


\section{CHAPTER II}

\section{REVIEW OF RELATED LITERATURE}

This chapter is divided into five sections. The first section briefly reviews the literature related to the historical development of program evaluation in the field of social sciences, and specifically the field of education. The purpose of the first section is construct a historical perspective of evaluation and program evaluation, and to also create an understanding of the present status of this field of study in education.

The second section reviews the practices and methodologies in the general field of program evaluation. This section reviews program theory, evaluation intent, and different evaluative methodologies presently used in evaluative practice.

The third section briefly reviews literature pertaining to perceiving and perception. Discussion on this topic attempts to reveal the impact this concept has when research attempts are made to ascertain perceptual differences among individuals and among groups of people.

The fourth section briefly discusses the theoretical assumption taken towards organizational behavior and how relevant theory relates to the Educational Service District in the State of Washington. The intent of this section is to develop a sense of relevance between the findings (information) of a study such as this one and the relationship organizational behavior has with the processes of a social organization.

The fifth, and last, section reviews the past and present status of research and literature pertaining to educational service districts. This section attempts to provide an overview of research and related literature. The intent of this section is to develop a 
background of information which may increase the potential effectiveness and efficiency of this study.

With the intent of human research being the desire to discover remedies to human problems and needs, it is pertinent to relate purpose to point in social research. The purpose of this study, as described before, is to investigate what "are" the perceptions of ESD 112's services and programs in terms of effectiveness and ineffectiveness. The findings from a study such as this are pointless and obscure without relating them to some conceptual structure which allows one to agree or disagree, postulate, and investigate further.

The ESD, being a social organization and existing for the purpose of serving socially aligned needs, should be viewed in a befitting manner. There is a need to identify the organizational process which fostered these perceptions in theoretical terms, and to explain the importance of the study's findings in relation to this process. Being a service organization the ESD will be characterized as an "open system" organization, and the relevance of study's findings will be identified in relation to the "feedback" process. It is also of importance to understand both the historical development of evaluation and program evaluation in both the social sciences and education. This will provide a foundation for better understanding the methodologies presently used in this field of study. Finally, it is important to review that literature directly related to educational service districts. This will create an understanding of the demeanor of this study in relation to previous work regarding educational service districts. To enmesh this study's routine with other research in the field will hopefully nurture more productive evaluation attempts in the future. 


\section{PROGRAMEVALUATION}

In developing a focused evaluation process it is necessary to distill and purify the terminal objective one is evaluating. This approach helps create an evaluative process which complements the evaluation intent and will allow one to more directly address procedures which are productive (Bickman, 1987; Hayman and Napier, 1975). An understanding of the general field of evaluation, and more specifically the field of program evaluation, helps cultivate this conceptual development. It allows the evaluator to define the procedural content of the evaluation process and also to refine the focus of the process which most effectively evaluates the desired intent.

This research project draws from the field of program evaluation in both intent and procedural implementation. The study's purpose is to evaluate the perceived effectiveness concerning ESD 112's programs and services held by its users or patrons.

\section{Evaluation Defined}

Evaluation in its broadest sense focuses on appraising the worth of some person, object, or thing. Funk and Wagnall's (1963) dictionary states evaluation as a approach which works, "To find or determine the amount, worth, etc., of; appraise." In Worthen and Sanders $(1987$, p. 22) work on educational evaluation, the authors simply define the concept and process of evaluation as, "Evaluation is the determination of a thing's value." Rossi and Wright (1976), who specialize in the field of social science research of policymaking, express that the process of evaluation research generates quantifiable results from which understandings and decisions can be formulated. In this process of evaluation there is a judgement of value made which is relative to what is being evaluated instead of comparative. This is all based on the notion that the results are still an estimate of value or worth towards some "thing." 
The meaning of evaluation does not appear to vary in substance or magnitude when reviewing the different definitions found in different disciplines of study (Davis, 1986). The context and content of the evaluation process, no matter what particular discipline one is most associated with, is still based on attaching a judgement or appraisal worth to some particular "thing." When evaluating people, situations, and objects, we are merely developing some internal classification in which to group, rank, or distinguish among concepts of likeness (Achenson and Gall, 1980; Black and English, 1986). Rossi and Freeman (1985, p. 19) describe program evaluation as, "a systematic application of social research procedures in assessing the conceptualization and design, implementation, and utility of social intervention programs."

Although the definitions of evaluation are as numerous as those individuals involved in the general field of evaluating objects, procedures, programs, and people, there are certain components prevalent in all descriptions of evaluation. These components include the processes of collecting, analyzing, and interpreting information for a specified purpose (Rossi and Freeman, 1985; Wolf, 1979; Sergiovanni and Starratt, 1983). These three components form a systematic procedure found in all evaluation, and generally serve as the vehicle in its implementation. Around these skeletal processes, the intent or function of each individual evaluation is carried to its desired conclusion.

This notion is further expanded by Davis (1986) in her literature review pertaining to evaluation found in different disciplines of study. She found that although there are no standardized criterion found from one discipline to another, that there are generalities which inherently bond all disciplines using evaluation processes. She identifies these general areas as, "definitions, history, and philosophy evaluation; approaches to evaluation; evaluation techniques; and issues in the practice of evaluation" (p. 10). It is common understanding among evaluators that some type of organized evaluation procedure will be used to glean results from the evaluation activity. The emphasis of those 
procedures will depend on the field or discipline in which the evaluation process is taking place. With this in mind, it is the content of whichever discipline within which one is working that is different, while the context of the actual evaluative process will be the same. The major theme which permeates all evaluation is one of developing and implementing evaluation procedures that better evaluate and facilitate people, objects, procedures, policy, or program.

\section{Historical Overview of Evaluation}

The technical, information-rich evaluation methodologies found today are a fairly recent development and are generally felt to be derivations of a field of discipline in a state of "infancy" (Rossi and Freeman, 1985). Worthen and Sanders (1987), and Guba and Lincoln (1981) refer to distant historical roots of evaluation by identifying examples of evaluation activity being demonstrated in China as early as 2200 B.C (p.12; p. 1). Rossi and Freeman (1985) date socially-related evaluation to the 1600 and 1700 s, when early researchers were chiefly concemed with numerical measurement for appraising social conditions in Europe (p. 20).

As the complexity of American and European societies increased over the last 150 to 200 years there has been a successive increase in the development, funding, and implementation of civil programs. A milestone, for example, in this process was the establishment of public schools in the United States during the 1800s (Tyack and Hansot, 1982). The public schools were, for the most part, the first socially-related endeavor for American taxpayers which was not related to national defense.

Corresponding to progressive increases in taxes which have supported these social organizations, have been the concerns of the taxed patrons, who, by direct community involvement have regulated schools and other civil services. Early evaluation was based on the subjective opinions of individuals and communities in which the civil organization operated. Most decisions regarding any social organization prior and up to this time were 
controlled by the dictates of the controlling religious denomination and the political system they fostered (Gutek, 1972; Worthen and Sanders, 1987; Tyack and Hansot, 1982).

As the industrialization and social sophistication of people in the United States and Europe increased, so did the social structures which provided social services to its people. It was not until the early years of the industrial revolution that institutions such as hospitals, schools, and governments lent themselves to a structure which could be evaluated. Even at this time, "evaluation" was an umbrella term which included testing, assessing, and fact finding (Travers, 1983; Williams and Bank, 1981)

Evaluation approaches around the turn of the century mirrored the scholarly studies of Fredrick Taylor, which sparked the onset of the "scientific-management" revolution (Kast and Rosenzweig, 1985; Bolman and Deal, 1984). From this point forward new directions of theoretical development exercised considerable influence in the manner and focus of social and business evaluation applications (Travers, 1983; Owens, 1981). This initial phase of evaluation continued through to the "human-relations" movement conceived by people such as Elton Mayo, Felix Roethlisberger, and Kurt Lewin in the 1930s and 1940s. This developing awareness of the science of evaluation coincided with the Western Electric's "Hawthome" research being conducted by Elton Mayo and other researchers on the "human" aspects of work during the 1920s and 1930s. Kurt Lewin and followers of his work were introducing social-psychological theory and techniques in evaluating people and human interactions.

The initial impact of World War II and soldiers returning home from the war saw a great increase in human research and evaluation. Evaluation methods and techniques which had been previously developed in direct relation to the needs of the war effort were being redirected toward improving society and individual standards of living (Ravitch, 1983). Along with this new attitude came pressure for social programs for the lessfortunate and the common good of the nation. By the 1950 s, large-scale evaluation 
programs were fairly standard in the United States and were being used in "delinquency prevention programs, penal-rehabilitation projects, psychotherapeutic and psychopharmological treatments, public housing programs, and community organization activities" (Rossi, Freeman, and Wright, 1979, p. 24).

As substantial funding from the federal level was appropriated in reaction to the successful launching of Sputnik, so increased the need for assessing the effectiveness and efficiency of these programs (Guba and Lincoln, 1981; Ravitch, 1983; Tyack, Lowe, Hansot, 1984).

From this point Worthen and Sanders (1987), Travers (1983), Guba and Lincoln (1981), and Wolf (1984) all identify the Elementary and Secondary Education Act of 1965 as the single most predominant factor elevating program evaluation and educational research to its present status. This legislation along with other programs instituted under President Lyndon Johnson's "Great Society" plan expanded the role of govemment in setting the direction of social programs. Under the direction of Robert Kennedy and the Congress, all monies distributed through the ESEA under the Titles I and III of the Act required annual evaluation activities (Wolf, 1979, p. 10; Berk, 1981). Concurrently, as Travers (1983) reports, Title IV of the same Act concerned itself with the development of research and research centers for the purpose of evaluation (p. 537). Coupled with the theoretical and practical applications being developed by people such as Lee Cronbach, Egon Guba, Elliot Eisner, and Michael Scriven, program evaluation catapulted itself into the educational and social program scene.

\section{Evaluation in Education}

Most historical writings pertaining to American education refer to people such as Horace Mann and Henry Barnard as those educators which first introduced the basics of evaluation to this field (Tyack and Hansot, 1982; Campbell, 1987). It was through their administrative and professional work in education that numeric applications were first used 
to gather information and assimilate it into pertinent reports. Travers' (1983) extensive investigation into the development and effects of research in education over the last 150 years portrays early educational promoters Henry Bernard and Horace Mann as those people building the foundation of research and evaluation in education. Henry Bemard reached prominence as Secretary of the State Board of School Commissioners in Connecticut and Commissioner of Education in Rhode Island. He was known for his ability to collect information and produce vast numeric evaluation reports (Travers, 1983). Horace Mann as the Secretary of the Board of Education in Massachusettses enveloped himself in an "educational crusade" (Tyack and Hansot, 1982). He devoted his life to improving the common school movement, in which he grudgingly acknowledged the use of statistics as a necessary component of achieving this dream (Travers, 1983, p. 22). These reports were most often conducted to produce information regarding prevailing education concerns of the time. The reports tended generally to focus on areas of administrative functioning, teacher training, supervision, and discipline (Travers, 1983; Worthen and Sanders, 1987). Even though the reporting of these results reflected interest in different aspects of the educational institution, they were usually tied to financial management concerns and did not effect the content or procedures of any program (Tyack and Hansot, 1982).

From about 1890 through the first two decades of the next century education was witness to a quickly evolving "measurement movement" (Campbell, 1987). This movement was driven by the "educational trust" made up of educators such as Ellwood P. Cubberly, George Strayer, Edward Thorndike, Leonard Ayres, and S.A. Courtis, among other notable professionals. Supported by bureaucrats like William Harris, the U.S. Commissioner of Education in 1889, the motion to assimilate facts and figures was entrenched in much of eduction (Travers, 1983; Worthen and Sanders, 1987). The 
"measurement movement" was fostered by the rapid transformation of the industrial community as it move into the zenith of the "industrial revolution" (Gutek, 1972).

This transformation in education was perpetuated by the adoption of the newly formed principles of "scientific management" which were spreading very rapidly in all sectors of industry. Conceptualized and developed by Fredrick Taylor, a mid-level engineer in the late 1800 s, "scientific management" was centered on mastering efficiency in industrial production. A key component of understanding how to create maximum production efficiency was in the collection of information, or the evaluation of the activity, and the manipulation of the activity to better production output. This formula, or process, was a precursor to future evaluation procedures. Schools using measurement applications were extremely bound to follow the scientific paradigm of evaluative inquiry.

The schools were quick to adopt the scientific concepts and emulate their methodologies within the schools. People such as Ellwood Cubberly and George Strayer were among the first to receive $\mathrm{PhDs}$ in educational administration from Teacher's College in 1905, and were examples of the new "professional" educators directing the schools. These people, along with other members of the educational trust began to build the "progressive" movement in education through scientific methodologies and professional networks. Tyack and Hansot (1982) recount; that educators like S.A. Courtis had administered some one-half million surveys in the first ten years of the 1900s; that Edward Thorndike and Henry Goddard were "quantitatively" studying learning behaviors; that Lewis Terman was working on a Stanford-Binet revision as early as 1916.

In other parts of the world, such as France, Alfred Binet was commissioned by his country's minister of public instruction to develop a screening process to separate the mentally handicapped from the regular classroom. The process led to the development of a published intelligence test (in 1904) which has been the foundation of all subsequent intelligence evaluation (Guba and Lincoln, 1981, Travers, 1983). 
Evaluation and measurement in public schools up to this time had not addressed the relationship of programs and curriculum used in the classroom. Most testing was implemented in order to compare individuals, schools, and districts. Tests and evaluation measures were standardized and norms were of main concern to the evaluators.

During the period of mid-1920s to the mid-1960s the measurement, or "testing," movement became progressively more predominant in schools across America. Statewide testing could be found in more than one-half of the United States by the mid-1930s. World War I and World War II had stimulated the need for intelligence and ability testing of new soldiers in service placement. Guba and Lincoln (1981) report that one researcher (Hildreth, 1945) was able to list 5,294 mental test and rating scales in the bibliography of her research report (p. 1).

There were changes unfolding in education as different educational researchers began to take dissimilar approaches to the evaluation process. Still, evaluative activities were very much fettered to the "scientific" process of numeric accumulation and comparative analysis. Then the renowned "Eight Year Study" implemented during the 1930 s and led by research director Ralph Tyler, helped set the stage for more intensive and rigorous study. Moving away from testing as the sole means of judging the worth of educational programs, more comprehensive evaluations were taking place in school districts around the States (Worthen and Sanders, 1987). Ralph Tyler introduced the notion that school curriculum needed to be developed from pertinent objectives. That these objectives would be the basis for training and guiding teachers, would guide the school district in the selection of materials, and would be the foundation of the testing procedures to be implemented.

Tyler introduced a revolutionary image of how the evaluation process needed to be executed in schools. Tyler believed that the standard "measurement approach" lacked value because it lacked the linking of relationships among components of the educational 
experience (Travers, 1983). He introduced an evaluation approach which focused on three major elements of the educational process. These three elements were educational objectives, actual learning experiences, and the appraisal procedures (Wolf, 1984). Through developing this new approach Tyler introduced the notion that there was a difference between the terms "evaluation" and "measurement." Evaluation was to describe the effects of treatments or learning experiences, whereas the notion of measurement was to describe and compare individuals and groups. Guba and Lincoln (1981) point out that although Tyler's endeavors precipitated a major restructuring in the field, there were limitations to his processes (p. 6). Tyler's model lacked rigorous guidelines, provisions for evaluating program objectives, and model standards which would help judged performance. Regardless, Tyler had a definite impact on the field of educational evaluation for decades to come. He redefined evaluation concepts and introduced evaluation procedures helpful to all educators.

Tyler's and Smith's culmination of the Eight Year Study led to the development of a evaluation manual in 1942 which was based on the use of program objectives as the evaluation criteria. This became the prevailing paradigm of educational evaluation for the next 25 years (Worthen and Sanders, 1987).

This era in American education continued to sanction a philosophical paradigm in which testing and achievement evaluation were of primary concern to the leaders of education. There was a slow change in the perspective of educational evaluation as the impact of Tyler's work was joined with social and psychological being conducted in social programs and industry (Rossi, Freeman, and Wright, 1979). Social planning agencies conceived by the "New Deal" legislation were having sociologists conduct studies in slums and poverty areas; looking for answers to national problems. These studies introduced new concepts of evaluation relating to the "before and after." Comparisons were made by looking at conditions before and after a program or procedure. This new approach added 
value to relationships between program activity and individual outcomes (Rossi, Freeman, and Wright, 1979).

Evaluation in the field of education remained much the same from the time Ralph Tyler introduced his evaluation concepts until the late 1950s. After World War II education was undertaking a new distinction in the structure of American culture. The colleges and universities were overflowing with young men supported by the first "GI" legislation from the GI Bill of Rights introduced in 1944. This opened the doors for many lower and middle class Americans to attend post-high school education (Ravitch 1983, Tyack, Lowe, and Hansot, 1984). Public schools were starting to be billed as the first step into the prosperous American life. Along with this growing interest in education came the need for evaluating programs, policies, procedures, and individuals.

The first real test of purpose and integrity of the American educational system came in late 1957, when the Russians launched the Sputnik satellite (Kirst, 1984). Guba and Lincoln (1981) report that millions of federal dollars were instantly allocated for the funding of new course development (p. 7). Programs were funded in physics, mathematics, chemistry, biology, social studies, and English. As these massive resources were expended it was expected that the products should be evaluated for effectiveness and worth. Problems occurred with these immense evaluation activities as program developers and evaluators were at odds about evaluation practices and applications (Guba and Lincoln, 1981).

Then the passage of the Elementary and Secondary Education Act in 1965 boosted educational evaluation into a position of importance it holds still today. Under the direction of Robert Kennedy and the Congress, all monies apportioned through the ESEA under the Titles I and III of the Act required annual evaluation activities to be performed by individual schools, school districts, and states (Wolf, 1979, p. 10; Berk, 1981). The amount of time and money spent on evaluation activities multiplied quickly. Title IV of the 
same Act concerned itself with the development of research and research centers for the purpose of evaluation (Travers, 1983, p. 537). Other more controversial research was happening concurrently to these major developments. These included: The Coleman report on school desegregation which was released in 1966; Project-TALENT evaluation of the early 1960s; The Head-Start evaluations in the mid-1960s (Berk, 1981).

People such as Lee Cronbach lead the way in redefining evaluation practices by moving away from comparative studies ideology in the early 1960 s. The new focus was on internal program characteristics and the cyclical development of the individual program. Working around the proliferating field of educational evaluation others such Michael Scriven, Elliot Eisner, and Egon Guba began to express their theoretical and practical applications to program evaluation (Guba and Lincoln, 1981).

The 1970s were witness to an increase in the amount and size of evaluation projects as federal support was increased and federal requirements became more stringent (Williams and Bank, 1981; Rossi and Freeman, 1985). Berk (1981) identifies amendments to past federal legislation (Educational Amendments of 1974, 1976 Amendments to the Vocational Educational Act, and the 1978 amendments to the Bilingual Education Act) as specific examples of a further refining of the role program evaluation was to play in education ( $\mathrm{p}$ 2.). The 1974 legislation pertaining to all Title I programs was the first to identify specific models of evaluation to be used by public schools in order to continue drawing federal funds. Other developments such as professional publications and joumals relating to program evaluation began to appear in the late 1970 s and early 1980s. This progression of events marked the establishment of a relatively new vein of academic study and practical application (Berk, 1981; Worthen and Sanders, 1987).

The recent explosion in theory and practical applications in field of educational evaluation has been compelled by several factors. The first is the significant influx of money specified for social and educational programs in the last 25 to 30 years (Rossi and 
Freeman, 1985). The second is the concurrent expenditure of funds from both the state and federal levels designated for evaluative purposes relating to these new educational programs (Sanders, 1986). The third reason is simply the lack of previous educational evaluation methodology literature (Berk, 1981). This void has allowed different people in the field to map a relatively new frontier in educational evaluation. People such as Worthen and Sanders, Berk, Guba, Eisner, Scriven, has all added to the progression of this field. It is an area of methodology which has not completely identified its boundaries and has yet to develop a solid, comprehensive definition of purpose. Nevertheless much thought and work has been expended on the field as it now stands.

\section{THE PRACTICE OF PROGRAM EVALUATION}

\section{Program Theory}

A precondition to the implementation of any effective evaluation process is the determination of the what, the who, and the why of the program being evaluated (Raizen and Rossi, 1981). This is often considered the development, or use, of "theory" to explain the context and substance of a program. Bickman (1987) states that program theory is, "the construction of a plausible and sensible model of how a program is supposed to work" (p. 6). Conrad and Miller (1987) call this same notion the "program philosophy," which is intended to express the essence of the whole program (p. 19). By developing a "theory" or "philosophy" of how the program works these authors believe a premise is established which will guide the subsequent evaluation methodology. This underlying goal directly influences social research methodologies used to evaluate and modify program planning, program monitoring, and program effectiveness. In following these methodologies the processes of evaluation are govemed by the ethical ideology that the activity itself will help improve the health, education, and welfare of the population it serves. 
The purpose of developing a theory relating to a specific program is to draw all the components of the program into single whole. This allows the evaluator(s) to ascertain the scope and dimensions of the evaluation activity and to map processes which will achieve accurate program evaluation (Hayman and Napier, 1975; AASA, 1982). In explaining the concept of program theory, Conrad and Miller (1987) state:

Program philosophy is that system of theories and values that defines and guides the structure, population, process, and outcomes of the program. This definition assumes that the philosophy comes before the physical and behavioral manifestations of the program, a deductive perspective. This perspective enables experimental methods; that is, the statement of hypothesis and their subsequent testing. (p. 22)

The authors express that the developed philosophy is what gives the program and related activities its meaning. This philosophy or theory will crystallize the perception of what function the program exercises. The importance of theory clarification is further related by Bickman (1987) in the following paralleled narrative:

The term "theory" as used by program developers and implementors typically is used to mean a vague notion or hunch not usually based on social science information. Often the objectives, goals, and theory underlying the program may be purposely ambiguous because of political concerns; that is, it may be kept intentionally vague in order to gain support from different groups. (p. 8)

Bickman explains in this passage that many times the purpose and intent of a program is never really brought to light. The goals, objectives, and activities of a program are kept obscure in order to maintain acceptance and approval from both those supporting and patronizing the program. This behavior will ultimately hinder any effective evaluation process.

A prerequisite of the evaluation process is the identification of those program components which illustrate what the program is all about (Epstein and Tripodi, 1977). This will require the definition of those elements pertinent to the processes associated with a program, and will assist in relating their interdependence to the program as a whole 
(Cronbach, 1982; Wolf, 1979). Developing a program theory will achieve the prerequisite activity.

Once the "program theory" or "program philosophy" has been identified and developed the evaluation process can proceed forward to specifying the purpose of the planned evaluation. This process will allow the evaluation activity to move into the planning stage by relating abstract concepts to empirical indicants. This will ultimately allow some process of systematic measurement to be implemented (Zeller and Carmines, 1980).

Formative and Summative Evaluation .

In the field of program evaluation it is first necessary to identify a purpose for implementing the evaluation if the effort is to have any redeeming value at its conclusion (Scriven, 1984). When a viable motive for an evaluation cannot be formally expressed at the onset of an evaluation process, the information gathered and any subsequent decisions made from that information will have meager constructive value (Anderson and Ball, 1978; Apple, 1974). The most basic question which must be asked after first deciding to implement a program evaluation is, "What is the general purpose of the study?" Once this question has been answered the ensuing evaluation processes and functions will be more intelligible at the initiation of the evaluation approach. This also allows for the evaluation to be classified in either the "formative" or "summative" categories of evaluation.

Although these are two terms are interrelated in their procedural intentions, both terms are descriptive of two fairly distinct concepts. The major difference is in how the results will be used at the completion of the evaluation (Popham, 1975).

As previously discussed, evaluation is an activity or process which is used to determine the value or caliber of effectiveness of some "thing." Formative and summative evaluation are two the concepts of evaluation which are most universally recognized 
(DeRoche, 1981; Worthen and Sanders, 1987, Anderson and Ball, 1978). DeRoche

(1981, p. 4)) describes the differences between the two concepts in the following narrative.

'Formative' evaluation refers to gathering and using information during the process of doing something. It is on-going, requiring continual feedback for decision making and change along the way. and 'Summative' evaluation refers to gathering and using information at the end of something. It is popular in research studies. It has been used in determining the effects of a program, project, or procedure. (p. 4)

Worthen and Sanders (1987) support these conceptual

definitions by differentiating between the two in the following statements:

Formative evaluation is conducted during the operation of a program to provide program directors evaluative information useful in improving the program, and Summative evaluation is conducted at the end of a program to provide potential consumers with judgements about that program's worth or merit. (p. 34)

Through these definitions the similarities and differences of the two types of evaluation are recognized as direct derivatives of the approach, or purpose, from which the evaluation activity is based. The formative approach is based on the assumption that information gathered will be fed back into the program system in order that the quality or function of the program improves (Tuckman, 1985). The summative approach is based on the notion of gathering information which determines or documents the end-value of a program (Sergiovanni and Starratt, 1983; Fitz-Gibbon and Morris, 1978). Once the general purpose of the evaluation process has been identified as either summative or formative, the next procedure is determining the most appropriate evaluation methodology.

\section{Evaluation Methodologies}

In relation to the historical perspectives touched on earlier, the field of program evaluation in education is just now attempting to establish a solid foundation of theoretical and practical application (Raizen and Rossi, 1981). A review of the literature indicates that program evaluation is slowly separating itself from the "measurement" or comparative 
paradigm that has dominated educational evaluation for so long (Worthen and Sanders, 1987; Hayman and Napier, 1975). Built on the evaluation principles set decades earlier by Ralph Tyler this newer perspective is more concemed with an internal perspective. Much of what propels this newer paradigm of educational evaluation comes from the culmination of techniques developed in the social, psychological, and educational fields of study over that last century. The increased interest and funding of social and educational programs in the 1960 s and 1970 s has highlighted the need for identifying commonalties in the evaluation process. This has lead to the creation of a number of agencies, professional organizations, and committees in the last two decades (i.e. National Institute of Education and Evaluation Research Society and the Joint Committee on Standards for Educational Evaluation). In conjunction with these groups many professional journals and publications such as Evaluation Review, Evaluation, and Evaluation News have also appeared. Aimed at establishing theoretical and practical applications to this field these publications began to appear in the late 1970s and early 1980s (Williams and Bank, 1981; Berk, 1981).

A major limiting factor for the infant field of program evaluation in education has been the establishment of strict guidelines and definitions concerning evaluation practices. Worthen and Sanders (1987) identify the "Standards for Evaluation of Educational Programs (Joint Committee on Standards for Educational Evaluation, 1981) and a parallel publication by the Evaluation Research Society in 1982 as the first real standards set in the field (p. 20). The ERS standards were developed with a much broader or comprehensive scope in mind, as the evaluation standards didn't set limitations of study to a particular field.

The number of models and approaches proclaimed by different committees, organizations, and individuals are numerous. The common factor though is the similarity in function and purpose of different methodologies. In order to illustrate these different 
methodologies it is necessary to touch upon purpose and content of general categories of evaluation. Because of discrepancies associated to the infantile characteristics of program evaluation field, the following descriptions will be suggestive instead of definitive in nature.

\section{Categories and Purposes of Evaluation}

At present there are six general categories of program evaluation recognized by the Evaluation Research Society (ERS) Standards Committee (Evaluation Studies Review Annual, 1982). These categories provide an excellent conceptual framework in which other categorical descriptions can be clustered. As illustrated in subsequent narrative, the categories and purposes of evaluation are somewhat lacking in specific boundary and often overlap into one or more other categories. These general categories are defined by the purpose of the evaluation mission and by the different types of evaluation techniques which are used. It is the sole determination of the evaluator(s) which will judge the intensity and specificity of the evaluation process. It is apparent that the approach, processes, or methodologies which are selected are based on the purpose which drives the evaluation process. The distinction between categories of evaluation is definitely subject to the perspectives held by those implementing the evaluation procedure (Rossi, 1979; Worthen and Sanders, 1987).

The ERS Standards Committee (Evaluation Studies Review Annual, 1982) lists these six categories as: "Front-end analysis," "Evaluability assessment," "Formative evaluation," "Impact evaluation," "Program monitoring," and "Evaluation of evaluation" (p. 682).

"Front-end analysis" includes evaluation activities which take place antecedent to the initial installation of a program. The goal of the evaluation process is to confirm and estimate related needs, identify human and financial resources, and to establish possible limitations in the operational functions of a future program. The outcome of this 
evaluation process should provide information which will help in establishing the initial worth and direction of a program. It will also be beneficial in addressing the level or amount of service which the program will be capable of effectively and efficiently supporting.

"Evaluability assessment" refers to evaluation activities which are implemented to determine whether other "types" of evaluation need to be introduced. The main concern for this evaluation process is analyzing the evaluability of the program, with specific focus on those characteristics that will help assist or repress the evaluation activity.

"Formative evaluation" is an evaluation activity which includes the systematic testing or appraising of a continuing program. The results or conclusions of this evaluation process are used to make decisions relating to program modifications. These modifications are considered to be improvements in the structure or function of a program and are sought out to strengthen the overall program's utility.

"Impact evaluation" is an evaluation exercise that focuses on how well a program is working. The information attained in an impact evaluation is usually used to make central decisions about the continuation or level at which a program will be provided. Information is most often gathered under the guise of "summative" evaluation, which by definition concentrates on the outcome or effectiveness of a program. This end-result information can be very powerful in critiquing the effectiveness of a program and can be potent in the decision making process.

"Program monitoring" includes those evaluation processes which monitor the processes, structure, and functions of existing programs. These evaluations can include traces of intended purposes found in other types of evaluation, but differ in that they are generally implemented as a continuous, periodic function of the program itself. In its purest form program monitoring is used with the idea of keeping a regimented evaluative 
process working on existing program continually. The intent of this regimented process can vary in intensity and scope, depending on the requirements of the evaluation.

"Evaluation of evaluation" deals mostly with the secondary evaluation of previously gathered evaluation information in order to derive or estimate the impact or effectiveness of different programs. This approach of evaluation can also use many different types of related evaluation approaches (metaevaluation) in an attempt to draw some type of summative conclusion about a program. Although this particular evaluation process shares many of the characteristics found in impact evaluation, it is secondary evaluative techniques, and is generally much more broad in scope than the evaluations it draws from.

Anderson and Ball (1978) formulate what they call "evaluation purposes," which nearly correspond to the general evaluation categories identified by the ERS Standards Committee (p. 14). The six evaluation purposes included in their work are: "I. To contribute to Decisions About Program Installation, II. To Contribute to Decisions About Program Continuation, Expansion, or Certification, III. To Contribute to Decisions About Program Modification, IV. To Obtain Evidence to Rally Support for a Program, V. To Obtain Evidence to Rally Opposition to a Program, and VI. To Contribute to the Understanding of Basic Psychological, Social, and Other Processes"(p. 3-4). Although these categorical headings appear to be more narrowly focused than those defined by the ERS Standards Committee, they do cover the vast spectrum of possible evaluation directions.

Raizen and Rossi (1981) simply group the possible types of program evaluation under the headings of, "Evaluations for Planning Programs" and "Evaluations of Existing Programs" (pp. 42-46). From these broad categories the researcher then sets the limitations and depth of the particular evaluation program. 
Guba and Lincoln (1981) identify four evaluation models which they feel entertains all the different evaluative intentions. The "countenance model" is rooted in the objectives orientation first instigated by Ralph Tyler. It has been extended to be more procedurally comprehensive and complex in recent years by people such as Robert Stake and James Popham (Stake, 1983; Popham, 1975). The "context-input-process-product model" which has definite similarities to "systems theory" focuses on the evaluative decisions to make in relation to the context of the program (Stufflebeam, et al., 1985; Tuckman, 1985). This model views the evaluation process as a function which is dependent on the decisionmaking structure within the program. It also defines the program as an entity which is in constant change. The "goal-free" model, the third model, shares many similarities of the "context-input-model." The main difference is that the focus of this model is on the effects of the program in relation to the educational needs (Scriven, 1984). The last model discussed is the "connoisseurship model" first introduced by Elliot Eisner as an alternative to most standard models (Eisner, 1985). This model is based on the notions of educational "connoisseurship" (the art of perceiving complexity of the situation) and educational criticism. These concepts are internally derived processes from which all evaluation processes are given value and worth in the analysis and judgement of some activity. It is a more holistic way of perceiving and evaluating the world around oneself.

Worthen and Sanders (1987) steer away from identifying specific evaluation models by identifying more general evaluation approaches (p. 145). These approaches include: "objectives-oriented evaluation approaches," "management-oriented evaluation approaches," "consumer-oriented evaluation approaches," "expertise-oriented evaluation approaches," "adversary-oriented evaluation approaches," and "naturalistic and participantoriented evaluation approaches." Each of these approaches contain similar components of evaluation models and approaches identified earlier. These authors develop the theme that evaluators should not be confined to limitations set by assuming the paradigms of a certain 
evaluation model. That each evaluation activity has somewhat of a different focus and serves a different purpose than any other evaluation activity.

Of interest to this investigation are the "consumer-oriented" and "managementoriented" approaches (Worthen and Sanders, 1987, p. 60). Consumer-oriented being concerned with generating evaluative information related to educational products. In this case the products are an educational service district's programs and services. The management-oriented approaches are concerned with generating information needed for decision-making at the managerial level. Both approaches are based on the general notions of an evaluation process including the identification of goals, objectives, or indicators, and systematically determining whether they have been achieved or observed (Stufflebeam, 1985; Guba and Lincoln, 1981).

\section{PERCEPTION AND PERCEIVING}

The concepts of perception and manner in which perception is developed by the individual person is of importance to this study. Understanding that perception is both a physiological and psychological phenomenon helps one understand why differences in perception occur among similar groups of people and individuals. A limited discussion of this topic will expose the impact this concept has when research attempts are made to ascertain perceptual differences.

Perception is a word that attempts to confine a somewhat borderless concept. The meaning of perception deals with the internal activity of a person processing information in relation to synthesizing external environmental stimuli (Dember and Warm, 1979). It includes the physiological and psychological actions and reactions of the body and mind when acknowledging, processing, and interpreting information. Depending on the vein of particular interest, one can find several theoretical stances supporting different views as to how and why perception happens (Michaels and Carello, 1981). 
The physiological stance primarily addresses the actions of body functions which are either reactive or manipulated in the process of bringing information into the body (Metzger, 1974; Royce, 1974). The psychological stance primarily addresses the functions of the mind in construing information into sensible, organized knowledge (Dember and Warm, 1979). Nevertheless both approaches are attempting to develop a conceptual framework of what is happening during the process of perceiving. Michaels and Corello (1981) distinguish between what they identify as two major categories of theory found in the "perception" field of study in the following narrative:

Proponents of the ecological view argue that perceptions is, quite simply, the detection of information. This approach is labeled 'direct' because a perceiver is said to perceive its environment. Knowledge of the world is thought to be unaided by inference, memories, or representations. Conversely, a second family of theories conceives of perception as 'mediated'-or, to contrast it with Gibson's theory, 'indirect'-and is so called because perception is thought to involve the intervention of memories and representations. (p. 1)

The theoretical approaches are then divided into two distinct theorem categories. The direct approaches of perception which are built on the belief that perception is "reality" at every instant of perceiving the multiple stimulations found in the environment. These theoretical approaches also believe that reality is not influenced by any secondary stimuli found in the mind or body of the perceiver. The indirect approaches of perception believe that any perception is mediated by psychological and physiological stimuli. These mediating stimuli affect how we perceive the environment, and thus effect true reality (Shaw and Bransford, 1977). These approaches rely heavily on the thought that perception is best described as active visual cognition that entails perceiving, remembering, and thinking about what was perceived from external stimuli.

Perception as an activity or process can be examined from a number of different theoretical viewpoints. The viewpoints generally fall into the categories of direct and indirect perception. The notable difference between the two theoretical stands is whether 
the process of perception is mediated with internal stimuli which distort or change true reality. The terminal function of either theoretical vein is to attempt to explain how the perceiver attains a usable pattern of knowledge to construct reality. The merging of the two fields of thought produces a more comprehensive, interactive approach which integrates perception processes with cognitive process (Klien, 1970). In doing so perception is an activity which functions as a dynamic component of the personality.

In relation to this study, which deals with perceptions of program effectiveness, it is necessary to draw from those views which support more of the psychological approaches to perception. Relating to the affective domain of feelings and emotions, research interest will primarily focus the result of the process of perceiving. This result is the culmination of pure thought which has been assimilated through the perceptual process (Pufall, 1977). The emphasize will be the developed feelings of patrons toward the programs and services of a specific educational service district. These developed feelings will be recognized as their "perception(s)."

\section{ORGANIZATIONAL THEORY AND THE EDUCATIONAL SERVICE DISTRICT}

To develop a comprehensive perception of the existence any organization creates, it is necessary to view the organization in a holistic manner. This means that all dependent components within and outside of an organization have to be given consideration as to their effect on how the organization actually works (Rapoport, 1986). This view perceives the organization as an entity which exists within a larger environment, being a mere component of a superior manifestation. This view also perceives the organization as a system which creates its own unique environment and one which is governed by the same laws of action and reaction found in the more comprehensive environment (Scott, 1987; Likert, 1967). Bolman and Deal (1984) explain this phenomenon through paraphrase of earlier work accomplished by Karl Weick on the subject of organizing: 
In translation (of Weick, 1969): Humans and human systems exist in an enacted environment. That is, the system's behavior continually influences the environment that it perceives. (We experience ourselves in a particular place only because our behavior led us there. Our own and others' past and present behavior influences the nature of the place the we experience.) There is always equivocality, or uncertainty, in the enacted environment, since the outside world is always complex and always changing. Organizing occurs whenever relationships (that is, patterns of interlocked behavior) form and begin to reduce some of the uncertainty in the environment (p. 228).

In further description of the existence of organizations, Gibson, Ivancevich, and Donnelly (1976) present the concept of "purpose" in organizations in the following narrative:

The primary rationale for the existence of organizations is that certain goals can be achieved only through the concerted action of groups of people. Thus, whether the goal is profit, providing education, religion, or health care, getting a candidate elected, or having a new football stadium constructed, organizations are characterized by their goal directed behavior. That is, they pursue goals and objectives that can be more efficiently and effectively achieved by the concerted action of individuals (p. 4).

Taking from these assumptions on how and why organizations exist, it is then necessary to focus on those conceptual descriptions that assist in defining both organizational structure and behavior.

\section{Service Organizations}

As with any service oriented organization the impetus to provide a desired service is of the upmost importance for its continuing health and survival. With constantly changing needs, both clients and patrons demand that a service organization purvey the needed service in direct relation to their immediate wants. These needs can range from the exigent to the acquiescent but are, nevertheless, needs expressed by one entity and needs fulfilled by another entity in the form of service.

The educational service district is an example of a service organization (Ginzberg, 1986). Its development and continued existence have been based on providing vital 
supplementary services needed by both public and private schools in the State of Washington (Ruel, 1986, Rorher, 1989).

In order to provide services vital to another organization's functioning, an educational service organization such as the educational service district must constantly refocus on the essence of its existence. It is necessary to reestablish its organizational purpose routinely in order to create a sense of organizational value, and initiate new goals. This must be accomplished in terms of both knowing and understanding what needs are desired from others, how can the organization internally assemble wanted solutions to these needs, and finally, how is the organization going to proffer these services.

\section{Systems Theory}

A theory which supports this line of thought can be found in the "systems-theory" (Kast and Rosenzweig, 1985). Through the use of abstract, descriptive analogies relating to organizational behavior, the theory contrives the interactive processes indicative of an organism functioning within a larger ecosystem (Bolman and Deal, 1987; Owens, 1981; Laszlo, 1972b.). In theory, the organization is perceived as an organism which is constantly moving and constantly changing in relation to its internal and external demands. This developing theory is based on the notion that one can integrate concepts and knowledge from the physical, biological, and social sciences in order to explain how any organization or organism will exist within its environment (Katz and Kahn in Kast and Rosenzweig 1978; Kramer and de Smit, 1977; von Bertalanffy, 1968).

An important concept which has emerged from the general systems theory is the notion of "open systems." The concept of open systems is based on the perception that many organizations, or systems, have permeable, fluctuating organizational boundaries. These organizations are open in the sense that they interact with sub-systems (within) and supra-systems (outside) in an organic existence. These organizations could not exist 
without the constant interaction and input of greater environment in which they operates (Kast and Rosenzweig, 1985).

\section{The ESD as an Open System}

Systems theorists promote the notion that social organizations are viewed as "open" systems. This is based on the fact that the organization has to constantly exchange information, energy, and materials with the external environment (Berrin, 1968; Laszlo, 1972c.). Since the educational service district is an organization which functions on the processes of this exchange, it should subsequently be viewed as an open system-as it is by this study.

One of the fundamental concepts held by the open systems theory refers to the "Input-Transformation-Output Model" of understanding organizational processes (Kast and Rosenzweig, 1985). This concept, though simple in structure, is indicative of the processes found in a service organization such as the educational service district. Understanding this process easily leads to understanding why an organization must know the perceptions its patrons have toward its services. Kast and Rosenzweig (1984) interpret this concept as such:

The open system can be viewed as a transformation model. In a dynamic relationship with its environment, it receives various inputs, transforms these inputs in some way, and exports outputs. (p. 107)

Owens (1981) specifically addresses the concept of the "open system" by describing how it relates to the educational organization in his diagram of the "inputprocess-output" system. He vividly diagrams the organizational process as one that includes all levels of personnel in the entire educational process (see Figure 2.).

As further discussed by Kast and Rosenzweig (1985), the importance of the inputtransformation-output model relates well to the continued existence of an organization:

The survival of the system, in effect, would not be possible without the continuous inflow, transformation, and outflow. In the biological or social 
system this is a continuous recycling process. The system must receive sufficient input of resources to maintain its operation and also to export the transformed resources to the environment in sufficient quantity to continue the cycle. Every surviving system must provide some output acceptable usually to a collateral or supra-system (p. 112).

This excerpt supports the notion that a service organization must be in constant interaction with the larger environment in order to have the ability to survive at least at a minimal level. This interaction is necessary to produce the information or basic knowledge required by the organization to evaluate past behaviors, present operations, and future organizational actions.

\begin{tabular}{|c|c|c|}
\hline $\begin{array}{l}\text { INPUTS } \\
\text { FROM } \\
\text { SOCIETY }\end{array}$ & $\longrightarrow$ EDUCATIONAL PROCESS - & $\begin{array}{c}\text { OUTPUTS } \\
\rightarrow \text { TO SOCIETY }\end{array}$ \\
\hline \begin{tabular}{|l|} 
Knowledge \\
Yolues \\
Goals \\
Money
\end{tabular} & $\begin{array}{l}\text { Structure (for example,grade levels, } \\
\text { classes, school levels, departments, } \\
\text { organizational hei rarchy) } \\
\text { People (for example, teachers, bus } \\
\text { drivers, counselors, coaches, } \\
\text { custodians, supervisors, dieticians, } \\
\text { administrators, nurses) } \\
\text { Technology (for example, buildings, } \\
\text { class schedules, curricula, } \\
\text { laboratories, libraries, chalkboards } \\
\text { books, audio-visual equipment, } \\
\text { buses) } \\
\text { Tasks (for example, teach classes; } \\
\text { serve food; run buses; administer } \\
\text { tests; account for funds; } \\
\text { stewardship; supervise personnel; } \\
\text { conduct extracurricular program) }\end{array}$ & $\begin{array}{l}\text { Individuals more } \\
\text { able to serve } \\
\text { themselves and } \\
\text { society because of } \\
\text { improved } \\
\text { 'Intellectual and } \\
\text { manual skills } \\
\text { - Powers of reason } \\
\text { ond snalysis } \\
\text { 'Volues, attitudes, } \\
\text { motivation } \\
\text { Creativity ond } \\
\text { inventiveness } \\
\text { Communication } \\
\text { skills } \\
\text { - Cultural } \\
\text { appreciation } \\
\text { - Understanding of } \\
\text { the world } \\
\text {-Sense of sociol } \\
\text { responsibility }\end{array}$ \\
\hline
\end{tabular}

Figure 2. Schooling as an input-process-output system. Adapted from Robert G. Owens, Organizational Behavior in Education (Englewood Cliffs, N.J.: Prentice Hall, Inc., 1981), p. 64. 
Another major concept of this theory, and one of specific interest to this study, is the notion of "feedback" (Berrin, 1968; Hanson, 1979). This concept pertains to any type of information which enters the organization as an "input" and affects the "outputs" during the internal processes (transformation) of a system (see Figure 3.). The information cycle works as the communication link between the organization and the environment within which it functions. This cycle provides pertinent information to an organization in terms of how successful its input, transformation, and output processes are functioning. More importantly, feedback works as a guide for any future change within the organization (Baumol, 1986). This function is a common component of all organizations and exists with varying gradations of effort put into the accumulation and analysis of this information.

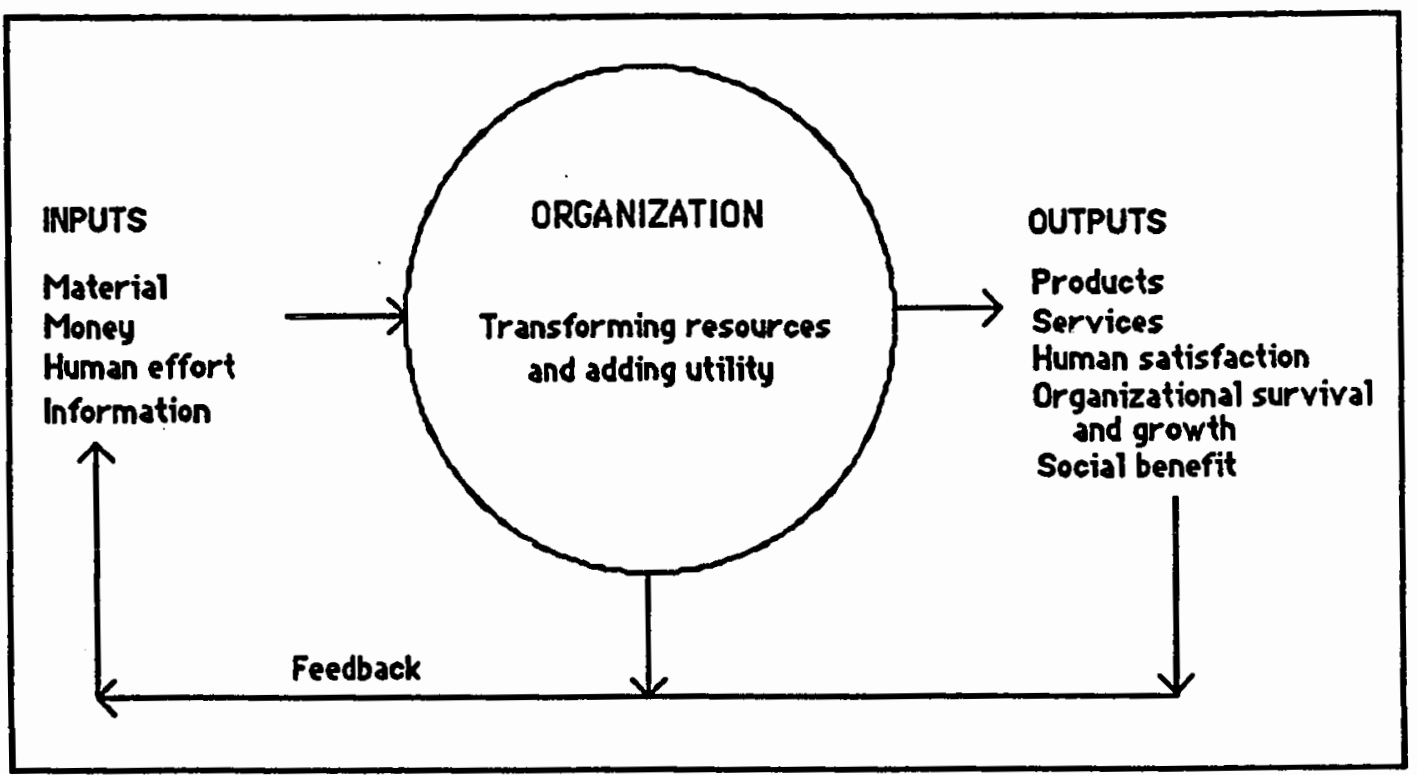

Eigure 3. The organization as a transformation system. Adopted from Fremont E. Kast and James Rosenzweig, Organization and Management: A Systems and Contingency Approach (New York, McGraw-Hill Book Company, 1985), p. 112.

From the theoretical view of organizational structure, and in particular the service oriented organization, the importance of information, or feedback, is central to continuation of the organization's existence (Czepiel, et al, 1987; Baumol, 1986; Stanback, et al, 1981). 
Feedback works as the stabilizing agent in any organizational processes. The amount, variation, and focus of the feedback govern the deviation from the normal processes of the organization, or what is most often referred to the homeostasis, or equilibrium, of the organization (Mattessich, 1978; Berrin, 1968; Kast and Rosenzweig, 1985).

How the organization interprets and reacts to feedback will determine subsequent fluctuations in the organization's internal processes. The educational service district which provides services and programs to patron school districts on a contractual or volunteer basis needs to have constant, reliable information in order to function in a progressive fashion. The perceived effectiveness of its programs and services will have a definite effect on the number and variety of services contracted (Fromhold 1989; Yule, 1989).

\section{PROGRAM EVALUATION AND EDUCATIONAL SERVICE DISTRICTS}

To effectively relate pertinent research regarding the content of this study, a discussion of existing research in the general field of educational services districts will be given first. This will help develop a sense of where research in this area is at the present time and what influences have directed this course of evolution. In the next section, specific literature relating to educational service district program evaluation will be covered. Narrative will cover the existing context and content of evaluations relating to the educational service district. Discussion regarding proposed evaluation components and evaluation strategies by authorities in this field will then be reviewed. This will lead to the discussion of a singular study on the same general topic of this study, and finally some concluding remarks.

\section{Research on Educational Service Districts}

As a result of the relative infancy of the educational service district in the State of Washington and the rest of the nation, only limited research can be found in this field of study (Turner, 1989; Ruel, 1986). A thorough review of the ERIC search, dissertation 
abstracts, and general library subject headings produced minimal literature pertaining to educational service districts. This also includes information regarding district or state collaboratives in the guise of a functional intermediate agency (Hughes and Achilles, 1976; Yin and Gwaltney, 1981). The majority of research and literature relating to educational service agencies primarily discusses implementation and organizational characteristics (Buchser, 1984; SW \& WC ECSU, 1980). Outside of an individual study investigating the effectiveness of educational service districts there is no related literature at this time (Ruel, 1986). This lack of information can be attributed to the lack of interest in this field, the newness of the educational service district concept, or the lack of credible approaches to analyzing and evaluating this type of organization (AAESA, 1979).

In conversation with Walter Turner, Executive Director of the American Association of Educational Services Agencies (AAESA), a division of the American Association of School Administrators, the notion that very little research on any area of educational services agencies was discussed (Tumer, 1989). Dr. Tumer attributed this fact to the newness of educational services agencies in most states, coupled with the reduction in funds or grants for such studies during the last nine years. Although educational service agencies had increased in numbers, funding, and scope during the wave of general interest in education generated during the 1960 s, most programs did not include an evaluation component as a major function of their internal program (AAESA, 1979). Also, being an educational service organization which operates outside of direct public view the educational service agency most often escapes the scrutiny local school districts are accustomed. There simply has been no concern, or pressure, on the part of many educational service districts to perform evaluations. Because of these reasons there has been little information gathered on the effectiveness of this type of educational organization. 
In conversation with Robert Stephens from the Department of Education, Policy, Planning, and Administration at the College of Education, University of Maryland, the discussion of this same notion of organizational infancy and the lack of funds to study this particular area were covered (Stephens, 1989). Determining which factor is most influential in stagnating research in this area is hard to do. Regardless, the interest and funds for research in this field of study have not been realized as of yet. Dr. Stephens has produced several research products for the American Association of Educational Service Agencies over the last decade. Dr. Stephens mentioned a few proposed projects introduced in the early 1980 s which were never followed through with due to the lack of funding interest (Stephens, 1989). Nevertheless, a few of these proposed projects add insight into possible evaluative processes and techniques directed at educational service agencies. It was suggested that what is needed at the present time are exploratory evaluative strategies which will work as examples for future evaluative activities. A few of the reports issued by the American Association of Educational Service Districts have specifically addressed evaluation topics. These will be discussed later in this section.

The state of dormancy in evaluation of educational service agencies can be attributed to the environment which the majority of these organizations exist within. The educational service agency is found in a precarious position, working as the middle agency between the state education office and the local education agency (The Encyclopedia of Education,1971; Hughes and Achilles, 1976). The perception of the educational service agency being an office which gathers and disseminates information between the local and state education agencies is still prevalent. The view of a limited scope in organizational activity has fostered the notion that evaluation is not really necessary at this level, or at least has become secondary to other needs found in the state. A major problem with retaining this view relates to the changes being found in educational service agencies. $A$ rapid change toward instructional programs and services provided by most educational 
service agencies today rebuts the conservative view of past. This is especially true in the State of Washington, as permission to provide direct student services was given to educational service districts in 1981 (Rorher, 1988).

\section{Educational Service District Evaluation}

The educational service agency is caught in a position of providing services to two sets of clients: the state education agency and the local education agency. This is an important concept since the service agency is equally dependent on the other for its existence, either monetarily, in functioning, or both. These two agencies are inclined to take different perspectives in what properties of the service agency should be evaluated (AAESA, 1979). The local district would evaluate the service agency in terms of providing resources, services, and programs useful to their mission of educating the individual student. This evaluation would be more oriented toward instructional processes. The state education agency would most often evaluate the service agency in terms of exercising administrative functions regarding the management functions of individual school districts. This evaluation would be more oriented toward administrative processes.

With the inclusion of direct student services, as found in the State of Washington, the evaluation orientation toward instructional processes is enhanced. These newer services also dictates the inclusion of a larger, more diverse population being included in the evaluation population. The complete realm of certificated professionals found in local school districts are now more interactive with the educational service agencies service and programs. This increased interaction enhances the grasp these individuals have on the service agency functioning through multiples of prejudices influencing program development and program modifications. 
Stephens, Perry, and Sanders (1989) in their paper, Desiening Organizational

Effectiveness Studies For Rural And Small School Districts, discuss the complexity of developing evaluation activities for smaller educational units. They state:

This is largely because the measure of quality (no sharp distinction between effectiveness and quality is being made here, even though the two terms could have different meanings depending upon their use in different contexts) of a rural school district is dependent on the theoretical approach being used, the purpose of the assessment, the perspective from which effectiveness is being judged, and other important issues and value judgements that must be made. (p. 7)

The authors describe the numerous variables which all effect the development, implementation, and conclusions of an evaluation project in one manner or another. It would be easy to apply this notion to most any evaluative process investigating the effectiveness of a program or service. The key to executing an evaluative activity investigating organizational effectiveness is in recognizing the evaluative criteria from which standards of effectiveness can be developed.

The American Association of Educational Services Agencies (1979) identifies the following characteristics as fundamental to the interest of a healthy service agency:

-an adequate legal framework in order to insure legitimacy of members of the state system of education -a reasonable degree of organizational stability in order to promote continuity in programming and staffing -a reasonable degree of organizational flexibility in order to respond to regional differences - a clear, unambiguous mission -ability to develop high quality programming ability to develop high quality staffing -a reasonable degree of fiscal independence and fiscal stability (p. 25)

These are the major areas of interest the educational service agencies are concerned with when evaluating the performance of the overall organization. The agency is interested in maintaining control of these components in order to interact with the external environment in a self-sustaining manner. Keeping these views in mind it is necessary to understand those concerns which will influence the point of view that local school district 
is going to take when evaluating the educational service agency. The American Association of Educational Services Agencies (1979) state that during the evaluation of an educational service district the local school district will judge different features of the agency in terms of what services inhibit or facilitate the functioning of the district. The AAESA (1979) list the following district needs as those which will be used as judging criteria:

-the maintenance of a degree of autonomy in policy development -flexibility in programming to meet locally determined priorities -flexibility in staffing -the best use of local resources for the achievement of locally established priorities the provision of external support efforts that are based on the needs of the local school districts -the provision of external support efforts that are definite, reliable, and accessible -the provision of external support efforts that complement the districts' activities and are not in competition with their functions -the provision of external support efforts that are of equal or superior quality in programming and staffing than that possible by the districts -the provision of mechanism that make possible the substantial involvement of the districts in the decision processes of external support efforts (pp. 24 25)

In attempting to understand the client and service provider relationship, it is necessary to draw from the two different perspectives identified above. This is necessary to adequately address the complexities of an evaluation of an educational service agency. Understanding the perspectives of each organization will be instrumental in recognizing values and prejudices effecting the evaluative process.

\section{ESD Effectiveness Research}

Nationally, the only research specifically related to the topic of this study has been a statewide research project investigating the effectiveness of educational services districts in the State of Washington (Ruel, 1986). Ruel (1986) conducted a study looking at the perceived effectiveness of educational service districts from across the State of Washington. The study investigated the differences found among different categories of 
Washington educators (teachers, administrators, ESD employees, etc.) throughout the nine service districts now operating in the state. The survey was based on an inquiry strategy using general topic questions dealing with all services and programs which the ESD provides.

The emphasis of Ruel's study was to develop a sense of what the present status was in relation to ESDs in Washington State at that time. The study was comprehensive in terms that it surveyed all levels of educators on all services and programs offered by ESDs. The programs and services were dealt with through identifying general categories of services (i.e. business services) and developing a question pertaining to that particular topic. This approach was used due to the variations of programs initiated and developed by individual educational service units within the state. The survey questionnaire was based on five demographic questions and fifty-eight effectiveness rating questions. These fiftyeight questions condensed the different general services and programs offered by all ESDs in the state into common topic questions.

Several major findings of the study are discussed here briefly. The findings of the study displayed that the majority of respondents felt the ESDs were effective in carrying out the majority of their programs and services. It was also found that teachers and educational staff associates were most often unaware of a program or service offered by their ESD, or were unable to rate these services. On the other hand, superintendents most often rated ESD programs and services as being effective. The superintendents were also very knowledgeable of almost all services. It was also found that as the size of the school district increased the amount of services and programs used by the district decreased. In conjunction with this, the smaller districts who patronized their ESD more often were found to rate the ESD more effective. There was a large amount of variability in the knowledge and effectiveness ratings found among central office personnel (Ruel, 1986, pp. 222-224). 
In conversation with Gary Ruel, the areas of future research suggested in his study were discussed as possible influences in the development of this investigation (1989). Dr. Ruel expressed that although he did not specifically identify the investigation of a single ESD unit in his study, he did feel that it could be extremely productive to pursue this line of inquiry. This opinion was supported by the fact that the educational service district in the State of Washington is quickly progressing toward a cooperative, service-oriented organization, and that the role of the educational service district as solely a regulatory state agency is fading. Through investigating a single ESD unit, the findings of a study may be more relevant to providing pertinent information about how patrons feel about individual programs and services.

\section{Conclusion}

To reiterate, other than the study discussed previously, no past research related to investigating the perceived effectiveness of an educational service district's programs and services could be found (Ruel, 1986). Research and literature regarding the general study of educational service districts is still in a stage of infancy (Stephens,1989; Turner,1989). At present there is no common body of knowledge relating to educational service districts from which to draw inferences, make related judgements, or develop formative and summative evaluative strategies. This is especially true in the area of evaluating services and programs offered by the individual organization. It may be said that this particular vein of study is in the embryonic stage and is in need of both research and appropriate research methodology.

As the organizational objective of the educational service district moves away from a regulatory agency structure toward the service-oriented organization as in the State of Washington and across the Nation, the need to be more responsive to patrons will increase. This will increase the need for decision making information relevant to educational service organizations. It will also mean more interaction with patrons in terms of evaluation 
activities focused on the effectiveness of different services and programs offered by the educational service district. 


\section{CHAPTER III}

\section{METHODOLOGY}

This research study investigated the perceptions of effectiveness concerning an educational service district in the State of Washington. The intent of this study was to ascertain what perceptions are presently held by public school educators towards the programs and services provided by their regional educational service district. The organization of focus was Educational Service District 112, located in Southwest Washington State. The perceptions of effectiveness were drawn from certificated educators and school board members who are employed or associated with the 30 public school districts served by ESD 112.

The narrative in this chapter will explain the methodology which was used for this study. The chapter is divided into seven sections. The first section provides an explanation of the study's conceptual framework. This section begins by identifying the questions which provided the impetus for this study and discusses the general hypotheses investigated. The second section discusses the sample (respondents) of the study. The third section of the chapter extends discussion from the second section by providing the reader with an overview of the survey respondents. The fourth section discusses the survey instrument. The fifth section discusses the field testing routine used before the initial survey distribution. The sixth section discusses the distribution and collection processes used for the survey instrument. The seventh section provides the reader with an explanation of the data analysis procedures used in Chapter IV. 


\section{CONCEPTUAL FRAMEWORK}

To properly illustrate both the content and purpose of this study it is necessary to identify the originating questions and discuss the concepts and academic work from which the study was developed. This will clarify the intent of the researcher and the purpose and structure of the study itself.

\section{Originating Ouestions}

The thrust of this study was to answer the major questions: "What is the present status of program and service effectiveness as perceived by the patrons of Educational Service District 112?," and "Is ESD 112 perceived as a viable component of the educational system in the State of Washington?" Supportive questions: "Are ESD 112's services and programs perceived as effective by various educator groups?," "What programs are perceived as effective and what programs are perceived as ineffective, and by whom?," and "What characteristics, both personal and professional, might influence differences in perceived program effectiveness?" Also of primary importance to this study is the question: "What evaluative approach or research methodology can be used to productively identify these perceptions of effectiveness?"

These questions evolved from the notion that as the organizational objective of the educational service district increasingly departs from the regulatory agency of the past toward a more comprehensive service-oriented organization, the need to be responsive to patrons' needs will increase. This will demand more information regarding the effectiveness of programs and services being offered. It will also demand evaluative approaches applicable to generating useful information. Results from these inquiries will aid in decision-making conceming program development, service implementation, and service revision. 
Study Hypotheses

For the purpose of managing the data in the statistical analysis portion of this study, several "general" hypotheses were developed. These were used to develop several different groups of hypotheses concerned with specific lines of inquiry and different types of statistical testing. The Primary, Secondary, and Demographic analysis sections found in Chapter IV each identify the hypotheses used in those individual sections. These hypotheses were that:

-No differences exist in the mean responses of the various characteristic groups (by position, years of experience in present district, years of experience in the State of Washington, district size, county location, and degree level) on those question rating the effectiveness of Educational Service District 112.

-No differences exist in the proportions of respondents, according to professional position (teachers, principal, assistant principal, board member, and central office personnel) falling into different response categories on questions regarding general information topics.

-No differences exist in the proportions of respondents, according to profession position (teachers, principal, assistant principal, board member, and central office personnel) falling into different response categories on questions regarding demographic topics.

-No differences exist in the mean responses of the position groups, while adjusting for the affects of district size, county location, and degree level on those question rating the effectiveness of Educational Service District 112.

\section{Conceptual Framework and Review of Literature}

For the purpose of developing a foundation of knowledge from which to initiate both an effective and efficient research procedure, a literature review encompassing four topic areas prefaced the development of the final study methodology. These four areas of 
related literature included the topics of Educational Service Districts, Program Evaluation, Perception, and Organizational Theory.

Educational Service Districts. The purpose for reviewing the literature regarding educational service districts was an attempt to ascertain the volume and depth of any academic or practical research related to this topic. It was assumed that it would be crucial to review any information relating to educational service districts which would effect the expediency and effectiveness of this study.

Program Evaluation. Due to the relative newness of this study area a broad, comprehensive approach was taken when developing the content and structure of this study. Through reviewing the literature relating to educational service districts it was evident that investigative approaches were either non-existent or were not wholly useful in this particular setting. For this reason literature relating to the practical aspects and techniques of evaluation and program evaluation were consulted.

Two main concerns prompted literature review in this area. First, in order for relevant information to be gathered in this educational setting a conceptual approach to the evaluation process had to be developed. Second, evaluative techniques were needed in the research process in order to create a substantive research methodology. Review of historical, theoretical, and practical aspects of program evaluation assisted in developing the research methodology used for this study. Understanding the conceptual notions supporting varying evaluative approaches and methodologies was of primary interest in this literature review.

Perception and Perceiving, It was necessary to review pertinent theoretical literature concerning perception in order to arrive at major assumptions of the study. One set of literature believing that the perceptions of individuals are uniquely personal and uniquely different. Another set of literature believing that perceptions have no greater or 
lesser value than the value attached by the individual through their personal knowledge base.

There will be no argument in this study as to which of the two major theoretical stands is more applicable, either "direct perception" or "indirect perception" (Klien, 1970; Dember and Warm, 1979). This study, however, is consistent with the concept of "indirect perception." This concept is based on the notion that our perceived reality is always being mediated by feelings, emotions, and past experiences (Michaels and Corrello, 1981; Shaw and Bransford, 1977).

Organizational Theory. Literature pertaining to organizational theory was reviewed in order to bring contextual relevance to the findings of the study. The educational service district was identified as an "open system" organization (Kast and Rosenzweig, 1985). The importance of information in the form of "feedback" was identified as a critical component in the process of open system organizations such as the educational service district (Scott, 1987; Berrin, 1968). Most often considered formative information, this feedback works as the single major agent which redefines and reshapes the internal processes and outputs or products of an organization (Hanson, 1979).

\section{Conceptual Perspectives of the Study}

This study should be viewed from several conceptual perspectives. First, the study is most associated with the conceptual domain of descriptive research, and is considered to be an endeavor in that vein of study (Ary, 1985). Second, although the primary intention of this study was to yield descriptive information (most often associated with "summative" evaluations), it was also intended that information generated would be used for "formative" purposes (Worthen and Sanders, 1987; DeRoche, 1981; ERS Standards Committee, 1982). Third, the general evaluative category would be best described as an impact evaluation study based on "perceptions" (ERS Standards Committee, 1982). Fourth, the actual methodology used to gather information resulted in the gleaning of appropriate 
concepts and procedures from those models often associated with the "management" and "consumer" approaches of evaluation (Worthen and Sanders, 1987; Guba and Lincoln, 1981; ERS Standards Committee, 1982; Scriven, 1981; Stephens, Perry, and Sanders, 1989). And finally, conceptually, the significance of the research findings lays in the notion that educational service districts exist as an "open system," which are critically dependent upon constant "feedback" from the surrounding environment (Kast and Rosenzweig, 1985; Scott , 1987; Hanson, 1979).

\section{Discussion of Conceptual Perspectives and Methodology}

Due to the newness and individual characteristics of the field of inquiry being investigated, no single investigative model could be identified as the most befitting procedure to adopt. Therefore, the procedures used in this evaluative process are designed to address the characteristics specific to this study. As identified by Worthen and Sanders (1987), who discuss the importance of making the evaluation procedure match the situation instead of the reverse:

It is ironic that in a field with such a rich array of altemative evaluation approaches, there still exists a tendency to fall prey to the 'law of the instrument' fallacy, rather than adapting or inventing evaluation methods to meet our needs. (p. 53)

Pursuing a path from the general to the specific, the study methodology should be considered along the line of thought discussed in the following narrative.

As the major intent of this investigation is to obtain information concerning the current status of a phenomenon, this study should be considered descriptive research (Ary, 1985). The summation of this research study, including the review of literature, the methodology, and the reporting of the findings, was specifically used to identify "what exists" in this line of inquiry at the present time.

The investigative view taken in this research is one of seeing the study as an "impact" evaluation, based solely on the perceptions of individuals who use the services of 
Educational Service District 112 (ERS Standards Committee, 1982). As an "impact" evaluation, the research process examines the value of the programs and services through assessing the effect they have on users, or patrons perceptions. Conceptually identified as "utilitarian" by Worthen and Sanders (1987), this study's approach is concerned with the overall impact on the total group instead of just the individual (p. 48). The utilitarian approach emphasizes the functioning of a program or organization in regards to the "public" it serves and the program's or organization's effectiveness.

Subsequent to the utilitarian view assumed was the identification of the evaluative approaches most appropriate to this research investigation (Worthen and Sanders, 1987). Due to the situation and manner in which it was decided the information would be gathered, the conceptual notions supporting two approaches were adopted, i.e., the "managementoriented" and the "consumer-oriented"approaches (Worthen and Sanders, 1987, p. 60). The consumer-oriented approaches are most often associated with generating evaluative information related to educational products. In this case, the products are an educational service district's programs and services. The management-oriented approaches are concerned with generating information needed for decision-making at the managerial level. Both types of approaches are based on the general notions of an evaluation process including the identification of objectives or indicators and the systematic determination of whether they have been achieved or observed (Stufflebeam, 1985; Guba and Lincoln, 1981).

A specific evaluative approach which was the primary model used in this study was Stufflebeam's CIPP (context-input-process-product) evaluation model (Guba and Lincoln, 1981). Of the four types of evaluations identified by Stufflebeam (i.e. context evaluation, input evaluation, process evaluation, and product evaluation), the "product" evaluation framework aligned with the needs of this research study. This component of the model is based on the notion that ESD programs and services are considered products. Further 
applicable to the methodology of this study was Stufflebeam's proposed outline, or steps, when approaching an evaluation activity. Worthen and Sanders (1987) identify these steps as: (1) Focusing the Evaluation, (2) Collection of Information, (3) Organization of Information, (4) Analysis of Information, (5) Reporting of Information, and (6) Administration of Evaluation (p. 79).

Although no specific steps or procedures were adopted from the consumer-oriented approaches, they did add conceptual insight into the study process. For example, Scriven's product evaluation approach distinguishes several concerns which need to be considered from the consumer's perspective when evaluating a product or program (Worthen and Sanders, 1987). Through identifying the concerns which the consumer may have in relation to the evaluation of a product, the evaluator may be better able to create a more effective and productive evaluation activity (Scriven, 1981; 1984).

\section{STUDY POPULATION}

The population of this study included school board members, superintendents, principals, assistant principals, central office personnel, and teachers and certificated support personnel within ESD 112 service area. The survey was sent to all school board members, all superintendents, all principals, assistant principals, and all central office personnel involved in curriculum, instruction, or special services. The survey was also sent to all classroom teachers and certified support personnel found in those school districts with $\mathbf{2 0 0 0}$ or fewer students, and to a proportional random cluster sampling of those teacher members found in districts with more than 2000 students. This sample was obtained by random selection of school units (school buildings) and surveying of the entire certificated staff of each of these units.

The sample included board members $(N=150)$, district superintendents $(N=30)$, all building principals $(\mathrm{N}=125)$, all assistant principals $(\mathrm{N}=54)$, and certificated central 
office personnel $(\mathrm{N}=55)$. The study sample also included: a) the entire teacher and certificated support population of districts with 2000 or fewer students $(N=747)$, and b) a proportional random cluster sample of teachers and certificated support personnel found in those districts with more than 2000 ( $\mathrm{N}=346$ ). The certificated support personnel included staff such as reading specialists, math specialists, counselors, and resource room teachers, among others.

The first portion of the teacher sample (which included support personnel) was selected from all buildings in those districts with $\mathbf{2 0 0 0}$ or fewer students. This teacher sample comprised $22.0 \%$ of the teachers and support personnel in the ESD 112 service area.

The proportional random cluster teacher sample (which included support personnel) included those teachers found in districts with more than $\mathbf{2 0 0 0}$ students. This sample was drawn from $78.0 \%$ of the teacher population found in the ESD 112 service area. It was decided to implement a proportional random cluster sample from those districts with more than $\mathbf{2 0 0 0}$ students due to the disproportionate amount of teachers found in this category and the lack of accessibility to the individual respondent. A random sample of not less than $10.0 \%$, or 250 teachers, was determined to be representative of the teachers found in large districts.

School buildings found in the large school district stratification were sub-divided into high schools, middle schools, and elementary schools. A number of buildings from each group were randomly selected. The number of buildings included in this sample was based on estimating the average teaching staff of buildings within each of the three school level categories and then selecting enough buildings from each category to generate a near equal number (teachers from each school grade level category) of teachers or a proportional random cluster sample (Table I). Random selection was accomplished by writing each building's name on a piece of paper and placing them by category in a small box, and then 
having a person not associated with the study randomly select two high schools, four middle schools, and five elementary schools.

The actual number of surveys distributed to the schools selected for this category included: 2 high schools $(\mathrm{N}=117), 4$ middle schools $(\mathrm{N}=100)$, and five elementary schools $(\mathrm{N}=129)$. These numbers are based on the sum of actual teacher-to-student ratios for each individual school selected at the state funding ratio of 50-to-1000.

\section{TABLE I}

TEACHER TO STUDENT RATIOS FOR HIGH SCHOOLS, MIDDLE SCHOOLS, AND ELEMENTARY SCHOOLS FOUND IN DISTRICTS WITH MORE THAN TWO-THOUSAND STUDENTS

\begin{tabular}{llccl}
\hline $\begin{array}{l}\text { Number of } \\
\text { Schools }\end{array}$ & $\begin{array}{l}\text { Total Number } \\
\text { of Students }\end{array}$ & $\begin{array}{c}\text { Average } \\
\text { Building Pop. }\end{array}$ & $\begin{array}{c}\text { Average Teacher } \\
\text { Staff at } 50 / 1000\end{array}$ & $\begin{array}{c}\text { Range of } \\
\text { Student Pop. }\end{array}$ \\
\hline 11 & 13,135 & 1194 & 60 & $760-1444$ \\
17 & 10,289 & 605 & 30 & $422-850$ \\
55 & 25,521 & 464 & 23 & $120-665$ \\
\hline
\end{tabular}

\section{RESPONDENT OVERVIEW}

From the 1507 people surveyed a total of 769 people responded, for a $51.0 \%$ overall response rate (Table II). The superintendent's and central office personnel's response rate was $73.0 \%$, with 62 of the 85 superintendents and central office personnel responding. The principal's response rate was $88.0 \%$, with 109 of the 125 principals responding. The assistant-principal's response rate was $63.0 \%$, with 34 of the 54 assistant-principals responding. The board member's response rate was $30.0 \%$, with 45 of the 150 board members responding. The teacher's and support personnel's response rate was $47.0 \%$, with 519 of the 1093 teachers and support personnel responding. 
Table III provides further breakdown of these aggregate categories by illustrating the numbers of respondents found in the individual occupational groups identified on the survey instrument.

TABLE II

SURVEY DISTRIBUTION AND RETURN RATES IN ACTUAL NUMBERS AND PERCENTAGES BY AGGREGATE CATEGORIES

\begin{tabular}{lccc}
\hline Position Groups & $\begin{array}{c}\text { Total Surveys } \\
\text { Sent }\end{array}$ & $\begin{array}{c}\text { Total Surveys } \\
\text { Retumed }\end{array}$ & $\begin{array}{c}\text { Total Percent } \\
\text { Retumed }\end{array}$ \\
\hline School Board Member & 150 & 45 & $30 \%$ \\
Central Office/Superintendent & 85 & 62 & $73 \%$ \\
Principals & 125 & 109 & $88 \%$ \\
Asst. Principals & 54 & 34 & $63 \%$ \\
Teachers/Support Personnel & 1093 & 519 & $47 \%$ \\
Totals & 1507 & 769 & $51 \%$ \\
\hline
\end{tabular}

The respondent retum rates show that nearly $68.0 \%$ of the 769 respondents were either teachers or certificated support personnel. Fourteen percent of the total respondents were principals and $4.0 \%$ of the total respondents were assistant principals. It also showed that a little over $8.0 \%$ of the respondents were central office personnel or superintendents, and $6.0 \%$ of the respondents were board members. 
TABLE III

\section{RESPONDENT RETURN RATES IN ACTUAL NUMBERS AND PERCENT OF TOTAL SURVEYS BY OCCUPATIONAL CATEGORIES}

\begin{tabular}{|c|c|c|c|c|}
\hline $\begin{array}{l}\text { Position Groups } \\
\text { and } \\
\text { Sub-Groups }\end{array}$ & $\begin{array}{l}\text { Number of } \\
\text { Surveys } \\
\text { Sent }\end{array}$ & $\begin{array}{l}\text { Number of } \\
\text { Surveys } \\
\text { Returned }\end{array}$ & $\begin{array}{l}\text { Group } \\
\text { Retum } \\
\text { Rate }\end{array}$ & $\begin{array}{l}\text { Percent of Total } \\
\text { Retumed }\end{array}$ \\
\hline Teacher & 1093 & & $47.0 \%$ & \\
\hline $\begin{array}{l}\text { Elementary } \\
\text { Middle School } \\
\text { High School } \\
\text { District Support Personnel } \\
\text { ESD } 112 \text { Support Personnel }\end{array}$ & & $\begin{array}{c}203 \\
115 \\
136 \\
47 \\
18\end{array}$ & & $\begin{array}{c}26.4 \% \\
15.0 \% \\
17.7 \% \\
6.1 \% \\
2.3 \%\end{array}$ \\
\hline Principal & 125 & & $88.0 \%$ & \\
\hline $\begin{array}{l}\text { Elementary } \\
\text { Middle School } \\
\text { High School }\end{array}$ & & $\begin{array}{l}66 \\
23 \\
20\end{array}$ & & $\begin{array}{l}8.6 \% \\
3.0 \% \\
2.6 \%\end{array}$ \\
\hline Assistant Principal & 54 & & $63.0 \%$ & \\
\hline $\begin{array}{l}\text { Elementary } \\
\text { Middle School } \\
\text { High School }\end{array}$ & & $\begin{array}{c}0 \\
10 \\
24\end{array}$ & & $\begin{array}{l}0.0 \% \\
1.3 \% \\
3.1 \%\end{array}$ \\
\hline $\begin{array}{l}\text { School Board Member } \\
\text { School Board Member }\end{array}$ & 150 & 45 & $30.0 \%$ & $5.9 \%$ \\
\hline $\begin{array}{l}\text { Central Office } \\
\text { Central Office Personnel } \\
\text { Superintendent }\end{array}$ & 85 & $\begin{array}{l}35 \\
27\end{array}$ & $73.0 \%$ & $\begin{array}{l}4.6 \% \\
3.5 \%\end{array}$ \\
\hline Totals & 1507 & 769 & $51.0 \%$ & $100 \%$ \\
\hline
\end{tabular}

\section{SURVEY INSTRUMENT}

The content of the survey instrument was drawn from several sources. The majority of the survey instrument items were drawn either from the ESD 112's Services Matrix or the ESD 112's program and services pamphlet. The service matrix consisted of a display of the general programs and services within the Instructional and Curriculum and Special Services Divisions of ESD 112 (Appendix 1). The pamphlet consisted of a comprehensive listing and description of programs and services offered. The Curriculum Support Services are identified as a sub-division of the Instructional Services Division, as are the Instructional Media services. The Special Services Division included the Special Education Cooperatives as a sub-division of its programs and services. 
Opportunities were made for the administrative staff of ESD 112 to have input on the content of the survey instrument. These included individual and group meetings and written solicitations requesting information and input regarding the instrument. Revisions were made as appropriate.

Another source of information used in the construction of this survey instrument was a similar survey developed for the purpose of assessing the effectiveness of ESDs in a statewide study recently performed in the State of Washington (Ruel, 1986).

A single, 62 item survey instrument was constructed and distributed to all categories of respondents (Appendix 1). Concise directions explaining how to answer the survey items were provided. Respondents answered the survey on the same sheet on which the items were written. The entire survey was then returned through the ESD 112 Integrated Delivery Service. The survey instrument was structured in such a way that the last item of the survey led into oversized printed directions on how to return the completed instrument.

The survey instrument was divided into two major sections. The first section included occupational and general information items. The second section of the instrument included effectiveness rating items pertaining to programs and services in the areas of instruction and curriculum and special services, and also questions regarding the total ESD organization. The questions pertaining to instructional and curriculum services and programs were grouped into sub-sections on the second portion of the survey because of shared personnel and resources at ESD 112.

The occupational information portion contained in the first section of the survey included six items. These items included the subjects of: (a) position, (b) employment years in district, (c) teaching years in Washington, (d) size of district, (e) county location of school district, and $(f)$ level of education. 
The general information portion contained in the first section of the survey included eight items. These eight items inquired into the issues of: (a) understanding of purpose of the ESD, (b) extent of involvement in the program, (c) knowledge of district's involvement in ESD programs, (d) general orientation of the types of programs and services used by district, (e) impact of ESD on personal work, (f) constraints and difficulties in accessing ESD services, ( $g$ ) responsiveness of ESD to individual's needs, and (h) opinions concerning whether individual district should contract services.

The remaining 48 items asked the respondents to rate the effectiveness of the "total" ESD organization and the effectiveness of individual programs and services. These 48 rating questions were divided into three distinct sections on the survey. The first effectiveness rating question section was concerned with the "total" ESD 112 program. This section consisted of 10 "general effectiveness" rating items. The last two sections of items pertained to "Instructional and Curriculum" and "Special Services Division" programs and services. Both the "Instructional and Curriculum" portion and the "Special Services" portion of questions began by asking the respondent to identify whether she or he had enough knowledge to rate the programs and services within each division by marking either yes or no. Respondents marking "yes" continued through the instrument item by item. Respondents marking "no" moved to the next section of questions.

The same items and response rating scale were used by all respondents on the survey. The rating scale presented to the respondent was placed before the items being rated (beginning with question 15). The scale ranged from "extremely effective" to "extremely ineffective." Actual rating scale included: 1 = extremely effective, 2 =very effective, 3 = effective, 4 = ineffective, $5=$ very ineffective, $6=$ extremely ineffective, and $0=$ No Information $/$ A $=$ Not Applicable. The responses were marked in a box accompanying each rating item. 
In order to have a common concept of what "effectiveness" meant in relation to this study, several descriptive indicators were developed. These indicators were developed through discussion with ESD 112 staff members and through expanding on common definitions of effectiveness found in the literature (Ruel, 1986; Stephens, Perry, and Sanders, 1989). The indicators were listed on the survey instrument itself in the section preceding the effectiveness rating items.

At the end of the instrument, gratitude for completing the survey was offered and steps for returning the survey instrument were detailed.

A cover letter, which was signed by the author of this study, explained the purpose of this study and was sent with all surveys (letter and questionnaire are found in Appendix 1).

\section{FIELD TESTING}

The survey instrument was field tested with four staff members from ESD 112, two retired teachers, two retired principals, and one ESD 112 board member. All members of this group were from the State of Washington. Each person involved in the field testing exercise had a survey instrument delivered to them in a sealed envelope. A cover sheet providing instructions for reviewing and critiquing the survey instrument was provided with each survey instrument. Each respondent was asked about the completion time, the effectiveness of the cover letter, the cleamess of survey directions, and the general structure and content of the survey. All individuals involved in the field testing were then interviewed on the content, structure, and appearance of the survey instrument. Comments were collected and minor revisions were made to the instrument. 


\section{DATA COLLECTION}

The survey instrument was distributed during the second week of October, 1989. The instruments were packaged into 30 different envelopes. One envelope was addressed to each of the 30 public school districts in the ESD 112 service area. Each envelope contained survey instruments for the superintendent, for all central office personnel (identified as assistant superintendents, directors, and administrative assistants), for all principals and assistant principals in the district, and for all school board members.

For those districts with 2000 or fewer students, an envelope containing survey instruments for all certificated staff (teachers and certificated support personnel) was addressed to each school building. For those buildings selected in the proportional random cluster sample of districts with more than 2000 students, individually addressed envelopes (by school building name) of survey instruments were enclosed in the district envelope. Those envelopes addressed to individual school buildings, regardless of the size of the district, included the principals, assistant principals, and all teacher and certificated support personnel survey instruments.

All surveys were coded with an identification number on the bottom left-hand corner of the last page. The surveys were coded sequentially by district, occupation, and building (e.g. 9T-2). The district code was a number from one through 30 , representing the 30 individual districts (e.g. $9=$ Ridgefield). The occupational code was a letter(s) signifying the various professional occupations found within the district (e.g. $\mathrm{T}=$ teacher). These occupational codes included; S for "superintendent," B for "board member," DO for "district office personnel," P for "principal," VP for "assistant principal," and T for "teacher" and all "certificated support personnel." The building number was determined by the number of buildings found in the district and the order in which the building was registered in the 1988-89 Washington Education Directory (e.g. 2 = the second building found in the directory under that district). 
The surveys were delivered to each district through the use of ESD 112's Integrated Service Delivery (mailing system) network. All envelopes were addressed and delivered to the superintendent's office of each district for distribution to the employees of that district. The district envelope was addressed specifically to the secretary of the superintendent of each district. The district secretary was identified as the person who would distribute the surveys to the proper persons and/or buildings. A cover letter explaining the contents of the district envelope and the instructions for distributing and returning the surveys was included. All surveys included in the envelopes were addressed to a position; no individual names were used in this study.

Within each district envelope there was a series of packets and envelopes. Packets of surveys were bundled for the appropriate number of people found in a job category. Packets were included for board members, superintendents, and central office personnel. Packets were also included for principals and assistant principals in those districts with more than 2000 students, unless a specific principal or assistant principal of a building were included in the proportional random cluster sample. The survey instruments for these principals and assistant principals were then enclosed in the building envelope.

For those districts with $\mathbf{2 0 0 0}$ or fewer students, individual building envelopes were included in the district envelope. These envelopes included a cover letter explaining the contents of the district envelope and the instructions for distributing and returning the surveys was included. The building secretary was identified as the person who would distribute the surveys to the proper persons. The building envelope contained a survey for the principal, any assistant principals, and all teachers and certificated support personnel in the building.

All survey respondents were instructed to retum their instruments to their district office (via their building or district office secretary) to be returned to the ESD mail room. The ESD 112 delivery network consists of two vans which distribute and collect mail at 
every district in the service area three times during a normal work week. Return envelopes were included for each district and each school building included in the study. The return envelopes were marked "Survey-To ESD 112."

The 1988-89 Washington Education Directory was referenced in order to estimate the number of teacher and support personnel surveys needed in individual buildings. The same directory was also used to identify the number of all building principals, assistant principals, and central office personnel in the areas of curriculum, instruction, and special services.

Survey instruments were numbered for the purpose of identifying return rates and to send follow-up survey completion reminders. Group numbering by building was used for teachers and support personnel and school board members. Individual numbering was used for all other respondents. The Washington Education Directory was used to assign and record individual and building/group numbers. Numbers marked on the survey instrument only identified the position and location of the respondent and was not connected to any individual name.

Each district superintendent was mailed two letters before the actual distribution of the survey. The first letter was mailed two months before the distribution of the survey. This letter presented a brief overview of the purpose of the study and also requested support for the survey in the form of discussing the survey with staff. The second letter was one month before the distribution of the survey. This letter included a reminder of the study's implementation date and a "fact sheet" detailing the procedures of the study from a district level perspective.

The district secretary was also contacted two months before sending the survey instrument. This letter outlined the routine and procedures for distributing and collecting the instruments within his or her district. 
Each building principal received a letter one month before the study. This letter included a request for support and included a "fact sheet" detailing the procedures of the study from a building level perspective.

The first reminder to complete the survey was sent seven days after the initial distribution of the survey instrument. This consisted of a brief one page reminder to all superintendents, central office personnel, principals and assistant principals. The principals or contact persons of those schools included in the cluster sample were contacted by phone to help remind the teaching staff through school bulletins and staff meetings.

A second reminder was sent fourteen days after the initial distribution of the survey instrument. This consisted of a modified reminder sent the first time, and several copies of the survey instrument to replace lost or misplaced ones. The reminder included a message of subtle urgency.

The final reminder was directed at all superintendents, central office personnel, and building principals. Superintendents were asked to remind school board members for a final time, while those building principals with teaching staff being surveyed were asked to remind their personnel. This reminder included a "thank you" for any time and effort given to the study.

All instruments returned to the office were placed in large mailing envelopes, marked "Survey-To ESD 112," and delivered to the ESD 112 mailing room. The envelopes were placed in a sealed box located in the delivery service supervisor's office (so it could be locked at night), and were picked up once each week for five weeks by the investigator.

\section{DATA ANALYSIS}

In order to develop the findings from this investigation which would answer the major questions put forth in this study, and also to answer supportive questions pertinent 
to this line of inquiry, the author adopted a sequential data analysis strategy. The following narrative provides an outline of the data analysis sequence used in Chapter IV.

The first phase of this strategy is to present the reader with an overview of the study sample and subsequent return rates. Actual counts and percentages are used in this section. This information was presented earlier in the narrative of this chapter, whereas all remaining data analysis is presented in Chapter IV.

To continue in this same line of inquiry, the reader is then presented with a descriptive analysis of the demographic questions one through six. Since the major focus of this study is to look at the differences in perceived effectiveness among educator groups, each demographic question is supported by narrative detailing an analysis of the question according the five position groups used in this study. General information questions seven through 14 are also presented as a total respondent group. Modes and percentages are used in this section.

The narrative then presents three sections of descriptive analysis pertaining to the effectiveness rating questions which comprise the remainder of the survey instrument. Each of the general effectiveness questions is supported by descriptive information regarding position groups, years of experience groups, district size groups, county location groups, and degree level groups. Since more than two-thirds of all respondents did not respond, or could not answer the specific program and service effectiveness rating questions (questions 26 through 62), only the total group descriptive analysis will be given for these thirty-six questions. In order to address the needs of the "most common" reader of this study, the author has placed emphasis on the presentation of the effectiveness rating questions by developing individual descriptive tables to supplement the narrative of each question. Group response numbers, percentages, means, and standard deviations are used in this section. 
The fourth component of the data analysis sequence, or the primary analysis, was to investigate whether significant differences existed in the responses given on the effectiveness rating questions according to different grouping variables. The mean responses for position groups were tested for significant differences on all 46 effectiveness rating questions. The mean responses for years of experience groups, district size groups, county location groups, and degree level group were tested for significant differences on the $\mathbf{1 0}$ general effectiveness questions. For all those questions found to produce significant differences in the mean responses, paired mean comparison tests were performed to identify which groups differed significantly. Analysis of variance (ANOVA) and pairwise mean comparison (Tukey-Kramer) tests are used in this section.

The next stage of the data analysis sequence, or the secondary analysis, further analyzes the position groups by investigating whether there are significant differences among the proportions of respondents found in different categories defined by the seven "general information" questions and two "gate" questions. Chi-square tests of significance and group percentages are used in this section.

The final segment of the data analysis strategy was to provide a demographic analysis on portions of the information gathered from the survey instrument. This first part of this analysis included an investigation into whether significant differences existed among the proportions of respondents, according to position, found in the different categories defined in the demographic questions two through six. Second, after finding significant differences in position, district size, county location, and degree level group responses on the general effectiveness questions through ANOVA testing, further data analysis was performed. The purpose of this section was to investigate whether there were significant differences in the mean responses of different position groups on the general effectiveness questions, when adjusting for the possible effects district size, county location, and degree 
level may have. Chi-square tests of significance and analysis of covariance (ANCOVA) tests were used in this section.

Original data from the first three questions of the survey instrument were collapsed into fewer classifications before the analysis of the data was started. The 13 position group classifications included in the first question were collapsed to include five group classifications. Data from the second and third questions regarding years of experience in district and years of experience in the State of Washington were collapsed to include three group classifications. All response information gathered by the survey instrument was treated as discrete data.

Responses from all the effectiveness rating questions which indicated no information/not applicable were altered from a zero ("0") to a no response (".") in the data set in order to delete an numeric value which would affect values of the mean responses of the groups and categories studied. By retaining the zero value the mean responses given by groups would have been inaccurately lowered.

The reporting of the mean responses on all effectiveness rating questions was developed by rounding the response to the nearest whole number and assigning the effectiveness rating definition given to that numeric response.

Probability levels for all statistical testing, except the multiple comparison tests, were stated in the actual numbers as generated by the computer statistics software package. The results of all multiple comparison testing performed on the mean responses of different characteristics groupings are reported at the $\leq .05$ level.

The following chapter, Chapter IV, provides the reader with an analysis of the data gathered from the 769 survey respondents. Chapter IV is divided into five sections: (1) A descriptive demographic and general information question analysis, (2) A descriptive analysis of the 46 effectiveness rating items, (4) A primary analysis of testing for significance differences in group response means on different effectiveness rating 
questions, (5) A secondary analysis testing for significant differences in the proportions of groups identifying with different categories on the general information questions, and (6) A demographic analysis testing for significant differences in the proportions of groups identifying with different categories on the demographic information questions and tests of significance relating to the effects of different demographic characteristics on rating responses. 


\section{CHAPTER IV}

\section{RESEARCH FINDINGS}

The intent of this research project was to investigate the perceptions of effectiveness conceming an educational service district in the State of Washington. The investigation was designed to ascertain what perceptions are presently held by public school educators in regards to the instructional, curriculum, and special services programs and services provided by Educational Service District 112, in Southwest Washington. This chapter will present the findings derived from the responses of a 62 item survey instrument developed to investigate the perceived program and service effectiveness (Appendix 1). Of the 1507 survey instruments distributed for this study a total of 769 were returned, which resulted in a 51\% retum rate (see Table II and Table III).

In order to present the results in a coherent, orderly fashion this chapter has been written in five sections described in the following narrative. A results summary is provided at the first of each of the following sections, briefly describing the findings for that section of data analysis.

The first section will provide a descriptive overview of the data accumulated with regard to the demographic and general information contained in the first 14 questions of the survey. This will provide the reader with an understanding of the demographic characteristics of the total group of respondents.

The second section will discuss the total group mean responses concerning the remaining 46 effectiveness rating questions. This is divided into three sub-sections dealing with both general and specific effectiveness rating questions. The first sub-section will discuss the general effectiveness rating questions 15 through 24 which concerns ESD 112 
as a singular unit. The general effectiveness questions will also provide descriptive information pertaining to position, years of experience, district size, county location, and degree level. The next two sub-sections will discuss the Instructional and Curriculum effectiveness questions 25 through 43 and the Special Services effectiveness questions 45 through 62. The questions from these two sub-sections are concerned with the effectiveness ratings of specific, or individual programs and services within these separate divisions of the ESD.

The third section will provide the reader with a primary analysis of the data. The data analysis in this section investigated whether any significant difference existed between the various demographic groups and categories and their mean effectiveness ratings. Primary emphasis will be directed at the comparison of different professional education positions and all 46 ESD effectiveness rating questions. There will also be a section regarding years of experience, district size, county location, and degree in relation to the general effectiveness rating questions 15 through 24.

The fourth section will fumish the reader with a secondary analysis of the data by investigating whether significant differences existed between the proportions of position groups responding to the eight general information questions (7 through 14), and the two "gate" questions (25 and 44).

The fifth section of this chapter will provide the reader with demographic analysis of the data. The first portion of this section will investigate whether significant differences existed between the proportions of position groups responding to the demographic questions two through six. The second portion of this section will provide the reader with a look at the effects different demographic variables had on position category responses to the general effectiveness rating questions 15 through 24. 
DEMOGRAPHIC AND GENERAL INFORMATION OVERVIEW OF RESPONDENTS

The first section of the survey consisted of two groups of questions. The first group of questions are classified as occupational demographic questions. These six questions deal specifically with professional educational job related topics. The second set of questions, questions 7 through 14, are general information questions relating to perceptions of program value, individual involvement, and organizational purpose. The following section will detail the findings from each of these two groups of questions. Analysis of the first question, present position, was discussed in Chapter III (Respondent Overview) and will not be discussed here.

As the major emphasis of this study is to investigate how various professional educational positions perceive ESD 112 and its programs and services, analysis of the each demographic questions will include a section describing "position" group percentages found in different demographic categories.

\section{Summary of Occupational Demographic and General Information Analysis}

Occupational Demographics. The results of the occupational demographic questions portray the survey respondents as having an average of 11 years experience in their present school district and a little more than 14 years of experience in the State of Washington. The majority of the respondents hold a master's degree of some type, while all but a minor portion of the remaining respondents hold a bachelor's degree. Almost three-fourths of the respondents are employed in either Clark County or Cowlitz County, while the remaining one-fourth of respondents come from Klickitat County, Pacific County, Skamania County, or Wahkiakum County. The largest portion of the respondents presently work in school districts which have more than 2000 students and which are located in Clark County, Washington. 
General Information. While more than $95 \%$ of the total group responded that their district uses some type of service provided by ESD 112, over half of the same group indicated that they have moderate or minimal understanding of the functions of Educational Service District 112. Nearly one-half of the respondents feel the ESD has somewhat of an affect on their job, while one-third of the group said the ESD has very little or no effect on their job.

Almost three-fourths of the respondent group implied that they have been involved with five or fewer programs and services, with less than one-fifth of the respondent group being involved in more than five programs or services. A full two-thirds of the respondent group replied that they encountered some type of constraint when accessing ESD 112 services, with the largest percentage of that group identifying distance as the major problem.

Nearly three-fourths of the respondents indicated that they felt ESD 112 provides timely services, while nearly one-fifth of the respondents indicated the opposite. Lastly, four-fifths of the respondents feel that their district should contract certain services and programs from ESD 112 which their district cannot adequately supply, while a little more than one-tenth of the respondents believe their district should not contract programs and services from the ESD.

\section{Years of Employment in Present District.}

Question two in the occupational demographic section requested that the respondents indicate the numbers of years which they have been employed with their present district. This question was included to help determine how balanced the overall group was in terms of years of employment with their present school district. The findings reveal that $52.9 \%$ of the respondents had been with their present school district for less than 10 years, while $47.1 \%$ had been with their school district more than 10 years. Also, $13.8 \%$ of the respondents indicated they had been with their present school district more 
than 20 years, while $1.0 \%$ of the total group had been with their present district for 30 or more years.

Position Group. The largest percentage of all five position groups had been with their present district for 10 years or less, with the majority of all groups except the principal's group falling into this category (Table IV). The teacher and assistant principals groups closely match each other in their percentage distributions among the three classifications. Original data were collapsed into three different years of experience groups, each based on 10 year intervals. Since only $1.0 \%$ of the respondents indicated more than 30 years of experience in their present district, this group was included in the 21 or more years of experience group.

\section{TABLE IV}

PERCENTAGE OF RESPONDENTS ACCORDING TO FIVE POSITION GROUPS AND THREE YEARS OF EXPERIENCE IN DISTRICT CATEGORIES

\begin{tabular}{lccccc}
\hline $\begin{array}{l}\text { Categories by Ex- } \\
\text { perience Sub- } \\
\text { groups }\end{array}$ & Teacher & Principal & $\begin{array}{c}\text { Assistant } \\
\text { Principal }\end{array}$ & $\begin{array}{r}\text { Board } \\
\text { Member }\end{array}$ & $\begin{array}{c}\text { District } \\
\text { Office }\end{array}$ \\
\hline 0-10 Years & $52.2 \%$ & $39.4 \%$ & $52.9 \%$ & $84.4 \%$ & $59.6 \%$ \\
$11-20$ Years & $35.8 \%$ & $35.7 \%$ & $29.4 \%$ & $13.3 \%$ & $24.1 \%$ \\
$21+$ Years & $11.9 \%$ & $24.7 \%$ & $17.6 \%$ & $2.2 \%$ & $16.1 \%$ \\
no response & $0.0 \%$ & $0.0 \%$ & $0.0 \%$ & $0.0 \%$ & $0.0 \%$ \\
\hline Totals & $100.0 \%$ & $100.0 \%$ & $100.0 \%$ & $100.0 \%$ & $100.0 \%$ \\
\hline
\end{tabular}

\section{Years of Employment in State}

The third question of the occupational demographic section requested the respondents to indicate how many years they had been employed in education in the State of Washington. This question was included to help determine how balanced the overall group was in terms of years of employment in the State of Washington. The findings 
show that $63.2 \%$ of the respondents have been employed in the State of Washington for 10 or more years. The data also shows that $23.4 \%$ of the respondents have been employed in Washington for more than 20 years, while $2.0 \%$ of the respondents indicated they had been employed in the State of Washington for more than 30 years.

Position Group As illustrated in Table V, the board member group reflects the same percentages as they did in the years of experience in present district question (Table IV). All groups except the board member group had a large majority of their respondents indicating 11 or more years of experience in the State of Washington, with the largest

TABLE V

PERCENTAGE OF RESPONDENTS ACCORDING TO FIVE POSITION GROUPS AND THREE YEARS OF EXPERIENCE IN THE STATE OF WASHINGTON CATEGORIES

\begin{tabular}{lccccc}
\hline $\begin{array}{l}\text { Categories by } \\
\text { Experience Sub- } \\
\text { groups }\end{array}$ & Teacher & Principal & $\begin{array}{r}\text { Assistant } \\
\text { Principal }\end{array}$ & $\begin{array}{r}\text { Board } \\
\text { Member }\end{array}$ & $\begin{array}{r}\text { District } \\
\text { Office }\end{array}$ \\
\hline $0-10$ Years & $41.2 \%$ & $11.0 \%$ & $20.6 \%$ & $84.4 \%$ & $19.4 \%$ \\
$11-20$ Years & $40.9 \%$ & $44.0 \%$ & $50.0 \%$ & $13.3 \%$ & $37.1 \%$ \\
$21+$ Years & $17.9 \%$ & $45.0 \%$ & $29.4 \%$ & $2.2 \%$ & $43.5 \%$ \\
no response & $0.0 \%$ & $0.0 \%$ & $0.0 \%$ & $0.0 \%$ & $0.0 \%$ \\
\hline Totals & $100.0 \%$ & $100.0 \%$ & $100.0 \%$ & $100.0 \%$ & $100.0 \%$ \\
\hline
\end{tabular}

percentage of the principal's and district office's respondents indicated more than 20 years experience. Original data were collapsed into three different years of experience categories, each based on 10 year intervals. Since only $2.0 \%$ of the respondents indicated more than 30 years of experience, this group was included in the 21 or more years of experience group. 


\section{District Size}

The fourth question in the demographic section asked for a response identifying the size of district the respondent is presently employed in. Thirty-three percent (33.4\%) of the survey responses came from districts with student enroliments of more than 2000 students. Ten percent (9.9\%) came from districts with 1301 to 2000 students. Twenty-three percent (23.0\%) come from those districts with 801 to 1300 students. The findings also show that $16.4 \%$ of the respondents are from districts with 301 to 800 students. The remaining 13.3\% of the respondents coming from those districts with 300 or less students. Four percent (4.0\%) of the respondents did not specify district size.

Position Groups. Table VI illustrates the percentage of respondents belonging to the five different position groups identified in this study according to the size of district. The size of district is based on the number of students enrolled (1988-1989 academic school year). Whereas the teacher category can be seen to have a fairly even distribution of

TABLE VI

PERCENTAGE OF RESPONDENTS ACCORDING TO FIVE POSITION GROUPS AND FIVE DIFFERENT DISTRICT SIZE CATEGORIES

\begin{tabular}{lrrrrr}
\hline $\begin{array}{l}\text { Categories by } \\
\text { District Size Sub- } \\
\text { groups }\end{array}$ & Teacher & Principal & $\begin{array}{r}\text { Assistant } \\
\text { Principal }\end{array}$ & $\begin{array}{r}\text { Board } \\
\text { Member }\end{array}$ & $\begin{array}{r}\text { District } \\
\text { Office }\end{array}$ \\
\hline $0-300$ students & $14.3 \%$ & $.9 \%$ & $0 \%$ & $35.6 \%$ & $16.1 \%$ \\
$301-800$ students & $20.6 \%$ & $7.3 \%$ & $2.9 \%$ & $11.1 \%$ & $8.1 \%$ \\
$801-1200$ students & $26.2 \%$ & $15.6 \%$ & $11.8 \%$ & $31.1 \%$ & $9.7 \%$ \\
$1200-2000$ student & $9.6 \%$ & $13.8 \%$ & $17.6 \%$ & $4.4 \%$ & $4.8 \%$ \\
$2001+$ students & $23.5 \%$ & $62.4 \%$ & $64.7 \%$ & $15.6 \%$ & $61.3 \%$ \\
no response & $5.8 \%$ & $0 \%$ & $2.9 \%$ & $2.2 \%$ & $0 \%$ \\
\hline Totals & $100.0 \%$ & $100.0 \%$ & $100.0 \%$ & $100.0 \%$ & $100.0 \%$ \\
\hline
\end{tabular}


respondents from all five classifications of district size, the majority of all the other classifications, except board members, came from those districts with an enrollment of more than 2000 students. As expected, both principals and assistant principals percentage increased with the size of district size categories representing larger districts.

\section{County Distribution of Respondents}

Question five inquired into the county which the respondent's present school district is located. Fifty-two percent (52.0\%) of the survey responses came from Clark County, which encompasses four of the six largest school districts surveyed in this study. Seventeen percent (16.9\%) of the responses came from Cowlitz County, which encompasses two of the six largest school districts. Klickitat County accounted for $13.1 \%$ of the surveys returned. Six percent (5.6\%) of the surveys returned were from Pacific County. Seven percent (6.5\%) of the respondents were identified as from Skamania County, and three percent (2.6\%) of the surveys responses were from Wahkiakum. One percent $(0.5 \%)$ of the responses did not respond with a county response.

Position Groups As Table VII depicts at least half or more of all the position groups, except the board member group, identified themselves as coming from Clark County. The next largest percentage of all groups, except the board members again, identified themselves as being employed in Cowlitz County. Pacific, Skamania, and Wahkiakum Counties accounted for $16.0 \%$ or less of all groups except the board member group. 
TABLE VII

PERCENTAGE OF RESPONDENTS ACCORDING TO FIVE POSITION

GROUPS AND SIX DIFFERENT COUNTY CATEGORIES

\begin{tabular}{lrrrrr}
\hline $\begin{array}{l}\text { Categories by } \\
\text { County Sub- } \\
\text { groups }\end{array}$ & Teacher & Principal & $\begin{array}{r}\text { Assistant } \\
\text { Principal }\end{array}$ & $\begin{array}{r}\text { Board } \\
\text { Member }\end{array}$ & $\begin{array}{r}\text { District } \\
\text { Office }\end{array}$ \\
\hline Clark & $49.7 \%$ & $62.4 \%$ & $70.6 \%$ & $24.4 \%$ & $62.9 \%$ \\
Cowlitz & $19.7 \%$ & $23.9 \%$ & $20.6 \%$ & $17.8 \%$ & $12.9 \%$ \\
Klickitat & $13.9 \%$ & $4.6 \%$ & $5.9 \%$ & $31.1 \%$ & $12.9 \%$ \\
Pacific & $6 \%$ & $4.6 \%$ & $0 \%$ & $11.1 \%$ & $3.2 \%$ \\
Skamania & $6.7 \%$ & $3.7 \%$ & $2.9 \%$ & $13.3 \%$ & $6.5 \%$ \\
Wahkiakum & $3.3 \%$ & $.9 \%$ & $0 \%$ & $2.2 \%$ & $1.6 \%$ \\
no response & $.8 \%$ & $0 \%$ & $0 \%$ & $0 \%$ & $0 \%$ \\
\hline Totals & $100.0 \%$ & $100.0 \%$ & $100.0 \%$ & $100.0 \%$ & $100.0 \%$ \\
\hline
\end{tabular}

Education Levels of Respondents

The last question of the occupational demographic section, question six, inquired into the level of education presently held by the respondent. Fifty-three percent $(53.2 \%)$ of the respondents identified themselves as holding a master's degree. Thirty-nine percent (38.8\%) of the responses specified that they held a bachelor's degree. Four percent (4.2\%) of the respondents indicated they possessed a doctorate's degree of some type. Three percent (3.1\%) recognized themselves as having a high school diploma, while $0.8 \%$ of the respondents did not specify their educational level.

Position Groups Table VIII illustrates that the majority of the principal, assistant principal, and district office personnel groups responded that they held a master's degree, with the entire assistant principal's group indicating having a master's degree. The board member group indicated the majority of that group had at least a bachelor's level degree. 
The central office group responded that almost one-third (29.0\%) of their group had a doctorate level degree.

TABLE VIII

PERCENTAGE OF RESPONDENTS ACCORDING TO FIVE POSITION GROUPS AND FOUR DIFFERENT DEGREE LEVEL CATEGORIES

\begin{tabular}{lrrrrr}
\hline $\begin{array}{l}\text { Categories by } \\
\text { Degree Sub-groups }\end{array}$ & Teacher & Principal & $\begin{array}{r}\text { Assistant } \\
\text { Principal }\end{array}$ & $\begin{array}{r}\text { Board } \\
\text { Member }\end{array}$ & $\begin{array}{r}\text { District } \\
\text { Office }\end{array}$ \\
\hline HS Diploma & $.2 \%$ & $.9 \%$ & $0 \%$ & $46.7 \%$ & $1.6 \%$ \\
Bachelor's & $53.4 \%$ & $0 \%$ & $0 \%$ & $37.8 \%$ & $6.5 \%$ \\
Master's & $44.5 \%$ & $91.7 \%$ & $100 \%$ & $11.1 \%$ & $62.9 \%$ \\
PhD/EdD & $.8 \%$ & $7.3 \%$ & $0 \%$ & $4.4 \%$ & $29.0 \%$ \\
no response & $1.2 \%$ & $0 \%$ & $0 \%$ & $0 \%$ & $0 \%$ \\
\hline Totals & $100.0 \%$ & $100.0 \%$ & $100.0 \%$ & $100.0 \%$ & $100.0 \%$ \\
\hline
\end{tabular}

\section{Respondent's Understanding of ESD's Purpose}

The first question in the general information section of the questionnaire, question seven, inquired into how well the person felt they understood the functions and purposes of ESD 112. The respondent was given the option of five responses ranging from "complete understanding" to "no understanding."

The largest percentage of the respondents, $40.8 \%$ of the people returning the survey felt that they had a moderate understanding of the functions and purpose of ESD 112. The findings also showed that $38.8 \%$ of the respondents felt that they possessed good understanding of ESD 112 functions and purpose. Fifteen percent (15.0\%) of the returned surveys specified only minimal understanding of the ESD 112 functions. Four percent (4.4\%) of the respondents indicated complete understanding of the ESD 112 functions. One percent $(0.5 \%)$ did not respond to this question. 
ESD 112 Program Involvement

Question eight on the survey instrument asked how many ESD 112 programs and services the educator thought they had been involved with over the last two years of employment. The respondent was presented six response options ranging from "no programs/services" involvement to "all programs" involvement.

Seventy-two percent ( $72.0 \%$ ) of the survey responses specified that they had been involved with one-to-five programs or services provided by ESD 112. Thirteen-percent (13.4\%) of the respondents indicated that they had been involved with 6 to 10 programs. Nine percent $(9.4 \%)$ of responses specified that they had not been involved with any programs or services provided by ESD 112 . Three percent (3.0\%) of the respondents recognized that they had been involved with eleven-to-twenty programs, and $0.8 \%$ of the groups specified involvement with more than 20 programs. One percent $(1.3 \%)$ did not respond to this question, and a single respondent specified that he/she had been involved with all the ESD 112 programs and services.

\section{Knowledge of District Using ESD 112 Services}

Question nine requested that the respondent acknowledge whether or not they knew that their district used any of the services provide by ESD 112. The respondent was given three response options that include: "yes," "no," or "unknown."

Ninety-six percent $(95.8 \%)$ of the survey respondents specified that they had knowledge of their district using one or more of the services provided ESD 112. The findings also showed that $4.0 \%$ responded that they did not know if their district was using any of the ESD 112 services, while $0.4 \%$ responded that they knew that their district did not use any ESD 112 services. Less than one percent (0.1\%) of those surveyed did not respond to this question. 
Types of Service and Programs Used by Districts

Question 10 asked the respondent to specify the type or orientation of the programs their district contracted or used from ESD 112. The four possible response categories given on the survey instrument included: "mostly student oriented," "mostly teacher oriented," "mostly administrative oriented," or "some combination of those above."

Sixty-five percent (64.5\%) of the respondents surveyed felt that their district uses some combination of student, teacher, and administrative oriented programs provided by ESD 112. Sixteen percent (15.6\%) felt that most of the ESD 112 programs used by their district was student oriented. Twelve percent (12.0\%) felt that most of the programs were teacher oriented, while $3.3 \%$ felt that their district used most administrative oriented services.

\section{Effect of ESD 112 on Present Position}

The fifth question in the general information section, question 11, was interested in finding out how much the respondent felt ESD 112 affected their present "position". The respondent was given five possible responses which included: "very much," "somewhat," very little," "not at all," and "don't know."

Forty-six percent (46.0\%) of the respondents specified that the ESD somewhat affected their present position within their school district. Thirty-percent (29.9\%) said that the ESD affected their position very little. Fourteen percent (13.8\%) specified that the ESD affected their present position very much. Six percent (5.7\%) of the respondents felt that the ESD did not affect their position at all. One percent (1.4\%) specified they did not know how much affect the ESD had on their position. Three percent (3.1\%) did not responded to this particular question. 
Access constraints to ESD 112 Services

Question twelve asked the respondents to identify what constraints they encountered in accessing ESD 112 services and programs. The respondent was given seven possible responses ranging from "none" to a "combination of reasons."

Twenty-seven percent (26.5\%) of the survey responses specified that there were no constraints to accessing ESD 112 services. Twenty-five percent (24.6\%) of the respondents felt that distance constrained their access to the ESD. Nineteen percent (18.9\%) felt there were a combination of reasons which acted a constraints in accessing ESD 112 services. Fifteen percent (15.0\%) of the respondents felt that the lack of information was the major constraint. Four percent (4.0\%) of the respondents specified that conflicting working hours constrained their access to ESD 112. Four percent (3.6\%) of the respondents identified reason associated with their district as the constraining factor. Two percent (2.0\%) identified finances as the factor constraining access to ESD 112. Six percent (5.5\%) of the respondents elected not to answer this question.

\section{Timely Services Provided By ESD 112}

Question 13 asked the respondents to express whether or not they felt ESD 112 provided timely services to districts, teachers, and students. The survey instrument provided either a "yes" or "no" response on this question.

Seventy-two percent (72.0\%) of the surveys returned indicated that ESD 112 provides timely services in distributing materials, providing communications, and executing services and programs. Eighteen percent (17.6\%) of the respondents felt that ESD 112 did not provide timely services to schools districts. Ten percent $(10.4 \%)$ of the respondents did not respond to this question. 
District Contracting of ESD 112 Programs and Services

The last question on the general information section, question 14, requested that the respondent specify whether they felt their district should contract services from ESD 112. The survey instrument provided either a "yes" or "no" response on this question.

Seventy-nine percent (79.2\%) of those people responding specified that their district should contract with ESD 112 for certain services and programs. Eleven percent (11.4\%) of the people responding felt that their district should not contract with ESD 112 for certain services and programs. Nine percent (9.4\%) of the respondents did not respond to this question.

\section{GENERAL EFFECTIVENESS RATING QUESTIONS}

The following section will provide the reader with a descriptive analysis of each of the primary effectiveness rating questions included in the survey instrument. This discussion will focus on the findings from question 15 through 24, which consist of general effectiveness rating questions concerning ESD 112 as a single, or whole, organization. These questions were developed directly from the effectiveness indicators which were developed and placed on the survey instrument at the beginning of the effectiveness rating questions. These indicators were included for the purpose of assisting the respondent formulate a concept of effectiveness in relation to the ESD 112's effectiveness as a service organization.

The results for this section will be presented by first providing the reader with a brief description regarding the topic of the survey question and a short explanation of the intent of the question. Then the total group responses will be given. Each question will be supplemented with a table describing the percentages of respondents falling into the different effectiveness rating categories. The table also presents the reader with the mean response and standard deviation for each individual question, along with the total 
percentages of respondents on the "effective" and "ineffective" ends of the effectiveness continuim. The effectiveness rating scale included six possible responses other than indicating a "no information/not applicable" response, or just not responding at all. These included the following categories: One meaning "extremely effective," Two meaning "very effective," Three meaning "effective," Four meaning "ineffective," Five meaning "very ineffective," and Six meaning "extremely ineffective." All mean responses were rounded to the nearest whole number and reported by the value definition given to the nearest numeric response discussed in the previous sentence.

Each table will be followed by brief statement regarding how the respondents answered according to position groups, years of educational experience in present district groups, years of educational experience in the State of Washington groups, district size groups, county groups, and educational degree level of the respondents. Extended discussion regarding how these subgroups responded will only be given if two or more of the subgroups provided a different mean response on the question being examined.

Position group data analysis will be based on the five groups of: teacher, principal, assistant principal, board member, and central office personnel. Years of experience data analysis will be based on the three groups of: 0-10 years of experience, $11-20$ years of experience, and 21 or more years of experience. District size data analysis will include the five groups of: 0-300 students, 301-800 students, 801-1200 students, 1201-2000 students, and 2000 or more students. County location data analysis will include the six groups of: Clark County, Cowlitz County, Klickitat County, Pacific County, Skamania County, and Wahkiakum County. The degree level data analysis will be based on: High School Diploma, Bachelor's degree, Master's degree, and PhD/EdD. 
Summary of General Effectiveness Rating Questions

The respondent group as a whole, gave ESD 112 an effective rating on all 10 of the general effectiveness questions. Nearly two-thirds to three fourths of the total group responded with one of the three effective rating responses on every general effectiveness question except one, question 23, pertaining to useful evaluation practices. Still, one-half of the respondents responded with one of the three effective rating responses on this question. In contrast, only one-tenth to one-fifth of the total groups of respondents responded with an ineffective rating on any one of the 10 general effectiveness questions. When asked to rate ESD 112's overall program, almost three-fourths of the respondents rated the ESD as effective to extremely effective, while one-tenth of the group responded with one of the three ineffective ratings.

For supplementary information pertaining to specific responses according to demographic grouping (by position, years of experience in present district, years of experience in the State of Washington, district size, county location, and degree level) the reader is asked to refer to response tables found in Appendix 2.

\section{Providing Satisfactory Services}

Question 15 asked the respondent to rate the effectiveness of ESD 112 in providing satisfactory and relevant services to its district patrons. This question was meant to imply whether ESD 112 provided programs and services that the respondent felt were useful and relevant to their needs as professional educators.

The total group of respondents gave an effective rating to ESD 112 on this question, with a mean response of three (2.870) on the effectiveness rating scale of one to six. Approximately $80.0 \%$ of the respondents responded with an effective rating, while less than $10.0 \%$ responded with an ineffective rating. A little more than $10.0 \%$ of the total group did not respond to this question (Table IX). 
Response by Position Groups. The largest percentage of all position groups indicated that they felt the ESD was effective in providing relevant services to its patrons, with each category having a mean response of three on the six point effectiveness rating scale (Appendix 2, Table LXIX).

Response by Years of Experience Groups. The three different years of experience groups (for both Years of Experience in Present District and Years of Experience in State of Washington) indicated that ESD 112 was effective in providing satisfactory and relevant services to its patrons. Each years of experience category indicated a mean response of three on the six point effectiveness rating scale (Appendix 2, Tables LXXII and LXXV).

TABLE IX

TOTAL GROUP RATING RESPONSE PERCENTAGES PERTAINING TO ESD 112 AND THE EFFECTIVENESS OF PROVIDING SATISFACTORY AND RELEVANT SERVICES

\begin{tabular}{|c|c|c|c|c|c|c|c|}
\hline \multicolumn{3}{|c|}{ Mean Response $=2.870$} & \multicolumn{2}{|c|}{$N=769$} & \multicolumn{3}{|c|}{ Standard Deviation $=.766$} \\
\hline Rating Scale & 1 & 2 & 3 & 4 & 5 & 6 & 0 \\
\hline $\begin{array}{l}\text { Value } \\
\text { Definition }\end{array}$ & $\begin{array}{c}\text { Extremely } \\
\text { Effective }\end{array}$ & $\begin{array}{c}\text { Very } \\
\text { Effective }\end{array}$ & Effective & Ineffective & $\begin{array}{c}\text { Very } \\
\text { Ineffective }\end{array}$ & $\begin{array}{l}\text { Extremely } \\
\text { Ineffective }\end{array}$ & $\begin{array}{l}\text { NANNo } \\
\text { Response }\end{array}$ \\
\hline $\begin{array}{l}\text { Response } \\
\text { Percentage }\end{array}$ & $3.1 \%$ & $17.6 \%$ & $58.5 \%$ & $6.6 \%$ & $1.2 \%$ & $1.3 \%$ & $11.7 \%$ \\
\hline Numbers & 24 & 135 & 450 & 51 & 9 & 10 & 90 \\
\hline Totals & Effective & $79.2 \%$ & <-o-m & $\cdots$ & Ineffective & $=9.1 \%$ & \\
\hline
\end{tabular}

Response by District Size Groups. All five position groups rated ESD 112 as effective in providing satisfactory and relevant services to its patrons, with each category having a mean response of three on the effectiveness rating scale of one to six (Appendix 2, Table LXVIII).

Response by County Location Groups. The six county groups rated the ESD as effective in providing satisfactory and relevant services to its patrons. All six county 
groups had a mean response of three on the six point effectiveness rating scale (Appendix 2, Table LXXXI).

Response by Degree Level Groups. The "high school diploma" group rated the ESD as "very effective" in providing satisfactory and relevant services to patrons, with a mean response of two on the effectiveness rating scale of one to six. All the other degree level groups indicated an effective rating, with a mean response of three on the six point effectiveness rating scale (Appendix 2, Table LXXXIV).

\section{Demonstrating Useful Knowledge and Information}

Question 16 asked the respondent to rate how effective ESD 112 is when "demonstrating useful knowledge and information" to the professional educator and to districts. This question was meant to convey whether the respondent felt ESD 112 provided practical knowledge and information to them in their professional educator role.

The total group response reflected an effective rating to ESD 112 on this question, with a mean response of three (2.767) on the effectiveness rating scale of one to six. Approximately $80.0 \%$ of the total group responded with an effective rating, while a little more than $10.0 \%$ responded with an "ineffective rating" (Table X).

\section{TABLEX}

\section{TOTAL GROUP RATING RESPONSE PERCENTAGES PERTAINING TO ESD 112 AND THE EFFECTIVENESS OF DEMONSTRATING USEFUL KNOWLEDGE AND INFORMATION}

\begin{tabular}{|c|c|c|c|c|c|c|c|}
\hline \multicolumn{3}{|c|}{ Mean Response $=2.767$} & \multicolumn{2}{|c|}{$N=769$} & \multicolumn{3}{|c|}{ Standard Deviation $=.828$} \\
\hline Rating Scale & 1 & 2 & 3 & 4 & 5 & 6 & 0 \\
\hline $\begin{array}{l}\text { Value } \\
\text { Definition }\end{array}$ & $\begin{array}{l}\text { Extremely } \\
\text { Effective }\end{array}$ & $\begin{array}{c}\text { Very } \\
\text { Effective }\end{array}$ & Effective & Ineffective & $\begin{array}{c}\text { Very } \\
\text { Ineffective }\end{array}$ & $\begin{array}{l}\text { Extremely } \\
\text { Ineffective }\end{array}$ & $\begin{array}{l}\text { NANNo } \\
\text { Response }\end{array}$ \\
\hline $\begin{array}{l}\text { Response } \\
\text { Percentage }\end{array}$ & $5.6 \%$ & $22.1 \%$ & $49.9 \%$ & $8.2 \%$ & $1.4 \%$ & $0.7 \%$ & $13.0 \%$ \\
\hline Numbers & 43 & 170 & 377 & 63 & 11 & 5 & 100 \\
\hline Totals & Effecti & e $77.6 \%$ & $<-$ & $\ldots$ & Ineffectiv & $=10.3 \%$ & \\
\hline
\end{tabular}


Response by Position Group. The board member and central office personnel groups both responded that ESD 112 was "very effective" in demonstrating useful knowledge and information to educators and local school districts. Both groups had a mean response of two on the six point effectiveness rating scale. The teacher, principal, and assistant principal groups all indicated the ESD was effective in demonstrating useful knowledge and information with a mean response of three on the six point effectiveness rating scale (Appendix 2, Table LXIX).

Response by Years Experience Groups. The three different years of experience groups (for both Years of Experience in Present District and Years of Experience in State of Washington) indicated that ESD 112 was effective in demonstrating useful knowledge and information to educators and local districts. All three groups had a mean response of three on the six point effectiveness rating scale (Appendix 2, Table LXXII and LXXV).

Response by District Size Groups. The five district size groups indicated that ESD 112 was effective in demonstrating useful knowledge and information. All five groups had a mean response of three on the six point effectiveness rating scale (Appendix 2, Table LXXVIII).

Response by County Location Groups. All six county groups responded that they felt ESD 112 was effective in demonstrating useful knowledge and information, with each of the six groups having a mean response of three on the six point effectiveness rating scale (Appendix 2, Table LXXXI).

Response by Degree Level Groups. The four degree level groups each indicated an effective rating of ESD 112 in demonstrating useful knowledge and information, with each category having a mean response of three on the six point effectiveness rating scale (Appendix 2, Table LXXXIV). 


\section{Timeliness Fashion of Services}

Question 17 asked the respondent to rate the ESD 112 when "providing services in a timely fashion." The purpose of this question was to ascertain whether ESD 112 provided services to the respondent in a timeframe which allowed for the service to be an effective and efficient component of their work.

An effective rating was given to ESD 112 on this question, with the total group replying with a mean response of three (2.918) on the effectiveness rating scale of one to six. A little more than $70.0 \%$ of the total group responded with some form of effective reply, while close to $20.0 \%$ of the total group indicated an "ineffective" reply. Right at $13.0 \%$ of the group did not respond to this question (Table XI).

\section{TABLE XI}

TOTAL GROUP RATING RESPONSE PERCENTAGES PERTAINING TO ESD 112 AND EFFECTIVENESS OF PROVIDING SERVICES IN A TIMELY FASHION

\begin{tabular}{|c|c|c|c|c|c|c|c|}
\hline \multicolumn{3}{|c|}{ Mean Response $=2.918$} & \multicolumn{2}{|c|}{$N=769$} & \multicolumn{3}{|c|}{ Standard Deviation $=.906$} \\
\hline Rating Scale & 1 & 2 & $\overline{3}$ & 4 & 5 & 6 & 0 \\
\hline $\begin{array}{l}\text { Value } \\
\text { Definition }\end{array}$ & $\begin{array}{l}\text { Extremely } \\
\text { Effective }\end{array}$ & $\begin{array}{c}\text { Very } \\
\text { Effective }\end{array}$ & Effective & Ineffective & $\begin{array}{c}\text { Very } \\
\text { Ineffective }\end{array}$ & $\begin{array}{l}\text { Extremely } \\
\text { Ineffective }\end{array}$ & $\begin{array}{l}\text { NA/No } \\
\text { Response }\end{array}$ \\
\hline $\begin{array}{l}\text { Response } \\
\text { Percentage }\end{array}$ & $3.9 \%$ & $21.3 \%$ & $45.1 \%$ & $13.8 \%$ & $1.6 \%$ & $1.7 \%$ & $12.6 \%$ \\
\hline Numbers & 30 & 164 & 347 & 106 & 12 & 13 & 97 \\
\hline Totals & Effectiv & $=70.3 \%$ & -1 & $--->>$ & Ineffect & $=17.1 \%$ & \\
\hline
\end{tabular}

Response by Position Groups. The central office personnel groups indicated that they felt the ESD was very effective in providing services in a timely fashion to school district patrons, having a mean response of two on the six point effectiveness rating scale (Appendix 2, Table LXIX). All four other groups indicated ESD 112 was effective in providing services in a timely fashion, with each group having a mean response of three on the six point effectiveness rating scale. 
Response by Years of Experience Groups. The three different years of experience groups (for both Years of Experience in Present District and Years of Experience in State of Washington) indicated that ESD 112 was effective in providing services in a timely fashion to its patrons. All three groups had a mean response of three on the six point effectiveness rating scale (Appendix 2, Table LXXII and LXXV).

Response by District Size Groups. The five different district size groups all indicated that they felt ESD 112 was effective in providing services in a timely fashion to its patrons. All five groups had a mean response of three on the six point effectiveness rating scale (Appendix 2, Table LXXVIII).

Response by County Location Groups. The six county groups rated ESD 112 as effective in providing services in a timely fashion to its patrons. Each of the six groups had a mean response of three on the six point effectiveness rating scale (Appendix 2, Table LXXXI).

Response by Degree Level Groups. The high school diploma category rated ESD 112 as "very effective" in providing services in timely fashion to its patrons, with a mean response of two on the six point effectiveness rating scale. All three other groups indicated that the ESD was effective in providing services in a timely fashion. Each of these groups had a mean response of three on the six point effectiveness rating scale (Appendix 2, Table LXXXIV).

\section{Meeting Needs through Resources and Skills}

Question 18 inquired into how effective the respondent felt ESD 112 was in "having the resources and skills to meet the needs of students, teachers, and districts." The intent of this question was to let the respondent rate how effective they felt ESD 112 was in having effective resources and skills in order the meet the demands or needs of their patrons. 
The respondents gave ESD 112 an overall effective rating to ESD 112 on this question by indicating a mean response of three (2.826) on the effectiveness rating scale of one to six. Close to $75.0 \%$ of the respondents indicated an effective rating, while a little more than $10.0 \%$ of the total group gave an "ineffective" rating. Almost $15.0 \%$ of the total group did not respond to this question (Table XII).

Response by Position Groups. The board member group indicated that they felt ESD 112 was "very effective" in having the resources and skills to meet the needs of the students, teachers, and districts, by responding with a mean response of two on the six point effectiveness rating scale. The teacher, principal, assistant principal, and central office personnel groups all rated ESD 112 as effective on this same question, with each of these groups having a mean response of three on the six point effectiveness rating scale (Appendix 2, Table LXIX).

\section{TABLE XII}

TOTAL GROUP RATING RESPONSE PERCENTAGES PERTAINING TO ESD 112 AND THE EFFECTIVENESS OF MEETING THE NEEDS OF PATRON DISTRICTS THROUGH RESOURCES AND SKMLS

\begin{tabular}{|c|c|c|c|c|c|c|c|}
\hline \multicolumn{3}{|c|}{ Mean Response $=2.826$} & \multicolumn{2}{|c|}{$N=769$} & \multicolumn{3}{|c|}{ Standard Deviation $=.788$} \\
\hline Rating Scale & 1 & 2 & 3 & 4 & 5 & 6 & 0 \\
\hline $\begin{array}{l}\text { Value } \\
\text { Definition }\end{array}$ & $\begin{array}{l}\text { Extremely } \\
\text { Effective }\end{array}$ & $\begin{array}{c}\text { Very } \\
\text { Effective }\end{array}$ & Effective & Ineffective & $\begin{array}{c}\text { Very } \\
\text { Ineffective }\end{array}$ & $\begin{array}{l}\text { Extremely } \\
\text { Ineffective }\end{array}$ & $\begin{array}{c}\text { NA/No } \\
\text { Response }\end{array}$ \\
\hline $\begin{array}{l}\text { Response } \\
\text { Percentage }\end{array}$ & $3.5 \%$ & $21.3 \%$ & 49.3\% & $9.4 \%$ & $0.9 \%$ & $0.8 \%$ & $14.8 \%$ \\
\hline Numbers & 27 & 164 & 379 & 72 & 7 & 6 & 114 \\
\hline Totals & Effective & $=74.1 \%$ & $<-\cdots$ & $m-\cdots$ & Ineffectiv & $=11.1 \%$ & \\
\hline
\end{tabular}

Response by Years of Experience Groups. The three different years of experience groups (for both Years of Experience in Present District and Years of Experience in State of Washington) indicated that ESD 112 was effective in having the resources and skills to 
meet the needs of students, teachers, and districts. All three groups had a mean response of three on the six point effectiveness rating scale (Appendix 2, Tables LXXII and LXXV).

Response by District Size Groups. The five different district size groups all indicated that they felt ESD 112 was effective in having the resources and skills to meet the needs of students, teachers, and districts. All five groups had a mean response of three on the six point effectiveness rating scale (Appendix 2, Table LXXVIII).

Response by County Location Groups. The six county groups rated ESD 112 as effective in having the resources and skills to meet the needs of students, teachers, and districts. Each of the six groups had a mean response of three on the six point effectiveness rating scale (Appendix 2, Table LXXXI).

Response by Degree Level Groups. The high school diploma category rated ESD 112 as "very effective" in having the resources and skills to meet the needs of students, teachers, and districts, with a mean response of two on the six point effectiveness rating scale. All four other groups indicated that the ESD was effective on this same question. Each of these groups had a mean response of three on the six point effectiveness rating scale (Appendix 2, Table LXXXIV).

\section{Having the Resources and Skills to Adjust}

Question 19 inquired into how effective the respondent felt ESD 112 was in "having the resources and skills to adjust to the individual needs of students, teachers, and districts." This question was designed to inquire into how effective the respondent felt ESD 112 was in adjusting to, and providing for, the individual needs of the students, teachers, and districts.

The total group of respondents indicated an effective rating when replying to this question, with an overall mean response of three (3.031) on a rating scale of one to six. Around $60.0 \%$ of the respondents gave an effective rating on this question, while almost 
$20.0 \%$ responded with an "ineffective" rating. A little more than $20 \%$ of the total group did not respond to this question (Table XIII).

\section{TABLE XIII}

TOTAL GROUP RATING RESPONSE PERCENTAGES PERTAINING TO ESD 112 AND THE EFFECTIVENESS OF RESOURCES AND SKIILS TO ADJUST TO INDIVIDUAL NEEDS OF STUDENTS, TEACHERS, AND DISTRICTS

\begin{tabular}{|c|c|c|c|c|c|c|c|}
\hline \multicolumn{3}{|c|}{ Mean Response $=3.031$} & \multicolumn{2}{|c|}{$N=769$} & \multicolumn{3}{|c|}{ Standard Deviation $=.822$} \\
\hline Rating Scale & 1 & 2 & 3 & 4 & 5 & 6 & 0 \\
\hline $\begin{array}{l}\text { Value } \\
\text { Definition }\end{array}$ & $\begin{array}{l}\text { Extremely } \\
\text { Effective }\end{array}$ & $\begin{array}{c}\text { Very } \\
\text { Effective }\end{array}$ & Effective & Ineffective & $\begin{array}{c}\text { Very } \\
\text { Ineffective }\end{array}$ & $\begin{array}{l}\text { Extremely } \\
\text { Ineffective }\end{array}$ & $\begin{array}{l}\text { NA/No } \\
\text { Response }\end{array}$ \\
\hline $\begin{array}{l}\text { Response } \\
\text { Percenlage }\end{array}$ & $3.1 \%$ & $13.5 \%$ & $45.1 \%$ & $14.0 \%$ & $1.6 \%$ & $1.7 \%$ & $20.9 \%$ \\
\hline Numbers & 24 & 104 & 347 & 108 & 12 & 13 & 161 \\
\hline pals & Effecti & $=61.7$ & & 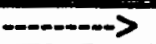 & Ineffect & $=17.3 \%$ & \\
\hline
\end{tabular}

Response by Position Groups. Every position category indicated that they felt the ESD was effective in having the resources and skills to adjust to the individual needs of students, teachers, and districts. Each of the five position groups had a mean response of three on the six point effectiveness rating scale (Appendix 2, Table LXIX).

Response by Years of Experience Groups. The three different years of experience groups (for both Years of Experience in Present District and Years of Experience in State of Washington) indicated that ESD 112 was effective in having the resources and skills to adjust to the individual needs of students, teachers, and districts. All three groups had a mean response of three on the six point effectiveness rating scale (Appendix 2, Table LXII and $L X X V$ ).

Response by District Size Groups. The five different district size groups all indicated that they felt ESD 112 was effective in having the resources and skills to adjust to the individual needs of students, teachers, and districts. All five groups had a mean response of three on the six point effectiveness rating scale (Appendix 2, Table LXXVII). 
Response by County Groups. The Pacific County category rated ESD 112 as "ineffective" in having the resources and skills to adjust to the individual needs of students, teachers, and districts, with a mean response of four on the six point effectiveness rating scale. All other county groups rated the ESD as effective on this same question, with each of these five groups having mean response of three on the six point effectiveness rating scale (Appendix 2, Table LXXXI).

Response by Degree Level Groups. The High School Diploma category rated ESD 112 as "very effective" in having the resources and skills to adjust to the individual needs of students, teachers, and districts. This group had a mean response of two on the six point effectiveness rating scale. The other three groups all rated the ESD as effective on this same question, with each these three groups having a mean response of three on the six point effectiveness rating scale (Appendix 2, Table LXXXIV).

\section{ESD 112 Interpersonal Skills}

Question 20 asked the respondent how effective they felt the ESD was in "having the interpersonal skills to work effectively with teachers and administrators in schools." The motive for this question was find out how effective the respondent felt ESD 112's interpersonal skills were when working with teachers and administrators in socially interactive situations.

The total group of respondents gave ESD 112 an effective rating on this question, with a mean response of three (2.811) on the effectiveness rating scale of one to six. A little more than $70.0 \%$ of the respondents replied with an effective rating response, while $10.0 \%$ of the total group of respondents gave an ineffective response. Almost $20.0 \%$ of the respondents did not respond to this question (Table XIV).

Response by Position Groups. Each of the five different position groups indicated that they felt the ESD was effective in having the interpersonal skills to work effectively 
with teachers and administrators in schools. All five position groups had a mean response of three on the six point effectiveness rating scale (Appendix 2, Table LXIX).

TABLE XIV

TOTAL GROUP RATING RESPONSE PERCENTAGES PERTAINING TO ESD 112 AND THE EFFECTTVENESS OF INTERPERSONAL SKILLS

\begin{tabular}{|c|c|c|c|c|c|c|c|}
\hline \multicolumn{3}{|c|}{ Mean Response $=2.811$} & \multicolumn{2}{|c|}{$N=769$} & \multicolumn{3}{|c|}{ Standard Deviation $=.808$} \\
\hline Rating Scale & 1 & 2 & 3 & 4 & 5 & 6 & 0 \\
\hline $\begin{array}{l}\text { Value } \\
\text { Definition }\end{array}$ & $\begin{array}{l}\text { Extremely } \\
\text { Effective }\end{array}$ & $\begin{array}{c}\text { Very } \\
\text { Effective }\end{array}$ & Effective & Ineffective & $\begin{array}{c}\text { Very } \\
\text { Ineffective }\end{array}$ & $\begin{array}{l}\text { Extremely } \\
\text { Ineffective }\end{array}$ & $\begin{array}{l}\text { NA/No } \\
\text { Response }\end{array}$ \\
\hline $\begin{array}{l}\text { Response } \\
\text { Percentage }\end{array}$ & $4.6 \%$ & $19.0 \%$ & $47.1 \%$ & $8.6 \%$ & $1.3 \%$ & $0.5 \%$ & $19.0 \%$ \\
\hline Numbers & 35 & 146 & 362 & 66 & 10 & 4 & 146 \\
\hline Totals & Effective & $=70.7 \%$ & & $m-\cdots$ & Ineffectiv & $=10.4 \%$ & \\
\hline
\end{tabular}

Response by Years of Experience Groups. The three different years of experience groups (for both Years of Experience in Present District and Years of Experience in State of Washington) indicated that ESD 112 was effective in having the interpersonal skills to work effectively with teachers and administrators in schools. All three groups had a mean response of three on the six point effectiveness rating scale (Appendix 2, Table LXXII and LXXV).

Response by District Size Groups. The five different district size groups all indicated that they felt ESD 112 was effective in having the interpersonal skills to work effectively with teachers and administrators in schools. All five groups had a mean response of three on the six point effectiveness rating scale (Appendix 2, Table LXXVIII).

Response by County Groups. The six different county groups rated ESD 112 as effective in having the interpersonal skills to work effectively with teachers and administrators in schools. Each of the six groups had a mean response of three on the six point effectiveness rating scale (Appendix 2, Table LXXXI). 
Response by Degree Level Groups. The High School Diploma category rated ESD 112 as "very effective" in having the interpersonal skills to work effectively with teachers and administrators in schools. This group had a mean response of two on the six point effectiveness rating scale. The other three groups all rated the ESD as effective on this same question, with each these three groups having a mean response of three on the six point effectiveness rating scale (Appendix 2, Table LXXXIV).

\section{Promoting Teaching in Classroom}

Question 21 inquired into how effective the respondent felt ESD 112 was in "providing services which ultimately promote the teaching processes found in the classroom." As the primary impetus having the educational system is to educate children, this question inquired into how effective the respondent felt ESD 112 was in providing services which promote classroom instruction.

The total respondent group rated ESD 112 as effective on this question, with a mean response of three (2.962) on the effectiveness rating scale of one to six (Table XV).

\section{TABLE XV}

TOTAL GROUP RATING RESPONSE PERCENTAGES PERTAINING TO ESD 112 AND THE EFFECTIVENESS OF PROVIDING SERVICES WHICH PROMOTE TEACHING PROCESSES IN CLASSROOM

\begin{tabular}{|c|c|c|c|c|c|c|c|}
\hline \multicolumn{3}{|c|}{ Mean Response $=2.962$} & \multicolumn{2}{|c|}{$N=769$} & \multicolumn{3}{|c|}{ Standard Deviation $=.925$} \\
\hline$\overline{\text { Rating Scale }}$ & 1 & 2 & 3 & 4 & 5 & 6 & 0 \\
\hline $\begin{array}{l}\text { Value } \\
\text { Definition }\end{array}$ & $\begin{array}{l}\text { Extremely } \\
\text { Effective }\end{array}$ & $\begin{array}{l}\text { Very } \\
\text { Effective }\end{array}$ & Effective & Inefiective & $\begin{array}{c}\text { Very } \\
\text { Ineffective }\end{array}$ & $\begin{array}{l}\text { Extremely } \\
\text { Ineffective }\end{array}$ & $\begin{array}{l}\text { NANo } \\
\text { Response }\end{array}$ \\
\hline $\begin{array}{l}\text { Response } \\
\text { Percentage }\end{array}$ & $3.8 \%$ & $18.2 \%$ & $44.1 \%$ & $13.0 \%$ & $2.1 \%$ & $1.8 \%$ & $17.0 \%$ \\
\hline Numbers & 29 & 140 & 339 & 100 & 16 & 14 & 131 \\
\hline & Effectil & $=66.19$ & & & Ineffecti & $=16.9 \%$ & \\
\hline
\end{tabular}


Two-thirds of the respondents replied with an effective rating, while a little less than $20.0 \%$ of the respondents replied with an ineffective rating. Seventeen percent of the respondents did not reply to this question.

Response by Position Groups. All five of the different position groups indicated that they felt the ESD was effective in providing services which ultimately promote the teaching processes found in the classroom. Each of the five different position groups had a mean response of three on the six point effectiveness rating scale (Appendix 2, Table LXIX).

Response by Years of Experience Groups. The three different years of experience groups (for both Years of Experience in Present District and Years of Experience in State of Washington) indicated that ESD 112 was effective in providing services which ultimately promote the teaching processes found in the classroom. All three groups had a mean response of three on the six point effectiveness rating scale (Appendix 2, Table LXXII and LXXV).

Response by District Size Groups. The five different district size groups all indicated that they felt ESD 112 was effective in providing services which ultimately promote the teaching processes found in the classroom. All five groups had a mean response of three on the six point effectiveness rating scale (Appendix 2, Table LXXVIII).

Response by County Groups. The Pacific County category rated ESD 112 as "ineffective" in providing services which ultimately promote the teaching processes found in the classroom, with a mean response of four on the six point effectiveness rating scale. The other five county groups rated the ESD as effective on this same question, with each of these five groups having mean response of three on the six point effectiveness rating scale (Appendix 2, Table LXXXI).

Response by Degree Level Groups. Each of the four degree level groups rated ESD 112 as effective in providing services which ultimately promote the teaching processes 
found in the classroom. Each of the four degree level groups had a mean response of three on the six point effectiveness rating scale (Appendix 2, Table LXXXIV).

\section{Administration of Programs and Services}

Question 22 asked the respondent to rate the effectiveness of the ESD in "having the resources to productively administer programs and services" within their organization. The purpose of this question was to inquire as to whether the respondent felt ESD 112 efficiently and effectively executed programs and services provided to educators and school districts.

An overall effective rating was given by the total respondent group, with a mean response of three (2.870) on the effectiveness rating scale of one to six. A little less than $70.0 \%$ of the respondents replied with an effective rating, while around $15.0 \%$ of the respondents replied with an "ineffective" rating. Twenty percent of the respondents did not respond to this question (Table XVI).

TABLEXVI

TOTAL GROUP RATING RESPONSE PERCENTAGES PERTAINING TO ESD 112 HAVING RESOURCES AND SKILLS TO PRODUCTIVELY ADMINISTER PROGRAMS AND SERVICES

\begin{tabular}{|c|c|c|c|c|c|c|c|}
\hline \multicolumn{3}{|c|}{ Mean Response $=2.870$} & \multicolumn{2}{|c|}{$\mathbf{N}=769$} & \multicolumn{3}{|c|}{ Standard Deviation $=.832$} \\
\hline Rating Scale & 1 & 2 & 3 & 4 & 5 & 6 & 0 \\
\hline $\begin{array}{l}\text { Value } \\
\text { Definition }\end{array}$ & $\begin{array}{l}\text { Extremely } \\
\text { Effective }\end{array}$ & $\begin{array}{c}\text { Very } \\
\text { Effective }\end{array}$ & Effective & Ineffective & $\begin{array}{c}\text { Very } \\
\text { Ineffective }\end{array}$ & $\begin{array}{l}\text { Extremely } \\
\text { Ineffective }\end{array}$ & $\begin{array}{c}\text { NANNo } \\
\text { Response }\end{array}$ \\
\hline $\begin{array}{l}\text { Response } \\
\text { Percentage }\end{array}$ & $3.4 \%$ & $19.4 \%$ & $43.6 \%$ & $10.5 \%$ & $1.7 \%$ & $0.7 \%$ & $20.8 \%$ \\
\hline Numbers & 26 & 149 & 335 & 81 & 13 & 5 & 160 \\
\hline Totals & Effective & $=66.4 \%$ & $<-\infty$ & $\cdots$ & Ineffectiv & $e=12.9 \%$ & \\
\hline
\end{tabular}

Response by Position Groups. All five of the position groups indicated that they felt the ESD was effective in having the resources to productively administer programs and 
services within their organization. Each of the five different position groups had a mean response of three on the six point effectiveness rating scale (Appendix 2, Table LXIX)

Response by Years of Experience Groups. The three different years of experience groups (for both Years of Experience in Present District and Years of Experience in State of Washington) indicated that ESD 112 was effective in having the resources to productively administer programs and services within their organization. All three groups had a mean response of three on the six point effectiveness rating scale (Appendix 2, Table LXXII and LXXV).

Response by District Size Groups. The five different district size groups all indicated that they felt ESD 112 was effective in having the resources to productively administer programs and services within their organization. All five groups had a mean response of three on the six point effectiveness rating scale (Appendix 2, Table LXVIII).

Response by County Groups. The six different county groups rated ESD 112 as effective in having the resources to productively administer programs and services within their organization. Each of the six county groups had a mean response of three on the six point effectiveness rating scale (Appendix 2, Table LXXXI).

Response by Degree Level Groups. Each of the four degree level groups rated ESD 112 as effective in having the resources to productively administer programs and services within their organization. Each of the four degree level groups had a mean response of three on the six point effectiveness rating scale (Appendix 2, Table LXXXIV).

\section{Providing Useful Evaluations}

Question 23 inquired into how effective the respondent felt ESD 112 was in "providing useful evaluations of students and personnel involved in programs and services" which they provided to school districts. The intent of this question was to have the respondent rate how effective they feel ESD 112 is providing evaluations of students 
(i.e. in special education, speech therapy) and personnel (i.e. teaching special eduction, motor therapy) which enhance the productivity of the educational process.

The total respondent group indicated an effective rating toward ESD 112 on this question, with a overall mean response of three (3.155) on the effectiveness rating scale of one to six. Almost $50.0 \%$ of the respondents replied with an effective rating, while almost $17.0 \%$ of the respondents replied with an ineffective rating. More than one-third of the respondents did not reply to this question (Table XVI).

Response by Position Groups. All five of the position groups indicated that they felt ESD 112 was effective in providing useful evaluations of students and personnel involved in programs and services they provide to school districts. Each of the five different groups had a mean response of three on the six point effectiveness rating scale (Appendix 2, Table LXIX).

\section{TABLE XVII}

TOTAL GROUP RATING RESPONSE PERCENTAGES PERTAINING TO ESD 112 PROVIDING USEFUL EVALUATIONS OF STUDENT AND PERSONNEL INVOLVED IN PROGRAMS AND SERVICES

\begin{tabular}{|c|c|c|c|c|c|c|c|}
\hline \multicolumn{3}{|c|}{ Mean Response $=3.155$} & \multicolumn{2}{|c|}{$N=769$} & \multicolumn{3}{|c|}{ Standard Deviation $=.847$} \\
\hline Rating Scale & 1 & 2 & 3 & 4 & 5 & 6 & 0 \\
\hline $\begin{array}{l}\text { Value } \\
\text { Definition }\end{array}$ & $\begin{array}{l}\text { Extremely } \\
\text { Effective }\end{array}$ & $\begin{array}{c}\text { Very } \\
\text { Effective }\end{array}$ & Effective & Ineffective & $\begin{array}{c}\text { Very } \\
\text { Ineffective }\end{array}$ & $\begin{array}{l}\text { Extremely } \\
\text { Ineffective }\end{array}$ & $\begin{array}{l}\text { NA/No } \\
\text { Response }\end{array}$ \\
\hline $\begin{array}{l}\text { Response } \\
\text { Percentage }\end{array}$ & $1.6 \%$ & $8.5 \%$ & $38.0 \%$ & $13.3 \%$ & $2.6 \%$ & $10 \%$ & $355 \%$ \\
\hline Numbers & 12 & 65 & 289 & 102 & 20 & 8 & 273 \\
\hline Totals & Effectiv & $48.1 \%$ & <-o- & $m-\infty$ & Ineffecti & $=16.9 \%$ & \\
\hline
\end{tabular}

Response by Years of Experience Groups. The three different years of experience groups (for both Years of Experience in Present District and Years of Experience in State of Washington) indicated that ESD 112 was effective in providing useful evaluations of students and personnel involved in programs and services they provide to school districts. 
All three of these groups had a mean response of three on the six point effectiveness rating scale (Appendix 2, Tables LXXII and LXXV).

Response by District Size Groups. The five different district size groups all indicated that they felt ESD 112 was effective in providing useful evaluations of students and personnel involved in programs and services they provide to school districts. All five district size groups had a mean response of three on the six point effectiveness rating scale (Appendix 2, Table LXVIII).

Response by County Groups. The Pacific County category rated ESD 112 as "ineffective" in providing useful evaluations of students and personnel involved in programs and services they provide to school districts. This category had a mean response of four on the six point effectiveness rating scale. The other five county groups rated the ESD as effective on this same question, with each of these five groups having mean response of three on the six point effectiveness rating scale (Appendix 2, Table LXXXI).

Response by Degree Level Groups. Each of the four degree level groups rated ESD 112 as effective in providing useful evaluations of students and personnel involved in programs and services they provide to school districts. Each of the four degree level groups had a mean response of three on the six point effectiveness rating scale (Appendix 2, Table LXXXIV).

\section{ESD 112's Overall Program}

Question 24 requested that the respondent to respond to how effective they felt ESD 112 was in "its overall program." The purpose of this question was to give the respondent the opportunity to give a single rating response on their general feeling towards the effectiveness of the total ESD 112 organization.

The overall ESD 112 program was rated as effective on this question, with the total group having a mean response of three (2.913) on the effectiveness rating scale of one to six. Seventy-five percent of the respondents replied with an effective rating, while a little 
more than $10.0 \%$ of the total group responded with an "ineffective" rating. Around $15.0 \%$ of the respondents did not reply to this question (Table XVIII).

Response by Position Groups. All five of the different position groups indicated that they felt ESD 112 was effective in its overall, or total, program. Each of the five different position groups had a mean response of three on the six point effectiveness rating scale (Appendix 2, Table LXIX).

Response by Years of Experience Groups. The three different years of experience groups indicated that ESD 112 was effective in its overall, or total, program. All three groups had a mean response of three on the six point effectiveness rating scale (Appendix 2, Tables LXXII and LXXV).

\section{TABLE XVIII}

TOTAL GROUP RATING RESPONSE PERCENTAGES PERTAINING TO ESD 112 AND THE EFFECTIVENESS OF THE ORGANIZATION'S OVERALL PROGRAM

\begin{tabular}{|c|c|c|c|c|c|c|c|}
\hline \multicolumn{3}{|c|}{ Mean Response $=2.913$} & \multicolumn{2}{|c|}{$N=769$} & \multicolumn{3}{|c|}{ Standard Deviation $=.748$} \\
\hline Rating Scale & 1 & 2 & 3 & 4 & 5 & 6 & 0 \\
\hline $\begin{array}{l}\text { Value } \\
\text { Definition }\end{array}$ & $\begin{array}{l}\text { Extremely } \\
\text { Effective }\end{array}$ & $\begin{array}{c}\text { Very } \\
\text { Effective }\end{array}$ & Effective & Ineffective & $\begin{array}{c}\text { Very } \\
\text { Ineffective }\end{array}$ & $\begin{array}{l}\text { Extremely } \\
\text { Ineffective }\end{array}$ & $\begin{array}{l}\text { NANNo } \\
\text { Response }\end{array}$ \\
\hline $\begin{array}{l}\text { Response } \\
\text { Percentage }\end{array}$ & $2.5 \%$ & $16.4 \%$ & $55.5 \%$ & $8.6 \%$ & $1.3 \%$ & $0.9 \%$ & $14.8 \%$ \\
\hline Numbers & 19 & 126. & 427 & 66 & 10 & 7 & 114 \\
\hline Totals & Effectil & $=74.4 \%$ & 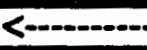 & $-\infty->$ & Ineffective & $=10.8 \%$ & \\
\hline
\end{tabular}

Response by District Size Groups. The five different district size groups all indicated that they felt ESD 112 was effective in its overall, or total, program. All five groups had a mean response of three on the six point effectiveness rating scale (Appendix 2, Table LXXVIII).

Response by County Groups. The six different county groups rated ESD 112 as effective in its overall, or total, program. Each of the six county groups had a mean response of three on the six point effectiveness rating scale (Appendix 2, Table LXXI). 
Response by Degree Level Groups. The High School Diploma category rated ESD 112 as "very effective" in its overall, or total, program. This group had a mean response of two on the six point effectiveness rating scale. The other three groups all rated the ESD as effective on this same question, with each these three groups having a mean response of three on the six point effectiveness rating scale (Appendix 2, Table LXXXIV).

\section{SPECIFIC PROGRAM AND SERVICE RATING QUESTIONS}

This portion of the chapter will discuss the two remaining sections of the survey instrument which deal with specific programs and services. First, questions regarding programs and services found in the Instructional and Curriculum Services will be examined. This will include questions 26 through 43 from the survey instrument. Second, questions concerning programs and services from the Special Services Division will be examined. This will include questions 45 through 62 .

Questions 25 and 44 were developed as "gate-questions" for the purpose of allowing the respondent to indicate whether or not they had enough knowledge of the two different service divisions to answer groups of subsequent questions. These two questions will be discussed before the curriculum and instruction and special services effectiveness questions discussion.

The results for this section will be presented by first providing the reader with a sentence regarding the topic of the survey question and the overall, or total group response. Then a table describing the percentages of respondents falling into the different effectiveness rating groups will be presented. The effectiveness rating scale included six possible responses other than indicating a "no information/not applicable" response, or just not responding at all. These included the following categories: one meaning "extremely effective," two meaning "very effective," three meaning "effective," four meaning "ineffective," five meaning "very ineffective," and six meaning "extremely ineffective." All 
mean responses were rounded to the nearest whole number and reported by the value definition given to the nearest numeric response discussed in the previous sentence. The table also presents the reader with the mean response and standard deviation for each individual question.

Since the majority of respondents indicated that they did not have enough knowledge to rate any of the specific programs and services provided by ESD 112 in the areas of instruction and curriculum and special services, all supplementary information pertaining to position, years of experience, district size, county location, and degree level will be provided in the appendices.

\section{Overall Knowledge of Specific Programs and Services}

Questions 25 and 44 were developed as "gate questions" for the last two effectiveness rating sections of the survey. These questions allowed the respondent to answer either "yes" or "no" on his or her ability to rate the section of questions immediately following the gate question. If the respondent answered "yes" he or she could continue on by answering the subsequent question section, or answer "no" and ignore the subsequent question section.

\section{Summary of Overall Knowledge of Specific Programs and Services}

Nearly two-thirds of the respondents indicated that they did not know enough about the Instructional and Curriculum programs and services to adequately rate their effectiveness. Nearly two-thirds of the respondents indicated that they did not know enough about the Special Services programs and services to adequately rate their effectiveness.

\section{Knowledge About Cumiculum and Instruction}

Question 25 asked the respondent whether they felt he or she knew "enough about any of the curriculum and instructional services" to properly rate them. Almost two-thirds 
of the respondents felt that they did not know enough about the curriculum and

instructional services to adequately rate them. A little over one-third of the respondents felt they possessed enough knowledge about the curriculum and instruction programs to rate them. More than two percent of the respondents elected not to respond to this question (Table XIX).

\section{TABLE XIX}

TOTAL GROUPRESPONSE PERCENTAGES TO OVERALL KNOWLEDGE OF SPECIFIC ESD 112 PROGRAMS AND SERVICES IN THE AREAS OF INSTRUCTION AND CURRICULUM AND SPECIAL SERVICES

\begin{tabular}{lccc}
\hline & \multicolumn{4}{c}{$\mathrm{N}=769$} & & \\
\hline Gate Questions by Topic & $\begin{array}{c}\text { Percent of Group } \\
\text { Responding Yes }\end{array}$ & $\begin{array}{c}\text { Percent of Group } \\
\text { Responding No }\end{array}$ & $\begin{array}{c}\text { Percent of Group } \\
\text { With No Response }\end{array}$ \\
\hline $\begin{array}{l}\text { 25. Adequate Knowledge to Rate } \\
\text { Effectiveness of ESD 112 }\end{array}$ & $34.9 \%$ & $62.8 \%$ & $2.3 \%$ \\
$\begin{array}{l}\text { Curriculum and Instruction } \\
\text { Services }\end{array}$ & $\mathrm{n}=268$ & $\mathrm{n}=483$ & $\mathrm{n}=18$ \\
\hline $\begin{array}{l}\text { 44. Adequate Knowledge to Rate } \\
\text { Effectiveness of ESD 112 } \\
\text { Special Services }\end{array}$ & $32.4 \%$ & $63.2 \%$ & $4.4 \%$ \\
\hline
\end{tabular}

\section{Knowledge About Special Services}

Question 44 asked the respondent whether they felt they had knowledge "enough about any of the special services division's" programs to adequately rate them. Again, almost two-thirds of the respondents felt that they did not have enough knowledge of the special services division of ESD 112 to adequately rate them. Close to one-third of the respondents felt that they did have enough knowledge to rate the special services division of the ESD. A little over four percent chose not to respond to this question (Table XIX).

\section{Summary of Specific Program and Services Effectiveness Rating Ouestions}

The total group of respondents gave an effective rating response on all the Instructional and Curriculum services effectiveness rating questions with the exception of one very effective rating response. The very effective rating was given on question 41 , 
which pertained to the Instructional Media Cooperative Staff. Nearly two-thirds or more of the respondents either did not respond or were not able to adequately rate each of the 18 Instructional and Curriculum programs and services questions.

The total group of respondents gave an effective rating response on all the Special Services Division's effectiveness rating questions. Again, at least two-thirds or more of the respondents either did not respond or were not able to adequately rate each of the 18 Special Services Division questions.

Total Curriculum and Instructional Program

Question 26 asked the respondents to rate the total curriculum and instructional program offered by ESD 112. The purpose for this question was to inquire into how effective the respondent felt the curricular and instructional programs and services offered by ESD 112 were by rating them as a single program.

The total group rated the curriculum and instructional services of ESD 112 as effective, with a mean response of three (2.987) on the six point effectiveness rating scale (Table XX). Almost $30.0 \%$ of the respondents replied with an effective rating, while $5.0 \%$ gave an ineffective rating. Two-thirds of the respondents did not respond to this question.

\section{TABLE XX}

TOTAL GROUP RATING RESPONSE PERCENTAGES PERTAINING TO ESD 112 AND THE EFFECTIVENESS OF THE TOTAL INSTRUCTIONAL AND CURRICULUM PROGRAM

\begin{tabular}{|c|c|c|c|c|c|c|c|}
\hline \multicolumn{3}{|c|}{ Mean Response $=2.897$} & \multicolumn{2}{|c|}{$N=769$} & \multicolumn{3}{|c|}{ Standard Deviation $=.811$} \\
\hline Rating Scale & 1 & 2 & 3 & 4 & 5 & 6 & 0 \\
\hline $\begin{array}{l}\text { Value } \\
\text { Definition }\end{array}$ & $\begin{array}{l}\text { Extremely } \\
\text { Effective }\end{array}$ & $\begin{array}{c}\text { Very } \\
\text { Effective }\end{array}$ & Effective & Ineffective & $\begin{array}{c}\text { Very } \\
\text { Ineffective }\end{array}$ & $\begin{array}{l}\text { Extremely } \\
\text { Ineffective }\end{array}$ & $\begin{array}{l}\text { NA/No } \\
\text { Response }\end{array}$ \\
\hline $\begin{array}{l}\text { Response } \\
\text { Percentage }\end{array}$ & $1.0 \%$ & $8.3 \%$ & $19.9 \%$ & $4.0 \%$ & $0.5 \%$ & $0.5 \%$ & $65.8 \%$ \\
\hline Numbers & 7 & 64 & 153 & 31 & 4 & 4 & 506 \\
\hline Totals & Effecti & $=29.2 \%$ & <------ & $\cdots>$ & Ineffectiv & $5.0 \%$ & \\
\hline
\end{tabular}


Curriculum and Instruction Staff

Question 27 requested that the respondents rate the effectiveness of ESD 112's curriculum and instructional staff. The purpose for this question was to have the respondent rate how effective the ESD curriculum and instructional staff is when providing services to the school district. The respondents rated the curriculum and instructional staff as effective when providing services, with a mean response of three (2.876) on the six point effectiveness rating scale (Table XXI). A little less than $30.0 \%$ of the respondents

TABLE XXI

TOTAL GROUP RATING RESPONSE PERCENTAGES PERTAINING TO ESD 112 AND THE EFFECTIVENESS OF THE INSTRUCTIONAL AND CURRICULUM DIVISION'S STAFF

\begin{tabular}{|c|c|c|c|c|c|c|c|}
\hline \multicolumn{3}{|c|}{ Mean Response $=2.876$} & \multicolumn{2}{|c|}{$N=769$} & \multicolumn{3}{|c|}{ Standard Deviation $=.954$} \\
\hline Rating Scale & 1 & 2 & 3 & 4 & 5 & 6 & 0 \\
\hline $\begin{array}{l}\text { Value } \\
\text { Definition }\end{array}$ & $\begin{array}{l}\text { Extremely } \\
\text { Effective }\end{array}$ & $\begin{array}{c}\text { Very } \\
\text { Effective }\end{array}$ & Effective & Ineffective & $\begin{array}{c}\text { Very } \\
\text { Ineffective }\end{array}$ & $\begin{array}{l}\text { Exiremely } \\
\text { Ineffective }\end{array}$ & $\begin{array}{l}\text { NANo } \\
\text { Response }\end{array}$ \\
\hline $\begin{array}{l}\text { Response } \\
\text { Percentage }\end{array}$ & $2.0 \%$ & $8.5 \%$ & $17.4 \%$ & $4.0 \%$ & $0.9 \%$ & $0.8 \%$ & $66.4 \%$ \\
\hline Numbers & 15 & 65 & 134 & 31 & 7 & 6 & 511 \\
\hline Totals & Effectiv & $=27.9 \%$ & $\ldots \ldots$ & $\cdots$ & Ineffecti & $=5.7 \%$ & \\
\hline
\end{tabular}

indicated an effective response on this question, while less than $6.0 \%$ of the total group gave an ineffective reply. A little more than $66.0 \%$ of the respondents did not reply to this question.

\section{Cumriculum and Instruction Communication Devices}

The 28th question on the survey requested the respondent to rate the ESD 112 communication devices which pertained to curriculum and instructional services.

The total group gave the communications devices regarding the curriculum and instructional programs and services an effective rating, by indicating a mean response of three (2.873) on the six point effectiveness rating scale. Twenty-seven percent of the 
respondents replied with an effective rating, while less than $6.0 \%$ gave an ineffective reply. More than $67.0 \%$ of the respondents did not indicate an answer on this question (Table XXII).

TABLE XXII

TOTAL GROUP RATING RESPONSE PERCENTAGES PERTAINING TO ESD 112 AND THE EFFECTIVENESS OF THE COMMUNICATION DEVICES CONCERNING CURRICULUM AND INSTRUCTIONAL PROGRAMS AND SERVICES

\begin{tabular}{|c|c|c|c|c|c|c|c|}
\hline \multicolumn{3}{|c|}{ Mean Response $=2.873$} & \multicolumn{2}{|c|}{$N=769$} & \multicolumn{3}{|c|}{ Standard Deviation $=.916$} \\
\hline Rating Scale & 1 & 2 & 3 & 4 & 5 & 6 & 0 \\
\hline $\begin{array}{l}\text { Value } \\
\text { Definition }\end{array}$ & $\begin{array}{l}\text { Extremely } \\
\text { Effective }\end{array}$ & $\begin{array}{c}\text { Very } \\
\text { Effective }\end{array}$ & Effective & Ineffective & $\begin{array}{c}\text { Very } \\
\text { Ineffective }\end{array}$ & $\begin{array}{l}\text { Extremely } \\
\text { Ineffective }\end{array}$ & $\begin{array}{l}\text { NA/No } \\
\text { Response }\end{array}$ \\
\hline $\begin{array}{l}\text { Response } \\
\text { Percentage }\end{array}$ & $1.7 \%$ & $8.5 \%$ & $16.6 \%$ & $4.7 \%$ & $0.5 \%$ & $0.5 \%$ & $67.4 \%$ \\
\hline Numbers & 13 & 65 & 128 & 36 & 4 & 5 & 518 \\
\hline Totals & Effecti & $=26.89$ & -1 & $----->$ & neffecti & $=5.7 \%$ & \\
\hline
\end{tabular}

Curriculum and Instructional Resources

Question 29 asked the respondents to rate the "ESD as an information and resource center for Curriculum and Instructional matters."

An overall effective rating was indicated by the total group of respondents. The mean response for the total group was three (2.886) on the six point effectiveness rating scale. Almost $\mathbf{2 8 . 0 \%}$ of the respondents responded with an effective rating, while less than 7.0\% responded with an ineffective rating. More than $67.0 \%$ of the respondents did not reply to this question (Table XXIII). 
TABLE XXIII

TOTAL GROUP RATING RESPONSE PERCENTAGES PERTAINING TO THE EFFECTIVENESS OF ESD 112 AS AN INFORMATION AND RESOURCE CENTER FOR INSTRUCTIONAL AND CURRICULUM MATTERS

\begin{tabular}{|c|c|c|c|c|c|c|c|}
\hline \multicolumn{3}{|c|}{ Mean Response $=2.886$} & \multicolumn{2}{|c|}{$N=769$} & \multicolumn{3}{|c|}{ Standard Deviation $=.962$} \\
\hline Rating Scale & 1 & 2 & 3 & 4 & 5 & 6 & 0 \\
\hline $\begin{array}{l}\text { Value } \\
\text { Definition }\end{array}$ & $\begin{array}{c}\text { Extremely } \\
\text { Effective }\end{array}$ & $\begin{array}{c}\text { Very } \\
\text { Effective }\end{array}$ & Effective & Ineffective & $\begin{array}{c}\text { Very } \\
\text { Ineffective }\end{array}$ & $\begin{array}{l}\text { Extremely } \\
\text { Ineffective }\end{array}$ & $\begin{array}{l}\text { NANo } \\
\text { Response }\end{array}$ \\
\hline $\begin{array}{l}\text { Response } \\
\text { Pexcentage }\end{array}$ & $2.1 \%$ & $8.6 \%$ & $16.9 \%$ & $5.3 \%$ & $0.4 \%$ & $0.9 \%$ & $65.8 \%$ \\
\hline Numbers & 16 & 66 & 130 & 41 & 3 & 7 & 506 \\
\hline Totals & Effective & $=27.6 \%$ & <-- & 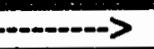 & Ineffective & $=6.6 \%$ & \\
\hline
\end{tabular}

Curriculum and Instruction Inservices

The 30th question asked the respondents to rate the effectiveness of inservices provided by ESD 112 in the areas of curriculum and instruction.

The total group rated the curriculum and instructional inservices provided by ESD 112 as effective, with a mean response of (2.845) on the six point effectiveness rating scale (Table XXIV). Twenty-nine percent of the respondents replied with an effective rating,

\section{TABLE XXIV}

TOTAL GROUP RATING RESPONSE PERCENTAGES PERTAINING TO ESD 112 AND THE EFFECTIVENESS OF INSERVICES PROVIDED IN THE AREAS OF CURRICULUM AND INSTRUCTION

\begin{tabular}{|c|c|c|c|c|c|c|c|}
\hline \multicolumn{3}{|c|}{ Mean Response $=2.845$} & \multicolumn{2}{|c|}{$N=769$} & \multicolumn{3}{|c|}{ Standard Deviation $=.942$} \\
\hline Rating Scale & 1 & 2 & 3 & 4 & 5 & 6 & 0 \\
\hline $\begin{array}{l}\text { Value } \\
\text { Definition }\end{array}$ & $\begin{array}{l}\text { Extremely } \\
\text { Effective }\end{array}$ & $\begin{array}{c}\text { Very } \\
\text { Effective }\end{array}$ & Effective & Ineffective & $\begin{array}{c}\text { Very } \\
\text { Ineffective }\end{array}$ & $\begin{array}{l}\text { Extremely } \\
\text { Ineffective }\end{array}$ & $\begin{array}{l}\text { NANNo } \\
\text { Response }\end{array}$ \\
\hline $\begin{array}{l}\text { Response } \\
\text { Percentage }\end{array}$ & $2.5 \%$ & $8.8 \%$ & $17.4 \%$ & $5.3 \%$ & $0.5 \%$ & $0.7 \%$ & $64.8 \%$ \\
\hline Numbers & 19 & 68 & 134 & 41 & 4 & 5 & 498 \\
\hline Totals & Effective & $=28.7 \%$ & $<-\cdots$ & $\overline{m-\cdots>}$ & Ineffectiv & $=6.5 \%$ & \\
\hline
\end{tabular}


while less than $7.0 \%$ responded with an ineffective rating. Nearly $65.0 \%$ of the respondents did not indicate an answer on this question.

\section{Educational Technology Services}

Question 31 requested the respondents to rate the effectiveness of the services provided by the Educational Technology Center (ESD 112 Computer Lab).

The total group of respondents indicated that they felt the services provided by the Educational Technology Center as being effective. The mean response for the total group was three (2.682) on the six point effectiveness rating scale (Table XXV). More than

\section{TABLE XXV}

TOTAL GROUP RATING RESPONSE PERCENTAGES PERTAINING TO ESD 112 AND THE EFFECTIVENESS OF THE SERVICES PROVIDED BY THE EDUCATIONAL TECHNOLOGY CENTER

\begin{tabular}{|c|c|c|c|c|c|c|c|}
\hline \multicolumn{3}{|c|}{ Mean Response $=2.682$} & \multicolumn{2}{|c|}{$N=769$} & \multicolumn{3}{|c|}{ Standard Deviation $=.885$} \\
\hline Rating Scale & 1 & 2 & 3 & 4 & 5 & 6 & 0 \\
\hline $\begin{array}{l}\text { Value } \\
\text { Definition }\end{array}$ & $\begin{array}{l}\text { Extremely } \\
\text { Effective }\end{array}$ & $\begin{array}{c}\text { Very } \\
\text { Effective }\end{array}$ & Effective & Ineffective & $\begin{array}{l}\text { Very } \\
\text { Ineffective }\end{array}$ & $\begin{array}{l}\text { Extremely } \\
\text { Ineffective }\end{array}$ & $\begin{array}{l}\text { NA/No } \\
\text { Response }\end{array}$ \\
\hline $\begin{array}{l}\text { Response } \\
\text { Percentage }\end{array}$ & $2.5 \%$ & $6.4 \%$ & $13.5 \%$ & $2.2 \%$ & $0.0 \%$ & $0.4 \%$ & $75.0 \%$ \\
\hline Numbers & 19 & 49 & 104 & 17 & $\mathbf{0}$ & 3 & 577 \\
\hline Total & $\overline{\text { Effect }}$ & $=22.4$ & & - & Ineffect & $=2.6 \%$ & \\
\hline
\end{tabular}

$22.0 \%$ of the respondents gave an effective rating on this question, while less than $3.0 \%$ responded with an ineffective rating. Seventy-five percent of the respondents did not reply to this question.

Inservice Grant Committee

Question 32 requested that the respondents rate the effectiveness of the Inservice Grant Committee in allocating funds for staff development and inservice projects. 
The Inservice Grant Committee was rated as being effective by the total group of respondents, with a mean response of three (2.823) on the six point effectiveness rating scale (Table XXVI). Twenty percent of the total group responded with an effective rating on this question, while less than $5.0 \%$ replied with an ineffective rating. Seventy-five percent of the respondents did not respond on this question .

\section{TABLE XXVI}

TOTAL GROUP RATING RESPONSE PERCENTAGES PERTAINING TO ESD 112 AND THE EFFECTIVENESS OF THE INSERVICE GRANT COMMITTEE

\begin{tabular}{|c|c|c|c|c|c|c|c|}
\hline \multicolumn{3}{|c|}{ Mean Response $=2.823$} & \multicolumn{2}{|c|}{$N=769$} & \multicolumn{3}{|c|}{ Standard Deviation $=.971$} \\
\hline Rating Scale & 1 & 2 & 3 & 4 & 5 & 6 & 0 \\
\hline $\begin{array}{l}\text { Value } \\
\text { Definition }\end{array}$ & $\begin{array}{l}\text { Extremely } \\
\text { Effective }\end{array}$ & $\begin{array}{c}\text { Very } \\
\text { Effective }\end{array}$ & Effective & Ineffective & $\begin{array}{c}\text { Very } \\
\text { Ineffective }\end{array}$ & $\begin{array}{l}\text { Extremely } \\
\text { Ineffective }\end{array}$ & $\begin{array}{l}\text { NA/No } \\
\text { Response }\end{array}$ \\
\hline $\begin{array}{l}\text { Response } \\
\text { Percentage }\end{array}$ & $2.1 \%$ & $6.2 \%$ & $12.0 \%$ & $3.9 \%$ & $0.3 \%$ & $0.5 \%$ & $75.0 \%$ \\
\hline Numbers & 16 & 48 & 92 & 30 & 2 & 4 & 577 \\
\hline Totals & Effective & $=20.3 \%$ & $<-$ & $\ldots$ & Ineffectiv & $=4.7 \%$ & \\
\hline
\end{tabular}

\section{Student Teacher Pilot Program}

Question 33 requested the respondent to indicate how effective they felt the Student Teacher Pilot Program was in the public school systems in the ESD 112 service area.

The total group indicated they felt the Student Teacher Pilot Program was effective, having a mean response of three (2.776) on the six point effectiveness rating scale. Nearly $17.0 \%$ of the respondents replied with an effective rating, while a little more than $3.0 \%$ of the respondents gave an ineffective rating. Close to $80.0 \%$ of the respondents did not indicate an answer on this question (Table XXVII).

\section{Teacher Assistance Propram}

Question 34 asked the respondents to rate the effectiveness of ESD 112's Teacher Assistance Program. 
The overall group rated ESD 112's Teacher Assistance Program as effective, with a mean response of three (2.831)) on the six point effectiveness rating scale (Table XXVII).

TABLE XXVII

TOTAL GROUP RATING RESPONSE PERCENTAGES PERTAINING TOESD 112 AND THE STUDENT TEACHER PILOT PROGRAM

\begin{tabular}{|c|c|c|c|c|c|c|c|}
\hline \multicolumn{3}{|c|}{ Mean Response $=2.776$} & \multicolumn{2}{|c|}{$N=769$} & \multicolumn{3}{|c|}{ Standard Deviation $=1.000$} \\
\hline Rating Scale & 1 & 2 & 3 & 4 & 5 & 6 & 0 \\
\hline $\begin{array}{l}\text { Value } \\
\text { Definition }\end{array}$ & $\begin{array}{l}\text { Extremely } \\
\text { Effective }\end{array}$ & $\begin{array}{l}\text { Very } \\
\text { Effective }\end{array}$ & Effective & Ineffective & $\begin{array}{c}\text { Very } \\
\text { Ineffective }\end{array}$ & $\begin{array}{l}\text { Extremely } \\
\text { Ineffective }\end{array}$ & $\begin{array}{l}\text { NANo } \\
\text { Response }\end{array}$ \\
\hline $\begin{array}{l}\text { Response } \\
\text { Percentage }\end{array}$ & $1.8 \%$ & $5.6 \%$ & $9.5 \%$ & $2.6 \%$ & $0.3 \%$ & $0.5 \%$ & $79.7 \%$ \\
\hline Numbers & 14 & 43 & 73 & 20 & 2 & 4 & 613 \\
\hline Totals & Effective & $16.9 \%$ & $5-\infty+\infty$ & $m$ & Ineffectiv & $=3.4 \%$ & \\
\hline
\end{tabular}

TABLE XXVIII

TOTAL GROUP RATING RESPONSE PERCENTAGES PERTAINING TO ESD 112 AND THE EFFECTIVENESS OF THE TEACHER ASSISTANCE PROGRAM

\begin{tabular}{|c|c|c|c|c|c|c|c|}
\hline \multicolumn{3}{|c|}{ Mean Response $=2.831$} & \multicolumn{2}{|c|}{$N=769$} & \multicolumn{3}{|c|}{ Standard Deviation $=1.025$} \\
\hline Rating Scale & 1 & 2 & 3 & 4 & 5 & 6 & 0 \\
\hline $\begin{array}{l}\text { Value } \\
\text { Definition }\end{array}$ & $\begin{array}{l}\text { Extremely } \\
\text { Effective }\end{array}$ & $\begin{array}{c}\text { Very } \\
\text { Effective }\end{array}$ & Effective & Ineffective & $\begin{array}{c}\text { Very } \\
\text { Ineffective }\end{array}$ & $\begin{array}{l}\text { Extremely } \\
\text { Ineffective }\end{array}$ & $\begin{array}{l}\text { NA/No } \\
\text { Response }\end{array}$ \\
\hline $\begin{array}{l}\text { Response } \\
\text { Percentage }\end{array}$ & $1.7 \%$ & $6.2 \%$ & $9.1 \%$ & $4.0 \%$ & $0.1 \%$ & $0.7 \%$ & $78.4 \%$ \\
\hline Numbers & 13 & 48 & 70 & 29 & 1 & 5 & 603 \\
\hline Totals & Effective & $=17.0 \%$ & $<-\cdots$ & $\cdots-\cdots$ & Ineffectiv & $=4.8 \%$ & \\
\hline
\end{tabular}

Seventeen percent of the respondents responded with an effective rating to this question, with nearly $5.0 \%$ of the total group replying with an ineffective rating. More than $78.0 \%$ of the respondents did not respond to this question. 
Whole Lanquage Support Group

The 35th question of the survey requested that the respondents rate the effectiveness of the Whole Language Support Group.

The total group of respondents indicated that the Whole Language Support Group program was felt to be effective. The mean response for the total group was three (2.727) on the six point effectiveness rating scale. More than $14.0 \%$ of the total group responded with an effective rating on this question, while less than $3.0 \%$ responded with an ineffective rating. Almost $83.0 \%$ of the respondents did not respond to this question (Table XXIX).

TABLE XXIX

TOTAL GROUP RATING RESPONSE PERCENTAGES PERTAINING TO ESD 112 THE EFFECTIVENESS OF THE WHOLE LANGUAGE SUPPORT GROUP

\begin{tabular}{|c|c|c|c|c|c|c|c|}
\hline \multicolumn{3}{|c|}{ Mean Response $=2.727$} & \multicolumn{2}{|c|}{$N=769$} & \multicolumn{3}{|c|}{ Standard Deviation $=.974$} \\
\hline Rating Scale & 1 & 2 & 3 & 4 & 5 & 6 & 0 \\
\hline $\begin{array}{l}\text { Value } \\
\text { Definition }\end{array}$ & $\begin{array}{l}\text { Extremely } \\
\text { Effective }\end{array}$ & $\begin{array}{c}\text { Very } \\
\text { Effective }\end{array}$ & Effective & Ineffective & $\begin{array}{c}\text { Very } \\
\text { Ineffective }\end{array}$ & $\begin{array}{l}\text { Extremely } \\
\text { Ineffective }\end{array}$ & $\begin{array}{c}\text { NANo } \\
\text { Response }\end{array}$ \\
\hline $\begin{array}{l}\text { Response } \\
\text { Percentage }\end{array}$ & $1.8 \%$ & $4.7 \%$ & $7.7 \%$ & $2.3 \%$ & $0.1 \%$ & $0.3 \%$ & $82.8 \%$ \\
\hline Numbers & 14 & 36 & 59 & 20 & 1 & 2 & 637 \\
\hline Totals & Effectiv & $=14.2 \%$ & 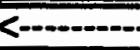 & $m$ & Ineffectiv & $=2.7 \%$ & \\
\hline
\end{tabular}

\section{Student Involved Programs}

Question 36 asked the respondents to rate the effectiveness of student involved programs, which ESD 112 provides to the school districts in its service area.

The total group indicated that they felt that the student involved programs were effective, with a mean response of three (2.858) on the six point effectiveness rating scale. More than $19.0 \%$ of the respondents replied with an effective rating on this question, while less than $4.0 \%$ of the total group responded with an ineffective rating. Seventy-seven percent of the respondents did not respond to this question (Table XXX). 
TABLE XXX

TOTAL GROUP RATING RESPONSE PERCENTAGES PERTAINING TO ESD 112 AND THE EFFECTIVENESS OF STUDENT INVOLVED PROGRAMS

\begin{tabular}{|c|c|c|c|c|c|c|c|}
\hline \multicolumn{3}{|c|}{ Mean Response $=2.858$} & \multicolumn{2}{|c|}{$N=769$} & \multicolumn{3}{|c|}{ Standard Deviation $=.873$} \\
\hline Rating Scale & 1 & 2 & 3 & 4 & 5 & 6 & 0 \\
\hline $\begin{array}{l}\text { Value } \\
\text { Definition }\end{array}$ & $\begin{array}{l}\text { Extremely } \\
\text { Effective }\end{array}$ & $\begin{array}{l}\text { Very } \\
\text { Effective }\end{array}$ & Effective & Ineffective & $\begin{array}{c}\text { Very } \\
\text { Ineffective }\end{array}$ & $\begin{array}{l}\text { Extremely } \\
\text { Ineffective }\end{array}$ & $\begin{array}{l}\text { NA/No } \\
\text { Response }\end{array}$ \\
\hline $\begin{array}{l}\text { Response } \\
\text { Percentage }\end{array}$ & $1.2 \%$ & $5.7 \%$ & $12.2 \%$ & $3.0 \%$ & $0.5 \%$ & $0.3 \%$ & $77.1 \%$ \\
\hline Numbers & 9 & 44 & 94 & 23 & 4 & 2 & 593 \\
\hline Totals & Effecti & $=19.1 \%$ & $<-\cdots$ & $\cdots$ & Ineffective & $=3.8 \%$ & \\
\hline
\end{tabular}

Traffic Safety Cooperative

Question 37 requested that the respondents indicate how effective they felt the ESD 112 Traffic Safety Cooperative was in providing effective services and programs in this area.

The total respondent group indicated that the Traffic Safety Cooperative was considered effective. The mean response for the total group was three (2.879) on the six point effectiveness rating scale (Table XXXI). A little more than $11.0 \%$ of the respondents

TABLE XXXI

TOTAL GROUP RATING RESPONSE PERCENTAGES PERTAINING TO ESD 112 THE EFFECTIVENESS OF THE TRAFFIC SAFETY COOPERATIVE

\begin{tabular}{|c|c|c|c|c|c|c|c|}
\hline \multicolumn{3}{|c|}{ Mean Response $=2.879$} & \multicolumn{2}{|c|}{$N=769$} & \multicolumn{3}{|c|}{ Standard Deviation $=.824$} \\
\hline Rating Scale & 1 & 2 & 3 & 4 & 5 & 6 & 0 \\
\hline $\begin{array}{l}\text { Value } \\
\text { Definition }\end{array}$ & $\begin{array}{l}\text { Extremely } \\
\text { Effective }\end{array}$ & $\begin{array}{l}\text { Very } \\
\text { Effective }\end{array}$ & Effective & Ineffective & $\begin{array}{c}\text { Very } \\
\text { Ineffective }\end{array}$ & $\begin{array}{l}\text { Extremely } \\
\text { Ineffective }\end{array}$ & $\begin{array}{l}\text { NA/No } \\
\text { Response }\end{array}$ \\
\hline $\begin{array}{l}\text { Response } \\
\text { Percentage }\end{array}$ & $0.5 \%$ & $2.9 \%$ & $7.7 \%$ & $1.6 \%$ & $0.0 \%$ & $0.3 \%$ & $87.1 \%$ \\
\hline Numbers & 4 & 22 & 59 & 12 & 0 & 2 & 670 \\
\hline Totals & Effectiv & $=11.1 \%$ & $<-\cdots$ & $-\cdots-\infty$ & Ineffectiv & $=1.9 \%$ & \\
\hline
\end{tabular}


replied with an effective response, while less than $2.0 \%$ responded with an ineffective response. Eighty-seven percent of the respondents did not respond to this question.

\section{Substance-Abuse Programs}

Question 38 on the survey instrument asked the respondents to rate ESD 112's Substance-Abuse programs.

The total group of respondents indicated that they felt the Substance-Abuse programs provided by the ESD were effective, with a total group mean response of three (3.036) on the six point effectiveness rating scale (Table XXXII). Sixteen percent of the respondents indicated and effective rating on this question, while less than $6.0 \%$ replied with an ineffective rating. Seventy-eight percent of the respondents did not respond to this question.

TABLE XXXII

TOTAL GROUP RATING RESPONSE PERCENTAGES PERTAINING TO ESD 112 AND THE EFFECTIVENESS OF THE SUBSTANCE-ABUSE PROGRAMS

\begin{tabular}{|c|c|c|c|c|c|c|c|}
\hline \multicolumn{3}{|c|}{ Mean Response $=3.036$} & \multicolumn{2}{|c|}{$N=769$} & \multicolumn{3}{|c|}{ Standard Deviation $=.965$} \\
\hline Rating Scale & 1 & 2 & 3 & 4 & 5 & 6 & 0 \\
\hline $\begin{array}{l}\text { Value } \\
\text { Definition }\end{array}$ & $\begin{array}{c}\text { Extremely } \\
\text { Effective }\end{array}$ & $\begin{array}{c}\text { Very } \\
\text { Effective }\end{array}$ & Effective & Ineffective & $\begin{array}{c}\text { Very } \\
\text { Ineffective }\end{array}$ & $\begin{array}{l}\text { Extremely } \\
\text { Ineffective }\end{array}$ & $\begin{array}{l}\text { NA/No } \\
\text { Response }\end{array}$ \\
\hline $\begin{array}{l}\text { Response } \\
\text { Percentage }\end{array}$ & $1.0 \%$ & $4.3 \%$ & $10.7 \%$ & $4.7 \%$ & $0.3 \%$ & $0.7 \%$ & $78.4 \%$ \\
\hline Numbers & 8 & 33 & 82 & 36 & 2 & 5 & 603 \\
\hline Totals & Effective & $=16.0 \%$ & $<-\cdots$ & $\ldots$ & Ineffectiv & $=5.7 \%$ & \\
\hline
\end{tabular}

\section{Project Write}

Question 39 requested that the respondents rate the effectiveness of the Project Write program offered by ESD 112. 
The total group of respondents indicated that they felt the Project Write program provided by the ESD was effective, with a mean response of three (2.947) on the six point effectiveness rating scale (Table XXXIII). Eighteen percent of the respondents replied

\section{TABLE XXXIII}

TOTAL GROUP RATING RESPONSE PERCENTAGES PERTAINING TO ESD

112 AND THE EFFECTIVENESS OF THE PROJECT WRITE PROGRAM

\begin{tabular}{|c|c|c|c|c|c|c|c|}
\hline \multicolumn{3}{|c|}{ Mean Response $=2.947$} & \multicolumn{2}{|c|}{$N=769$} & \multicolumn{3}{|c|}{ Standard Deviation $=1.002$} \\
\hline Rating Scale & 1 & 2 & 3 & 4 & 5 & 6 & 0 \\
\hline $\begin{array}{l}\text { Value } \\
\text { Definition }\end{array}$ & $\begin{array}{c}\text { Extremely } \\
\text { Effective }\end{array}$ & $\begin{array}{c}\text { Very } \\
\text { Effective }\end{array}$ & Effective & Ineffective & $\begin{array}{c}\text { Very } \\
\text { Ineffective }\end{array}$ & $\begin{array}{l}\text { Extremely } \\
\text { Ineffective }\end{array}$ & $\begin{array}{l}\text { NA/No } \\
\text { Response }\end{array}$ \\
\hline $\begin{array}{l}\text { Response } \\
\text { Percentage }\end{array}$ & $0.9 \%$ & $5.7 \%$ & $11.2 \%$ & $2.9 \%$ & $0.4 \%$ & $0.9 \%$ & $78.0 \%$ \\
\hline Numbers & 7 & 44 & 86 & 22 & 3 & 7 & 600 \\
\hline Totals & Effective & $=17.8 \%$ & $<\ldots$ & $\ldots>$ & Ineffective & $=4.2 \%$ & \\
\hline
\end{tabular}

with an effective rating, while a little more than $4.0 \%$ responded with an ineffective rating. Seventy-eight percent of the respondents did not respond to this question.

\section{Practitioners' Workshops}

Question 40 solicited a rating response from the respondent pertaining to the practitioners' Workshops.

The total group response indicated that the Practitioners' Workshops were felt to be effective. The total group mean response was three (2.785) on the six point effectiveness rating scale. Eighteen percent of the respondents replied with an effective rating on this question, while a little less than $3.0 \%$ replied with an ineffective rating. Close to $80.0 \%$ of the respondents did not reply to this question (Table XXXIV).

\section{Instructional Media Cooperative Staff}

Question 41 asked the respondents to rate the effectiveness of the staff of the Instructional Media Cooperative. 
A very effective rating was given to the staff of ESD 112's Instructional Media Cooperative by the total group of respondents. The mean response for the total group was two (2.429) on the six point effectiveness rating scale (Table XXXV). More than 27.0\%

\section{TABLE XXXIV}

TOTAL GROUP RATING RESPONSE PERCENTAGES PERTAINING TO ESD 112 AND THE EFFECTIVENESS OF THE PRACTIONERS' WORKSHOP

\begin{tabular}{|c|c|c|c|c|c|c|c|}
\hline \multicolumn{3}{|c|}{ Mean Response $=2.785$} & \multicolumn{2}{|c|}{$N=769$} & \multicolumn{3}{|c|}{ Standard Deviation $=.891$} \\
\hline Rating Scale & 1 & 2 & 3 & 4 & 5 & 6 & 0 \\
\hline $\begin{array}{l}\text { Value } \\
\text { Definition }\end{array}$ & $\begin{array}{l}\text { Exiremely } \\
\text { Effective }\end{array}$ & $\begin{array}{l}\text { Very } \\
\text { Effective }\end{array}$ & Effective & Ineffective & $\begin{array}{c}\text { Very } \\
\text { Ineffective }\end{array}$ & $\begin{array}{l}\text { Extremely } \\
\text { Ineffective }\end{array}$ & $\begin{array}{c}\text { NA/No } \\
\text { Response }\end{array}$ \\
\hline $\begin{array}{l}\text { Response } \\
\text { Percentage }\end{array}$ & $1.7 \%$ & $4.6 \%$ & $11.7 \%$ & $2.0 \%$ & $0.4 \%$ & $0.3 \%$ & $79.5 \%$ \\
\hline Numbers & 13 & 35 & 90 & 15 & 3 & 2 & 611 \\
\hline Totals & Effecti & $=18.0 \%$ & 1-1 & $m$ & Ineffectiv & $=2.7 \%$ & \\
\hline
\end{tabular}

of the respondents responded with an effective rating to this question, while $2.0 \%$ replied with an ineffective rating. Over $70.0 \%$ of the respondents did not respond to this question.

TABLE XXXV

TOTAL GROUP RATING RESPONSE PERCENTAGES PERTAINING TO ESD 112 AND THE EFFECTIVENESS OF INSTRUCTIONAL MEDIA STAFF

\begin{tabular}{|c|c|c|c|c|c|c|c|}
\hline \multicolumn{3}{|c|}{ Mean Response $=2.429$} & \multicolumn{2}{|c|}{$N=769$} & \multicolumn{3}{|c|}{ Standard Deviation $=.941$} \\
\hline Rating Scale & 1 & 2 & 3 & 4 & 5 & 6 & 0 \\
\hline $\begin{array}{l}\text { Value } \\
\text { Definition }\end{array}$ & $\begin{array}{l}\text { Extremely } \\
\text { Effective }\end{array}$ & $\begin{array}{c}\text { Very } \\
\text { Effective }\end{array}$ & Effective & Ineffective & $\begin{array}{c}\text { Very } \\
\text { Ineffective }\end{array}$ & $\begin{array}{l}\text { Extremely } \\
\text { Ineffective }\end{array}$ & $\begin{array}{c}\text { NANNo } \\
\text { Response }\end{array}$ \\
\hline $\begin{array}{l}\text { Response } \\
\text { Percentage }\end{array}$ & $4.9 \%$ & $9.9 \%$ & $12.6 \%$ & $1.3 \%$ & $0.3 \%$ & $0.4 \%$ & $70.6 \%$ \\
\hline Numbers & 38 & 76 & 97 & 10 & 2 & 3 & 543 \\
\hline Totals & Effective & $=27.4 \%$ & & $m$ & Ineffective & $=2.0 \%$ & \\
\hline
\end{tabular}


Secondary Instruction Media Services

The 42nd question on the survey requested that the respondents rate the effectiveness of services other than the films and videos they receive from ESD 112's Instructional Media Cooperative.

An effective rating was given by the total group of respondents pertaining to the services other than films and videos given by this Cooperative, with a total group mean response of three (2.605) on the six point effectiveness rating scale. A little more than $24.0 \%$ percent of the group replied with an effective rating, while less than $2.0 \%$ replied with an ineffective rating. Seventy-four percent of the respondents did not reply to this question (Table XXXVI).

\section{TABLE XXXVI}

TOTAL GROUP RATING RESPONSE PERCENTAGES PERTAINING TO ESD 112 AND THE EFFECTIVENESS OF INSTRUCTIONAL MEDIA SERVICES

\begin{tabular}{|c|c|c|c|c|c|c|c|}
\hline \multicolumn{3}{|c|}{ Mean Response $=2.605$} & \multicolumn{2}{|c|}{$\mathbf{N}=769$} & \multicolumn{3}{|c|}{ Standard Deviation $=.873$} \\
\hline$\overline{\text { Rating Scale }}$ & 1 & 2 & 3 & 4 & 5 & 6 & 0 \\
\hline $\begin{array}{l}\text { Value } \\
\text { Definition }\end{array}$ & $\begin{array}{l}\text { Extremely } \\
\text { Effective }\end{array}$ & $\begin{array}{l}\text { Very } \\
\text { Effective }\end{array}$ & Effective & Ineffective & $\begin{array}{c}\text { Very } \\
\text { Ineffective }\end{array}$ & $\begin{array}{l}\text { Extremely } \\
\text { Ineffective }\end{array}$ & $\begin{array}{l}\text { NA/No } \\
\text { Response }\end{array}$ \\
\hline $\begin{array}{l}\text { Response } \\
\text { Percentage }\end{array}$ & $3.0 \%$ & $6.9 \%$ & $14.3 \%$ & $1.4 \%$ & $0.0 \%$ & $0.4 \%$ & $74.0 \%$ \\
\hline Numbers & 23 & 53 & 110 & 11 & 0 & 3 & 569 \\
\hline Totals & Effectiv & $=24.2 \%$ & $<-\cdots$ & $-\cdots$ & Ineffectiv & $=1.8 \%$ & \\
\hline
\end{tabular}

\section{Instructional Media Cooperative's Films and Videos}

The last question of the Instructional and Curriculum services portion of the survey, question 43, asked the respondents to rate the effectiveness of the films and videos they receive from the Instructional Media Cooperative.

The total group of respondents indicated that the films and videos received from the cooperative were effective, with the total group mean response of three (2.550) on the six point effectiveness rating scale. Nearly $30.0 \%$ of the total group responded with an 
effective rating on this question, while $3.0 \%$ of the respondents replied with an ineffective rating. More than $67.0 \%$ of the respondents did not respond to this question (Table XXXVII).

\section{TABLE XXXVII}

TOTAL GROUP RATING RESPONSE PERCENTAGES PERTAINING TO ESD 112 AND THE EFFECTIVENESS OF THE FILMS AND VIDEOS PROVIDED BY THE INSTRUCTIONAL MEDIA COOPERATTVE

\begin{tabular}{|c|c|c|c|c|c|c|c|}
\hline \multicolumn{3}{|c|}{ Mean Response $=2.550$} & \multicolumn{2}{|c|}{$N=769$} & \multicolumn{3}{|c|}{ Standard Deviation $=1.047$} \\
\hline$\overline{\text { Rating Scale }}$ & 1 & 2 & 3 & 4 & 5 & 6 & 0 \\
\hline $\begin{array}{l}\text { Value } \\
\text { Definition }\end{array}$ & $\begin{array}{l}\text { Extremely } \\
\text { Effective }\end{array}$ & $\begin{array}{c}\text { Very } \\
\text { Effective }\end{array}$ & Effective & Ineffective & $\begin{array}{l}\text { Very } \\
\text { Ineffective }\end{array}$ & $\begin{array}{l}\text { Extremely } \\
\text { Ineffective }\end{array}$ & $\begin{array}{l}\text { NA/No } \\
\text { Response }\end{array}$ \\
\hline $\begin{array}{l}\text { Response } \\
\text { Percentage }\end{array}$ & $4.8 \%$ & $10.7 \%$ & $14.2 \%$ & $1.2 \%$ & $1.0 \%$ & $0.8 \%$ & $67.4 \%$ \\
\hline Numbers & 37 & 82 & 109 & 9 & 8 & 6 & 518 \\
\hline & Effecti & 29.79 & & & neffecti & $=3.0 \%$ & \\
\hline
\end{tabular}

\section{Total Special Services Program}

The first question in the Special Services Division effectiveness rating section, question 45, requested that the respondents rate the effectiveness of the Special Services programs as a total program.

This question was interested in assessing how effective the whole Special Services division of ESD 112 was perceived. An effective rating by the total group of respondents was given to the total Special Services program, with the total group mean response of three (2.634) on the six point effectiveness rating scale. More than $30.0 \%$ of the respondents responded with an effective rating on this question, while a little more than $3.0 \%$ responded with an ineffective rating. Nearly $67.0 \%$ of the respondents did not respond to this question (Table XXXVIII). 


\section{Special Service Staff}

Question $\mathbf{4 6}$ of the survey instrument asked that the respondents rate the effectiveness of the Special Services division's staff members.

An overall effective rating was given by the total group of respondents, with the total group mean response of three (2.523) on the six point effectiveness rating scale (Table XXXIX). More than $30.0 \%$ of the total group responded with an effective rating, while

\section{TABLE XXXVIII}

TOTAL GROUP RATING RESPONSE PERCENTAGES PERTAINING TO ESD 112 AND THE EFFECTIVENESS OF THE TOTAL SPECIAL SERVICE'S PROGRAM

\begin{tabular}{|c|c|c|c|c|c|c|c|}
\hline \multicolumn{3}{|c|}{ Mean Response $=2.634$} & \multicolumn{2}{|c|}{$\mathbf{N}=769$} & \multicolumn{3}{|c|}{ Standard Deviation $=.842$} \\
\hline Rating Scale & 1 & 2 & 3 & 4 & 5 & 6 & 0 \\
\hline $\begin{array}{l}\text { Value } \\
\text { Definition }\end{array}$ & $\begin{array}{l}\text { Extremely } \\
\text { Effective }\end{array}$ & $\begin{array}{c}\text { Very } \\
\text { Effective }\end{array}$ & Effective & Ineffective & $\begin{array}{c}\text { Very } \\
\text { Ineffective }\end{array}$ & $\begin{array}{l}\text { Extremely } \\
\text { Ineffective }\end{array}$ & $\begin{array}{l}\text { NA/No } \\
\text { Response }\end{array}$ \\
\hline $\begin{array}{l}\text { Response } \\
\text { Percentage }\end{array}$ & $2.3 \%$ & $11.8 \%$ & $16.0 \%$ & $2.5 \%$ & $0.5 \%$ & $0.3 \%$ & $66.6 \%$ \\
\hline Numbers & 18 & 91 & 123 & 19 & 4 & 2 & 512 \\
\hline Totals & Effectiv & $=30.1 \%$ & $<-\infty$ & $\cdots$ & Ineffectiv & $=3.3 \%$ & \\
\hline
\end{tabular}

\section{TABLE XXXIX}

TOTAL GROUP RATING RESPONSE PERCENTAGES PERTAINING TO ESD 112 AND THE EFFECTIVENESS OF THE SPECIAL SER VICES DIVISION'S STAFF

\begin{tabular}{|c|c|c|c|c|c|c|c|}
\hline \multicolumn{3}{|c|}{ Mean Response $=2.523$} & \multicolumn{2}{|c|}{$N=769$} & \multicolumn{3}{|c|}{ Standard Deviation $=.907$} \\
\hline$\overline{\text { Rating Scale }}$ & 1 & $\mathbf{2}$ & 3 & 4 & 5 & 6 & 0 \\
\hline $\begin{array}{l}\text { Value } \\
\text { Definition }\end{array}$ & $\begin{array}{l}\text { Extremely } \\
\text { Effective }\end{array}$ & $\begin{array}{l}\text { Very } \\
\text { Effective }\end{array}$ & Effective & Ineffective & $\begin{array}{c}\text { Very } \\
\text { Ineffective }\end{array}$ & $\begin{array}{l}\text { Extremely } \\
\text { Ineffective }\end{array}$ & $\begin{array}{l}\text { NA/No } \\
\text { Response }\end{array}$ \\
\hline $\begin{array}{l}\text { Response } \\
\text { Pexcentage }\end{array}$ & $4.2 \%$ & $11.7 \%$ & $14.3 \%$ & $2.2 \%$ & $0.8 \%$ & $0.1 \%$ & $66.7 \%$ \\
\hline Numbers & 32 & 90 & 110 & 17 & 6 & 1 & 513 \\
\hline otals & Effectiv & $=30.2 \%$ & & 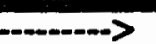 & Ineffectiv & $=3.1 \%$ & \\
\hline
\end{tabular}

more than $3.0 \%$ responded with an ineffective rating. Nearly $67.0 \%$ of the respondents did not reply to this question . 
Special Services Communication Devices

The third question of the Special Service's section on the questionnaire, question 47, requested that the respondents rate the effectiveness of the ESD communications devices concerning different Special Service's programs.

An overall effective rating was given by the total group of respondents, with a total group mean response of three (2.875) on the six point effectiveness rating scale. Close to $25.0 \%$ of the total group replied with an effective rating to this question, while less than $7.0 \%$ of the respondents responded with an ineffective rating. Nearly $69.0 \%$ of the respondents did not respond to the this rating question (Table $\mathrm{XI}$ ).

\section{TABLEXI}

TOTAL GROUP RATING RESPONSE PERCENTAGES PERTAINING TO ESD 112 AND THE EFFECTIVENESS OF COMMUNICATION DEVICES CONCERNING SPECIAL SERVICE'S PROGRAMS

\begin{tabular}{|c|c|c|c|c|c|c|c|}
\hline \multicolumn{3}{|c|}{ Mean Response $=2.875$} & \multicolumn{2}{|c|}{$N=769$} & \multicolumn{3}{|c|}{ Standard Deviation $=.947$} \\
\hline Rating Scale & 1 & 2 & 3 & 4 & 5 & 6 & 0 \\
\hline $\begin{array}{l}\text { Value } \\
\text { Definition }\end{array}$ & $\begin{array}{l}\text { Extremely } \\
\text { Effective }\end{array}$ & $\begin{array}{c}\text { Very } \\
\text { Effective }\end{array}$ & Effective & Ineffective & $\begin{array}{c}\text { Very } \\
\text { Ineffective }\end{array}$ & $\begin{array}{l}\text { Extremely } \\
\text { Ineffective }\end{array}$ & $\begin{array}{l}\text { NA/No } \\
\text { Response }\end{array}$ \\
\hline $\begin{array}{l}\text { Response } \\
\text { Percentage }\end{array}$ & $2.1 \%$ & $7.7 \%$ & $15.1 \%$ & $5.5 \%$ & $0.3 \%$ & $0.7 \%$ & $68.8 \%$ \\
\hline Numbers & 16 & 59 & 116 & 42 & 2 & 5 & 529 \\
\hline Totals & Effectiv & $=24.9 \%$ & $<-\cdots+\cdots$ & $\ldots$ & Ineffecti & $=6.5 \%$ & \\
\hline
\end{tabular}

\section{Special Services Resources}

Question 48 requested that the respondents rate the effectiveness of the Special Services division of the ESD as a resource center for special education matters.

An overall effective rating was given by the total group of respondents, with a total group mean response of three (2.700) on the six point effectiveness rating scale (Table XII). Nearly $26.0 \%$ of the respondents replied with an effective rating to this question, 
while less than $6.0 \%$ responded with an ineffective rating. Sixty-nine percent of the respondents did not respond to this question.

\section{TABLE XII}

\section{TOTAL GROUP RATING RESPONSE PERCENTAGES PERTAINING TO ESD 112 AND THE EFFECTIVENESS OF THE SPECIAL SERVICES DIVISION AS A RESOURCE CENTER FOR SPECIAL EDUCATION MATTERS}

\begin{tabular}{|c|c|c|c|c|c|c|c|}
\hline \multicolumn{3}{|c|}{ Mean Response $=2.700$} & \multicolumn{2}{|c|}{$N=769$} & \multicolumn{3}{|c|}{ Standard Deviation $=.995$} \\
\hline Rating Scale & 1 & 2 & 3 & 4 & 5 & 6 & 0 \\
\hline $\begin{array}{l}\text { Value } \\
\text { Definition }\end{array}$ & $\begin{array}{l}\text { Extremely } \\
\text { Effective }\end{array}$ & $\begin{array}{c}\text { Very } \\
\text { Effective }\end{array}$ & Effective & Ineffective & $\begin{array}{c}\text { Very } \\
\text { Ineffective }\end{array}$ & $\begin{array}{l}\text { Extremely } \\
\text { Ineffective }\end{array}$ & $\begin{array}{l}\text { NANNo } \\
\text { Response }\end{array}$ \\
\hline $\begin{array}{l}\text { Response } \\
\text { Percentages }\end{array}$ & $3.5 \%$ & $9.1 \%$ & $13.1 \%$ & $4.7 \%$ & $0.3 \%$ & $0.5 \%$ & $68.8 \%$ \\
\hline Numbers & 27 & 70 & 101 & 36 & 2 & 4 & 529 \\
\hline Totals & Effectiv & $=25.7 \%$ & & & Ineffectiv & $=5.5 \%$ & \\
\hline
\end{tabular}

\section{Special Services Inservices}

Question 49 of the survey instrument requested the respondents to rate the effectiveness of the inservices provided by the Special Services division in the area of special education.

Table XIII shows than an effective rating was given to the special education inservices provided through the ESD's Special Services division by the total group of respondents. The total group mean response was three (2.913) on the six point effectiveness rating scale. Twenty-one percent of the total group responded with an effective rating, while $6.0 \%$ replied with an ineffective rating. More than $73.0 \%$ of the respondents did not reply to this question. 
TABLE XLII

\section{TOTAL GROUP RATING RESPONSE PERCENTAGES PERTAINING TO ESD 112 AND THE EFFECTIVENESS OF INSERVICES PROVIDED BY THE SPECIAL SERVICES DIVISION}

\begin{tabular}{|c|c|c|c|c|c|c|c|}
\hline \multicolumn{3}{|c|}{ Mean Response $=2.913$} & \multicolumn{2}{|c|}{$N=769$} & \multicolumn{3}{|c|}{ Standard Deviation $=1.037$} \\
\hline Rating Scale & 1 & 2 & 3 & 4 & 5 & 6 & 0 \\
\hline $\begin{array}{l}\text { Value } \\
\text { Definition }\end{array}$ & $\begin{array}{l}\text { Extremely } \\
\text { Effective }\end{array}$ & $\begin{array}{c}\text { Very } \\
\text { Effective }\end{array}$ & Effective & Ineffective & $\begin{array}{c}\text { Very } \\
\text { Ineffective }\end{array}$ & $\begin{array}{l}\text { Extremely } \\
\text { Ineffective }\end{array}$ & $\begin{array}{l}\text { NA/No } \\
\text { Response }\end{array}$ \\
\hline $\begin{array}{l}\text { Response } \\
\text { Pencentages }\end{array}$ & $2.2 \%$ & $6.0 \%$ & $12.6 \%$ & $4.8 \%$ & $0.3 \%$ & $0.9 \%$ & $73.2 \%$ \\
\hline Numbers & 17 & 46 & 97 & 37 & 2 & 7 & 563 \\
\hline Totals & Effectiv & $=20.8 \%$ & 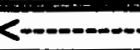 & $-\infty$ & Ineffectiv & $e=6.0 \%$ & \\
\hline
\end{tabular}

\section{Special Education Program Review}

Question 50 asked the respondents to rate the effectiveness of the Special Education Program Review service which monitors a district's compliance to federal and state rules and regulations.

An effective rating was given by the total group of respondents, with a total group mean response of three (2.768) on the six point effectiveness rating scale. Twenty-one percent of the respondents gave an effective rating on this question, while a little more than $3.0 \%$ responded with an ineffective rating. Seventy-five percent of the respondents did not reply to this question (Table $\mathrm{X} L \mathrm{III}$ ).

\section{Agency and Community Liaison}

The 51st question of the survey instrument asked the respondent to rate the effectiveness of the Agency and Community Liaison services provided by ESD 112.

An overall effective rating was given by the total group of respondents, with a total group mean response of three (3.068) on the six point effectiveness rating scale. Fourteen percent of the total group responded with an effective rating, while more than $5.0 \%$ of the 
respondents responded with an ineffective rating. Over $80.0 \%$ of the total group did not respond to this question (Table XIIV).

\section{TABLE XIIII}

\section{TOTAL GROUP RATING RESPONSE PERCENTAGES PERTAINING TO ESD 112 AND THE EFFECTIVENESS OF THE SPECIAL EDUCATION PROGRAM REVIEW SERVICE}

\begin{tabular}{|c|c|c|c|c|c|c|c|}
\hline \multicolumn{3}{|c|}{ Mean Response $=2.768$} & \multicolumn{2}{|c|}{$N=769$} & \multicolumn{3}{|c|}{ Standard Deviation $=.942$} \\
\hline Rating Scale & 1 & 2 & 3 & 4 & 5 & 6 & 0 \\
\hline $\begin{array}{l}\text { Value } \\
\text { Definition }\end{array}$ & $\begin{array}{l}\text { Extremely } \\
\text { Effective }\end{array}$ & $\begin{array}{c}\text { Very } \\
\text { Effective }\end{array}$ & Effective & Ineffective & $\begin{array}{l}\text { Very } \\
\text { Ineffective }\end{array}$ & $\begin{array}{l}\text { Extremely } \\
\text { Ineffective }\end{array}$ & $\begin{array}{l}\text { NANo } \\
\text { Response }\end{array}$ \\
\hline $\begin{array}{l}\text { Response } \\
\text { Percentages }\end{array}$ & $2.1 \%$ & $6.4 \%$ & $12.9 \%$ & $2.3 \%$ & $0.7 \%$ & $0.4 \%$ & $75.3 \%$ \\
\hline Numbers & 16 & 49 & 99 & 18 & 5 & 3 & 579 \\
\hline otals & fectiv & $=21.4 \%$ & & & $f$ & $3.4 \%$ & \\
\hline
\end{tabular}

\section{TABLE XIIV}

TOTAL GROUP RATING RESPONSE PERCENTAGES PERTAINING TO ESD 112 AND THE FILMS AND THE EFFECTIVENESS OF THE AGENCY AND COMMUNITY LIAISON SERVICES

\begin{tabular}{|c|c|c|c|c|c|c|c|}
\hline \multicolumn{3}{|c|}{ Mean Response $=3.068$} & \multicolumn{2}{|c|}{$\mathrm{N}=769$} & \multicolumn{3}{|c|}{ Standard Deviation $=1.067$} \\
\hline$\overline{\text { Rating Scale }}$ & 1 & 2 & $\overline{3}$ & 4 & 5 & 6 & 0 \\
\hline $\begin{array}{l}\text { Value } \\
\text { Definition }\end{array}$ & $\begin{array}{l}\text { Extremely } \\
\text { Effective }\end{array}$ & $\begin{array}{c}\text { Very } \\
\text { Effective }\end{array}$ & Effective & Ineffective & $\begin{array}{c}\text { Very } \\
\text { Ineffective }\end{array}$ & $\begin{array}{l}\text { Extremely } \\
\text { Ineffective }\end{array}$ & $\begin{array}{l}\text { NANNo } \\
\text { Response }\end{array}$ \\
\hline $\begin{array}{l}\text { Response } \\
\text { Percentages }\end{array}$ & $1.3 \%$ & $3.4 \%$ & 9.5\% & $3.6 \%$ & $0.7 \%$ & $0.8 \%$ & $80.8 \%$ \\
\hline Numbers & 10 & 26 & 73 & 28 & 5 & 6 & 621 \\
\hline Totals & Effectiv & $=14.2 \%$ & $=$ & $\cdots$ & Ineffecti & $=5.1 \%$ & \\
\hline
\end{tabular}

\section{Preschool Screening}

Question 52 requested that the respondents to rate ESD 112's Preschool Screening services which screens preschool children for possible developmental problems. 
An effective rating was given to the Preschool Screening services by the total group of respondents, with total group mean response of three (2.532) on the six point effectiveness rating scale. More than $23.0 \%$ of the respondents responded with an effective rating, while less than $2.0 \%$ of the respondents gave an ineffective rating on this question. Seventy-five percent of the respondents did not reply to this question (Table XILV).

TABLE XIV

TOTAL GROUP RATING RESPONSE PERCENTAGES PERTAINING TO ESD 112 AND THE EFFECTIVENESS OF THE PRESCHOOL SCREENING SERVICES

\begin{tabular}{|c|c|c|c|c|c|c|c|}
\hline \multicolumn{3}{|c|}{ Mean Response $=2.532$} & \multicolumn{2}{|c|}{$N=769$} & \multicolumn{3}{|c|}{ Standard Deviation $=.865$} \\
\hline Rating Scale & 1 & 2 & 3 & 4 & 5 & 6 & 0 \\
\hline $\begin{array}{l}\text { Value } \\
\text { Definition }\end{array}$ & $\begin{array}{l}\text { Extremely } \\
\text { Effective }\end{array}$ & $\begin{array}{c}\text { Very } \\
\text { Effective }\end{array}$ & Effective & Ineffective & $\begin{array}{c}\text { Very } \\
\text { Ineffective }\end{array}$ & $\begin{array}{l}\text { Extremely } \\
\text { Ineffective }\end{array}$ & $\begin{array}{l}\text { NA/No } \\
\text { Response }\end{array}$ \\
\hline $\begin{array}{l}\text { Response } \\
\text { Percentages }\end{array}$ & $2.9 \%$ & $8.1 \%$ & $12.4 \%$ & $0.9 \%$ & $0.3 \%$ & $0.3 \%$ & 75.3\% \\
\hline Numbers & 22 & 62 & 95 & 7 & 2 & 2 & 579 \\
\hline Totals & Effecti & $23.4 \%$ & & $\rightarrow$ & Ineffectiv & $=1.5 \%$ & \\
\hline
\end{tabular}

Audiological Services

Question 53 requested that the respondents rate the effectiveness of ESD 112's audiological and hearing services.

The response from the total group of respondents indicated an effective rating, with a total group mean response of three (2.561) on the six point effectiveness rating scale. Twenty-nine percent of the respondents replied with an effective rating on this question, while less than $3.0 \%$ of the respondents replied with an ineffective rating. More than $68.0 \%$ of the respondents did not respond to this question (Table XIVV). 
TABLE XLVI

TOTAL GROUP RATING RESPONSE PERCENTAGES PERTAINING

TO ESD 112 AND THE EFFECTIVENESS OF THE

AUDIOLOGICAL AND HEARING SERVICES

\begin{tabular}{|c|c|c|c|c|c|c|c|}
\hline \multicolumn{3}{|c|}{ Mean Response $=2.561$} & \multicolumn{2}{|c|}{$N=769$} & \multicolumn{3}{|c|}{ Standard Deviation $=.837$} \\
\hline Rating Scale & 1 & 2 & 3 & 4 & 5 & 6 & 0 \\
\hline $\begin{array}{l}\text { Value } \\
\text { Definition }\end{array}$ & $\begin{array}{l}\text { Extremely } \\
\text { Effective }\end{array}$ & $\begin{array}{c}\text { Very } \\
\text { Effective }\end{array}$ & Effective & Ineffective & $\begin{array}{c}\text { Very } \\
\text { Ineffective }\end{array}$ & $\begin{array}{l}\text { Extremely } \\
\text { Ineffective }\end{array}$ & $\begin{array}{l}\text { NANo } \\
\text { Response }\end{array}$ \\
\hline $\begin{array}{l}\text { Response } \\
\text { Percentages }\end{array}$ & $3.9 \%$ & $9.0 \%$ & $16.3 \%$ & $2.5 \%$ & $0.0 \%$ & $.1 \%$ & $68.3 \%$ \\
\hline Numbers & 30 & 69 & 125 & 19 & 0 & 1 & 525 \\
\hline Totals & Effective & $=29.2 \%$ & & $m$ & Ineffectiv & $e=2.6 \%$ & \\
\hline
\end{tabular}

Regional Early Childhood Coordination.

Question 54 asked the respondents to rate the effectiveness of the regional early childhood coordination services.

An overall effective rating was given by the total group of respondents concerning ESD 112's regional early childhood coordination service. The total group mean response was three (2.640) on the six point effectiveness rating scale (Table XIVII). Nineteen

\section{TABLE XLVII}

\section{TOTAL GROUP RATING RESPONSE PERCENTAGES PERTAINING} TO ESD 112 AND THE EFFECTIVENESS OF THE REGIONAL EARLY CHILDHOOD COORDINATION SERVICES

\begin{tabular}{|c|c|c|c|c|c|c|c|}
\hline \multicolumn{3}{|c|}{ Mean Response $=2.640$} & \multicolumn{2}{|c|}{$\mathrm{N}=769$} & \multicolumn{3}{|c|}{ Standard Deviation $=.959$} \\
\hline Rating Scale & 1 & 2 & 3 & 4 & 5 & 6 & 0 \\
\hline $\begin{array}{l}\text { Value } \\
\text { Definition }\end{array}$ & $\begin{array}{l}\text { Extremely } \\
\text { Effective }\end{array}$ & $\begin{array}{c}\text { Very } \\
\text { Effective }\end{array}$ & Effective & Ineffective & $\begin{array}{c}\text { Very } \\
\text { Ineffective }\end{array}$ & $\begin{array}{l}\text { Extremely } \\
\text { Ineffective }\end{array}$ & $\begin{array}{l}\text { NANNo } \\
\text { Response }\end{array}$ \\
\hline $\begin{array}{l}\text { Response } \\
\text { Percentages }\end{array}$ & $2.3 \%$ & $6.1 \%$ & $10.4 \%$ & $1.3 \%$ & $0.4 \%$ & $0.4 \%$ & $79.1 \%$ \\
\hline Numbers & 18 & 47 & 80 & 10 & 3 & 3 & 608 \\
\hline Totals & Effectiv & $=18.8 \%$ & K---...... & -...--> & Ineffectiv & $=2.1 \%$ & \\
\hline
\end{tabular}


percent of the respondents replied with an effective rating on this question, while a little more than $2.0 \%$ of the total group responded with an ineffective rating. Seventy-nine percent of the respondents did not reply to the this question.

\section{Seriously Behavior Disabled Program}

The 55th question of the survey instrument asked the respondents to rate the effectiveness of ESD 112's Seriously Behavior Disabled Program.

The total group response indicated an effective rating for the Seriously Behavior Disabled Program, with a total group mean response of three (2.993) on the six point effectiveness rating scale. Nearly $17.0 \%$ of the total group replied with an effective rating on this question, while less than $2.0 \%$ responded with an ineffective rating. Eighty percent of the respondents elected not to respond to this question (Table XIVIII).

\section{TABLE XLVIII}

\section{TOTAL GROUP RATING RESPONSE PERCENTAGES PERTAINING TO ESD 112 AND THE EFFECTIVENESS OF THE SERIOUSLY BEHAVIOR DISABLED PROGRAM}

\begin{tabular}{|c|c|c|c|c|c|c|c|}
\hline \multicolumn{3}{|c|}{ Mean Response $=2.993$} & \multicolumn{2}{|c|}{$\mathrm{N}=769$} & \multicolumn{3}{|c|}{ Standard Deviation $=1.131$} \\
\hline Rating Scale & 1 & 2 & 3 & 4 & 5 & 6 & 0 \\
\hline $\begin{array}{l}\text { Value } \\
\text { Definition }\end{array}$ & $\begin{array}{l}\text { Extremely } \\
\text { Effective }\end{array}$ & $\begin{array}{c}\text { Very } \\
\text { Effective }\end{array}$ & Effective & Ineffective & $\begin{array}{c}\text { Very } \\
\text { Ineffective }\end{array}$ & $\begin{array}{l}\text { Extremely } \\
\text { Ineffective }\end{array}$ & $\begin{array}{l}\text { NA/No } \\
\text { Response }\end{array}$ \\
\hline $\begin{array}{l}\text { Response } \\
\text { Percentages }\end{array}$ & $1.6 \%$ & $4.9 \%$ & $7.7 \%$ & $3.9 \%$ & $1.0 \%$ & $0.7 \%$ & $80.2 \%$ \\
\hline Numbers & 12 & 38 & 59 & 30 & 8 & 5 & 617 \\
\hline Totals & Effective & $14.1 \%$ & $<-\cdots$ & $m$ & Ineffecti & $=5.5 \%$ & \\
\hline
\end{tabular}

\section{School Psychological Services}

Question 56 requested that the respondents rate the effectiveness of the ESD's school psychological services.

The overall rating indicated by the total group of respondents was effective, with an total group mean response of three (2.901) on the six point effectiveness rating scale. 
Over $21.0 \%$ percent of the respondents replied with an effective rating on this question, while a little more than $6.0 \%$ replied with an ineffective rating. Seventy-two percent of the respondents did not respond to this question (Table XIIX).

\section{TABLE XLDX}

\section{TOTAL GROUP RATING RESPONSE PERCENTAGES PERTAINING TO ESD 112 AND THE EFFECTIVENESS OF THE SCHOOL PSYCHOLOGICAL SERVICES}

\begin{tabular}{|c|c|c|c|c|c|c|c|}
\hline \multicolumn{3}{|c|}{ Mean Response $=2.901$} & \multicolumn{2}{|c|}{$N=769$} & \multicolumn{3}{|c|}{ Standard Deviation $=1.095$} \\
\hline Rating Scale & 1 & 2 & 3 & 4 & 5 & 6 & 0 \\
\hline $\begin{array}{l}\text { Value } \\
\text { Definition }\end{array}$ & $\begin{array}{l}\text { Extremely } \\
\text { Effective }\end{array}$ & $\begin{array}{c}\text { Very } \\
\text { Effective }\end{array}$ & Effective & Ineffective & $\begin{array}{c}\text { Very } \\
\text { Ineffective }\end{array}$ & $\begin{array}{l}\text { Extremely } \\
\text { Ineffective }\end{array}$ & $\begin{array}{l}\text { NANNo } \\
\text { Response }\end{array}$ \\
\hline $\begin{array}{l}\text { Response } \\
\text { Percentages }\end{array}$ & $2.3 \%$ & $7.2 \%$ & $11.8 \%$ & $4.3 \%$ & $1.0 \%$ & $.9 \%$ & $72.4 \%$ \\
\hline Numbers & 18 & 55 & 91 & 33 & 8 & 7 & 557 \\
\hline Totals & Effectiv & $=21.3 \%$ & <--..... & $\cdots$ & Ineffectiv & $=6.2 \%$ & \\
\hline
\end{tabular}

\section{Communications Disorders Services}

Question 57 requested that the respondents rate the effectiveness of ESD 112's communications disorders services.

An overall effective rating was given by the total group of respondents concerning the communication disorders services, with a total group mean response of three (2.764) on the six point effectiveness rating scale. Twenty-one percent of the respondents responded with an effective rating on this question, while more than $4.0 \%$ of the respondents responded with an ineffective rating response. Seventy-five percent of the respondents did not respond to this question (Table L).

\section{Motor Therapy Services}

The 58 question on the survey instrument asked the respondents to rate the effectiveness of the motor therapy services provided by ESD 112. 
An overall effective rating was indicated by the total group of respondents, with a total group mean response of three (2.770) on the six point effectiveness rating scale. Twenty percent of the total group responded with an effective rating on this question, while a little more than $3.0 \%$ responded with an ineffective rating response. Seventy-seven percent of the respondents elected not to respond to this question (Table LI).

\section{TABLEL}

TOTAL GROUP RATING RESPONSE PERCENTAGES PERTAINING

TO ESD 112 AND THE EFFECTIVENESS OF THE

COMMUNICATIONS DISORDERS SERVICES

\begin{tabular}{lccccccc}
\hline \multicolumn{2}{c}{ Mean Response $=2.764$} & \multicolumn{2}{c}{$\mathrm{N}=769$} & \multicolumn{3}{c}{ Standard Deviation $=.956$} \\
\hline $\begin{array}{l}\text { Rating Scale } \\
\text { Value }\end{array}$ & 1 & 2 & 3 & 4 & 5 & 6 & 0 \\
$\begin{array}{l}\text { Definition } \\
\text { Extremely } \\
\text { Effective }\end{array}$ & $\begin{array}{c}\text { Very } \\
\text { Effective }\end{array}$ & Effective & Ineffective & $\begin{array}{c}\text { Very } \\
\text { Ineffective }\end{array}$ & $\begin{array}{c}\text { Extremely } \\
\text { Ineffective }\end{array}$ & $\begin{array}{c}\text { NANo } \\
\text { Response }\end{array}$ \\
$\begin{array}{l}\text { Percentages } \\
\text { Numbers }\end{array}$ & $2.0 \%$ & $7.5 \%$ & $11.8 \%$ & $3.0 \%$ & $0.7 \%$ & $0.4 \%$ & $74.6 \%$ \\
Totals & 15 & 58 & 91 & 23 & 5 & 3 & 574 \\
\hline
\end{tabular}

\section{TABLELI}

TOTAL GROUP RATING RESPONSE PERCENTAGES PERTAINING TO ESD 112 AND THE FILMS AND THE EFFECTTVENESS OF THE MOTOR THERAPY SERVICES

\begin{tabular}{|c|c|c|c|c|c|c|c|}
\hline \multicolumn{3}{|c|}{ Mean Response $=2.770$} & \multicolumn{2}{|c|}{$\mathbf{N}=769$} & \multicolumn{3}{|c|}{ Standard Deviation $=.863$} \\
\hline Rating Scale & 1 & 2 & 3 & 4 & 5 & 6 & 0 \\
\hline $\begin{array}{l}\text { Value } \\
\text { Definition }\end{array}$ & $\begin{array}{l}\text { Extremely } \\
\text { Effective }\end{array}$ & $\begin{array}{c}\text { Very } \\
\text { Effective }\end{array}$ & Effective & Ineffective & $\begin{array}{c}\text { Very } \\
\text { Ineffective }\end{array}$ & $\begin{array}{l}\text { Extremely } \\
\text { Ineffective }\end{array}$ & $\begin{array}{l}\text { NA/No } \\
\text { Response }\end{array}$ \\
\hline $\begin{array}{l}\text { Response } \\
\text { Percentages }\end{array}$ & $1.6 \%$ & $6.0 \%$ & $12.0 \%$ & $2.5 \%$ & $0.5 \%$ & $0.1 \%$ & $77.4 \%$ \\
\hline Numbers & 12 & 46 & 92 & 19 & 4 & 1 & 595 \\
\hline Totals & Effecti & $19.6 \%$ & 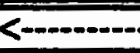 & $\cdots-->>$ & Ineffectiv & $=3.1 \%$ & \\
\hline
\end{tabular}


Preschool Handicapped Services

Question 59 of the survey instrument requested the respondents to rate the effectiveness of ESD 112's preschool handicap services.

An effective rating was indicated by the total respondent group, with a total group mean response of three (2.600) on the six point effectiveness rating scale. Fifteen percent of the total group of respondents responded with an effective rating on this question, while less than $2.0 \%$ of the respondents gave an ineffective rating response. Eighty-three percent of the respondents did not respond to this question (Table LII).

\section{TABLE LII}

TOTAL GROUP RATING RESPONSE PERCENTAGES PERTAINING TO ESD 112 AND THE EFFECTIVENESS OF THE PRESCHOOL HANDICAP SERVICES

\begin{tabular}{|c|c|c|c|c|c|c|c|}
\hline \multicolumn{3}{|c|}{ Mean Response $=2.600$} & \multicolumn{2}{|c|}{$\mathrm{N}=769$} & \multicolumn{3}{|c|}{ Standard Deviation $=.920$} \\
\hline Rating Scale & 1 & 2 & 3 & 4 & 5 & 6 & 0 \\
\hline $\begin{array}{l}\text { Value } \\
\text { Definition }\end{array}$ & $\begin{array}{l}\text { Extremely } \\
\text { Effective }\end{array}$ & $\begin{array}{l}\text { Very } \\
\text { Effective }\end{array}$ & Effective & Ineffective & $\begin{array}{l}\text { Very } \\
\text { Ineffective }\end{array}$ & $\begin{array}{l}\text { Extremely } \\
\text { Ineffective }\end{array}$ & $\begin{array}{l}\text { NANNo } \\
\text { Response }\end{array}$ \\
\hline $\begin{array}{l}\text { Response } \\
\text { Percentages }\end{array}$ & $2.1 \%$ & $4.8 \%$ & $8.5 \%$ & $1.0 \%$ & $0.4 \%$ & $0.1 \%$ & $83.1 \%$ \\
\hline Numbers & 16 & 37 & 65 & 8 & 3 & 1 & 639 \\
\hline obals & Effectiv & $=15.4 \%$ & & $\rightarrow$ & Ineffecti & $=1.5 \%$ & \\
\hline
\end{tabular}

\section{SESARA Program}

Question 60 of the survey instrument requested the respondents to rate the effectiveness of the ESD's SESARA program which trains special education support assistants in rural areas.

The total group indicated an effective rating of the SESARA program, with a total group mean response of three (2.862) on the six point effectiveness rating scale. Nine percent of the respondents replied with an effective rating response on this question, while 
more than $2.0 \%$ of the respondents responded with an ineffective rating response. Almost $89.0 \%$ of the respondents did not respond to this question (Table LIII).

\section{TABLE LIII}

TOTAL GROUP RATING RESPONSE PERCENTAGES PERTAINING TO ESD 112 AND THE EFFECTIVENESS OF THE SESARA PROGRAM

\begin{tabular}{|c|c|c|c|c|c|c|c|}
\hline \multicolumn{3}{|c|}{ Mean Response $=2.862$} & \multicolumn{2}{|c|}{$N=769$} & \multicolumn{3}{|c|}{ Standard Deviation $=1.002$} \\
\hline$\overline{\text { Rating Scale }}$ & 1 & 2 & 3 & 4 & 5 & 6 & 0 \\
\hline $\begin{array}{l}\text { Value } \\
\text { Definition }\end{array}$ & $\begin{array}{l}\text { Extremely } \\
\text { Effective }\end{array}$ & $\begin{array}{c}\text { Very } \\
\text { Effective }\end{array}$ & Effective & Ineffective & $\begin{array}{c}\text { Very } \\
\text { Ineffective }\end{array}$ & $\begin{array}{l}\text { Extremely } \\
\text { Ineffective }\end{array}$ & $\begin{array}{l}\text { NANo } \\
\text { Response }\end{array}$ \\
\hline $\begin{array}{l}\text { Response } \\
\text { Percentages }\end{array}$ & $0.8 \%$ & $3.0 \%$ & $5.5 \%$ & $1.4 \%$ & $0.4 \%$ & $0.3 \%$ & $88.7 \%$ \\
\hline Numbers & 6 & 23 & 42 & 11 & 3 & 2 & 682 \\
\hline
\end{tabular}

\section{Special Education Direct Services}

The 61st question requested the respondents to rate the Special Education Direct instruction Staff services, which are those services that include ESD 112 special education teachers and specialists that as "quasi-employees" of the individual district.

The total group response gave an effective rating to the Special Education Direct Services (Table LIV), with a total group mean response of three (2.804) on the six point

\section{TABLELIV}

TOTAL GROUP RATING RESPONSE PERCENTAGES PERTAINING TO ESD 112 AND THE EFFECTIVENESS OF THE SPECIAL EDUCATION DIRECT SERVICES

\begin{tabular}{|c|c|c|c|c|c|c|c|}
\hline \multicolumn{3}{|c|}{ Mean Response $=2.804$} & \multicolumn{2}{|c|}{$N=769$} & \multicolumn{3}{|c|}{ Standard Deviation $=.974$} \\
\hline Rating Scale & 1 & 2 & 3 & 4 & 5 & 6 & 0 \\
\hline $\begin{array}{l}\text { Value } \\
\text { Definition }\end{array}$ & $\begin{array}{l}\text { Extremely } \\
\text { Effective }\end{array}$ & $\begin{array}{c}\text { Very } \\
\text { Effective }\end{array}$ & Effective & Ineffective & $\begin{array}{c}\text { Very } \\
\text { Ineffective }\end{array}$ & $\begin{array}{l}\text { Extremely } \\
\text { Ineffective }\end{array}$ & $\begin{array}{l}\text { NANo } \\
\text { Response }\end{array}$ \\
\hline $\begin{array}{l}\text { Response } \\
\text { Percentages }\end{array}$ & $1.7 \%$ & $5.3 \%$ & $11.2 \%$ & $2.0 \%$ & $0.5 \%$ & $0.5 \%$ & $78.8 \%$ \\
\hline Numbers & 13 & 41 & 86 & 15 & 4 & 4 & 606 \\
\hline Totals & Effectiv & $=18.2 \%$ & - & $\ldots>$ & Ineffectiv & $=3.0 \%$ & \\
\hline
\end{tabular}


effectiveness rating scale. Eighteen percent of the respondent group responded with an effective rating response, while $3.0 \%$ of the total group replied with an ineffective rating response. Nearly $79.0 \%$ of the respondents did not reply to this question.

\section{Direct Instruction Service Staff}

The last question on the survey instrument, question 62, asked the respondents to rate the Special Education Direct Instruction Staff. Whereas question 61 was more concerned with the program's content and structure, this question was directed at the Direct Instruction staff members.

The total group gave an effective rating to the Special Education Direct Instruction staff, with a total group mean response of three (2.542) on the six point effectiveness rating scale. Twenty-one percent of the respondents responded with an effective rating on this question, while $2.0 \%$ of the total group responded with an ineffective rating. More than $76.0 \%$ of the respondents elected not to respond to this question (Table LV).

\section{TABLELV}

\section{TOTAL GROUP RATING RESPONSE PERCENTAGES PERTAINING TO ESD 112 AND THE EFFECTIVENESS OF THE SPECIAL EDUCATION DIRECT INSTRUCTION STAFF}

\begin{tabular}{|c|c|c|c|c|c|c|c|}
\hline \multicolumn{3}{|c|}{ Mean Response $=2.542$} & \multicolumn{2}{|c|}{$N=769$} & \multicolumn{3}{|c|}{ Standard Deviation $=.937$} \\
\hline Rating Scale & 1 & 2 & 3 & 4 & 5 & 6 & 0 \\
\hline $\begin{array}{l}\text { Value } \\
\text { Definition }\end{array}$ & $\begin{array}{l}\text { Extremely } \\
\text { Effective }\end{array}$ & $\begin{array}{l}\text { Very } \\
\text { Effective }\end{array}$ & Effective & Ineffective & $\begin{array}{c}\text { Very } \\
\text { Ineffective }\end{array}$ & $\begin{array}{l}\text { Extremely } \\
\text { Ineffective }\end{array}$ & $\begin{array}{c}\text { NANo } \\
\text { Response }\end{array}$ \\
\hline $\begin{array}{l}\text { Response } \\
\text { Percentages }\end{array}$ & $3.3 \%$ & $7.0 \%$ & $11.1 \%$ & $1.3 \%$ & $0.4 \%$ & $0.3 \%$ & $76.7 \%$ \\
\hline Numbers & 25 & 54 & 85 & 10 & 3 & 2 & 590 \\
\hline Totals & Effecti & $=21.4 \%$ & - & $m$ & Ineffectiv & $=2.0 \%$ & \\
\hline
\end{tabular}




\section{PRIMARY ANALYSIS}

This section of the chapter will provide the reader with a primary analysis of the data. The intent of this section is investigate whether there are significant differences in the mean responses of different grouping categories in regards to the general effectiveness questions from the survey instrument. The groups which are analyzed in this section are position, years of experience in present school district, years of experience in Washington State, district size, county location, and degree or level of education.

An analysis of variance (ANOVA) statistical test has been performed on the mean responses from the general effectiveness rating questions 15 through 24 for each of these groups. The same statistical test has been performed on question one, position, and the effectiveness rating questions 26 through 43 (Instructional and Curriculum Services) and 45 through 62 (Special Services Division). All ANOVA testing in this section is based on the assumption of the null hypothesis-that no difference existed in the mean responses of the various groups on those questions rating the effectiveness of ESD 112. The Bartlett test for homogeneity of variance produced significant results on all but three of the ANOVAs testing in the following section.

Each section of analysis of variance testing is followed by a paired comparison table illustrating the group mean response comparisons and the probability level. The TukeyKramer paired comparison test of significance was used for each of these questions. The direction for each of the paired comparisons (less than < or greater than >) is given for those group means found to be significantly different.

\section{Summary of Primary Analysis}

Position Groups, Effectiveness rating questions 26 through 43 were found to indicate significant differences among two or more of the position groups' mean responses. Paired comparison testing on the mean responses revealed that the teacher position group 
always had a significantly higher mean response than any other group in which they differed. Thus, the teacher position group always indicated the ESD was less effective than any other position group on these effectiveness rating questions. With the exception of three specific program and service effectiveness rating questions, none of the other position groups were found to differ significantly from each other. Also, the teacher and district office and teacher and principal groups were found to most often have a significant difference on their compared mean responses. Concurrently, the teacher and assistant principal group never differed significantly on any of the effectiveness rating questions.

Years of Experience. Analysis of variance testing on the years of experience in present district and years of experience in the State of Washington groups' mean responses did not produce significant results on any of the 10 general effectiveness questions.

Size of District Groups. Analysis of variance testing on the district size groups' mean responses indicated a significant difference among two or more of the groups on five of the 10 general effectiveness questions. Paired comparison testing indicated the 0-300 student size district and the 301-800 student size district most often differed significantly with another group in their response. Whereas the 0-300 student size district always had a significantly lower mean response than the other compared group, the 301-800 student size district always had a higher mean response. Thus, the 0-300 student size district rated the ESD as more effective than any other group in which they significantly differed, and the 301-800 student size district rated the ESD as less effective than any other group in which they significantly differed.

County Location Groups. Analysis of variance testing on the county location groups' mean responses indicated a significant difference among two or more of the groups on eight of the 10 general effectiveness questions. Paired comparison testing on the mean responses of these questions showed that the Pacific County group had a significantly higher mean response than any other group from which they were found to differ. The 
Clark County, Klickitat County, Skamania County, and Wahkiakum County groups always had significantly lower mean responses than any other group from which they were found to differ. No significant difference was found among any of the mean responses of any of these four groups on the $\mathbf{1 0}$ general effectiveness questions. Thus, Pacific County indicated the ESD was less effective than the groups in which they significantly differed, and the Clark County, Klickitat County, Skamania County, and Wahkiakum County groups indicated the ESD was more effective than the groups in which they differed significantly.

Degree Level Groups. Analysis of variance testing on the degree level groups' mean responses indicated a significant difference among two or more of the groups on seven of the 10 general effectiveness questions. The High School Diploma group had a significantly lower mean response than the Bachelor's degree and Master's degree group on all seven questions. The Bachelor's degree and Master's degree groups had significantly higher mean responses than the $\mathrm{PhD} / \mathrm{EdD}$ degree group on three of these questions. The Bachelor's degree group and master's degree group did not significantly differ from each other on any of these seven questions. Thus, the High School Diploma group indicated the ESD was more effective than any other group in which they significantly differed, and the Bachelor's degree and Master's degree group indicated the ESD was less effective than any other group in which they differed.

\section{Position and General Effectiveness Ratings}

The first set of analysis of variance testing was performed for the purpose of determining whether any significant difference existed between the group response means given by different position groups on the general effectiveness questions. This placed question one of the survey instrument, present position, as the independent variable and questions 15 through 24 , general effectiveness rating questions, as the dependent variable(s). Original data were collapsed within question one to include the following five 
position groups: teacher, principal, assistant principal, board member, and district office personnel. Questions 15 through 24 included a rating scale of one through six, with response one being extremely effective and response six being extremely ineffective. All questions in the general effectiveness rating section appeared to indicate a significant difference among two or more of the groups' mean responses (Table LVI).

\section{TABLELVI}

\section{A SUMMARY TABLE OF ANALYSIS OF VARIANCE TESTS PERFORMED ON GENERAL EFFECTIVENESS QUESTIONS FIFTEEN THROUGH TWENTY-FOUR BY POSITION GROUPS}

\begin{tabular}{|c|c|c|c|c|c|c|c|}
\hline Question Number & Teacher & $\begin{array}{l}\text { osition Gro } \\
\text { Principal }\end{array}$ & $\begin{array}{l}\text { ps and Me } \\
\text { Assist. } \\
\text { Principal } \\
\end{array}$ & $\begin{array}{l}\text { in Response } \\
\text { Board } \\
\text { Member } \\
\end{array}$ & $\begin{array}{c}\text { District } \\
\text { Office } \\
\end{array}$ & F-ratio & $\mathbf{P}$ \\
\hline 15. Relevant services & 2.996 & 2.697 & 2.767 & 2.512 & 2.583 & 9.167 & .001 \\
\hline $\begin{array}{l}\text { 16. Useful } \\
\text { Knowledge and } \\
\text { Information }\end{array}$ & 2.905 & 2.580 & 2.643 & 2.341 & 2.417 & 10.425 & .001 \\
\hline 17. Timely Services & 3.086 & 2.714 & 2.871 & 2.595 & 2.379 & 11.416 & .001 \\
\hline $\begin{array}{l}\text { 18. Meeting Needs } \\
\text { of Patrons }\end{array}$ & 2.909 & 2.753 & 2.733 & 2.359 & 2.705 & 5.425 & .001 \\
\hline $\begin{array}{l}\text { 19. Adjusting to } \\
\text { Individual Needs }\end{array}$ & 3.127 & 2.935 & 2.889 & 2.658 & 2.842 & 4.045 & .003 \\
\hline 20. Interpersonal Skills & 2.930 & 2.561 & 2.828 & 2.595 & 2.557 & 6.916 & .001 \\
\hline $\begin{array}{l}\text { 21. Promoting Teach- } \\
\text { ing process }\end{array}$ & 3.060 & 2.796 & 2.633 & 2.541 & 2.982 & 4.952 & .001 \\
\hline $\begin{array}{l}\text { 22. Productive Service } \\
\text { Administration }\end{array}$ & 2.995 & 2.729 & 2.690 & 2.622 & 2.517 & 6.910 & .001 \\
\hline 23. Useful Evaluations & 3.267 & 2.907 & 3.077 & 2.871 & 3.041 & 4.239 & .002 \\
\hline $\begin{array}{l}\text { 24. ESD } 112 \text { Total } \\
\text { Program }\end{array}$ & 3.045 & 2.727 & 2.857 & 2.558 & 2.567 & 11.141 & .001 \\
\hline
\end{tabular}

\section{Paired Comparisons on General Effectiveness Ouestions}

After finding that significant differences existed between the response means of two or more of the position groups on all 10 of the general effectiveness questions, paired 
comparisons tests were performed for each question. The intent of the paired comparison testing was to ascertain which groups differed significantly in their responses, and to also identify what direction the groups answered comparatively-more effective or less effective.

The findings reveal that in all paired comparisons on the general effectiveness questions, the teacher position group was found to have a significantly higher mean response than all other compared groups (Table LVII). The assistant principal group was

\section{TABLE LVII}

\section{POSITION GROUP MEAN RESPONSE PAIRED COMPARISONS AND COMPARISON PROBABILTTY LEVEL ON GENERAL EFFECTIVE- NESS QUESTIONS FIFTEEN THROUGH TWENTY-FOUR}

\begin{tabular}{|c|c|c|c|c|c|c|c|c|}
\hline \multirow[t]{2}{*}{$\begin{array}{l}\text { Question Number and } \\
\text { Topic }\end{array}$} & \multicolumn{8}{|c|}{$\begin{array}{l}\text { Direction of Position Groups Mean Responses Found to Differ Significantly and } \\
\text { Probability Level }\end{array}$} \\
\hline & Groups & $\mathbf{P}$ & Groups & $\mathbf{P}$ & Groups & $\mathbf{P}$ & Groups & $\mathbf{P}$ \\
\hline 15. Relevant Services & $\mathbf{T}>\mathbf{P}$ & .05 & $\mathrm{~T}>\mathrm{BM}$ & .05 & $T>D O$ & .05 & - & - \\
\hline $\begin{array}{l}\text { 16. Useful Knowledge } \\
\text { and Information }\end{array}$ & $\mathbf{T}>\mathbf{P}$ & .05 & $\mathrm{~T}>\mathrm{BM}$ & .05 & $\mathrm{~T}>\mathrm{DO}$ & .05 & - & - \\
\hline 17. Timely Services & $\mathbf{T}>\mathbf{P}$ & .05 & $\mathrm{~T}>\mathrm{BM}$ & .05 & $\mathrm{~T}>\mathrm{DO}$ & .05 & - & - \\
\hline $\begin{array}{l}\text { 18. Meeting Needs of } \\
\text { Patrons }\end{array}$ & $\mathbf{T}>\mathbf{B M}$ & .05 & - & - & - & - & - & - \\
\hline $\begin{array}{l}\text { 19. Adjusting to } \\
\text { Individual Needs }\end{array}$ & $\mathbf{T}>\mathbf{B M}$ & .05 & - & - & - & - & - & - \\
\hline 20. Interpersonal Skills & $\mathbf{T}>\mathbf{P}$ & .05 & $T>D O$ & .05 & - & - & - & - \\
\hline $\begin{array}{l}\text { 21. Promoting Teaching } \\
\text { Processes }\end{array}$ & $\mathbf{T}>\mathbf{B M}$ & .05 & - & - & - & - & - & - \\
\hline $\begin{array}{l}\text { 22. Productive Service } \\
\text { Administration }\end{array}$ & $\mathbf{T}>\mathbf{P}$ & .05 & $\mathrm{~T}>\mathrm{DO}$ & .05 & - & - & - & - \\
\hline 23. Useful Evaluations & $\mathbf{T}>\mathbf{P}$ & .05 & - & - & - & - & - & - \\
\hline $\begin{array}{l}\text { 24. ESD } 112 \text { Total } \\
\text { Program }\end{array}$ & $\mathbf{T}>\mathbf{P}$ & .05 & $\mathrm{~T}>\mathrm{BM}$ & .05 & $\mathrm{~T}>\mathrm{DO}$ & .05 & - & - \\
\hline$T=$ Teacher & & ice & rincipal & $\mathrm{BM}=\mathrm{BC}$ & ard Member & & $\mathrm{DO}=\mathrm{D}$ ist & Iffice \\
\hline
\end{tabular}


the only group that did not differ significantly from the teacher group on any of the 10 questions. As Table LVII illustrates, the principal, board member, and district office groups all had significantly lower means on seven of the 10 general effectiveness questions than did the teacher group. Also, there appeared to be no other significant differences among the mean responses of any of the other position groups on any of the 10 general effectiveness questions.

The results represent the fact that on all the general effectiveness questions the teacher group was found to have a significantly higher mean response than at least one of the other position groups. The principal, board member, and district office groups consistently had a lower mean response on all of the general effectiveness questions. This indicates that these three groups perceived ESD 112 as being more effective on these questions than did the teacher group.

\section{Position and Instructional and Curriculum Rating Questions}

The second set of analysis of variance testing was performed for the purpose of determining whether any significant difference existed between the group response means by different position groups on the Instructional and Curriculum questions. This placed question one of the survey instrument, present position, as the independent variable and questions 26 through 43, Instructional and Curriculum rating questions, as the dependent variable(s). Original data were collapsed within question one to include the following five position groups: teacher, principal, assistant principal, board member, and district office personnel. Questions 26 through 43 included a rating scale of one through six, with response one being extremely effective and response six being extremely ineffective. Those questions in the Instructional and Curriculum rating section which appear to indicate a significant difference between the responses of two or more of the position groups are presented in the following table (Table LVIII). 
TABLELVIII

A SUMMARY TABLE OF ANALYSIS OF VARIANCE TESTS PERFORMED ON SPECIFIC PROGRAM AND SERVICE QUESTIONS TWENTY-FIVE THROUGH FORTY-THREE BY POSITION GROUPS

\begin{tabular}{|c|c|c|c|c|c|c|c|}
\hline Question Number & Teacher & $\begin{array}{l}\text { osition Gro } \\
\text { Principal }\end{array}$ & $\begin{array}{l}\text { ups and } \mathrm{Me} \\
\text { Assist. } \\
\text { Principal }\end{array}$ & $\begin{array}{l}\text { in Respons } \\
\text { Boad } \\
\text { Member } \\
\end{array}$ & $\begin{array}{c}\text { District } \\
\text { Office } \\
\end{array}$ & F-ratio & $\mathbf{P}$ \\
\hline $\begin{array}{l}\text { 31. Ed Tech. Center } \\
\text { Services }\end{array}$ & 2.900 & 2.512 & 3.000 & 2.625 & 2.349 & 3.758 & .006 \\
\hline $\begin{array}{l}\text { 32. Inservice Grant } \\
\text { Committee }\end{array}$ & 3.131 & 2.512 & 2.727 & 2.333 & 2.667 & 4.404 & .002 \\
\hline $\begin{array}{l}\text { 33. Student Teacher } \\
\text { Pilot Program }\end{array}$ & 3.094 & 2.562 & 2.667 & 2.250 & 2.622 & 3.174 & .015 \\
\hline $\begin{array}{l}\text { 34. Teacher Assistance } \\
\text { Program }\end{array}$ & 3.100 & 2.522 & 2.750 & 2.500 & 2.794 & 2.581 & .039 \\
\hline $\begin{array}{l}\text { 41. Instructional Media } \\
\text { Staff }\end{array}$ & 2.565 & 2.375 & 2.727 & 2.500 & 2.024 & 2.979 & .020 \\
\hline 42. Films and Videos & 2.737 & 2.575 & 2.727 & 2.900 & 2.200 & 3.206 & .014 \\
\hline
\end{tabular}

Paired Comparisons on Instructional and Curriculum Questions

After finding that significant differences existed between the response means of two or more of the position groups on six of the Instructional and Curriculum questions, paired comparisons tests were performed for each question. The intent of the paired comparison testing was to ascertain which groups differed significantly in their responses and to identify what direction the groups answered comparatively-more effective or less effective.

The findings show that in all of the paired comparisons on the six Instructional and Curriculum questions were found to have a significant difference in the response means, the teacher position group was found to have a significantly higher mean response than all other compared groups. The assistant principal and board member groups were the only groups which did not differ significantly from the teacher position group on any of the six questions. As Table LIX illustrates, the principal and district office position 
groups each had significantly lower mean responses on three of the six Instructional and Curriculum questions. Also, there appeared to be no other significant differences among the mean responses of any of the other position groups on any of the six questions tested.

\section{TABLELXX}

\section{POSITION GROUP MEAN RESPONSE PAIRED COMPARISONS AND COMPARI - SON PROBABILITY LEVEL ON SPECIFIC PROGRAM AND SERVICE QUESTIONS TWENTY-FIVE THROUGH FORTY-THREE}

\begin{tabular}{|c|c|c|c|c|c|c|c|c|}
\hline \multirow{2}{*}{$\begin{array}{l}\text { Question Number and } \\
\text { Topic }\end{array}$} & \multicolumn{8}{|c|}{$\begin{array}{l}\text { Direction of Position Groups Mean Responses Found to Differ Significantly and } \\
\text { Probability Level }\end{array}$} \\
\hline & Group & $\mathbf{P}$ & Group & $\mathbf{P}$ & Group & $\mathbf{P}$ & Group & $\mathbf{P}$ \\
\hline $\begin{array}{l}\text { 31. Ed Tech Center } \\
\text { Services }\end{array}$ & $\mathrm{T}>\mathrm{DO}$ & .05 & - & - & - & - & - & - \\
\hline $\begin{array}{l}\text { 32. Inservices Grant } \\
\text { Committee }\end{array}$ & $\mathbf{T}>\mathbf{P}$ & .05 & - & - & - & - & - & - \\
\hline $\begin{array}{l}\text { 33. Sudent Teacher } \\
\text { Program }\end{array}$ & $\mathbf{T}>\mathbf{P}$ & .05 & - & - & - & - & - & - \\
\hline $\begin{array}{l}\text { 34. Teacher Assistance } \\
\text { Program }\end{array}$ & $\mathbf{T}>\mathbf{P}$ & .05 & - & - & - & - & - & - \\
\hline $\begin{array}{l}\text { 41. Instructional Media } \\
\text { Staff }\end{array}$ & $\mathrm{T}>\mathrm{DO}$ & .05 & - & - & - & - & - & - \\
\hline 42. Films and Videos & $\mathrm{T}>\mathrm{DO}$ & .05 & - & - & - & - & - & - \\
\hline
\end{tabular}

The results indicate that on these six Instructional and Curriculum effectiveness rating questions the teacher group was found to have a significantly higher mean response than at least one of the other position groups. The principal and district office groups were found to have significantly lower mean responses than the teacher group-indicating these two groups perceived ESD 112 as being more effective than did the teacher group.

\section{Position and Special Services Division Rating Questions}

The second set of analysis of variance testing was performed for the purpose of determining whether any significant difference existed between the group response means 
given by different position groups on the Special Services Division rating questions (Table $\mathrm{LX}$ ). This placed question one of the survey instrument, present position, as the independent variable and questions 45 through 62, Special Services Division rating questions, as the dependent variable(s). Original data were collapsed within question one to include the following five position groups: teacher, principal, assistant principal, board

\section{TABLELX}

\section{A SUMMARY TABLE OF ANALYSIS OF VARIANCE TESTS PERFORMED ON SPECIFIC PROGRAM AND SERVICE EFFECTIVENESS RATING QUESTIONS FORTY-FIVE THROUGH SIXTY-TWO BY POSITION GROUPS}

\begin{tabular}{|c|c|c|c|c|c|c|c|}
\hline Question Number & Teacher & $\begin{array}{l}\text { osition Grol } \\
\text { Principal }\end{array}$ & $\begin{array}{l}\text { ps and } M \\
\text { Assist. } \\
\text { Principal }\end{array}$ & $\begin{array}{l}\text { Respons } \\
\text { Boad } \\
\text { Member }\end{array}$ & $\begin{array}{l}\text { District } \\
\text { Office } \\
\end{array}$ & F-ratio & $\mathbf{P}$ \\
\hline $\begin{array}{l}\text { 45. Total Special } \\
\text { Services Program }\end{array}$ & 2.845 & 2.460 & 2.333 & 2.643 & 1.971 & 9.622 & .001 \\
\hline $\begin{array}{l}\text { 46. Special Services } \\
\text { Staff }\end{array}$ & 2.724 & 2.237 & 2.500 & 2.455 & 1.944 & 6.727 & .001 \\
\hline $\begin{array}{l}\text { 47. Special Services } \\
\text { Communications }\end{array}$ & 3.161 & 2.532 & 2.667 & 2.846 & 2.176 & 11.061 & .001 \\
\hline $\begin{array}{l}\text { 48. ESD } 112 \text { as SPED } \\
\text { Resource Center }\end{array}$ & 3.007 & 2.444 & 2.000 & 2.538 & 1.886 & 12.518 & .001 \\
\hline 49. SPED Inservice & 3.195 & 2.744 & 2.667 & 2.900 & 2.125 & 8.118 & .001 \\
\hline $\begin{array}{l}\text { 50. SPED Program } \\
\text { Review }\end{array}$ & 3.076 & 2.526 & 2.500 & 2.500 & 2.182 & 7.921 & .001 \\
\hline $\begin{array}{l}\text { 56. Psychological } \\
\text { Services }\end{array}$ & 3.122 & 2.529 & 2.333 & 2.909 & 2.240 & 5.274 & .001 \\
\hline $\begin{array}{l}\text { 57. Communications } \\
\text { Disorders }\end{array}$ & 2.933 & 2.579 & 2.500 & 2.556 & 2.346 & 2.785 & .028 \\
\hline $\begin{array}{l}\text { 61. Direct Instructional } \\
\text { Staff Cooperative }\end{array}$ & 3.061 & 2.621 & 2.333 & 2.700 & 2.000 & 6.769 & .001 \\
\hline $\begin{array}{l}\text { 62. Direct Instructional } \\
\text { Staff }\end{array}$ & 2.703 & 2.467 & 2.333 & 2.727 & 1.833 & 4.818 & .001 \\
\hline
\end{tabular}


member, and district office personnel. Questions 45 through 62 included a rating scale of one through six, with response one being extremely effective and response six being extremely ineffective. Table LX presents those questions in the Special Services Division rating section which appear to indicate a significant difference between the responses of two or more of the position groups.

\section{Paired Comparisons on Instructional and Curriculum Questions}

After finding that significant differences existed between the response means of two or more of the position groups on 10 of the 18 Special Services questions, paired comparisons were performed on the means for each these questions. The intent of the paired comparison testing was to ascertain which position groups differed significantly in their responses and to identify what direction the groups answered comparatively-more effective or less effective.

The results of the mean comparison testing indicate that in all 10 of the 18 Special Services questions tested, the teacher group was found to have a significantly higher mean response than either/or the principal or district office groups (Table LXI). It was also found that on two of the 10 Special Services questions tested, the principal group was found to have significantly higher mean responses than the district office group. Finally, the board member group was found to have a significantly higher mean response the district office group on one question. There appeared to be no other significant differences among the mean responses of any of the other position groups on any of the 10 questions.

The results show that on all 10 of the Special Services questions tested, the teacher group was found to have a significantly higher mean response than the principal or district office group. This indicates that these two groups perceive ESD 112 as being more effective than the teacher group on these questions. The results also showed that the principal group was found to have a significantly higher mean response than the district office group on two of the Special Services questions, and the board member group having 
a significantly higher response than the district office group. This indicates that the district office group perceives ESD 112 as being more effective than the principal group on these two questions, and the board member group perceiving the ESD as less effective on this one question.

TABLE LXI

POSITION GROUP MEAN RESPONSE PAIRED COMPARISONS AND COMPARISON PROBABILITY LEVEL ON GENERAL EFFECTIVENESS QUESTIONS FORTY-FIVE THROUGH SIXTY-TWO

\begin{tabular}{|c|c|c|c|c|c|c|c|c|}
\hline \multirow[t]{2}{*}{$\begin{array}{l}\text { Question Number and } \\
\text { Topic }\end{array}$} & \multicolumn{8}{|c|}{$\begin{array}{l}\text { Direction of Position Groups Mean Responses Found to Differ Significantly and } \\
\text { Probability Level }\end{array}$} \\
\hline & Group & $\mathbf{P}$ & Group & $P$ & Group & $\mathbf{P}$ & Group & $\mathbf{P}$ \\
\hline $\begin{array}{l}\text { 45. Total Special } \\
\text { Services Division }\end{array}$ & $\mathrm{T}>\mathrm{P}$ & .05 & $\mathrm{~T}>\mathrm{DO}$ & .05 & $\mathrm{P}>\mathrm{DO}$ & .05 & - & - \\
\hline $\begin{array}{l}\text { 46. Special Services } \\
\text { Staff }\end{array}$ & $\mathbf{T}>\mathbf{P}$ & .05 & $\mathrm{~T}>\mathrm{DO}$ & .05 & - & - & - & - \\
\hline $\begin{array}{l}\text { 47. Special Services } \\
\text { Communications }\end{array}$ & $\mathbf{T}>\mathbf{P}$ & .05 & $\mathrm{~T}>\mathrm{DO}$ & .05 & - & - & - & - \\
\hline $\begin{array}{l}\text { 48. ESD } 112 \text { as SPED } \\
\text { Resource Center }\end{array}$ & $\mathbf{T}>\mathbf{P}$ & .05 & $\mathrm{~T}>\mathrm{DO}$ & .05 & - & - & - & - \\
\hline 49. SPED Inservice & $\mathrm{T}>\mathrm{DO}$ & .05 & $\mathrm{P}>\mathrm{DO}$ & .05 & - & - & - & - \\
\hline $\begin{array}{l}\text { 50. SPED Program } \\
\text { Review }\end{array}$ & $\mathbf{T}>\mathbf{P}$ & .05 & $\mathrm{~T}>\mathrm{DO}$ & .05 & - & - & - & - \\
\hline $\begin{array}{l}\text { 56. School } \\
\text { Psychological } \\
\text { Services }\end{array}$ & $\mathbf{T}>\mathbf{P}$ & .05 & $\mathrm{~T}>\mathrm{DO}$ & .05 & - & - & - & - \\
\hline $\begin{array}{l}\text { 57. Communications } \\
\text { Disorders }\end{array}$ & $\mathrm{T}>\mathrm{DO}$ & .05 & - & - & - & - & - & - \\
\hline $\begin{array}{l}\text { 61. Direct Instructional } \\
\text { Staff Cooperative }\end{array}$ & $\mathrm{T}>\mathrm{DO}$ & .05 & - & - & - & - & - & - \\
\hline $\begin{array}{l}\text { 62. Direct Instructional } \\
\text { Staff }\end{array}$ & $\mathrm{T}>\mathrm{DO}$ & .05 & $\mathrm{BM}>\mathrm{DO}$ & .05 & - & - & $=$ & - \\
\hline
\end{tabular}


Years of Experience in Present District and General Effectiveness Ratings

The fourth set of analysis variance testing was performed for the purpose of determining whether any significant difference existed between the group response means given by different years of experience in present school district groups on the general effectiveness questions. This placed question two of the survey instrument, years of experience in present district, as the independent variable and questions 15 through 24 (general effectiveness rating questions) as the dependent variable(s). Question two included the following three categories of years of experience: 0-10 years, 11-20 years, $21+$ years. Questions 15 through 24 included a rating scale of one through six, with response one being extremely effective and response six being extremely ineffective.

An analysis of variance test on each of the means given by the three years of experience groups produced no significant results on the general effectiveness questions 15 through 24.

\section{Years of Experience in State of Washington and General Effectiveness Ratings}

The fifth set of analysis variance testing was performed for the purpose of determining whether any significant difference existed between the group response means given by different years of experience in the State of Washington groups on the general effectiveness questions. This placed question three of the survey instrument, "years of experience in the State of Washington" as the independent variable and questions 15 through 24 (general effectiveness rating questions) as the dependent variable(s). Question three included the following three categories of years of experience: 0-10 years, 11-20 years, 21+ years. Questions 15 through 24 included a rating scale of one through six, with response one being extremely effective and response six being extremely ineffective.

An analysis of variance test on each of the means given by the three years of experience in the State of Washington groups produced no significant results on the general effectiveness questions 15 through 24. 


\section{District Size and General Effectiveness Ratings}

The fourth set of analysis variance testing was performed for the purpose of determining whether any significant difference existed between the group response means given by different district size groups on the general effectiveness questions. This placed question four of the survey instrument, district size, as the independent variable and questions 15 through 24 , general effectiveness rating questions, as the dependent variable(s). Question four included the following five groups of district size according to the number of students enrolled in the district: 0-300, 301-800, 801-1300, 1301-2000, and 2001 or more. Questions 15 through 24 included a rating scale of one through six, with response one being extremely effective and response six being extremely ineffective. Those questions in the general effectiveness rating section which appear to indicate a significant difference between the responses of two or more of the district size groups are presented in the following table (Table LXII).

TABLE LXII

A SUMMARY TABLE OF ANALYSIS OF VARIANCE TESTS PERFORMED ON GENERAL EFFECTIVENESS RATING QUESTIONS FIFTEEN THROUGH TWENTY-FOUR BY DISTRICT-SIZE GROUPS

\begin{tabular}{|c|c|c|c|c|c|c|c|}
\hline Question Number & $0-300^{D}$ & $\begin{array}{l}\text { trict Size } \\
301-800\end{array}$ & $\begin{array}{l}\text { roups and } \\
801-1300\end{array}$ & $\begin{array}{l}\text { Iean Respon } \\
1301-2000\end{array}$ & $2001+$ & F-ratio & $\mathbf{P}$ \\
\hline 15. Relevant services & 2.742 & 2.918 & 3.006 & 2.864 & 2.805 & 1.566 & .043 \\
\hline 17. Timely Services & 2.781 & 3.055 & 3.066 & 2.758 & 2.788 & 4.071 & .003 \\
\hline $\begin{array}{l}\text { 18. Meeting Needs of } \\
\text { Patrons }\end{array}$ & 2.573 & 2.860 & 2.909 & 2.857 & 2.835 & 2.793 & .026 \\
\hline $\begin{array}{l}\text { 21. Promoting Teach- } \\
\text { ing process }\end{array}$ & 2.865 & 3.131 & 3.084 & 2.968 & 2.819 & 3.004 & .018 \\
\hline $\begin{array}{l}\text { 24. ESD } 112 \text { Total } \\
\text { Program }\end{array}$ & 2.759 & 2.991 & 3.025 & 2.938 & 2.833 & 2.706 & .030 \\
\hline
\end{tabular}




\section{Paired Comparisons on General Effectiveness Questions}

After finding that significant differences existed between the response means of two or more of the district size groups on five of the general effectiveness questions, paired comparisons were performed on the means for each question. The intent of the paired comparison testing was to ascertain which groups differed significantly in their responses and to identify what direction the groups answered comparatively-more effective or less effective.

The findings show that in all paired comparisons on the general effectiveness questions, the 0-300 district size group was found to have a lower mean response on all those questions in which they differed significantly from another group (Table LXIII). The

\section{TABLE LXIII}

\section{DISTRICT SIZE GROUP MEAN RESPONSE PAIRED COMPARISONS AND COMPARISON PROBABILITY LEVEL ON GENERAL EFFECTIVE- NESS QUESTIONS FIFTEEN THROUGH TWENTY-FOUR}

\begin{tabular}{|c|c|c|c|c|c|c|c|}
\hline \multirow[t]{2}{*}{$\begin{array}{l}\text { Question Number and } \\
\text { Topic }\end{array}$} & \multicolumn{7}{|c|}{$\begin{array}{c}\text { Direction of District Size Group Mean Responses Found to Differ Significantly } \\
\text { and Probability Level }\end{array}$} \\
\hline & Group & $\mathbf{P}$ & Group $\quad \mathbf{P}$ & Group & $\mathbf{P}$ & Group & $\mathbf{P}$ \\
\hline 15. Relevant Services & $\begin{array}{l}0.801- \\
300<1300\end{array}$ & .05 & $\begin{array}{l}301-1301 \\
800>2000.05\end{array}$ & - & - & - & - \\
\hline 17. Timely Services & $\begin{array}{l}301-1301 \\
800>2000\end{array}$ & .05 & $\begin{array}{l}301- \\
800>2001.05\end{array}$ & - & - & - & - \\
\hline $\begin{array}{l}\text { 18. Meeting Needs of } \\
\text { Patrons }\end{array}$ & $\begin{array}{l}0- \\
300<800\end{array}$ & .05 & - & - & - & - & - \\
\hline $\begin{array}{l}\text { 21. Promoting Teaching } \\
\text { Processes }\end{array}$ & $\begin{array}{l}0- \\
300<800\end{array}$ & .05 & $\begin{array}{l}301- \\
800>2001 \quad .05\end{array}$ & $\begin{array}{l}801- \\
1300>200\end{array}$ & .05 & - & - \\
\hline $\begin{array}{l}\text { 24. ESD } 112 \text { Total } \\
\text { Program }\end{array}$ & $\begin{array}{l}0- \\
300<800\end{array}$ & .05 & $\begin{array}{l}0.801- \\
300<1300.05\end{array}$ & $1300>200$ & .05 & - & - \\
\hline $0-300$ students & 00 sturdents & 801. & 1300 students & $01-2000$ stud & & $2001+$ & ents \\
\hline
\end{tabular}

301-800 district size group was found to have a higher mean response on all those question in which the differed significantly from another group. The 801-1300 district size group 
was found to have a higher mean response than the $2001+$ district size group on two of the general effectiveness questions.

The results indicate that the 0-300 district size group perceived ESD 112 as more effective than any of the other district size groups in which the differed significantly, and the 301-800 district size group perceived ESD 112 as less effective than any to the other district size groups in which the differed significantly (Table LXII). Besides the 0-300 size district, the smaller sized school district group which was found to differ significantly from a larger size district group tended to perceive the ESD as less effective by having a higher mean response.

\section{County Location and General Effectiveness Ratings}

The fifth set of analysis variance testing was performed for the purpose of determining whether any significant difference existed between the group response means given by different county groups on the general effectiveness questions (Table LXIV). This placed question five of the survey instrument, county location of district, as the independent variable and questions 15 through 24 (general effectiveness rating questions) as the dependent variable(s). Question five included the following six county location categories: Clark, Cowlitz, Klickitat, Pacific, Skamania, and Wahkiakum. Questions fifteen through twenty-four included a rating scale of one through six, with response one being extremely effective and response six being extremely ineffective. Table LXIV presents those questions in the general effectiveness rating section which appear to indicate a significant differences between the mean responses of two or more of the county location groups.

\section{Paired Comparisons on General Effectiveness Questions}

After finding that significant differences existed between the response means of two or more of the county location groups on eight of the general effectiveness questions, 
paired comparisons were performed on the means for each question. The intent of the paired comparison testing was to ascertain which groups differed significantly in their responses and to identify what direction the groups answered comparatively-more effective or less effective (Table LXV).

\section{TABLE LXIV}

\section{A SUMMMARY TABLE OF ANALYSIS OF VARIANCE TESTS PERFORMED ON GENERAL EFFECTIVENESS RATING OUESTIONS FIFTEEN THROUGH TWENTY-FOUR BY COUNTY GROUPS}

\begin{tabular}{|c|c|c|c|c|c|c|c|c|}
\hline Question Number & Clark & $\begin{array}{l}\text { County } \\
\text { Cow- } \\
\text { litz }\end{array}$ & $\begin{array}{c}\text { Sroups an } \\
\text { Klick- } \\
\text { itat } \\
\end{array}$ & $\begin{array}{l}\text { dMean } F \\
\text { Pacific }\end{array}$ & $\begin{array}{c}\text { esponse } \\
\text { Skam- } \\
\text { ania } \\
\end{array}$ & $\begin{array}{l}\text { Wahki- } \\
\text { akum }\end{array}$ & F-ratio & $\mathbf{P}$ \\
\hline 15. Relevant services & 2.835 & 3.052 & 2.670 & 3.308 & 2.804 & 2.750 & 5.829 & .001 \\
\hline 17. Timely Services & 2.845 & 3.037 & 2.813 & 3.410 & 2.864 & 3.000 & 3.571 & .003 \\
\hline $\begin{array}{l}\text { 18. Meeting Needs of } \\
\text { Patrons }\end{array}$ & 2.860 & 2.938 & 2.551 & 3.054 & 2.667 & 2.737 & 3.927 & .002 \\
\hline $\begin{array}{l}\text { 19. Adjusting to } \\
\text { Individual Needs }\end{array}$ & 3.010 & 3.186 & 2.852 & 3.600 & 2.883 & 2.842 & 5.240 & .001 \\
\hline 20. Interpersonal Skills & 2.789 & 2.943 & 2.652 & 3.206 & 2.732 & 2.722 & 3.231 & .007 \\
\hline $\begin{array}{l}\text { 21. Promoting Teach- } \\
\text { ing process }\end{array}$ & 2.885 & 3.102 & 2.924 & 3.629 & 2.905 & 2.632 & 5.452 & .001 \\
\hline 23. Useful Evaluations & 3.126 & 3.242 & 3.063 & 3.677 & 3.029 & 2.938 & 3.267 & .007 \\
\hline $\begin{array}{l}\text { 24. ESD-112 Total } \\
\text { Program }\end{array}$ & 2.894 & 3.008 & 2.733 & 3.400 & 2.842 & 2.737 & 4.883 & .001 \\
\hline
\end{tabular}

The results indicated that in all paired comparisons on the general effectiveness questions the Clark County, Klickitat County, Skamania County, and Wahkiakum County groups had a significantly lower mean response on those questions in which they were found to differ significantly from another group. On the other hand, the Pacific County group was found to have significantly higher mean responses on those questions in which they were found to differ significantly from another group. Cowlitz County was the only county group found to have both significantly lower mean response than Pacific County 
when they differed, and a significantly higher mean response in comparison with all other groups.

\section{TABLELXV}

\section{COUNTY GROUP MEAN RESPONSE PAIRED COMPARISONS AND \\ COMPARISON PROBABILITY LEVEL ON GENERAL EFFECTIVE -NESS QUESTIONS FIFTEEN THROUGH TWENTY-FOUR}

\begin{tabular}{|c|c|c|c|c|c|c|c|c|}
\hline \multirow[t]{2}{*}{$\begin{array}{l}\text { Question Number and } \\
\text { Topic }\end{array}$} & \multicolumn{8}{|c|}{$\begin{array}{l}\text { Direction of County Group Mean Responses Found to Differ Significantly and } \\
\text { Probability Level }\end{array}$} \\
\hline & Group & $\mathrm{P}$ & Group & $\mathbf{P}$ & Group & $\mathbf{P}$ & Group & $\mathbf{P}$ \\
\hline $\begin{array}{l}\text { 15. Relevant } \\
\text { Services }\end{array}$ & $\mathbf{C L}<\mathbf{P A}$ & .05 & $\mathrm{KL}<\mathrm{PA}$ & .05 & PA > SK & .05 & PA $>$ WA & .05 \\
\hline $\begin{array}{l}\text { 17. Timely } \\
\text { Services }\end{array}$ & $\mathrm{CL}<\mathrm{CO}$ & .05 & $\mathrm{CL}<\mathrm{PA}$ & .05 & $\mathrm{CO}<\mathrm{PA}$ & .05 & $\mathbf{K L}<\mathbf{P A}$ & .05 \\
\hline 17. Cont & $\mathbf{P A}>\mathbf{S K}$ & .05 & - & - & - & - & - & - \\
\hline $\begin{array}{l}\text { 18. Meeting Need } \\
\text { of Patrons }\end{array}$ & PA > SK & .05 & - & - & - & - & - & - \\
\hline $\begin{array}{l}\text { 19. Adjusting to } \\
\text { Needs }\end{array}$ & $\mathrm{CL}<\mathrm{PA}$ & .05 & $\mathbf{K L}<\mathrm{PA}$ & .05 & PA > SK & .05 & PA > WA & .05 \\
\hline $\begin{array}{l}\text { 20. Interpersonal } \\
\text { Skills }\end{array}$ & $\mathbf{C L}<\mathbf{P A}$ & .05 & $\mathbf{K L}<\mathbf{P A}$ & .05 & PA > SK & .05 & PA > WA & .05 \\
\hline $\begin{array}{l}\text { 21. Promoting } \\
\text { Teach Process }\end{array}$ & $\mathbf{C L}<\mathbf{P A}$ & .05 & $\mathrm{CO}<\mathrm{PA}$ & .05 & $\mathrm{CO}>\mathrm{WA}$ & .05 & $K L<P A$ & .05 \\
\hline 21. Cont. & $\mathrm{PA}>\mathrm{SK}$ & .05 & $\mathrm{PA}>\mathrm{WA}$ & .05 & - & - & - & - \\
\hline $\begin{array}{l}\text { 23. Useful } \\
\text { Evaluations }\end{array}$ & $\mathrm{CO}<\mathrm{PA}$ & .05 & $\mathbf{K L}<\mathbf{P A}$ & .05 & PA > SK & .05 & PA > WA & .05 \\
\hline $\begin{array}{l}\text { 24. ESD } 112 \\
\text { Total Program }\end{array}$ & $\mathrm{CL}<\mathrm{PA}$ & .05 & $\mathbf{K L}<\mathbf{P A}$ & .05 & PA > SK & .05 & $\mathbf{P A}>\mathbf{W A}$ & .05 \\
\hline $\mathrm{CL}=$ Clark & $\mathbf{K L}=$ & ickita & $\mathrm{PA}=\mathrm{Pa}$ & & SK=Skaman & & WA $=$ Wah & iakum \\
\hline
\end{tabular}

The results show that of all the county groups, the Pacific County group consistently gave a higher mean response than any of the county groups in which they were found to significantly differ. This would indicate that the Pacific County group perceives ESD 112 as less effective than any other county groups on these eight general effectiveness rating questions. The Pacific County group made up more than $95.0 \%$ percent of the 
significantly different paired comparisons. The results would also indicate that the Clark County, Klickitat County, Skamania County, and Wahkiakum County groups all perceived ESD 112 as more effective than any of the other county groups in which they were found to significantly differ.

\section{Educational Level and General Effectiveness Ratings}

The last set of analysis variance testing was performed for the purpose of determining whether any significant difference existed between the group response means given by different educational level groups on the general effectiveness questions (Table LXVI). This placed question six of the survey instrument, highest educational level

\section{TABLE LXVI}

\section{A SUMMARY TABLE OF ANALYSIS OF VARIANCE TESTS PERFORMED ON GENERAL EFFECTIVENESS RATING QUESTIONS FIFTEEN THROUGH TWENTY-FOUR BY DEGREE LEVEL GROUPS}

\begin{tabular}{|c|c|c|c|c|c|c|}
\hline Question Number & $\begin{array}{c}\text { Degre } \\
\text { H.S. } \\
\text { Diploma } \\
\end{array}$ & $\begin{array}{l}\text { Level Groups } \\
\text { Bachelor's } \\
\text { Degree }\end{array}$ & $\begin{array}{c}\text { ind Mean R } \\
\text { Master's } \\
\text { Degree } \\
\end{array}$ & $\begin{array}{c}\text { onses } \\
\text { PhD or } \\
\text { EdD }\end{array}$ & F-ratio & $\mathbf{P}$ \\
\hline 15. Relevant services & 2.286 & 2.951 & 2.876 & 2.643 & 5.969 & .001 \\
\hline $\begin{array}{l}\text { 16. Useful Knowledge } \\
\text { and Information }\end{array}$ & 2.096 & 2.794 & 2.797 & 2.679 & 5.048 & .002 \\
\hline 17. Timely Services & 2.333 & 3.066 & 2.881 & 2.571 & 6.971 & .001 \\
\hline $\begin{array}{l}\text { 18. Meeting Needs of } \\
\text { Patrons }\end{array}$ & 2.100 & 2.790 & 2.896 & 2.750 & 7.011 & .001 \\
\hline $\begin{array}{l}\text { 19. Adjusting to } \\
\text { Individual Needs }\end{array}$ & 2.400 & 3.030 & 3.067 & 3.074 & 3.650 & .012 \\
\hline 23. Useful Evaluations & 2.684 & 3.253 & 3.131 & 3.043 & 3.016 & .030 \\
\hline $\begin{array}{l}\text { 24. ESD } 112 \text { Total } \\
\text { Program }\end{array}$ & 2.318 & 2.976 & 2.930 & 2.643 & 6.642 & .001 \\
\hline
\end{tabular}

reached as the independent variable and questions 15 through 24 (general effectiveness rating questions) as the dependent variable(s). Question six included the following four 
categories of educational level: H.S. Diploma, Bachelor's, Master's, and $\mathrm{PhD}$ or EdD. Questions 15 through 24 included a rating scale of one through six, with response one being extremely effective and response six being extremely ineffective. Those questions in the general effectiveness rating section which appear to indicate a significant difference between the responses of two or more of the educational level groups are presented in the preceding table.

\section{Paired Comparisons on General Effectiveness Questions}

After finding that significant differences existed between the response means of two or more of the degree level groups on seven of the general effectiveness questions, paired comparisons were performed on the means for each question. The intent of the paired comparison testing was to ascertain which groups differed significantly in their responses and to identify what direction the groups answered comparatively-more effective or less effective (Table LXVII).

The findings of the paired comparisons reveal that seven general effectiveness questions were found to have a significant difference in the mean responses. The High School Diploma group had a significantly lower mean response than the Bachelor's Degree and Master's Degree groups on every question. Those paired comparisons that found a significant difference between the Bachelor's Degree or Master's Degree groups and the $\mathrm{PhD}$ degree group revealed that the $\mathrm{PhD}$ degree group had a significantly lower mean response than either of the other two groups. On the other hand, whenever a significant difference was found between the High School Diploma group and the PhD degree groupthe $\mathrm{PhD}$ degree group had a significantly higher mean response. The Bachelor's Degree and Master's Degree group did not differ significantly on any of these seven general effectiveness questions.

The results show that the High School Diploma group consistently had a lower mean response, which indicates the high school diploma group perceives ESD 112 as more 
effective on these seven general effectiveness questions than any other compared group. The results also show that although the PhD/EdD Degree group perceives ESD 112 more

\section{TABLE LXVII}

\section{DEGREE LEVEL GROUP MEAN RESPONSE PAIRED COMPARISONS AND COMPARISON PROBABILTY LEVEL ON GENERAL EFFECTIVENESS QUESTIONS FIFTEEN THROUGH TWENTY-FOUR}

\begin{tabular}{|c|c|c|c|c|c|c|c|}
\hline \multirow[t]{2}{*}{$\begin{array}{l}\text { Question Number and } \\
\text { Topic }\end{array}$} & \multicolumn{7}{|c|}{$\begin{array}{l}\text { Direction of Degree Level Groups Mean Responses Found to Differ } \\
\text { Significantly and Probability Level }\end{array}$} \\
\hline & Groups & $\mathbf{P}$ & Groups $\quad \mathbf{P}$ & Groups & $\mathbf{P}$ & Groups & $\mathbf{P}$ \\
\hline 15. Relevant Services & HSD $<$ BA & .05 & HSD $<$ MA .05 & $\mathbf{M A}>\mathbf{P h D}$ & .05 & - & - \\
\hline $\begin{array}{l}\text { 16. Useful Knowledge } \\
\text { and Information }\end{array}$ & HSD $<$ BA & .05 & HSD $<$ MA .05 & $\mathrm{HSD}<\mathrm{PhD}$ & .05 & - & - \\
\hline 17. Timely Services & HSD $<\mathbf{B A}$ & .05 & HSD $<$ MA .0S & $\mathrm{BA}>\mathrm{PhD}$ & .05 & $\mathrm{MA}>\mathrm{PhD}$ & .05 \\
\hline $\begin{array}{l}\text { 18. Meeting Needs of } \\
\text { Patrons }\end{array}$ & $\mathbf{H S D}<\mathbf{B A}$ & .05 & HSD $<$ MA .05 & $\mathrm{HSD}<\mathrm{PhD}$ & .05 & - & - \\
\hline $\begin{array}{l}\text { 19. Adjusting to } \\
\text { Individual Needs }\end{array}$ & HSD $<$ BA & .05 & HSD $<$ MA .05 & $\mathrm{HSD}<\mathrm{PhD}$ & .05 & - & - \\
\hline 23. Useful Evaluations & $\mathrm{HSD}<\mathrm{BA}$ & .05 & HSD $<$ MA .05 & - & - & - & - \\
\hline $\begin{array}{l}\text { 24. ESD } 112 \text { Total } \\
\text { Program }\end{array}$ & $\mathrm{HSD}<\mathrm{BA}$ & .05 & HSD $<$ MA .05 & $\mathbf{M A}>\mathrm{PhD}$ & .05 & - & - \\
\hline HSD=High School & loma & & Bachelor's & MA=Maste & & $\mathrm{PhD}=\mathrm{F}$ & EdD \\
\hline
\end{tabular}

effective than the Bachelor's Degree or Master's Degree group on some of these general effectiveness questions, the group still does not perceive the ESD as effective as does the High School Diploma group.

\section{SECONDARY ANALYSIS}

This section of the chapter will provide the reader with a secondary analysis of the data. The intent of this section was to investigate whether there were significant differences among the proportions of respondents, according to their professional position, falling into different response categories as defined by the seven general information questions and two 
"gate" questions contained on the survey instrument. The respondents were organized into position groups as identified by question one on the survey instrument. Original data identifying the 13 types of positions were collapsed into five position groups. These five position groups included: teacher, principal, assistant principal, board member, and central office personnel. A chi-square test of significance was performed in order to investigate whether any significant difference existed between the various positions held and the response of those questions mentioned above.

The general information questions included questions seven through 14 . These questions dealt with understandings of ESD 112, program involvement, program and service access, and opinions towards ESD services. The two "gate" questions were number 25 and 44. These two questions were placed at the beginning of the specific service and program rating questions regarding the Instructional and Curriculum and Special Services

Division services. This allowed the respondent to state whether they had enough knowledge of these ESD divisions to answer the subsequent rating questions in that section.

The following narrative will first present an overview of the each question topic, along with a description of the categories for each question. The hypothesis will then be stated, along with the results of the chi-square significance test used for each question. The mode percentage response for each position group will be then presented for discussion.

\section{Summary of Secondary Analysis}

To examine whether there were significant differences found in the proportions of position groups falling into different response categories on the eight general information questions, Chi-square tests of significance were performed. The findings indicate significant results on all but two of the general information questions tested.

There was a significant difference found between the various position groups and their understanding of the functions and purposes of ESD 112. Although the largest 
percentage of each group indicated "good" or "moderate" understanding of ESD 112's functions and purpose, nearly one-fourth of the "district office" group indicated "complete understanding" and one-fourth of the teacher group indicated "minimal" understanding.

Significant differences were also found between the position groups and their involvement with ESD 112 programs and services. The majority of every group except the district office group indicated they had been involved with "five or fewer" ESD programs in the last two years. Nearly half of the district office group indicated they had been involved with "six or more" ESD programs.

There were significant differences found among the various position groups and the types of programs services felt to be used by the respondents district. Although the largest percentage of each position group indicated that the "orientation of programs used by their district" was a "combination of orientations" (teacher, student administrative, etc.), one-fifth of the teacher group indicated a "student orientation" response and nearly one-fifth of the assistant principal group indicated a "teacher orientation."

Significant differences were found between position groups and the respondents' feelings concerning how much ESD 112 affected them in their present position. Whereas the largest percentage of respondents indicated the ESD affects their job "somewhat," over one-third of the teacher and assistant principal groups indicated a "very little" response, and over one-third of the district office group indicated a "very much" response.

Also, significant differences were found among position groups and the different constraints encountered when accessing services of the ESD. The largest percentage of the principal, board member, and district office groups indicated "no constraints," while onethird of the teacher group indicated "distance" as the major access constraint.

Lastly, significant differences were found between the various position groups, and whether they felt ESD 112 was providing "timely services" to its patrons. The teacher 
group had one-fourth of their group indicate that the ESD did not provide "timely" services, while one-tenth or less of every other position group gave this same response.

There were no significant differences found among the position groups and their personal knowledge as to whether their district used ESD 112 services. Nearly all respondents in each group responded that their district used at least some service provided by the ESD. Also, no significant differences were found among the position groups and whether they felt their district should contract services from ESD 112, with close to ninetenths of every group responding that their district should contract certain services.

\section{Personal Understanding of ESD 112}

Question seven on the survey instrument requested the respondent to rate his or her personal understanding of the functions and purposes of ESD 112. The respondent was given five different choices from which to respond. These five choices included: complete understanding, good understanding, moderate understanding, minimal understanding, and no understanding. The position groups included: teacher, principal, assistant principal, board member, and district office personnel.

The null hypothesis which was tested for this question stated: "There is no difference between the various groups of educational positions held by the respondents and their understanding of the functions and purposes of ESD 112's programs and services." A significant difference was found in the educationally-related position the respondent held and his or her understanding of the functions and purposes of ESD 112. Therefore, the null hypothesis was rejected on the basis of the following results: $x^{2}(16)=143.81 ; p \leq .01$.

The teacher (45.4\%) and assistant principal (47.1\%) respondent groups most often indicated that they had a "moderate understanding" of the functions and purposes of ESD 112. The principal (60.4\%), board member (46.7\%), and district office (58.0\%) groups indicated most often that they had a "good understanding" of these functions and services. While the central office personnel (25.8\%) indicated they had "complete understanding," 
less than $5.0 \%$ of all others groups gave this same answer. One-fifth of the teacher group (20.3\%) indicated that they had "minimal understanding" of ESD 112's functions, while less than $10.0 \%$ percent of all other position groups responded this way.

\section{Involvement With ESD 112 Programs}

Question eight on the survey instrument requested the respondent to respond to their actual involvement with programs and services provided by ESD 112 in the last two years. The respondent was given six choices from which to respond. These six choices included: no programs/services, 1-5 programs/services, 6-10 programs/services, 11-20 programs/services, more than 20 programs/services, and all programs. The position groups included: teacher, principal, assistant principal, board member, and district office personnel.

The null hypothesis which was tested for this question stated: "There is no difference between the various groups of educational positions held by the respondents and their involvement with programs and services provided by ESD 112 in the last two years." A significant difference was found in the position held by the respondent and their involvement with programs or services provided by ESD 112 in the last two years. Therefore, the null hypothesis was rejected on the basis of the following results: $x^{2}(20)=$ 102.26; $\mathrm{p} \leq .01$

All groups (teachers-76.9\%, principals-69.4\%, assistant principals-81.8\%, board members-67.5\%, district office personnel-45.2\%) indicated that they were most often involved with "1-5 programs and services" provided by ESD 112. Twelve percent or less of the teachers (9.3\%) and assistant principals (12.1\%) indicated they were involved in "610 programs and services," while $25.0 \%$ percent or more of the board members (25.0\%) and central office personnel (33.9\%) indicated they were involved in "6-10 programs and services." Not $1.0 \%$ or more of any group indicated that they had been involved with all programs and services offered by ESD 112. 
Knowledge of ESD 112 Use by District

Question nine requested the respondent to answer to his or her knowledge of whether their district presently used any of the services provided by ESD 112 . The respondents were given three choices from which to respond. These three choices included: yes, no, and unknown. The position groups included: teacher, principal, assistant principal, board member, and district office personnel.

The null hypothesis which was tested for this question stated: "There is no difference between the various groups of educational positions held by the respondents and their knowledge as to whether their district used any services provided by ESD 112" No significant difference was found in the position held by the respondent and their knowledge as to whether their district used any services provided by ESD 112 . Therefore, the null hypothesis was accepted on the basis of the following results: $x^{2}(8)=5.00 ; p \leq .76$.

More than ninety-five percent of all position groups (teachers-95.2\%, principals96.3\%, assistant principals- $97.0 \%$, board members- $100.0 \%$, district office personnel98.4\%) responded that they knew their district used at least some type or another of service or program provided by ESD 112 . Less than $5.0 \%$ of all groups responded with an "unknown" response.

\section{Types of Programs Used}

Question 10 of the survey instrument requested the respondent to identify what types of ESD 112 programs and services their district most used. The respondents were given four choices from which to respond. These four choices included: mostly student oriented, mostly teacher oriented, mostly administrative oriented, and some combination of those above. The position groups included: teacher, principal, assistant principal, board member, and district office personnel.

The null hypothesis which was tested for this question stated: "There is no difference between the various groups of educational positions held by the respondents and 
the orientation of ESD 112 programs and services they feel their district uses most." A significant difference was found in the position held by the respondent and the orientation of ESD 112 programs and services they feel their district uses most. Therefore, the null hypothesis was rejected on the basis of the following results: $x^{2}(12)=54.84 ; p \leq .01$.

The majority of all position groups (teachers-61.68\%, principals-80.19\%, assistant principals-69.70\%, board members-88.89\%, and central office personnel-77.05\%) indicated that they felt the programs and services used by their district were a "combination" of student, teacher, and administrative orientation. Whereas $20.3 \%$ of the teacher group felt the services used by their district were "mostly student oriented," $10.0 \%$ or less of all the other groups indicated this same response. Also, the teacher group (15.78\%) and the assistant principal group (18.18\%) indicated that the types of programs and services used by their district was "mostly teacher oriented," while less than $6.0 \%$ of all other groups indicated the same response.

\section{ESD 112 Effect on Position}

Question 11 of the survey instrument requested the respondent to indicate how much ESD 112 affects them in their present working position. The respondents were given five choices from which to respond. These five choices included: very much, somewhat, very little, not at all, don't know. The position groups included: teacher, principal, assistant principal, board member, and district office personnel.

The null hypothesis which was tested for this question stated: "There is no difference between the various groups of educational positions held by the respondents and their feeling as to how much ESD 112 affects them in their present working position." A significant difference was found in the position held by the respondent and their feeling as to how much ESD 112 affects them in their present working position. Therefore, the null hypothesis was rejected on the basis of the following results: $X^{2}(16)=69.94 ; P \leq .01$ 
All position groups (teachers-44.6\%, principals-59.3\%, assistant principals45.5\%, board members-58.1\%, and district office personnel-44.3\%) groups indicated most often that ESD 112 had "somewhat" of an affect on their present position. In contrast to the "somewhat" response, 37.7\% of the central office position group indicated that ESD 112 affected their job "very much," while $16.0 \%$ or less of all the other groups responded this same way. A large portion of the teacher group (36.4\%) and the assistant principal group (39.4\%) indicated that ESD 112 had "very little" effect on their position. Less than $7.0 \%$ of all groups indicated that they did not know how much the ESD affected them in their position.

\section{Constraints In Accessing ESD 112}

Question 11 of the survey instrument requested the respondent to identify what constraints he or she encountered in accessing ESD 112 services. The respondents were given seven choices from which to respond. These seven choices included: none, distance, conflicting working hours, finances, lack of information about ESD 112, reasons associated with local school district, and combinations of reasons. The position groups included: teacher, principal, assistant principal, board member, and district office personnel.

The null hypothesis which was tested for this question stated: "There is no difference between the various groups of educational positions held by the respondents and those constraints encountered when accessing ESD 112 services." A significant difference was found in the position held by the respondent and constraints encountered when accessing ESD 112 services. Therefore, the null hypothesis was rejected on the basis of the following results: $x^{2}(24)=78.91 ; p \leq .01$

The principals (42.1\%), assistant principals (28.1\%), board members (51.2\%), and central office personnel (45.9\%) groups indicated "none" most often in regards to the possible constraints they encountered when accessing ESD 112. The teacher position 
group (30.9\%) indicated "distance" as the most constraining factor encountered when accessing the ESD. Disregarding the board member group, around one-fifth (teacher$19.1 \%$, principal-24.3\%, assistant principal-21.8\%, central office personnel- $21.3 \%$ ) of all the other position groups indicated that a "combination of reasons" were encountered when accessing ESD 112. Less than $10.0 \%$ of all groups indicated that "reasons associated with their local school district" as an access constraint.

\section{Providing Timely Services}

Question 13 of the survey instrument requested the respondent to state whether they felt ESD 112 provided timely services, in regards to materials distribution, efficient communications, and executing services and programs. The respondents were given two choices from which to respond. These two choices included: yes and no. The position groups included: teacher, principal, assistant principal, board member, and district office personnel.

The null hypothesis which was tested for this question stated: "There is no difference between the various groups of educational positions held by the respondents and whether they feel ESD 112 provides timely services." A significant difference was found in the position held by the respondent and whether the felt ESD 112 provided timely services. Therefore, the null hypothesis was rejected on the basis of the following results: $X^{2}(4)=24.32 ; P \leq .01$.

The majority of all position groups (teachers- $75.2 \%$, principals- $92.0 \%$, assistant principals-90.3\%, board members-93.0\%, central office personnel-87.3\%) responded that they felt ESD 112 provided timely services by responding "yes" to question 13. Onefourth of the teachers $(24.8 \%)$ and a little more than one-tenth $(12.7 \%)$ of the central office personnel indicated that they felt ESD 112 did not provide timely services by responding "no" to question 13. The other three groups, principals, assistant principals, and board members, all had less than $10.0 \%$ of their group responded "no" to question 13. 


\section{District's Contracting Of ESD 112 Services}

Question 12 of the survey instrument requested the respondent to state whether they felt their district should contract certain services and programs from ESD 112. The respondents were given two choices from which to respond. These two choices included: yes and no. The position groups included: teacher, principal, assistant principal, board member, and district office personnel.

The null hypothesis which was tested for this question stated: "There is no difference between the various groups of educational positions held by the respondents whether they feel their district should contract certain programs and services from ESD 112." A significant difference was not found in the position held by the respondent and whether the felt their district should contract services and programs from ESD 112. Therefore, the null hypothesis was accepted on the basis of the following results : $x^{2}(4)=$ 5.16; $P \leq .27$.

The majority of all position groups (teachers-86.2\%, principals-88.7\%, assistant principals- $86.7 \%$, board members- $-97.8 \%$, central office personnel- $86.9 \%$ ) indicated that they felt their district should contract certain programs and services from ESD 112 by responding "yes" on question 14. Between $11.0 \%$ and $14.0 \%$ of all position groups (teacher-13.8\%, principals-11.3\%, assistant principals-13.3\%, central office personnel13.1\%), except the board member group (2.2\%), indicated that they felt their district should not contract services from ESD 112.

\section{Knowledge of Instructional and Cumiculum Services}

Question 25 of the survey instrument requested the respondent to state whether they felt they knew enough about any of the Curriculum and Instructional services to rate them. The respondents were given two choices from which to respond. These two choices included: yes and no. The position groups included: teacher, principal, assistant principal, board member, and district office personnel. 
The null hypothesis which was tested for this question stated: "There is no difference between the various groups of educational positions held by the respondents whether they felt the knew enough about the Curriculum and Instructional services to rate them." A significant difference was found in the position held by the respondent and whether the felt the knew enough about the Curriculum and Instructional services to rate them. Therefore, the null hypothesis was rejected on the basis of the following results: $X^{2}(4)=73.27 ; P \leq .01$

The only group which indicated that a majority of its respondents felt they knew enough about the Instructional and curriculum services to rate them, was the central office personnel group (79.0\%). The principal's group was evenly split, with one-half of the group (49.0\%) indicating "yes" they knew enough to rate instructional and curriculum services and one-half (50.9\%) indicating "no" they did not know enough to rate the same programs and services. The teachers (71.2\%), assistant principals (63.6\%), and board members (77.7\%) groups most often indicated that they felt they did not know enough about instructional and curriculum services provided by ESD 112 to rate them.

\section{Knowledge of Special Services Division}

Question 44 of the survey instrument requested the respondent to state whether they felt they knew enough about any of the Special Services programs to rate them. The respondents were given two choices from which to respond. These two choices included yes or no. The position groups included: teacher, principal, assistant principal, board member, and district office personnel.

The null hypothesis which was tested for this question stated: "There is no difference between the various groups of educational positions held by the respondents whether they felt the knew enough about the Special Services programs to rate them." A significant difference was found in the position held by the respondent and whether the felt 
the knew enough about the Special Service programs to rate them. Therefore, the null hypothesis was rejected on the basis of the following results: $X^{2}(4)=35.52 ; P \leq .01$

The majority of the teacher (69.7\%), principal (53.8\%,) assistant principal (90.9\%), and board member (71.1\%) groups responded that they felt they did not know enough about the Special Services Division of ESD 112 to rate the programs and services by answering "no" on question 44. The central office personnel position group (58.3\%) was the only group in which the majority responded "yes" on question 44, that they felt they could rate the Special Services Division's programs and services.

\section{DEMOGRAPHIC ANALYSIS}

The final section of this chapter provides further analysis of the general effectiveness rating questions investigated in the Primary Analysis section presented earlier. This section also provides further analysis of the different grouping variables discussed in the Demographic Overview presented at the beginning of this chapter.

There were two primary purposes for this section. First, the author wanted to investigate whether there were significant differences between the proportions of respondents, according to their present position, falling into different demographic categories as identified in questions two through six on the survey instrument (Appendix 1). These demographic questions requested the respondent identify their years of experience in present district, years of experience in the State of Washington, district size, county location, and the highest degree presently held.

The respondents were organized into position groups as identified by question one on the survey instrument. Original data identifying the thirteen types of positions were collapsed into five position groups. These five position groups included: teacher, principal, assistant principal, board member, and central office personnel. A chi-square test of significance was performed in order to investigate whether any significant difference 
existed between the various positions held and the proportions of respondents identifying themselves to particular categories on those questions mentioned above.

Second, the investigator decided to perform analysis of covariance testing on those general effectiveness rating questions found significant in the analysis of variance testing performed earlier. This included all the general effectiveness questions 15 through 24 .

The analysis of covariance testing was performed by having question one, position, as the independent variable and the mean responses to the general effectiveness questions 15 through 24 as the dependent variable. The demographic questions four (district size), five (county), and six (highest degree held) were each used as covariates. The intent was to investigate that when adjusting for the effects of the these demographic characteristics, was position still found to be a significant factor in the position groups response to the general effectiveness questions regarding ESD 112.

\section{Summary of Demographic Analysis}

Position Groups and Occupational Demographics. 'The findings from the Chisquare testing on position groups and the five demographic questions on the survey instrument produced significant results on all five questions.

The questions concerning years of experience in present district and years of experience in the State of Washington both produced significant results in proportions of the position groups found in the three years of experience groups. With regard to the years of experience in present district, in all groups except the principal group, had a majority of their respondents indicated 10 years, or less experience in their present district. The principal group was evenly distributed over the three different categories. In regards to the years of experience in the State of Washington, the largest percentage of the teacher and board member groups indicated 10 years or less experience in the State of Washington, while the largest percentage of the other three groups indicated more than 10 years of experience in the State. 
Significant differences were found between the proportions of position group respondents found in five different district size groups. The majority of the principal, assistant principal, and district office groups were from those districts with 2001 or more students, while the teacher and board member groups were fairly evenly distributed.

There were significant differences in the proportions of respondents found in the six county location groups. Whereas the largest percentage of the board member group came from Klickitat County the majority of the other four groups came from Clark County.

Lastly, significant differences were found in the proportions of respondents in the four degree level groups. While the largest percentage of the board member group indicated they had a high school diploma, nearly all the principal group and the entire assistant principal group indicated they had a master's degree. Almost one-third of the district office group indicated they had a $\mathrm{PhD} / \mathrm{EdD}$, with less than 10 percent of any other group indicating the same response.

Occupational Demographic Effects on Position Responses. The subsequent analysis of covariance testing revealed that after adjusting for the affects that district size, county location, or degree level may have had on the group mean responses, position was still a significant factor effecting those responses. All analysis of covariance testing produced significant results on the effect position had on the mean responses. These results were produced on all 10 of the general effectiveness questions with exception of one. This question (dealing with "productive service administration") did not produce significant results when the three covariates were used as independent variables in the earlier ANOVA testing.

\section{Years of Experience in District and Position Groups}

Question two on the survey instrument requested the respondent to indicate the years of experience they have had with the district in which they are presently employed. The respondents were given the choice of responding with any amount of years. The 
original data were collapsed into three categories. These three groups included: 0-10 years experience, 11-20 years experience, and 21 or more years experience. The position groups included: teacher, principal, assistant principal, board member, and district office personnel.

The null hypothesis which was tested for this question stated: "There is no difference in the proportions of different position groups found in the three different years of experience in present district groups." A significant difference was found between the proportions of respondents found in the different educational positions and the years of experience in their present district. Therefore, the null hypothesis was rejected on the basis of the following results: $X^{2}(8)=36.860 ; P \leq .01$.

The majority of the teacher (52.2\%), assistant principal (52.9\%), board member (84.4\%), and district office (59.7\%) groups indicated that they had been with their present school district for 10 years or less. The largest portion of the principal group (39.4\%) gave the same 10 year or less response. More than one-fourth of the district office personnel group (24.7\%) responded that they had been with their present district for 21 or more years, while less than $18.0 \%$ of all other groups replied the same way. Only a minimal amount of the board member group (2.2\%) have been with their districts for 21 years or more.

\section{Years of Experience in State and Position Groups}

Question two on the survey instrument requested the respondent to indicate the years of experience they have had in the State of Washington. The respondents were given the choice of responding with any amount of years. The original data were collapsed into three categories. These three groups included: $0-10$ years experience, $11-20$ years experience, and 21 or more years experience. The position groups included: teacher, principal, assistant principal, board member, and district office personnel. 
The null hypothesis which was tested for this question stated: "There is no difference in the proportions of different position groups found in the three different years of experience in the State of Washington categories." A significant difference was found between the proportions of respondents found in the different educational positions and the years of experience in the State of Washington. Therefore, the null hypothesis was rejected on the basis of the following results: $X^{2}(8)=115.540 ; P \leq .01$.

On this question the board member group responded nearly identically to the previous question, with $84.4 \%$ of the group holding this position in State of Washington for 10 years or less, and $2.2 \%$ holding this position for 21 years or more. The principal group indicated that only $11.1 \%$ of their group had been employed the state for 10 years or less, while between $20.6 \%$ and $41.2 \%$ of the other groups responded in this category. Nearly one-half of the principals (44.9\%) and district office (43.5\%) groups indicated they had been employed in the State of Washington for 21 years or more.

\section{District Size and Position Groups}

Question four on the survey instrument asked the respondent to identify the size of district in which they were presently employed. The respondents were given five choices from which to respond. These five choices included: 0-300 students, 301-800 students, 801-1300 students, 1301-2000 students, and 2001 or more students. The position groups included: teacher, principal, assistant principal, board member, and district office personnel.

The null hypothesis which was tested for this question stated: "There is no difference in the proportions of different position groups found in the five different size of district' categories." A significant difference was found between the proportions of respondents found in different educational positions and the size of district in which they were employed, Therefore, the null hypothesis was rejected on the basis of the following results: $X^{2}(16)=140.21 ; P \leq .01$. 
Well over the majority of the principal (62.4\%), assistant principal (66.7\%), central office (61:3\%) respondents indicated that they work in those districts with more than 2000 students. The largest proportion of the teacher $(27.8 \%)$ group indicated that they came from those districts with $800-1300$ students, while one-fourth (24.95\%) of the group indicated the came from those districts with more than 2000 students, and $21.9 \%$ came from those districts with $301-800$ students. One-third of the board members (36.36\%) responded that they came from districts with 300 or less students, with another $31.8 \%$ indicating they came from districts with $800-1300$ students.

\section{County Location and Position Groups}

Question four on the survey instrument asked the respondent to identify the county in which their district was located. The respondents were given six choices from which to respond. These six choices included: Clark, Cowlitz, Klickitat, Pacific, Skamania, and Wahkiakum. The position groups included: teacher, principal, assistant principal, board member, and district office personnel.

The null hypothesis which was tested for this question stated: "There is no difference in the proportions of different position groups found in the six different county location categories. A significant difference was found between the proportions of respondents found in different educational positions and the county location of the school district, Therefore, the null hypothesis was rejected on the basis of the following results: $X^{2}(20)=47.837 ; P \leq .01$

With the exception of the principal (23.9\%) group, less than $20.0 \%$ of any other position group came from a county other than Clark County. The largest portion of the teacher $(50.1 \%)$, principal $(62.4 \%)$, assistant principal $(70.6 \%)$, and district office $(62.9 \%)$ groups indicated that they came from Clark County. The largest portion of the board member (31.1\%) group responded that they came from Klickitat County, while around two percent (2.2\%) came from Wahkiakum County. 
Educational Level and Position Level

Question six on the survey instrument asked the respondent to identify the highest level of education they had received. The respondents were given four choices from which to respond. These four choices included: H.S. Diploma, Bachelor's degree, Master's degree, and $\mathrm{PhD} / \mathrm{EdD}$. The position groups included: teacher, principal, assistant principal, board member, and district office personnel.

The null hypothesis which was tested for this question stated: "There is no difference in the proportions of different position groups found in the four different degree level categories." A significant difference was found between the proportions of respondents found in different educational positions and the level of education attained. Therefore, the null hypothesis was rejected on the basis of the following results: $x^{2}(12)=$ 566.379; $\mathrm{P} \leq .01$.

The majority of the assistant principal (100.0\%), principal (91.7\%), and central office personnel (62.9\%) groups indicated that they held a master's degree, while the board member (46.6\%) group most often indicated that they held a high school diploma. The teacher (54.0\%) group most often indicated that they held a bachelor's degree, while another $45.0 \%$ indicated that they held a master's degree. Almost $29.0 \%$ of the district office group replied that they a doctorate, none of the assistant principal's group and less than $0.8 \%$ of the teacher's group indicated they held a doctorate degree.

\section{Analysis of Covariance on the General Effectiveness Questions}

The intent of this section was investigate whether there were significant differences in the mean responses of different position groups when responding to the general effectiveness questions, and adjusting for the possible effects that district size, county location, and education level may have had on these responses (Table LXVIII). An analysis of covariance statistical test was performed on the general effectiveness rating questions 15 through 24 for the purpose of testing these possible effects. The two 
demographic variables regarding years of experience in present district and years of experience in State of Washington were not included in the ANCOVA testing as the ANOVA testing performed earlier did not produce any significant results on any of the general effectiveness questions.

\section{TABLE LXVIII}

\section{A SUMMARY TABLE OF ANALYSIS OF COVARIANCE ADJUSTING FOR THE EFFECTS DISTRICT SIZE, COUNTY LOCATION, AND HIGHEST DEGREE LEVEL ATTAINED ON THE POSITION CATEGORY MEAN RESPONSES ON THE GENERAL EFFECTIVENESS QUESTIONS FIFTEEN THROUGH TWENTY-FOUR}

\begin{tabular}{|c|c|c|c|c|c|c|}
\hline \multirow[t]{2}{*}{ Question Number } & \multicolumn{2}{|c|}{$\begin{array}{c}\text { Position Effect With } \\
\text { District Size As } \\
\text { Covariate }\end{array}$} & \multicolumn{2}{|c|}{$\begin{array}{l}\text { Position Effect With } \\
\text { County Location As } \\
\text { Covariate }\end{array}$} & \multicolumn{2}{|c|}{$\begin{array}{l}\text { Position Effect With } \\
\text { Highest Degree Held as } \\
\text { Covariate }\end{array}$} \\
\hline & F-Ratio & $\mathbf{P}$ & F-Ratio & $\mathbf{P}$ & F-Ratio & $\mathbf{P}$ \\
\hline 15. Relevant services & 9.139 & .01 & 9.380 & .01 & 9.649 & .01 \\
\hline $\begin{array}{l}\text { 16. Useful Knowiedge } \\
\text { and Information }\end{array}$ & NA & NA & NA & NA & 12.839 & .01 \\
\hline 17. Timely Services & 9.787 & .01 & 11.182 & .01 & 11.155 & .01 \\
\hline $\begin{array}{l}\text { 18. Meeting Needs of } \\
\text { Patrons }\end{array}$ & 5.964 & .01 & 5.348 & .01 & 6.101 & .01 \\
\hline $\begin{array}{l}\text { 19. Adjusting to } \\
\text { Individual Needs }\end{array}$ & NA & NA & 4.382 & .01 & 5.143 & .01 \\
\hline 20. Interpersonal Skills & NA & NA & $\mathbf{7 . 4 0 0}$ & .01 & NA & NA \\
\hline $\begin{array}{l}\text { 21. Promoting Teach- } \\
\text { ing process }\end{array}$ & 4.409 & .01 & 5.237 & .01 & NA & NA \\
\hline $\begin{array}{l}\text { 22. Productive Service } \\
\text { Administration }\end{array}$ & NA & NA & NA & NA & NA & NA \\
\hline 23. Useful Evaluations & NA & NA & 4.469 & .01 & 4.322 & .01 \\
\hline $\begin{array}{l}\text { 24. ESD } 112 \text { Total } \\
\text { Program }\end{array}$ & 10.935 & .01 & 11.243 & .01 & 12.221 & .01 \\
\hline
\end{tabular}

This placed question one of the survey instrument, present position, as the independent variable and questions 15 through 24 , general effectiveness rating questions, as the dependent variables. An analysis of covariance statistical test was performed on 
each of the general effectiveness questions, using district size, county location, and educational level as covariates.

After adjusting for the effects that district size, county location, and degree level may have on the position groups mean responses on the general effectiveness questions, position was found to still be a significant factor in those responses. Those questions displaying a "NA" were not tested with an analysis of covariance since significant results were not produced when testing with the analysis of variance. The results show that district size, county location, and degree level have no significant effect on the way the respondent would have answered the general effectiveness question (Table LXVIII). 


\section{CHAPTER V}

\section{SUMMARY, CONCLUSIONS, AND RECOMMENDATIONS}

The purpose of this research project was to investigate the perceptions of effectiveness conceming an educational service district in the State of Washington. The investigation was designed to determine what perceptions were held by various groups of public school educators in regards to Educational Service District 112 as an organization, and in particular in regards to the Instructional and Curriculum and Special Services programs it provides.

The population studied was public school educators residing in the $\mathbf{3 0}$ different school districts in the six counties located in Educational Service District 112's service area (see Figure 1.). Teachers, school board members, principals, assistant principals, and district office personnel were included in this study. Data were gathered by means of a survey instrument, and a total of 769 respondents returned the survey from the total of 1507 distributed, resulting in a response rate of $51 \%$ (see Table II and Table III).

The investigative device used for this study was a 62-item survey instrument (Appendix 1). The instrument contained 14 demographic and general information questions, which were followed by 46 effectiveness rating questions. The 46 effectiveness rating questions inquired into the respondents perceptions of effectiveness regarding ESD 112 as an organization as well as their perceptions of individual programs and services.

The following narrative will present a summary of the findings culminating this research investigation. First, the primary research questions will be stated. Second, a summary of the findings will be presented. Third, in regards to the research findings, the conclusions and implications for ESD 112 will be discussed. Fourth, the limitations of this 
study will be recognized and detailed. Lastly, recommendations for possible future research will be presented.

\section{Research Questions}

The intent of this research investigation was to answer the following general research questions:

1. "Is Educational Service District 112 perceived as an effective educational component of the Southwest Washington public education system?"

2. "Are the programs and services provided by Educational Service District 112 perceived as effective by the educational community that the regional office is designed to serve?"

3. "Are Educational Service District 112's services and programs perceived as effective by different characteristic, or demographic, groups?"

4. "What characteristics, both personal and professional, might influence differences in perceived program effectiveness?"

5. "What evaluative approach or research methodology can be used to productively identify these perceptions of effectiveness?"

The first four general research questions listed above functioned as the basis for the subsequent questions used during the inquiry and analysis of data in this study. The fifth question pertaining to a possible research methodology, was posed for the purpose of finding an evaluative procedure which would assist in the development and implementation of an evaluation project in a setting such as this study. Discussion relating to the evaluative approach used in this study was not included in Chapter IV, as it was felt to be more appropriate to be included in the narrative later in this chapter. 


\section{SUMMARY OF RESEARCH FINDINGS}

The major portion of the survey instrument consisted of 46 effectiveness rating questions. This portion of the survey instrument was divided into three sub-sections of questions which included both general and specific effectiveness rating questions. The first sub-section of questions (general effectiveness questions) will be summarized first. An analysis of the two other sub-sections of questions (Instructional and Curriculum and Special Services effectiveness questions) will follow.

Probability levels for all statistical testing, except the multiple comparison tests, were stated in the actual numbers as gerierated by the computer statistics software package. The results of all multiple comparison testing performed on the mean responses of different characteristics groupings are reported at the $\leq .05$ level.

\section{General Effectiveness Questions}

The general effectiveness rating questions 15 through 24 were concerned with perceptions of effectiveness the respondents held toward Educational Service District 112 as a total organization (Appendix 1). The analysis of these 10 questions provide the following findings:

-According to the mean response the total respondent group gave ESD 112 an "effective" rating on all 10 of the general effectiveness questions. Between $60 \%$ and $80 \%$ of the total group responded with one of the three effective rating responses on every general effectiveness question except the question pertaining to useful evaluation practices (question 24.). On question 24, a little over $48 \%$ of the respondents answered with one of the three effectiveness rating responses on this question. Less than $18 \%$ of the total group responded with one of the three "ineffective" rating responses on any of these 10 rating questions, with the remainder of the group not responding. 
- When asked to rate the effectiveness of the total Education Service District 112 program, the entire group of respondents rated the ESD as "effective." Seventy-four percent of the respondent group responded with one of the three "effective" rating responses on this question, while a little less than $11 \%$ of the total group responded with one of the three "ineffective" rating responses.

-According to position groups, the teacher, principal, and assistant principal groups each responded with an "effective" rating on all 10 general effectiveness questions. The board member and district office groups each rated the ESD as "very effective" on two of the general effectiveness questions, while responding with an "effective" rating on all other questions. Both the board member and district office groups felt ESD 112 was "very effective" in providing useful knowledge and information to their district (question 16.). The district office group felt the ESD was "very effective" in providing timely services to their districts (question 17.), while the board member group felt the ESD was "very effective" in meeting the needs of patrons (question 18.).

-The two different respondent groupings pertaining to years of educational experience in present school district and years of educational experience in the State of Washington each rated ESD 112 as "effective" on all 10 of the general effectiveness rating questions.

-The five different size of district groups all rated ESD 112 as "effective" on all 10 general effectiveness questions.

-The Clark, Cowliz, Klickitat, Skamania, and Wahkiakum county groups responded with an "effective" rating on all 10 of the general effectiveness questions. The Pacific county group rated ESD 112 as "ineffective" on three of these same questions and "effective" on the remaining seven questions. The Pacific county group indicated ESD 112 was "ineffective" in: adjusting to individual needs (question 19.), promoting teaching 
processes (question 21.), and providing useful evaluations of students and staff (question 23.).

-According to the degree level groups, the high school diploma group rated the ESD as "very effective" on seven of the $\mathbf{1 0}$ general effectiveness rating questions (questions 15. 16., 17., 18., 19., 20., 24.), while the bachelor's, master's, and PhD/EdD group responded with an "effective" rating on all 10 questions.

\section{Specific Program and Service Effectiveness Rating Questions}

Questions 26 through 43 (Instructional and Curriculum services) and questions 45 through 62 (Special Services programs) were included on the survey instrument for the purpose of allowing the respondent to rate the effectiveness of specific programs and services. The analysis of these 36 questions provide the following findings:

Instructional and Curriculum Services. Sixty-four percent to $87 \%$ of the respondents either did not respond or were not able to adequately rate each of the 18 Instructional and Curriculum programs and services. Eleven percent to $30 \%$ of the total group of respondents responded with one of the three "effective" ratings on these 18 questions, while between $1 \%$ and $7 \%$ of the total group responded with one of the three "ineffective" ratings.

-The total group of respondents gave an "effective" rating response on all of the Instructional and Curriculum services effectiveness rating questions with the exception of one "very effective" rating response. The majority of those responding to these rating questions selected one of the three effective responses provided on all 18 questions. The "very effective" rating which was given by the total group pertained to the perceived effectiveness of the Instructional Media Cooperative Staff (question 41.).

-The total group of respondents rated the total Instructional and Curriculum program as "effective." Sixty-six percent of this same group abstained from responding to this question (question 26.), due to lack of personal knowledge or information to 
adequately rate the total Instruction and Curriculum program. Nearly $30 \%$ of the respondent group indicated one of the three "effective" responses on this question, while $5 \%$ of the total group indicated one of the three "ineffective" responses.

Special Services, Sixty-six percent to $89 \%$ of the respondents either did not respond, or were not able to adequately rate each of the 18 Special Services Division questions. Between $9.0 \%$ and $30.0 \%$ of the respondents indicated one of the three "effective" ratings on these questions, while between $1.0 \%$ and $7.0 \%$ responded with one of the three "ineffective" responses.

-The total group of respondents gave an "effective" rating response on all the Special Services Division's effectiveness rating questions, with the majority of those responding selecting one of the three effective answers. Nine to $30 \%$ of the total group responded with one of the three "effective" rating responses on each of the 18 Special Services rating questions, while $1 \%$ to $7 \%$ of the total group responded with one of the three "ineffective" ratings.

-The total group of respondents rated the total Special Services program as "effective." Sixty-six percent of this same group abstained from responding to this question (question 45.), due to the lack of knowledge or information to adequately rate the total Special Services program. Thirty percent of the total group of respondents responded with one of the three "effective" rating responses on this question, while $3 \%$ of the total group indicated one of the three "ineffective" ratings.

\section{Gate Questions}

Questions 25 and 44 were included as "gate" questions on the survey instrument for the purpose of allowing the respondent to respond to whether or not they had enough knowledge of the two different service divisions to answer subsequent groups of questions. The analysis of these two questions provide the following findings: 
-Sixty-three percent of the respondents indicated that they felt they did not possess enough knowledge conceming the ESD 112 Instructional and Curriculum services to adequately rate them. On the other hand, $35 \%$ of the respondents indicated they felt they possessed enough knowledge to rate the Instructional and Curriculum services.

-Sixty-three percent of the respondents indicated that they felt they did not possess enough knowledge regarding the ESD 112 Special Services programs to adequately rate them. Simultaneously, 32\% of the respondents indicated they felt they possessed adequate knowledge to properly rate the Special Services programs.

\section{Primary Analysis}

A primary analysis of the data was performed in order to investigate whether statistical differences existed among different grouping categories identified in this study. Analysis of variance (ANOVA) testing was performed to determine whether significant differences existed between different characteristic group means on the general effectiveness rating questions. For those questions found to produce significant results, the Tukey-Kramer paired comparison test of significance was used to identify which groups differed significantly and the direction of difference. The analysis of the data produced the following results:

-Analysis of variance testing indicated that 26 of the 46 effectiveness rating questions were found to suggest significant differences among two or more of the "position" group mean responses. Significant differences were found within "position" groups' mean responses on all 10 of the general effectiveness questions. Significant differences were also found within mean responses of the "position" groups on six of the Instructional and Curriculum rating questions and 10 of the Special Services rating questions.

-Paired comparison testing with respect to position groups revealed that the teacher group always had a significantly higher mean response than any group in which they were 
found to significantly differ. This higher mean response indicated the teacher group felt ESD 112 was "less effective" than the group in which they differed. The principal group was found to have a significantly higher mean response than the district office group on two Special Services questions (question 45. and 49.), and the board member group was found to have a significantly higher mean response than the district office group on one Special Services question (question 62.). Both the principal and board member groups indicated a "less effective" rating than the district office group on those questions with which they significantly differed. None of the other position groups were found to differ significantly from any other position group except the teacher group.

-Analysis of variance testing regarding the years of educational experience in present district and years of educational experience in the State of Washington groups' mean responses did not produce significant results on any of the $\mathbf{1 0}$ general effectiveness questions.

-According to district size, five of the 10 general effectiveness rating questions were found to indicate significant differences among two or more of the groups' mean responses (questions 15., 17., 18., 21., 24.).

-Paired comparison testing with respect to district size groups revealed that the 0300 size school district was always found to have a significantly lower mean response than any group from which they differed, indicating a "more effective" rating response than the differing group. The 301-800 size school district was always found to have a significantly higher mean response than any group from which they differed, indicating a "less effective" rating response than the differing group. Also, the 801-1300 size school district was found to have a significantly higher mean response than any differing school district, indicating a "less effective" rating response. The 0-300 size school district group always had a significantly lower mean response when differing from the 301-800 size school district group, indicating a "more effective" rating response. 
-Analysis of variance testing on the six different county location groups' mean responses indicated a significant difference among two or more of the groups on eight of the 10 general effectiveness questions (questions 15., 17., 18., 19., 20., 21., 23., 24.). -Paired comparison testing revealed that the Pacific County group always indicated a higher mean response than the groups with which they significantly differed, indicating a "less effective" rating. The Cowlitz County group was found to have a significantly lower mean response than the Pacific County group, but a significantly higher mean response than any other group with which they differed. This meant the Cowlitz County group perceived the ESD as "more effective" than the Pacific County group, but "less effective" than all other county groups in which they differed. The Clark County, Klickitat County, Skamania County, and Wahkiakum County groups always had significantly lower mean responses than any other group in which they were found to differ, indicating a more "effective" response. These four county groups (Clark County, Klickitat County, Skamania County, Wahkiakum County) were never found to differ significantly with each other in their mean responses.

-Analysis of variance testing on the four degree level groups' mean responses indicated a significant difference among two or more of the groups on seven of the 10 general effectiveness questions (questions 15., 16., 17., 18., 19., 23., 24.).

-Paired comparison testing revealed that the high school diploma group had a significantly lower mean response than the bachelor's degree and master's degree groups on all seven of those questions indicating significant differences in mean responses. This indicates than the high school diploma group gave a "more effective" response than these two groups. The high school diploma group also had significantly lower mean responses than did the $\mathrm{PhD}$ group on three of the general effectiveness questions (questions 16., 18., 19.). The bachelor's and master's degree groups did not significantly differ on any of these seven questions. When differing from the $\mathrm{PhD} / \mathrm{EdD}$ group, both the bachelor's degree and 
master's degree groups were found to have significantly higher mean responses, indicating a "less effective" rating.

\section{Secondary Analysis}

A secondary analysis of the data was performed to examine whether significant differences existed in the proportions of position groups falling into different response categories on the eight general information questions. Chi-square tests of significance produce the following results:

-A significant difference was found between the various position groups and their understanding of the functions and purposes of ESD 112.

-A significant difference was found between the various position groups and their involvement with ESD 112 programs and services.

-A significant difference was found between the various position groups and the types of ESD 112 programs and services felt to be used by the respondent's district.

-A significant difference was found between the various position groups and the respondent's feelings as to the degree in which ESD 112 affected them in their present position.

-A significant difference was found between the various position groups and the different constraints encountered when accessing ESD 112 services.

-A significant difference was found between the various position groups and whether the respondent felt ESD 112 provided timely services.

-No significant differences were found among the various position groups and their personal knowledge as to whether their district used ESD 112 services, and to whether the respondents felt their district should contract services from ESD 112. 
Demographic Analysis

For further analysis of the initial general effectiveness rating questions, analysis of covariance tests (ANCOVAs) were performed in order to investigate the effects of different demographic characteristics on the respondent's responses. Also, Chi-square tests of significance were used to investigate whether there were significant differences between the proportions of respondents, according to position, falling into different demographic categories. The analysis of the data produce the following results:

-Analysis of covariance testing revealed that after adjusting for the effects that district size, county location, and degree level may have on the five position groups' mean responses on the general effectiveness questions, that position was still found to be a significant factor effecting those responses.

-A significant difference was found among the proportion of position groups found in the three different years of experience in district and years of experience in the State of Washington groups.

-A significant difference was found between the proportions of position group respondents found in the five different district size categories.

-A significant difference was found between the proportions of position group respondents found in the six different county location categories.

-A significant difference was found between the proportions of position group respondents found in the four different degree level categories.

\section{Demographic Questions}

The first group of questions found in the survey instrument, questions one through six, were identified as occupational demographic questions. These questions referred to years of experience in district and state, district size, county location of district, and degree level of the respondent. Analysis of these questions produced the following findings: 
-The total group of respondents averaged 11 years of experience in their present school district. Fifty-three percent of the respondents indicated they have been with their school district less than 10 years, while $47 \%$ indicated they have been with their school district for more than 10 years.

-The total group of respondents averaged a little more than 14 years of experience in the State of Washington. Sixty-three percent of the respondents indicated they had more than 10 years of educational experience in the State of Washington, with more than $24 \%$ of the respondents indicating more than 20 years experience in the state.

-Thirty-three percent of the total respondent group presently work in school districts which have more than 2000 students, $10 \%$ work in districts with 1301 to 2000 students, $23 \%$ work in districts of $801-1300$ students and $16 \%$ work in districts of $301-800$ students. The remaining 13\% work in districts with fewer than 301 students.

-Almost $70 \%$ of the respondent group is employed in those school districts found in either Clark County or Cowlitz County. The remaining $30 \%$ of respondents come from school districts found in Klickitat County, Pacific County, Skamania County, or Wahkiakum County.

-Fifty-three percent of the total group of respondents hold a master's degree of some type, while $38 \%$ of the remaining respondents hold a bachelor's degree. Four percent of the respondents hold $\mathrm{a} \mathrm{PhD}$ and $3 \%$ of the respondents possess a high school diploma.

\section{General Information Questions}

The second section of the first group of questions found in the survey instrument, questions seven through 14 , were identified as general information questions. These questions related to perceptions of program value, individual involvement, and organizational purpose. The subsequent findings were derived from these eight questions: 
-Eighty-percent of the respondents indicated they had at the very least a "moderate understanding" of the functions and purposes of ESD 112, while 15\% of the group indicated "minimal" or "no understanding" of ESD 112 functions and purposes. Four percent of the respondents indicated "complete" understanding of the ESD's purpose.

-Seventy-two percent of the respondents indicated they had been involved with at least one to five of ESD 112 programs and services, with another $13 \%$ of the respondents indicating they have been involved with six to 10 programs and services. Nine percent of the respondents indicated they had not been involved with any of the ESD 112 programs and services.

-Ninety-six percent of the respondent group indicated that they knew their district used some type of program or service provided by ESD 112, while $4 \%$ indicated no knowledge of their district using ESD 112 services.

-Sixty-five percent of the respondents responded that they felt their district uses some combination of student, teacher, and administrative oriented programs provided by ESD 112, instead of some single orientation of programs or services.

-Forty-six percent of the respondents indicated that they felt ESD 112 "somewhat" affected their job, while $36 \%$ of the respondent group felt the ESD affected their job "very little" or "not at all."

-Twenty-seven percent of respondents indicated that they did not encounter any constraints when accessing ESD 112 services, while 25\% of the group indicated distance was a major constraint and $15 \%$ indicated the lack of information was a major constraint. Nineteen percent of the respondents indicated a combination of reasons as constraints.

-Seventy-two percent of the respondents indicated that they felt ESD 112 provided timely services in distributing materials, providing communications, and executing services and programs, while nearly $18 \%$ of the respondents disagreed with this statement. 
-Seventy-nine percent of the respondent group indicated that they felt their district should contract with ESD 112 for certain services and programs, while $11 \%$ of the respondents disagreed with this statement.

\section{Evaluative Approach and Research Methodology}

During the initial literature review for this investigation, it became evident to the author that previous literature pertinent to the investigative processes related to this line of inquiry was extremely limited. In order to promote the effectiveness and efficiency of both this study and possible future research, the author felt that it was prudent to included a ancillary study question in this investigation. This question asked; "What evaluative approach or research methodology can be used to productively identify these perceptions of effectiveness?" The intent of this question was to provide focus on identifying a possible research strategy which aligned to the needs of this study. Due to the structure of Educational Service District 112, and the manner in which programs and services are delivered, an evaluation process with a management orientation was felt to best suit this study.

The "CIPP Evaluation Model" (context, input, process, and product) was identified and used as the primary evaluative model for the development, implementation, and summation of this study (Guba and Lincoln, 1981; Worthen and Sanders, 1987). This model is based on the following six-step evaluation strategy: a) Focusing the Evaluation, b) Collection of Information, c) Organization of Information, d) Analysis of Information, e) Reporting of Information, and f) Administration of Evaluation. With the exception of the last step, "administration of evaluation," the author attempted to align the research process closely to these procedural stages. In viewing the researcher as an "objective" observer, or a "third-party" in this investigation, the last step of this strategy was seen more as a function of ESD 112 in its execution. It is the intent of the author that the narrative in this 
particular chapter will be productively used by ESD 112 when administering evaluation projects in the future.

The CIPP Evaluation Model proved to be useful for the investigative processes used in this research study. The sequential steps allowed the author to develop the investigation process in a pragmatic manner, working as both a cognitive map and a practical framework. First, by developing a focus on the total evaluation process-the boundaries, the limitations, and the direction of this investigation were recognized. This model also allowed the measurement criteria and research variables to be identified as a premise from which the ensuing methodology was formulated. Second, by addressing the information (data) collection processes, the author was able to develop a research instrument with the collaboration of the ESD 112 management and staff. This process proved to be extremely productive in developing an instrument with relevant content. This step also allowed the author to develop a research methodology for the efficient distribution and collection of information, which included typical logistical concerns regarding a survey research strategy. Third, through assessing the organization of pertinent information the author was able to conceptualize and develop a format which productively structured the survey instrument to draw the necessary information from the respondents. The next step focused on identifying those analytical procedures which were to be used to analyze the data. This allowed the author to develop a strategy for specifying those procedures which would answer the major research questions in terms of data analysis. The last stage of the CIPP Evaluation Model used in this study, which is concerned with reporting the findings of the study, provided a framework for the author to develop meaningful reporting strategies directed at different audiences affected by this study. 


\section{CONCLUSIONS AND IMPLICATIONS}

The following narrative will discuss several conclusions derived from the research findings and possible implications these findings may have for ESD 112 and the people and districts it serves.

-The results indicate that Educational Service District 112 as a total organization is viewed as an effective organization by the public school educators it serves. The results also indicate that ESD 112 is seen as an efficient organization in providing timely services and programs to patron districts and educators. If nothing more than a morale plaudit, ESD 112 enjoys the support of the people and organizations it is designed to serve. Knowing that the organization viewed as a functional component of the public school system in Southwest Washington, ESD 112 would have two viable future alternatives. One alternative would be continuing with the same organizational practices as used up to this point in time and maintain the organization's current status. The other alternative would be to isolate their positive organizational practices and use these to further solidify their place in the educational bureaucracy in Southwest Washington.

-A major finding of the study was the reported lack of information or knowledge on the part of the respondent about specific ESD programs and services. Nearly two-thirds of the respondents indicated that they did not feel that they had enough knowledge of the individual Instructional and Curriculum or Special Services programs and services to rate their effectiveness. As stated earlier in this study the mission of the ESD is: To ensure that every child receives equal and appropriate educational programs regardless of his/her residency in large or small districts, rural or urban communities, and socio-economic conditions. Also, a major thrust of the ESD is to link children, teachers, and schools with services through the use of information and coordination activities.

It may be pertinent for ESD 112 to address this knowledge deficit in order to determine whether more people should know about these services. This would help the 
ESD to examine whether it, as a state educational service organization, is fulfilling a possible bureaucratic obligation to inform the educators of Southwest Washington about the array of services available. This would also help to determine what impact increased knowledge and patron usage might have on the ESD's ability to effectively serve present users.

Differences in the numbers of respondents responding to different questions would appear to be associated with two different explanations: (a) Those items which asked general instead of specific questions of the respondents tended to have more responses since the respondent wasn't asked to draw from specific knowledge. (b) Those items which asked questions of more visible programs tended to have more responses, such as the questions regarding the Instructional Media Cooperative (films and videos)

-The findings indicated that regardless of the grouping criteria (position, years of experience, county location, district size, and degree level), all respondent groupings resulted in an overall effective rating. In this instance though, Pacific County tended to give lower overall effectiveness rating of ESD 112 than the other five county groups. It was the only demographic group to indicate any "ineffective" rating responses. It was also found that the Pacific County group always had significantly higher mean responses on the 10 general effectiveness questions than any other county group in which they differed, again indicating a "less effective" rating. As Pacific County is one of the furthest outlying counties in terms of distance from the ESD 112 offices, it may prove beneficial to aggressively investigate whether county location discrepancies actually exist and whether remedies are feasible if problems are found. Pacific County encompasses school district sizes between 301 and 1300 students, which supports earlier findings of these size school districts indicating significantly higher mean responses ("less effective") than all other sized school districts. 
-Continuing with the previous discussion related to grouping criteria, it was found that the board member and district office groups consistently rated ESD 112's services and programs as "more effective" than any of the other position groups.

The fact that the board member group had this perception of ESD 112 could be attributed to: (a) Seventy-eight percent of the board members coming from districts with 1200 or fewer students, which are districts typically more dependent upon specific services and thus more knowledgeable of ESD 112. (b) Information distributed to the board members usually coming directly from district superintendents and district office personnel, who as a position group rate the ESD higher than any other position group.

The fact that the district office group rated the ESD higher effectiveness rating than any other group could attributed to: (a) Being in an administrative position, this group may not be involved in the day to day routine or interpersonal interaction that the teacher or principal groups face. (b) Subsequently, the district office group may only receive the positive aspects of programs and services from direct staff. (c) From the perspective of the district office group, a program may be perceived as effective if it is monetarily efficient.

The less effective teacher position group response, as opposed to the district office group, could be attributed to the day to day interaction of ESD programs and staff. This interaction could bring to light those negative aspects of a program or service that would not surface without personal involvement.

Lastly, the high rating responses of the high school diploma group can be directly linked to the same factors identified as possible reasons for the board member group responses. All high school diploma group members are found within the board member position group.

Lastly, the high rating responses of the high school diploma group can be directly linked to the same factors identified as possible reasons for the board member group 
responses. All high school diploma group members are found within the board member position group.

-Related to the previous discussion, all but a very minor portion of the respondents feel their district should contract services from ESD 112. If the patrons retain these feelings, even though the vast majority feel they do not have adequate knowledge of the individual services and programs, ESD 112 should view this situation in a positive perspective in regards to potential service expansion and growth. If it were determined that the majority of patrons simply lacked knowledge of present services, and these were the services they felt their district should contract, then program expansion would be a possibility. If it was determined patrons desired new services, then program growth in other desired areas would be a possibility.

-Present position appears to have more of an influence on the respondent's effectiveness rating of Educational Service District 112 than does their years of experience in present district or the State of Washington, district size, county location, or level of education.

In reviewing the findings pertaining to years of experience in present district and years of experience in the State of Washington, the findings show that the majority of all position groups (except the board member) have 11 years or more experience in the State of Washington, with the largest portion of the principal and district office group having more than 21 years experience. On the other hand, the majority of each school district employee (except the principal group) have been with their district for less than 10 years. This could be viewed from the perspective of a mobile workforce and would lend credence to the notion that position may be the most effective way to address possible problems of perception. This would be based on the notion that individual feelings of effectiveness would not necessarily be connected to just district characteristic(s), but also personal characteristics. 
Statistical analysis indicated that when adjusting for the possible effects that district size, county location, or level of education may have had on various position groups' mean responses on the general effectiveness questions, that position remained a significant factor regarding those responses.

This would imply that the ESD should possibly address discrepancies in perceived program and service effectiveness from the perspective of position. By determining what combination of factors may lead to perception differences, the ESD may find different ways to serve the various individual educator groups more effectively.

- Those groups considered to be administrative in origin tend to rate Educational Service District 112 as more effective than instructional groups. Both the understanding of the functions and purposes of the ESD and the amount or variety of program involvement tend to be greater for administrative position groups in comparison to instructional/teacher groups.

Statistically significant differences were found among position groups on several factors relating to the ESD. The board member and district office group most often indicated "good or complete understanding" of the ESD and more "involvement" in programs and services. The teacher and assistant principal groups most often indicated "moderate understanding of the ESD and "minimal involvement" in programs and services. A large percentage of the central office group indicated that the ESD affected them "very much," while a large percentage of the teacher and assistant principal groups indicated a "very little" response. Whereas the administrative position groups indicated they did not encounter any constraints when accessing different ESD services, the teacher group indicated that "distance" was a major factor constraining their access to the ESD. A majority of the central office group responded "yes" to those questions asking whether they had enough knowledge to rate individual programs and services. On the other hand, the largest portion of the teacher and assistant principal groups responded with "no." 
There may be a need to determine "if" and "why" instructional personnel and administrative personnel are treated differently by ESD 112. The fact that the administrator is dealt with differently due to the authority or power of the position in determining program or service use may be a reason for these differences. As the instructional staff members continue to gain more power in deciding program use, their perceptions may change due to access to pertinent information. Identifying and rectifying adverse discrepancies would only help ESD 112 become more effective as a service organization.

-Over two-thirds of the respondents indicated that there was some type of constraint encountered when accessing the service provided by Educational Service District 112. Distance was the major access constraint identified by the respondent group. This would support the notion that the ESD should continue to investigate possibilities for making services more readily available to its patrons, especially to those districts a considerable distance from the ESD.

As discussed earlier, Pacific County is one of those counties farthest from ESD 112 's offices, and is the county group that consistently rated the ESD as "less effective" than other county groups on the general effectiveness questions. On the other hand, Skamania and Wahkiakum Counties could also be described as outlying districts, and these county groups gave the best overall effectiveness ratings of all six county groups. Researching why these two county groups rate the ESD higher may lead to some possible strategies on how to deal with the lower ratings indicated by the Pacific County group.

-School districts with more than 2000 students and school districts with 0-300 students had a nearly equal overall effectiveness response rate, with the more than 2000 student group having a slightly lower response mean (indicating a "more effective" rating response).

The fact that the more than 2000 sized school district group had such a high overall effectiveness rating could be attributed to the distribution of the district office group-which 
had the highest effectiveness position group rating response-and in which $100 \%$ of this group is found in the more than 2000 sized school district group. The 0-300 sized school district effectiveness rating could be attributed to the individual districts' dependence on so many of ESD 112's programs and services. Especially since this size of school district would have to rely on the ESD for so many necessary services that are minimized due to the number of staff members.

If the larger sized school districts do not depend on the services of the ESD as heavily as do the smaller sized school district, it would be beneficial to ESD 112 to investigate and compare what similar positive aspects the two groups have in common in regards to the ESD, if any. The ESD may have to look at program involvement for smaller districts and inservice involvement of the larger districts as the answer.

-Although discussion immediately following this paragraph will identify related findings from a previous study (Ruel, 1986), it should be noted here that the teacher position group included ESD 112 personnel (3\% of the teacher group and $2 \%$ of the total group). It is not known how much these affected the teacher group response, since 30\% or less of the teacher group responded on the last 36 rating questions. Ruel (1986) found that ESD personnel consistently rated ESD services as "always effective" or "frequently effective."

\section{Related Findings}

As mentioned in the review of the literature (Chapter III), a single investigation similar to this one was performed in a statewide study which included all ESDs in the State of Washington (Ruel, 1986). Although Ruel's study included a more diverse sample of respondents and investigated a broader range of services, the following findings from both studies appear to be similar:

-That an "effective" rating was most often given when respondents were asked to rate the effectiveness of the total ESD organization. 
-That a majority of the respondents found in both studies did not have enough knowledge about individual programs and services to properly rate them.

-That the majority of ESD programs and services are perceived as "effective" by the organization's patrons. Although Ruel's (1986) study was more comprehensive in the scope of services being investigated, he still found nearly $80 \%$ of these services were given an "effective" rating by respondents, with less than $9 \%$ of the services receiving an "ineffective" rating. This study found that all programs and services investigated were given an "effective" rating.

-That the district office or central office administrator groups (which includes assistant superintendents, directors, superintendents, etc.) were found to rate ESD programs and services as "more effective" than teachers and building administrators.

-That smaller sized school districts tended to indicate a "more effective" ratings of programs and services offered than larger school districts. It should be recognized that the smaller sized school districts are more dependent on ESD services than the larger school districts which can maintain their own programs. A difference in findings from this study shows two groups of smaller sized schools (301-800 to 801-1300 students) were found to have significantly higher response means than lager schools (more than 2000 students), indicating a "less effective" rating.

\section{Survey Instrument}

The survey instrument appears to have been effective in ascertaining the perceptions of effectiveness that public school educators held toward ESD 112. The author would recommend the use of the instrument in similar research situations or by ESD personnel. Although the content will definitely have to vary according to the specific offerings of the individual ESD, the survey instrument used in this study proved to be an effective and efficient research tool. 
In regard to future research, the instrument lends itself to appropriate modification. The variety and volume of information sought by the instrument can be changed on the basis of the programs and services offered by the target ESD and the purpose of the evaluation.

There are several points worth discussing that pertain to the future use of this instrument. First, the structure of the instrument provided a good format for collecting both a variety and volume of information from the respondents. Second, the content of the instrument allowed the author to draw direct conclusions about specific programs and individual services. Third, the survey instrument provided an efficient format for the transfer of information from the survey into the data set used for analysis. Fourth, the same survey instrument was used for all respondents and eliminated any data treatment problems associated with multiple survey strategies.

The author would recommend that any future research attempts which utilize this survey instrument direct close attention to the demographic and general information questions. Questions which may have strengthened the survey instrument used in this study are: a) Have you had direct contact with the ESD in you professional career? b) Do you feel you are an advocate of the ESD? and c) Do you feel the ESD is a necessary component of the public educational system?

\section{LIMITATIONS}

Factors which have been identified as possible limitations of this study are recognized and discussed in the following narrative.

1. The findings reported in this study are specific only to the respondents and educational environment presently found in the Educational Service District 112 service area. Although generalizations may be applicable to other ESD organizations in the State of 
Washington and the nation, complete confidence in generalizing these findings for anything more than identifying possible trends is unwarranted due to the limited focus of study.

2. The perceptual content and context of the individual respondent is limited to the knowledge base held by that individual. This is in regards to the different ESD 112 programs and services with which the respondent has been in contact.

3. The findings of this study relate to only the programs and services in the areas of curriculum, instruction, and special services which are offered by ESD 112. General questions regarding the total ESD 112 organization should be viewed with the understanding that there are many programs individual respondents will never come in contact with because of their position of employment.

4. The results generated from the sample used in this study may be different from what might be found if the whole population were used, due to errors in sampling. Thus, the findings from this study may not necessarily reflect the perceptions of all public school educators in the ESD 112 service area.

5. The survey was limited in scope and size to that which was felt to adequately assess different educators' perceptions of effectiveness. An exhaustive instrument would have been unmanageable to the respondents, and would likely would have decreased the response rate.

6. This study is subject to response errors given by individual respondents, and also to errors of estimation, tabulation, and the subsequent interpretation of findings that have been reported.

7. Data were collected by a "self-reporting" format and are subject to errors and personal biases of the subjects responding to the survey instrument. The self-administered questionnaire was based on a closed ended format for the purpose of compiling the results more efficiently, but relied on the respondents to state their perceptions accurately. In 
order to maintain complete confidentiality, this study did not attempt to ascertain the reasons for respondents' answers to questions.

8. Although 51\% of the population surveyed returned their surveys, the findings of this study may or may not be indicative of the perceptions held by the other $49 \%$ of the population not responding.

\section{FUTURE RESEARCH}

Drawing from the summary and conclusions of the findings previously discussed in this chapter, several suggestions for future research in this topic area are suggested.

1. What are the positive and negative organizational practices of an Educational Service District? What makes a good, effective ESD? What makes a poor, ineffective ESD?

2. What current organizational practices (e.g. structure, communication, interpersonal) are impacting the perceptions of ESD patrons? Do any of these practices have a positive effect on ESD patrons' perceptions of program effectiveness? Do any of these practices have a negative effect on ESD patrons' perceptions of program effectiveness?

3. How does an educational service district interact with different types of public school educators? What interpersonal processes happen at what levels of the Educational Service District and the individual school district?

4. What means of communication best disseminates information from the educational service district to the districts to which it provides services? With increased technology, is there a more effective and efficient way to communicate and/or provide services to districts, and in particular outlying districts? Where are ESD to district communication breakdowns likely to occur? Why, and what strategies might avert these breakdowns? 
5. What would be the feasibility of opening "satellite" educational service district offices which would provide more equitable service levels to outlying districts? Is there equality in the services provided by an educational services district to individual school districts?

6. What are the possible service limitations (how much, what kind) of an educational service district? Should the educational service district continue to grow as mid-level bureaucracy? Should the State be distributing funds currently going to ESDs to individual school districts? Do public school educators feel funds used to operate the educational service district could be more effectively and efficiently used at the district level?

7. Should the educational service district provide regular classroom instruction to a public school district? Specifically, how effective are the direct instructional programs offered by the educational service district?

8. What other types of evaluation would be effective in evaluating an Educational Service District? A qualitative approach? A different quantitative approach? Or some type of meta-evaluation strategy? 


\section{SELECTED BIBLIOGRAPHY}

\section{Printed Materials}

Achenson, K. A., \& Gall, M. D. (1980). Techniques in the clinical supervision of teachers. New York: Longman.

American Association of Educational Service Agencies (1979). Planning models for state systems of educational service agencies: Some conceptual \& methodological considerations. ESA Study Series/Report No. VIII. Arlington: American Association of School Administrators.

Anderson, S. B., \& Ball, S. (1978). The profession \& practice of program evaluation. San Francisco: Jossey-Bass.

Apple, M. E., Subkoviak , M. J., \& Lufler, H. S. Jr. (1974). Educational evaluation: Analysis and responsibility. Berkeley: McCutchan.

Ary, D., Jacobs, L. C., \& Razavieh, A. (1985). Introduction to research in education. (3rd ed.). New York: Holt, Rinehart \& Winston.

Baumol, W. J. (1968). Information technology \& the service sector: a feedback process. In G. Faulhaber, E. Noam, \& R. Tasley (Eds.), Services in transition: The impact of information technology on the service sector. Cambridge: Ballinger.

Berrin, K. F. (1968). General and social systems. New Brunswick: Rutgers University.

Berk, R. A. (Ed.). (1981). Educational evaluation methodology: The state of the art. Baltimore: John Hopkins University.

Bickman, L. (1987). The functions of program theory. In L. Bickman (Ed.), Using program theory in evaluation: New directions for program theory. (No. 33. pp. 517.). San Francisco: Jossey-Bass.

Black, J., \& English, F. (1986). What they don't tell you in schools of education about school administration. Lancaster, PA: Technomic.

Bolman, L., \& Deal, T. (1984). Modern approaches to understanding and managing organizations. San Francisco: Jossey-Bass.

Bossel, H., Klaczko, S., \& Muller, N. (1976). Systems theory in the social sciences. Basel: Birkhauser Verlag.

Boulding, K. E., (1985). The world as a total system. Beverly Hills: Sage Publications.

Brazosport Independent School District. (1981). Brazosport Independent School District Community Survey Summary. (ERIC. No. ED 242 009). Freeport, Texas. 
Bryk, A. S. (Ed.). (1983). Stakeholder-based evaluation. Using program theory in evaluation: New directions for program theory. San Francisco: Jossey-Bass.

Buchser, L. (1984). Maior state mandates for califomia county offices of education: The views from santa clara. (ERIC. No. ED 256 069). Master's Thesis, School of Education, San Jose State University.

Campbell, R. F., Cunnigham, L. L., Nystrand, R.O., \& Usdan, M. D. (1987). A history of thought and practice in educational administration. New York: Teachers College Press.

Carterette, E. C. \& Friedman, M. P. (1974). Handbook of perception: Volume 1. historical and philosophical roots of perception. New York: Academic Press.

Chen, G., Jamieson, J. M., Schkade, L. L., \& Smith, C. H. (Eds.). (1980). The general theory of systems applied to management and organization, VOL 1 . Seaside, CA: Intersystems Publications.

Conrad, K. J., \& Miller, T. Q. (1987). Measuring and testing program philosophy. In L. Bickman (Ed.), Using program theory in evaluation: New directions for program theory. (No. 33. pp. 19-41.). San Francisco: Jossey-Bass.

Cooley, W. W. \& Lohnes, P. R. (1976). Evaluation Research in Education. New York: Irvington.

Cook, T. (1984). Opportunities for evaluation in the next few years. Evaluation Studies Review Annual. (Vol. 9. pp. 49-80.). Beverly Hills: Sage.

Cooper, Harris M., Arkin, Robert M. (1983). On quantitative reviewing. Educational Studies Review Annual. (Vol. 8. pp. 167-172.). Beverly Hills: Sage.

Cronbach, L. J. (1982). Designing evaluations of educational and social programs. San Francisco: Jossey-Bass.

Czepiel, J. A., Congram. C. A., \& Shanahan, J. (1987). The services challenge: Integrating for competitive advantage. Chicago: American Marketing Association

Davis, B. G. (Ed.). (1986). Overview of the teaching of evaluation across the disciplines. New directions for program evaluation series: Evaluation research society. (March, No. 29. pp. 5-14.).

Dember, W. N., \& Warm, J.S. (1979). Psychology of perception. New York: Holt Rinehart and Winston.

DeRoche, E. F. (1981). An administrator's guide for evaluation programs and personnel. Boston: Allyn \& Bacon.

DeRoche, E. F. (1987). An administrator's guide for evaluating programs and personnel: An effective schools approach. (2nd ed.). Boston: Allyn \& Bacon. 
Dewey, H. B. (1909). History of education in washington preliminary edition issued for distribution at the a-y-p exposition. Olympia, Washington: Superintendent of Public Instruction. In G. P. Ruel, A Study of the Effectiveness of Educational Service Districts in the State of Washington (1986. dissertation.).

Downie, N.M., \& Heath, R.W. (1983). Basic Statistical Methods. (Sth ed.). New York: Harper \& Row.

Educational Service District 112, State of Washington (1989a). Organizational pamphlet of services and programs.

Educational Service District 112, State of Washington (1989b). Educational service district 112. (descriptive overview of ESD 112's purpose \& structure.).

Eisner, E. W. (1985). The art of educational evaluation. Philadelphia: The Falmer Press.

Deighton, L. C. (Ed. in chief.). (1971). The encyclopedia of education. Crowell-Collier Educational Corporation. New York: The Macmillan Company and The Free Press.

Epstein, I., \& Tripodi, T. (1977). Research techniques for program planning, monitoring, and evaluation. New York: Columbia University Press.

American Association of School Administrators. (1982). Evaluating educational programs. Arlington: AASA.

Evaluation Research Society Standards for Program Evaluation: ERS Standards Committee. (1982). Standards for evaluation practice: Evaluation studies review annual. (No. 15.). 681-692 San Francisco: Jossey-Bass.

Fitz-Gibbon, C. T., \& Morris, L.L. (1978). How to design a program evaluation. Beverly Hills: Sage Publications.

Funk \& Wagnalls: Standard College Dictionary. (1963). New York: Funk \& Wagnalls

Gibson, J. L., Ivancevich, J. M., \& Donnelly, J. H., Jr. (1976). Organizations: Behavior, structure, process. Dallas: Business Publications.

Ginzberg, E. (1986). Services in transition: The impact of information technology on the service sector. In G. Faulhaber, E. Noam, \& R. Tasley (Eds.). Cambridge: Ballinger Publishing Company.

Guba, E. G., \& Lincoln, Y. S. (1981). Effective evaluation. San Francisco: JosseyBass.

Gutek, G. L. (1972). A history of the westem educational experience. New York: Random House.

Hanson, E. M. (1979). Educational administration and organization behavior. Boston: Allyn \& Bacon.

Hayman, J. L., Jr., \& Napier, R. N. (1975). Evaluation in the schools: A human process for renewal. Monterey: Brooks/Cole. 
Hughes, L. W., \& Achilles., C. M. (1976). Educational cooperatives and regional education service. In S. E. Goodman (Ed.), Handbook on Contemporary Education. 89-94. New York: RR Bower.

Joint Committee on Standards for Educational Evaluation (1981). Standards for evaluations of educational programs, projects, and materials. New York: McGrawHill.

Kast, F., \& Rosenzweig, J. (1985). Organization and management: A systems and contingency approach. (4th ed.). New York: McGraw-Hill.

Kirst, M. (1984). Whe controls our schools. New York: W.H.Freeman.

Klien, G. S. (1970). Perception, motives, and personality. New York: Alfred A Knopf, Inc.

Kramer, N. J. T. A., \& de Smit , J. (1977). Systems thinking: Concepts and notions. Leiden, Netherlands: H.E. Stenfert Kroese B.V.

Laszlo, E. (1972). Introduction to systems philosophy. New York: Harper \& Row.

Laszlo, E. (1972). The relevance of general systems theory. New York: George Braziller, Inc.

Luft, J. (1984). Group processes: An introduction to proup processes. (3rd. ed.). Palo Alto: Mayfield.

Mattessich, R. (1978). Instrumental Reasoning \& Systems Methodology. Hingham, MA: D. Reidel Publishing.

Metzger, W. (1974). Consciousness, perception, and action. In E. C. Carterette, \& M. P. Friedman, Handbook of Perception: Volume 1. Historical \& Philosophical Roots of Perception, (Chap. 7.). New York: Academic Press.

Michaels, C. F., \& Carello, C. (1981). Direct perception. Englewood Cliffs: PrenticeHall.

Mouzelis, N. P. (1968). Organisation and bureaucracy. New York: Aldine Publishing

Owens, R. (1981). Organizational behavior in education. (2nd. ed.). Englewood Cliffs: Printice-Hall.

Popham, W. J. (1975). Educational evaluation. Englewood Cliffs: Printice-Hall.

Pufall, P. B. (1977). The development of thought: On perceiving and knowing. In $\mathbf{R}$. Shaw, \& J. Bransford (Eds.), Perceiving, Acting, \& Knowing: Toward \& Ecological Psychology. (Chap. 7.). Hillsdale, NJ: Lawrence Erlbaum Associates. 
Raizen, S. A., \& Rossi, P. H. (Eds.). (1981). Program evaluation in education: When? how? to what ends?. Committee on Program Evaluation in Education Assembly of Behavioral and Social Sciences National Research Council. Washington, D.C.: National Academy Press.

Rapoport, A. (1986). General systems theory. Kent, TN4 OHU, United Kingdom: Abacus Press.

Ravitch, D. (1983). The troubled crusade: American education 1945-1980. New York: Basic Books.

Rorher, K. J. (1988). Historical highlights of washington state county, intermediate, educational service units. (descriptive outline of historical development of ESDs.). unpublished document. (July 7, 1988.).

Rossi, P. H., \& Wright, R S. (1976). Evaluation research: An assessment of theory, practice, and politics. Evaluation Quarterly. (Vol. 1. No. 1 pp. 5-52.).

Rossi, P. H., Freeman, H. E., \& Wright, S. R. (1979). Evaluation: A systematic approach. Beverly Hills: Sage Publications.

Rossi, P. H., \& Freeman, H. E. (1985). Evaluation: A systematic approach. (Chap. 1. pp. 13-57.). Beverly Hills: Sage Publications.

Rothman, J. (1980). Social research and development in the human sciences. Englewood Cliffs: Prentice-Hall.

Royce, J. R. (1974). Cognition and knowledge: Psychological epistemology. In E. C. Carterette \& M. P. Friedman. Handbook of perception: Volume 1. historical and philosophical roots of perception. (Chapter 9.). New York: Academic Press.

Ruel, G. P. (1986). A study of the effectiveness of educational service districts in the state of washington. (Doctoral dissertation, Seattle University, 1986).

Scriven, M. (1984). Evaluation ideologies. Evaluation Studies Review Annual. (Vol. 9. pp. 49-80.). Beverly Hills: Sage.

Scott, R. W. (1987). Organizations: Rational, natural, and open systems. (2nd ed.). Englewood Cliffs: Prentice-Hall.

Sergiovanni, T., \& Starratt, R. (1983). Supervision: Human perspectives. New York: McGraw Hill.

Shaw, R., \& Bransford, J. (Eds.). (1977). Preceiving, acting and knowing: Toward an ecological psychology. Hillsdale, NJ: Lawrence Erlbaum Associates.

Stake, R. E. (1983). Stakeholder influence in the evaluation of cities-in schools. In A. S. Bryk (Ed.). Stakeholder-Based Evaluation, New Directions for Program

Evaluation Series. San Francisco: Jossey-Bass 
Stanback, T. M., Jr., Bearse, P. J., Noyelle, T. J., \& Karasek, R. A. (1981). Services: The new economy. Totowa, NJ: Allanheld, Osmunand Co.

Stephens, E. R., Perry, W. J., \& Sanders, J. R. (1989). Designing organizational effectiveness studies for nural and small school districts. Unpublished manuscript. Department of Education Policy, Planning, \& Administration, College of Education, University of Maryland, College Park, Maryland.

Stufflebeam, D. L., McCormick, C. H., Brinkerhoff, R.O., \& Nelson, C.O. (1985). Conducting educational needs assessment. Boston: Kluwer-Nijhoff Publishing.

Southwest \& West Central Educational Cooperative Service Unit. (1980). The SW \& WC ECSU Past \& Present. (ERIC. No. ED 186 183). Marshall, MN

Travers, R. M. W. (1983). How research has changed american schools. Kalamazoo, MI: Mythos Press

Tuckman, B. W. (1985). Evaluating instructional programs. (2nd ed.). Newton, MA: Allyn \& Bacon

Tumer, W. G. (1980). Educational service agencies: A national perspective. COMPACT. Denver. Education Commission of the States.

Tyack, D, Lowe, R., \& Hansot, E. (1984). Public schools in hard times; The great depression and recent years. Boston: Harvard University Press.

Tyack, D., \& Hansot, E. (1982). Mangers of virtue. New York: Basic Books.

Vockell, E. L. (1983). Educational research. New York: Macmillan.

von Bertalanffy, L. (1968). General system theory: Foundations, development, and applications. New York: George Braziller, Inc.

Williams, R. C., \& Bank, A. (1981). Uses of data to improve instruction in local school districts: Problems and possibilities. In C. B. Aslanian (Ed.). Improving Educational Evaluation Methods: Impact on Policy. Evaluation Research Society. 131-147. Beverly Hills: Sage Publications

Wolf, R. M. (1984). Evaluation in education. (2nd ed.). New York: Praeger.

Worthen, B. R., \& Sanders, J. R. (1987). Educational evaluation: Alternative approaches and practical quidelines. White Plains, NY: Longman.

Yin, R. K., \& Gwaltney, M. K. (1981). Organizations collaborating to improve educational practice. Abt. Associates, Inc., Cambridge, MA. National Institute of Education (ED). (ERIC. No. ED 207 190). Washington, D.C.

Zeller, R. A., \& Carmines, E. G. (1980). Measurement in the social sciences. New York: Cambridge University Press. 
Personal Interviews and Conversations

Barr-Cole, D. (1989). Administrative Assistant, Instructional \& Curriculum Services, Educational Service District 112, 1313 NE 134th St., Vancouver, WA 98685-2788

Fromhold, C.W. Fromhold (1989). Superintendent, Educational Service District 112, 1313 NE 134th St., Vancouver, WA 98685-2788

Mathews, Dennis (1989). Administrative Assistant, Special Services Division, Educational Service District 112, 1313 NE 134th St., Vancouver, WA 98685-2788

Roher, Kathy J. (1988-89-90). Director of Public Relations, Educational Service District 112,1313 NE 134th St., Vancouver, WA 98685-2788

Ruel, Gary P. (1988-89). Supervisor, Secondary Programs, Northshore School District, 18315 Bothell Way NE, Bothell, WA 98011

Stephens, E. Robert (1989). Department of Education Policy, Planning, and Administration, College of Education, University of Maryland, College Park, Maryland 20742

Turner, Walter (1989). Executive Director, American Association of Educational Service Agencies, American Association of School Administrators, 1801 North Moore St., Arlington, VA. 22209

Yule, Richard (1989). Assistant Superintendent, Instructional Services Division, Educational Service District 112, 1313 NE 134th St., Vancouver WA 98685-2788 
APPENDDX A

SURVEY INSTRUMENT 
Survey: Perceived Effectiveness of ESD 112 's Programs and Services

Burkeraend Iafermaltoe

1. What position do you bold is this divericat

Di Elementry Sctool Teacher

O2 Midie Schod Teacher

Q3 Hith Sebonl Tencher

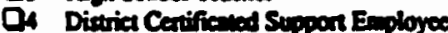
(Counder, Librerien, Specialia, ex)

OS ESD Cenifiand Suppon Employece (Specill Ed, Specth Spocinlin eta)

Q6 Elementery Selool Principal

O7 Midte Sebool Privipt

Q8 High Sctroct Priacipal

D9 Assisten Elemeatery School Principal

O10 Asciann Minde Sctool Principl

O11 Ascismon brith Sctool Principi

Q12 school Bond Member

Q13 Superinumiencenurl Ortice (Asa Suph, Director, cec)

2. How many years have you beea employed (or been a boend member) in this sebool divriact

Yans

3. How many years hrue youbeen eapployed (or been a bord member) in edracaion in the sute of Weshington?

Yeas

4. In whe size dietriat no you employed

Ot 0 - 300 suchess

Q2 301 - 800 andean

Q3 3001 - 1300 andeals

Q1 1301 - 2000 sodens

Os $2001+$ sondents

5. In when county is your fistia bected?
Q1 Clat
Q2 Comliz
Q3 Klickive
Q4 Pxific
Os Stamania
Q6 Wahkinam

6. Highes educavions level reachad?
Ot H.S. Diplom
Q 2 Bechalocis
Q3 Mastcr's
Ds PhDEJD

Geoeral Information

7. How weuld you me pour understanding of the functions and purpoes of ESD 112?

Ot Complese underanding

Or coodundersonding

Os Modenie udentending

O4 Minimal adersunding

Os No enderseading

8. To ntere erlex have you been involved with programs or services provided by ESD 112 in the last iwo $y=x$ ?

Q1 No propresaftarvices

C. 1.5 proprempervices

Qo 6-10progenefervices

Q1 11-20 progremstservices

DS More chm 20 proprums/services

Q6 All progrems

9. To your bowledec does your district use ANY eavices provides by ESD III?

Di Ya $\mathrm{O}_{2} \mathrm{No}_{0}$

Q3 Unknown

[IF No or Ubibnow, CO TO QUESTION 14.]

10. When topes of prograses and services does your distriat une?

Q1 Mouty Sudin oriented

Q. Moady Teacher criented

D3 Mady Administrative oriented

QA some combination of those sbove

11. Io your preven pocition, bow does ESD 112 affect yoo of your wadt

Or Vory mist

Q. Somevine

Os Vory liete

Qs Not as all

Qs Dan't bow

12. Thu conduints do you encounter in accessing ESD 112 ervioent

Oi None

De Distunce

Di conficting wotking hours

O4 Finence

D5 Leck of information aboul ESD 112

O6 Ressons asocirted with local district

Oz Combination of rescons

13. Do you fal ESD 112 provides timely servires (i.e. materials disuibution, efficient communicatitns. exceutung services and programs)?
Q) Yes
Q2 No

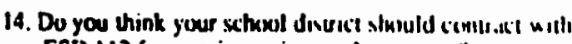
ESD II? fox centain services and propreams"
J) Yes
32 vis 
Pleace keep in mind when wowering the following quexions, the cousep of EFFECTIVENESS implies...

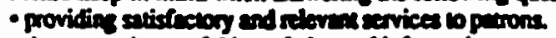

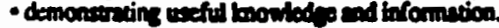

- providing servides in a tincly faction.

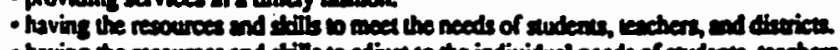

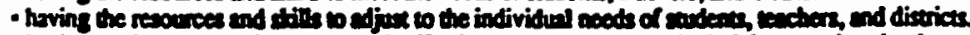

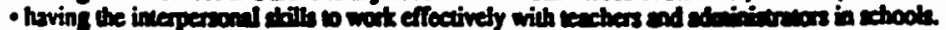

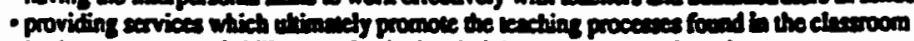

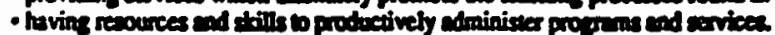

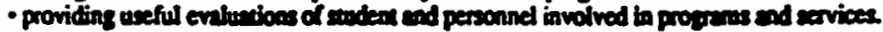

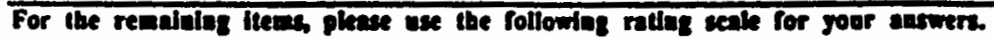

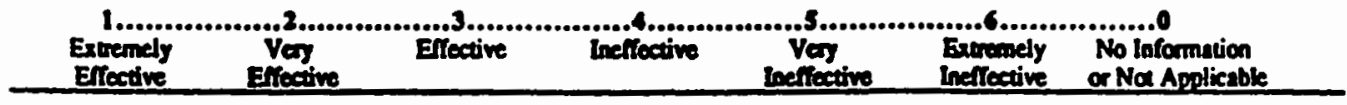

How effective would you ane ESD 112 ih.m.

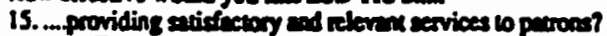
01
Q2
Q 3
04
Q 5
Q 6
00

16. ...demonstruting ueful browidese and information?

17. ...providing envices th 2 tindy fahion?

18. mhaving

$\mathrm{Q}_{2} \mathrm{Q}_{3}$

04 as

Q 6

00

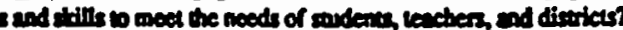

0 I

Q 2

Q 3

Q 4

Q 5

Q 6

00

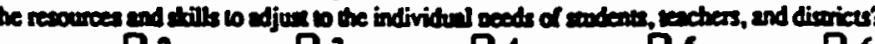

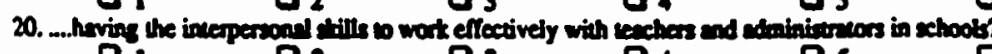

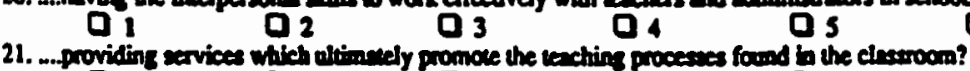

$\mathrm{Q}_{1} \mathrm{Q}_{2} \mathrm{Q}_{3} \mathrm{Q}_{4} \mathrm{Q}_{3}$

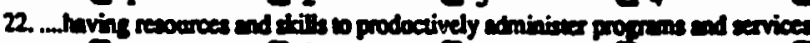

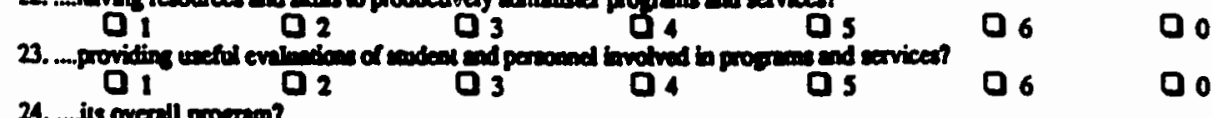

24. ...ils ovendl progrem?

$\mathbf{D}_{1} \mathrm{a}$

Q 3

Q4

Q 5

06

00

Instructibanl and Curricalon Services: Many of the servien end cocopentives associnted with curriculum and insuruction

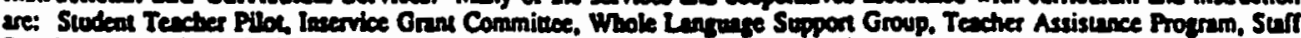

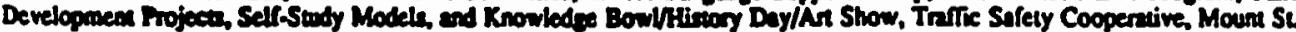

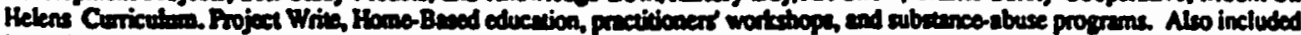

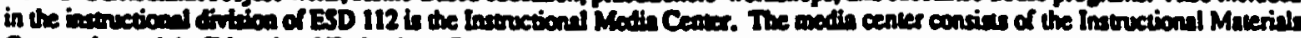

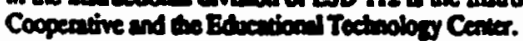

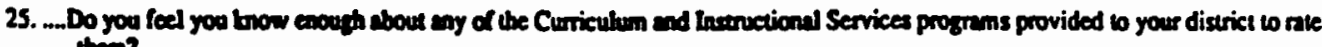
them?

Q 1 YES $Q_{2}$ NO...........If YES continue with item 26., and nie those ilems. If NO go wo ilem 4.

How Eftective would you rite the ..........

26. ....Toul Curriculum and Instrectional programs and services oftered by ESD 112 in your district?
$\mathbf{Q} 1$
$\mathbf{Q}_{2}$
Q 3
Q 4
Q 5
כ 6
Q 0

27. ...Curriculum end Inservectional STAFF in providing services to you district?

Q 1

$\mathbf{Q} 2$

03

04

Os 26

a 0

21.....ESD communicuion devices conceming Curriculum and Inanuctional programs and scrvicis?

Q I

Q 2 व

Q 4

Os

J 6

בo

PLEASE RETURN THIS SURVEY WITIII 5 DAYS

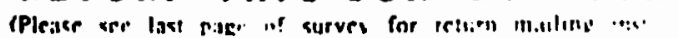




\begin{tabular}{|c|c|c|c|c|}
\hline $\begin{array}{l}\text { Erivemely } \\
\text { Elloetive }\end{array}$ & Efroctive Ineflective & $\begin{array}{l}\text { Very } \\
\text { neffective }\end{array}$ & $\begin{array}{l}\text { Extremely } \\
\text { Ineffective }\end{array}$ & $\begin{array}{l}\text { No.... information } \\
\text { or Nol Applicable }\end{array}$ \\
\hline 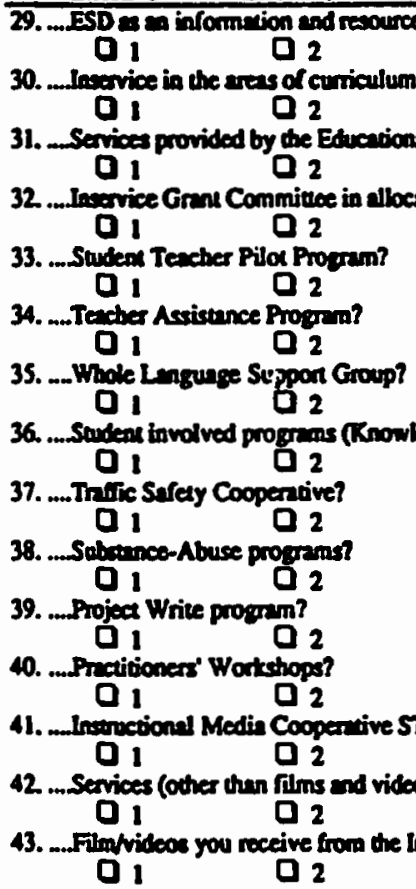 & 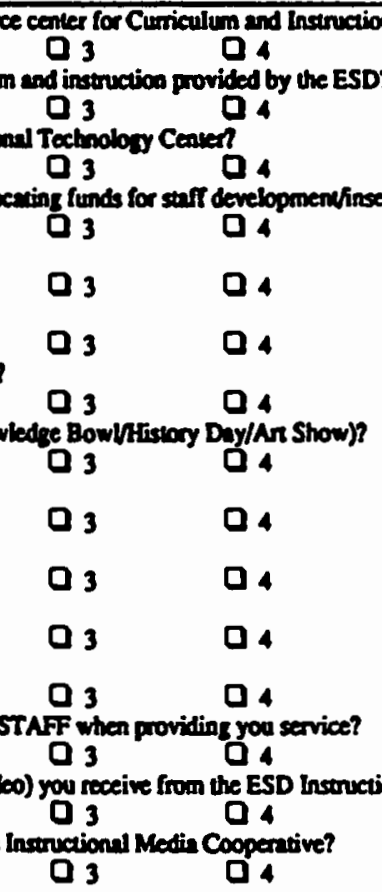 & 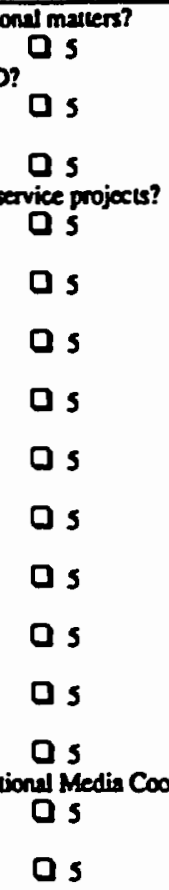 & $\begin{array}{l}Q_{6} \\
Q_{6} \\
Q_{6} \\
Q_{6} \\
Q_{6} \\
Q_{6} \\
Q_{6} \\
Q_{6} \\
Q_{6}\end{array}$ & 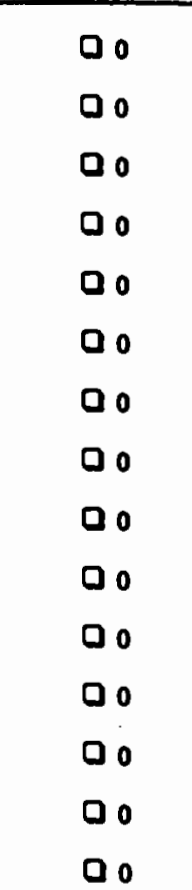 \\
\hline
\end{tabular}

Spectal Services Dlvialon: This division's services include: Inservice Trainiag and Program Review. Seriously Behevior

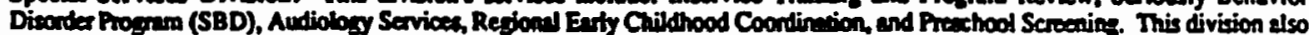
includes the Special Educution. Itinerum, and Direct Instroction coopernives These include: Psychologicel Services,

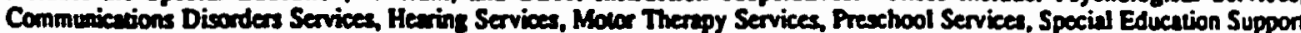
Assistants in Runl Aress (SESARA). The Special Educution Direct Instruction services provides districts with master texchers. clessoom teachers, and cheroom ascistonts in specideducation.

44. ....Do you feel you know esough about any of the Spocisl Services progrens provided wo your district to rate them? Q 1 YES $\mathrm{Q} 2$ NO................If YES, contizue with item 45., and nite those ilems. If NO go to the retum mailiag instructions on next page.

How Elfective would you rate the.........

45. ....Toul Special Services properms oftered by ESD $112 ?$

$\begin{array}{lllllll}0_{1} & Q_{2} & Q_{3} & 0_{4} & Q_{5} & Q_{6} & 0_{0}\end{array}$ 46. ....Special Services STAFF in providing ervices on your district?

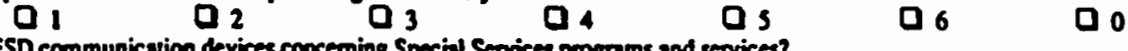

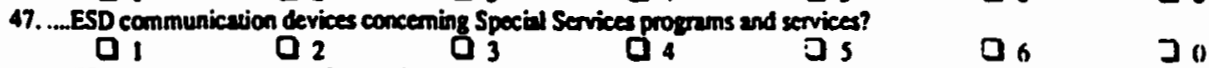

4R. ....ESD as a resource cented for specid education maters? $\begin{array}{llllll}0_{1} & \mathrm{O}_{2} & \mathrm{O}_{3} & \mathrm{O}_{4} & \mathrm{~J}_{3} & \mathrm{~J}_{6}\end{array}$

49. Inservice provided by Special Service in the ares of spocial education?

$\begin{array}{lllllll}J_{1} & Q_{2} & Q_{3} & Q_{4} & J_{5} & J_{0} & J_{1}\end{array}$

PI.TAASE RETURN THIS SURVI:Y WITIIN 5 DAYS

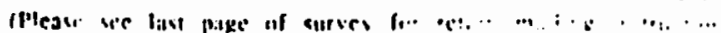




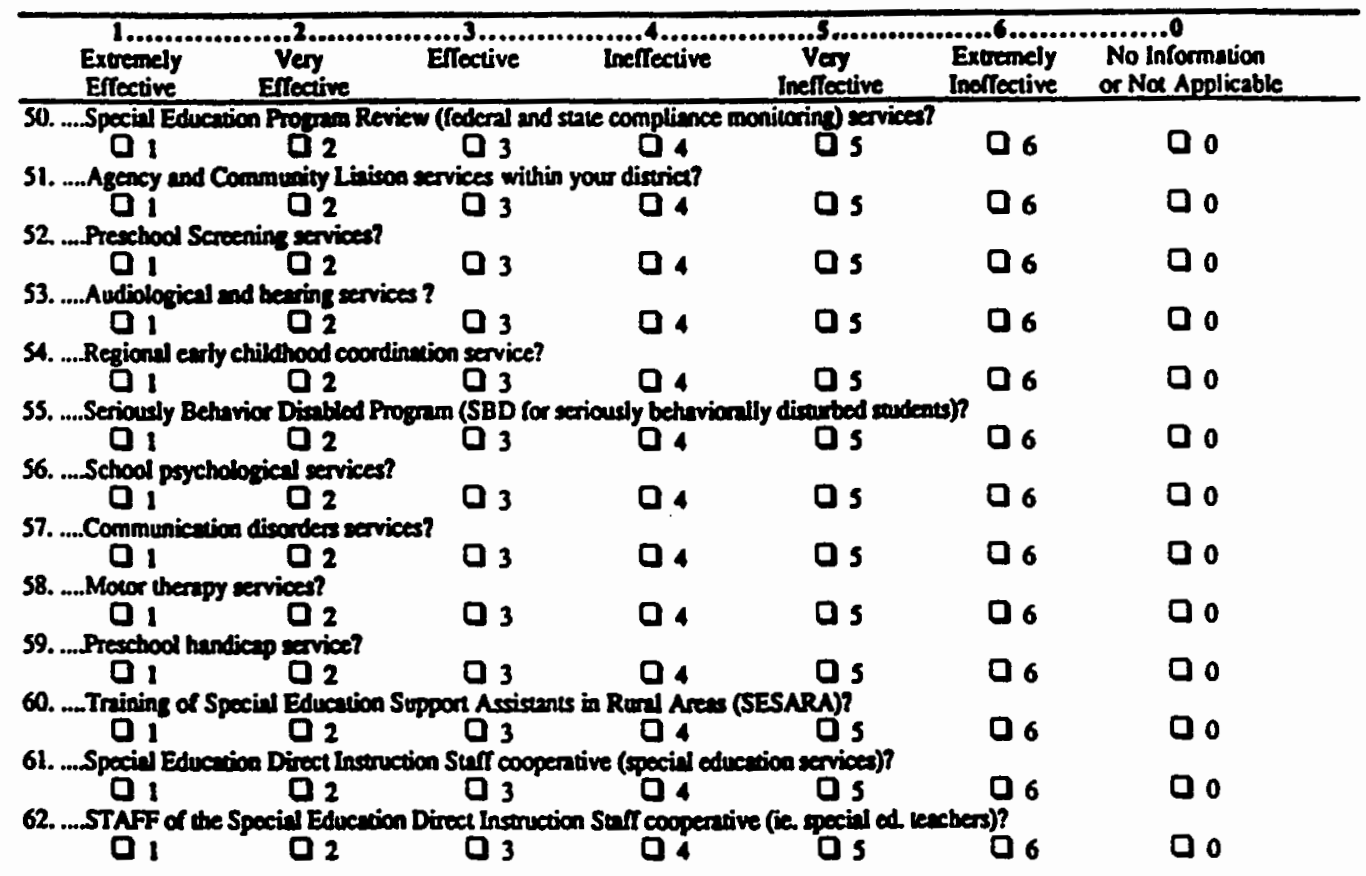

Thank You For Completing This Survey!

\section{RETURN MAILING INSTRUCTIONS}

A. If you are a BOARD MEMBER, SUPERINTENDENT, or a member of the CENTRAL OFFICE STAFF please retum this survey to your district office for a retum mailing to ESD 112.

\section{OR}

B. If you are a TEACHER, SUPPORT PERSONNEL, PRINCIPAL, or ASSISTANT PRINCIPAL. please retum this survey to your building secretary for a retum mailing to LSD I12-via your district office.

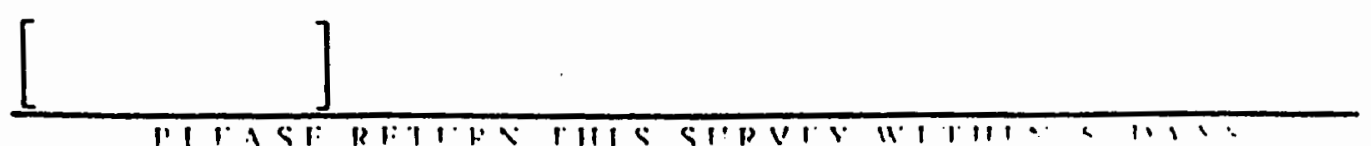




\section{APPENDIX B \\ SUMMARY TABLES OF MEAN RESPONSES AND PERCENTAGES OF RESPONDENTS}

According to:

Position Grouping

Years of Experience in Present District Grouping

Years of Experience in State of Washington Grouping

District Size Grouping

County Location Grouping

Degree Level Grouping 


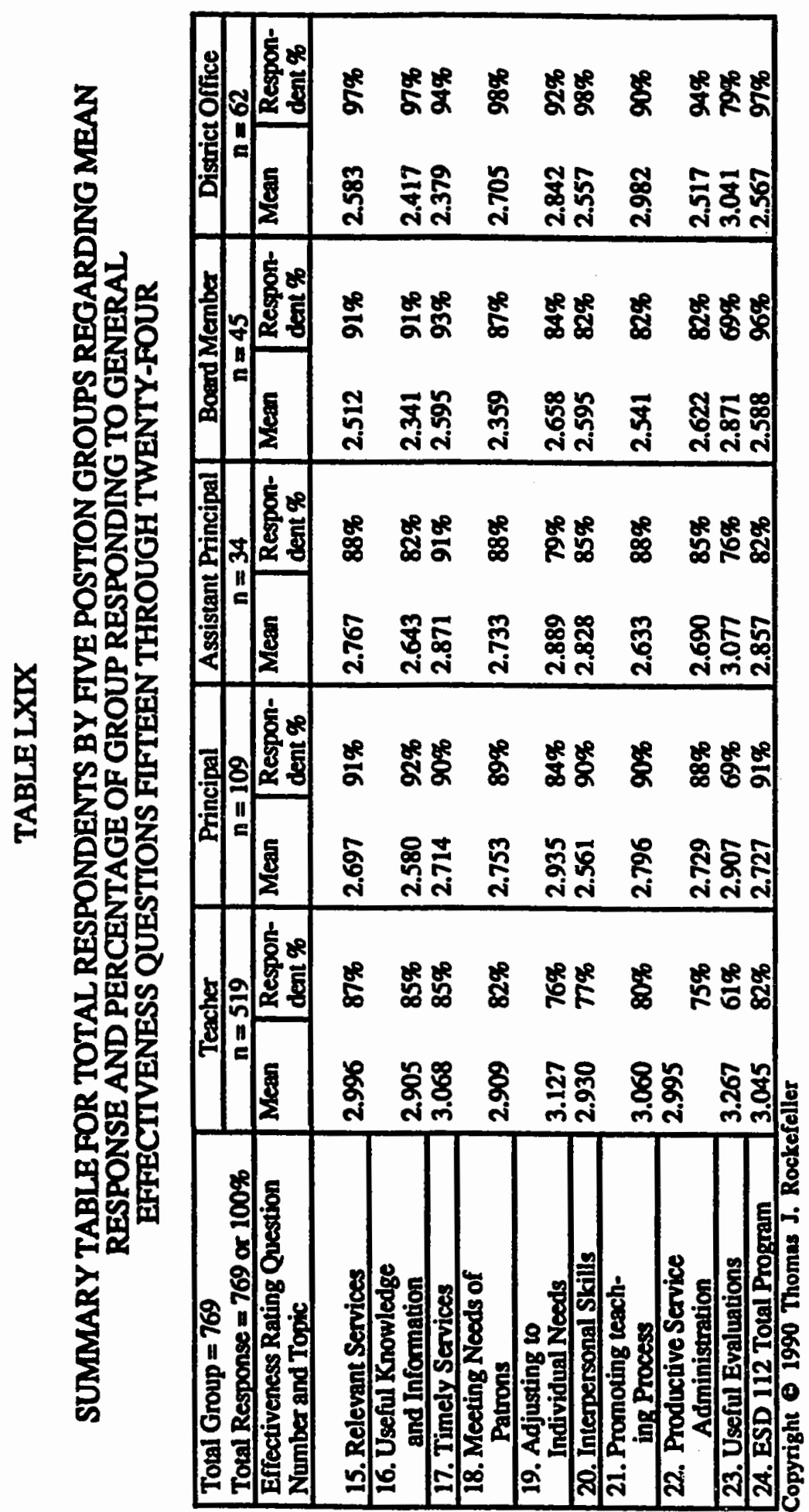




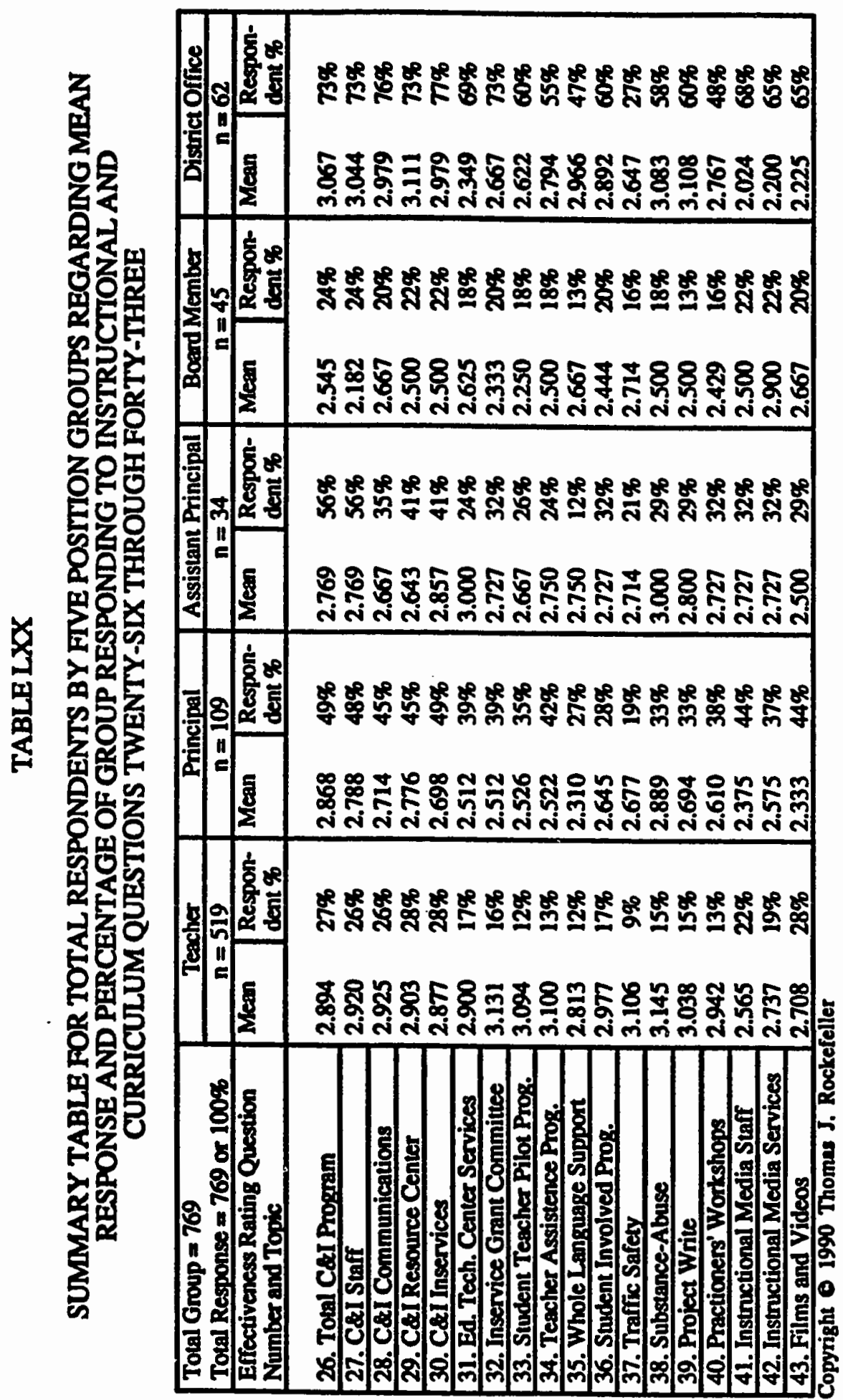




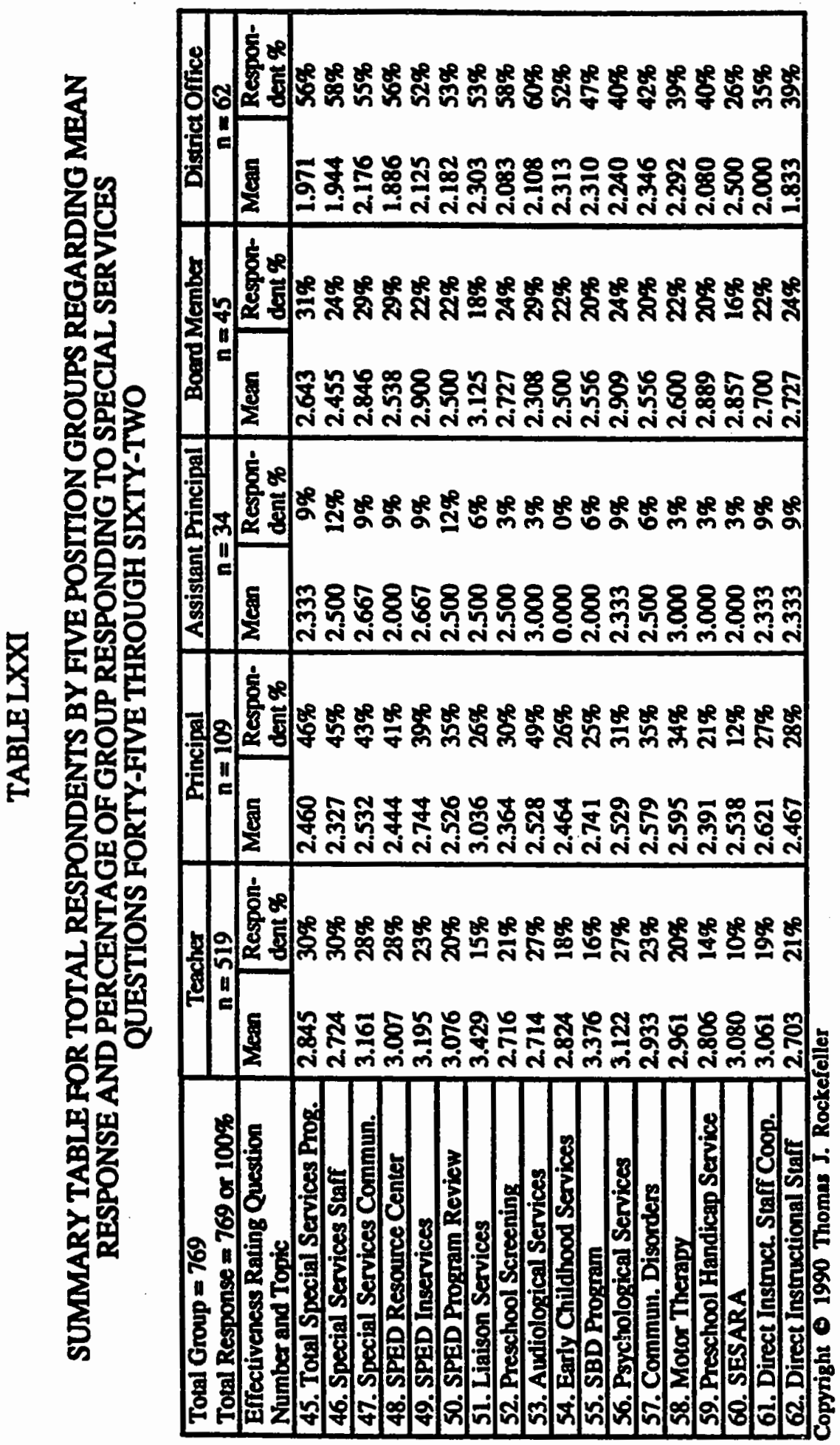




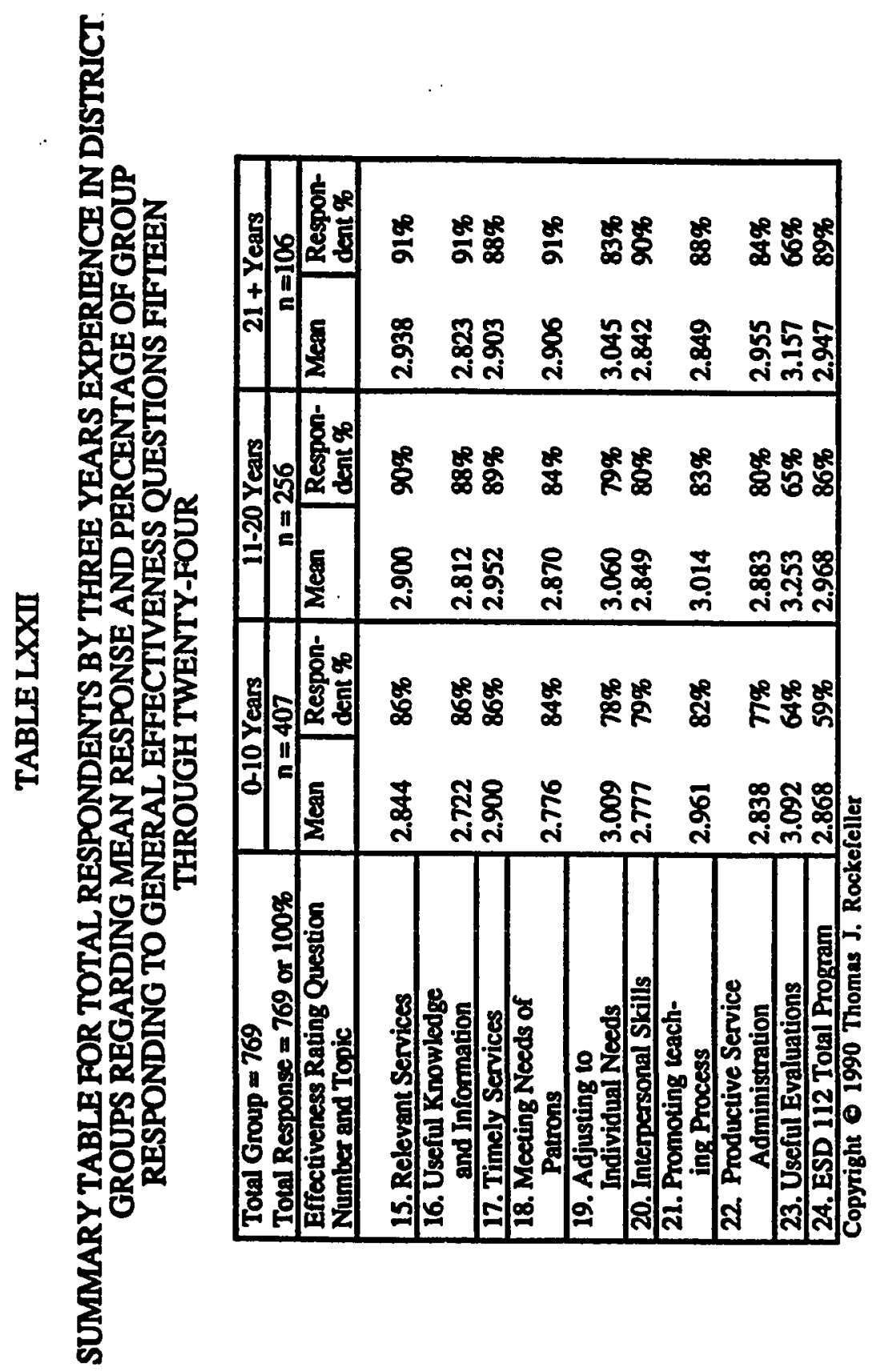




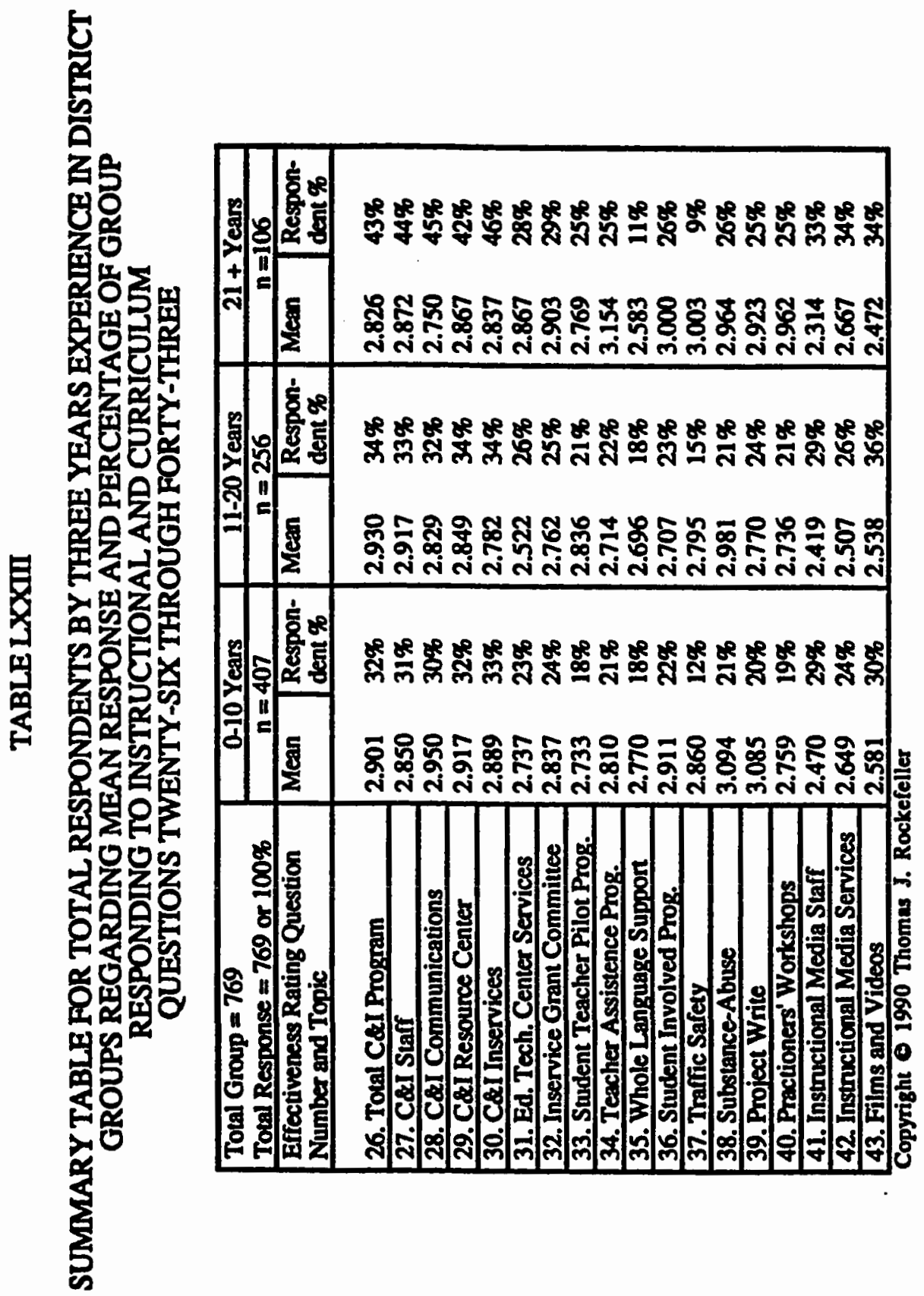




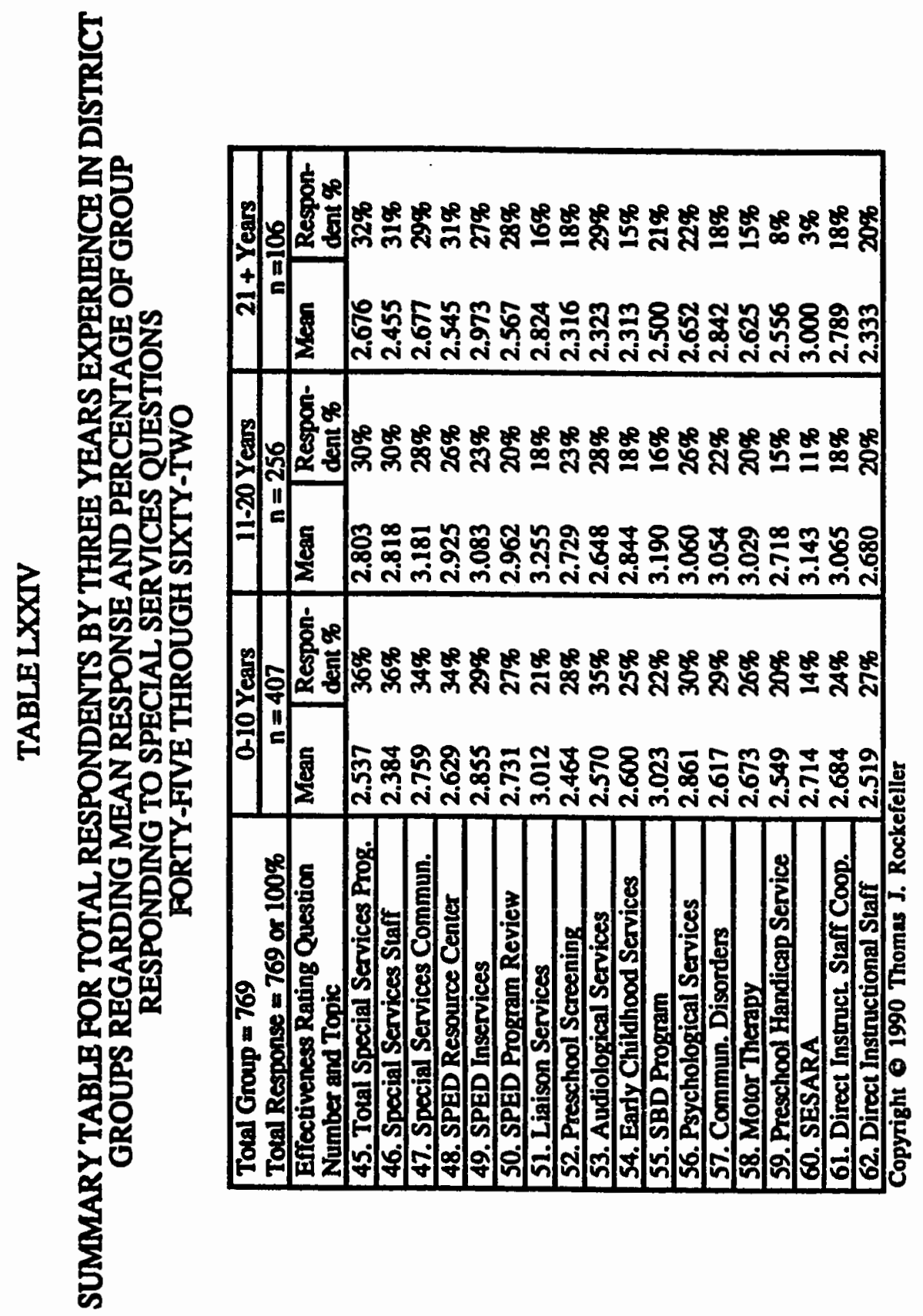




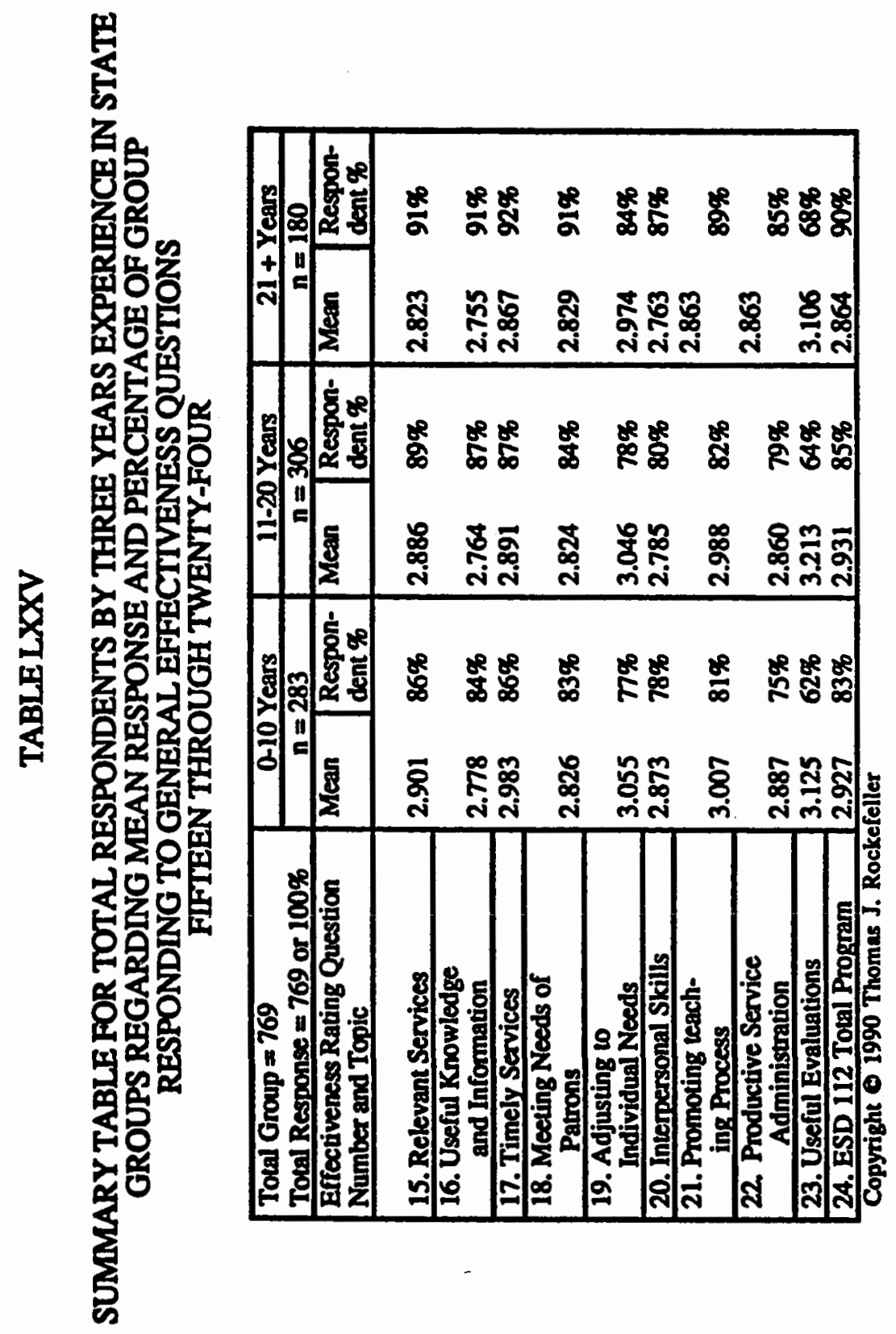




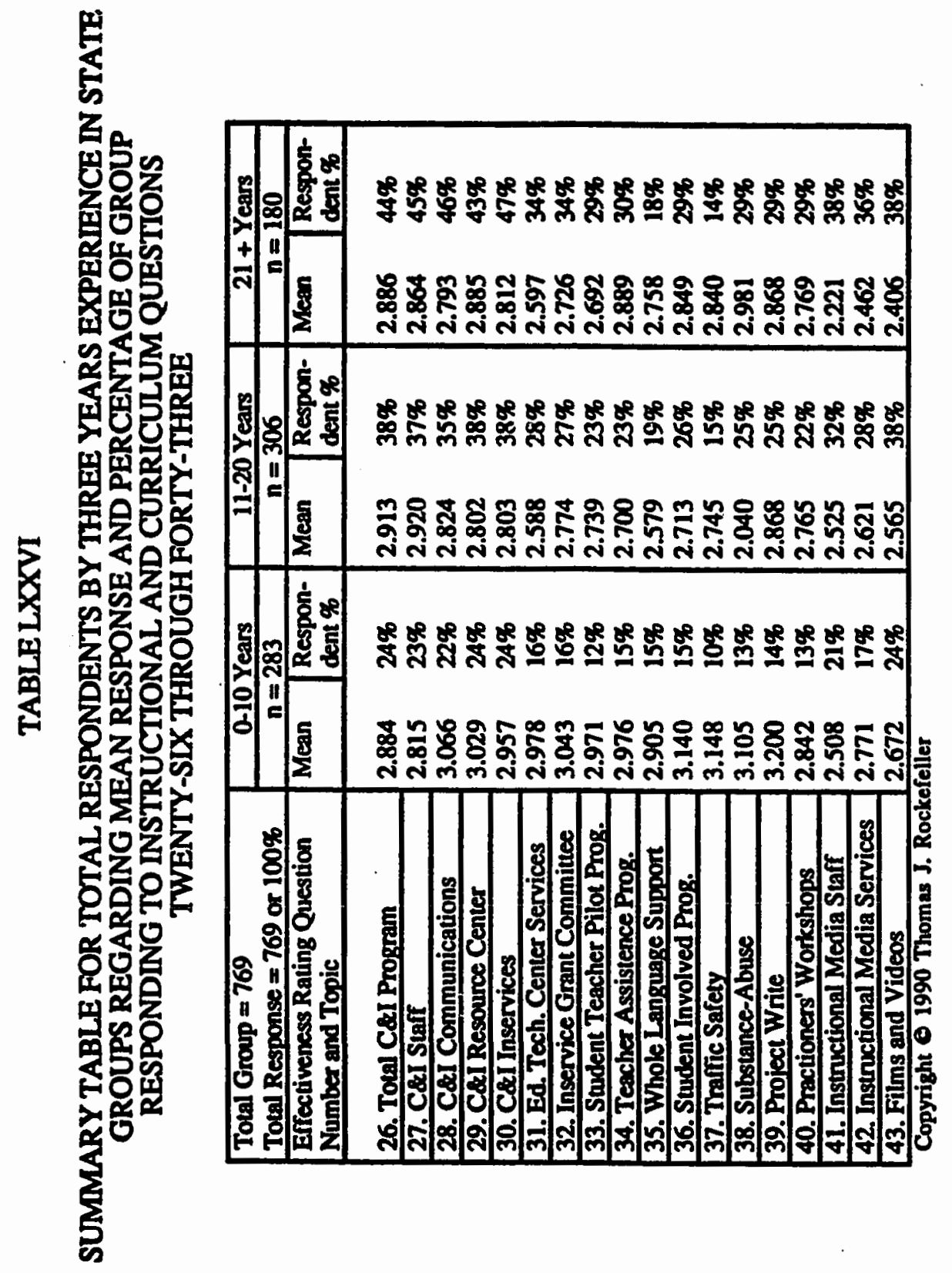




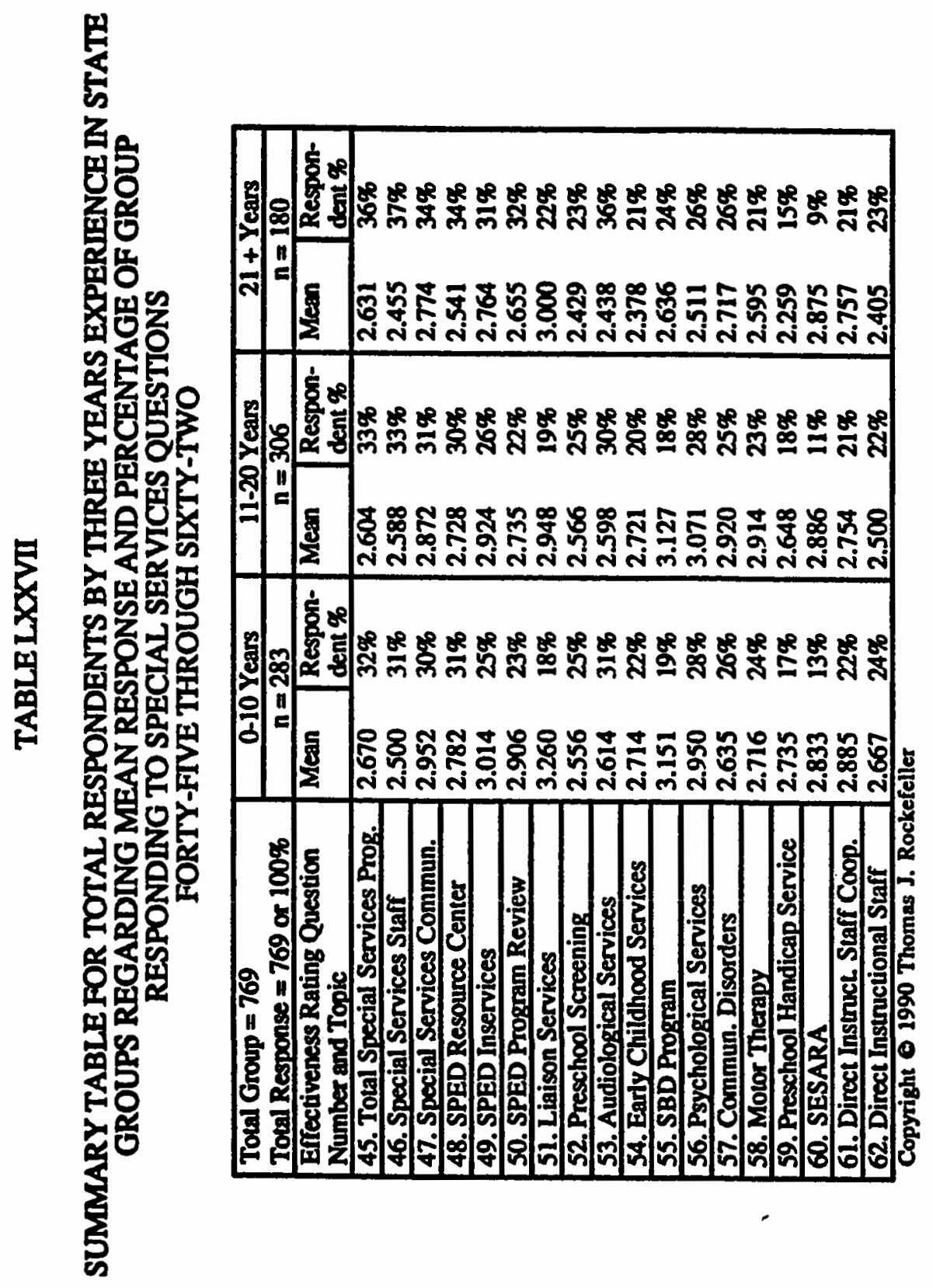




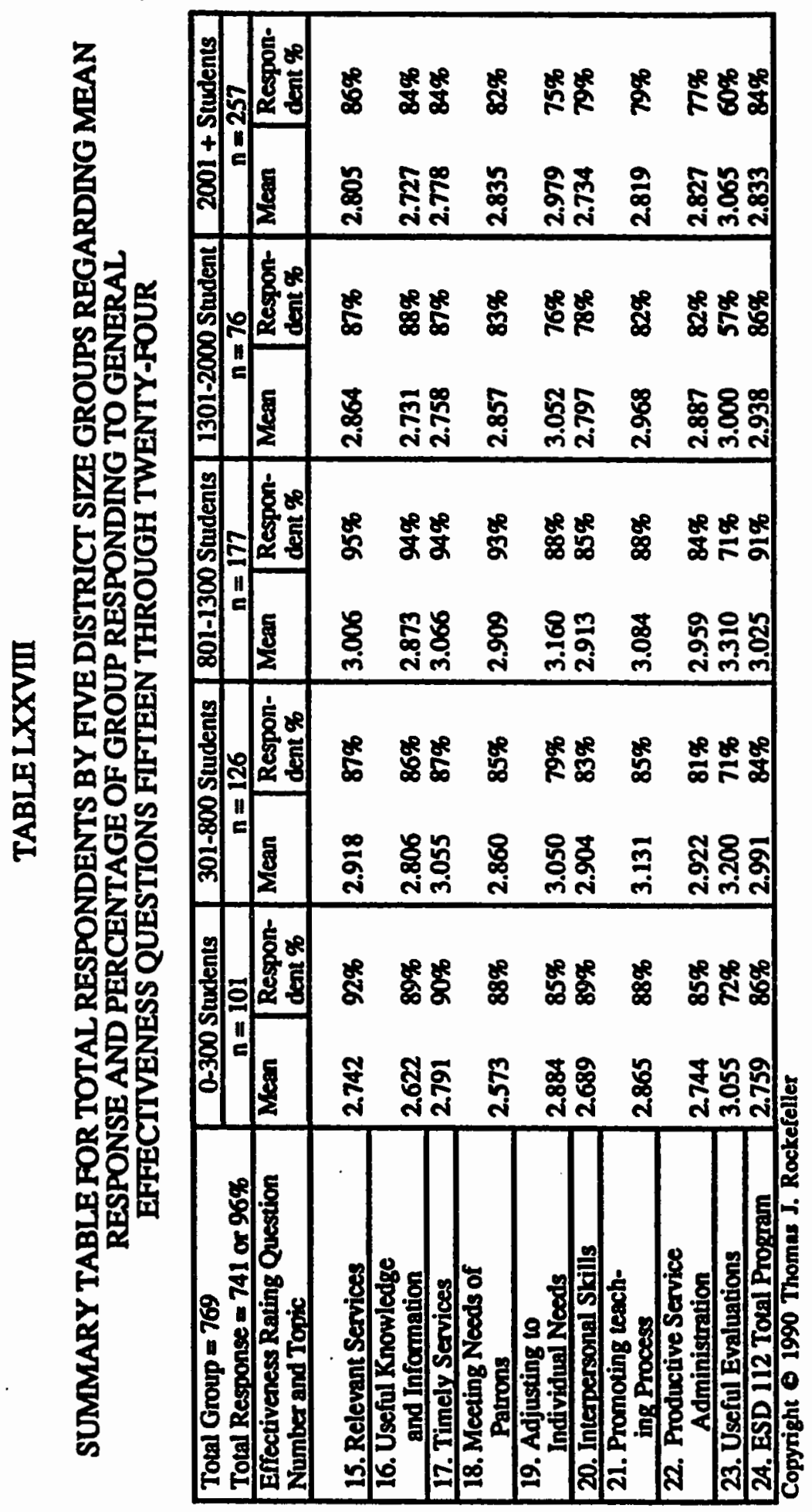




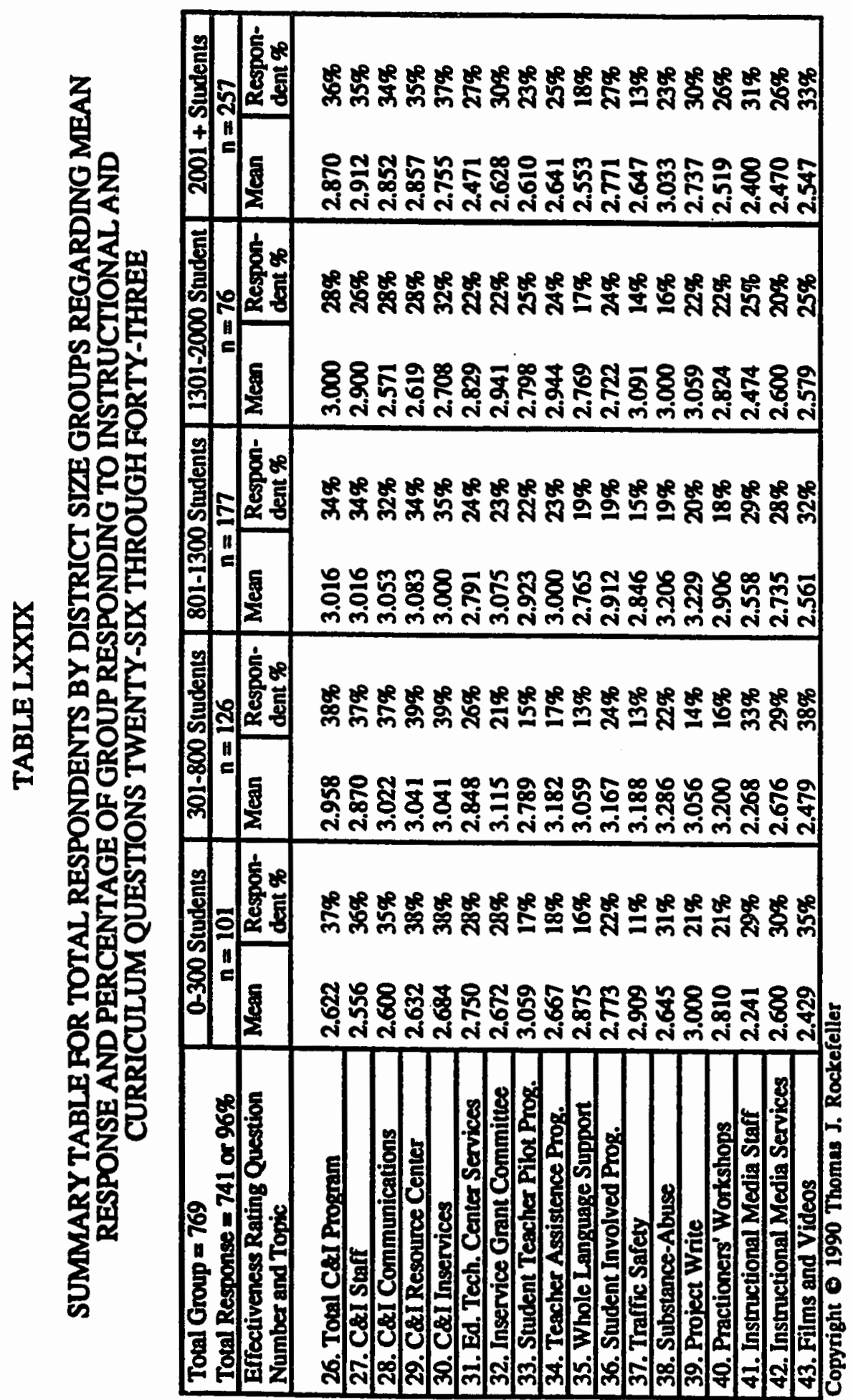




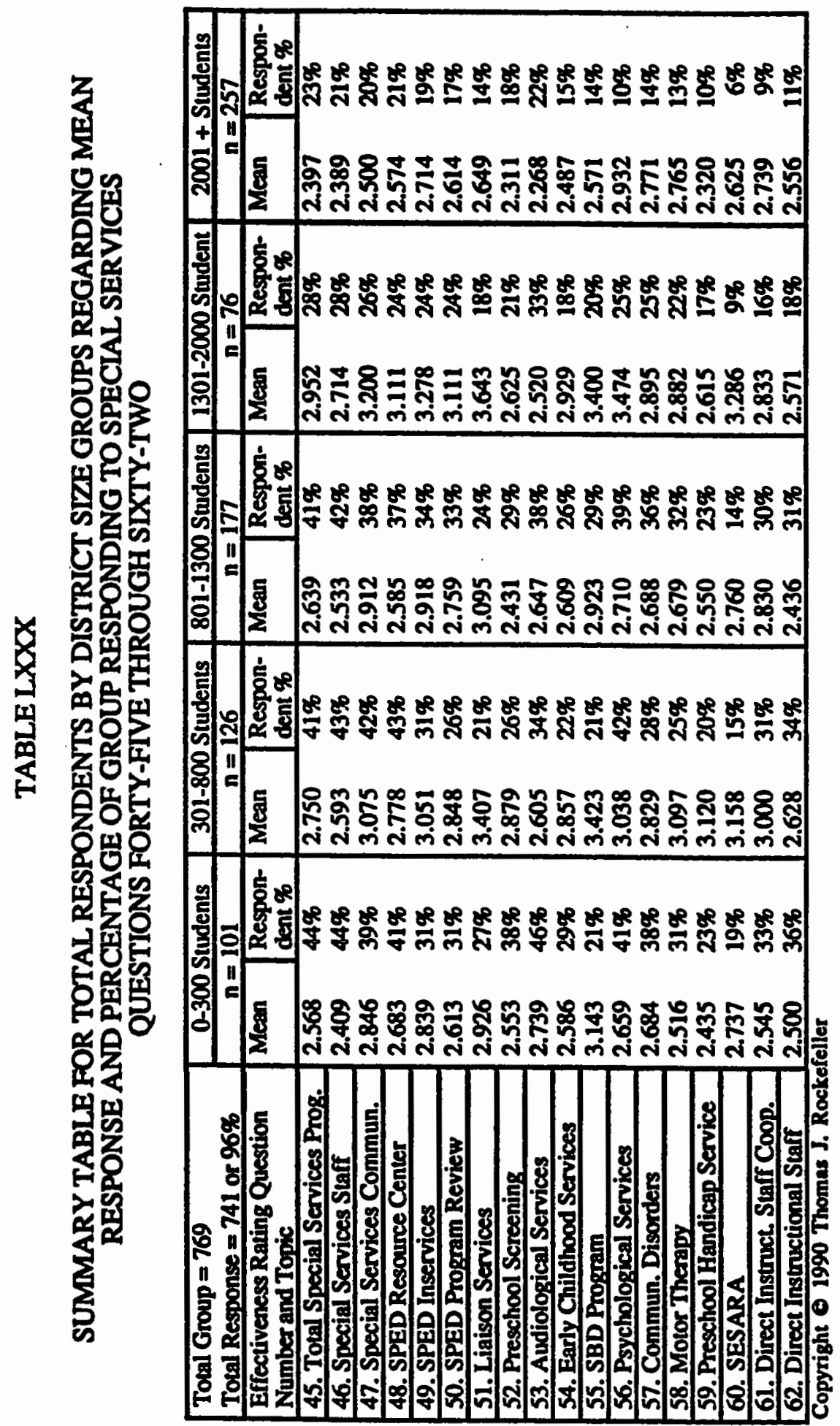




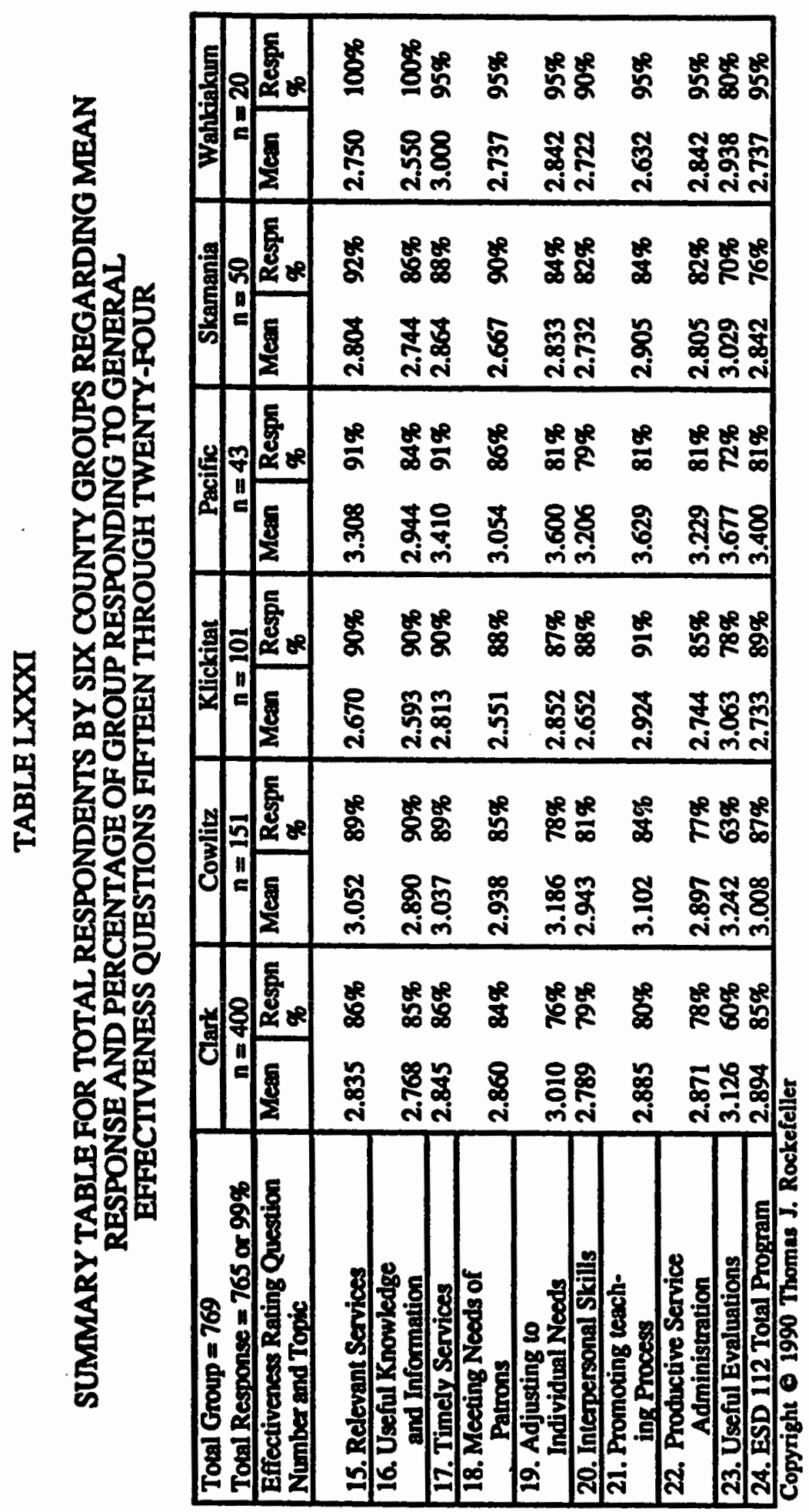




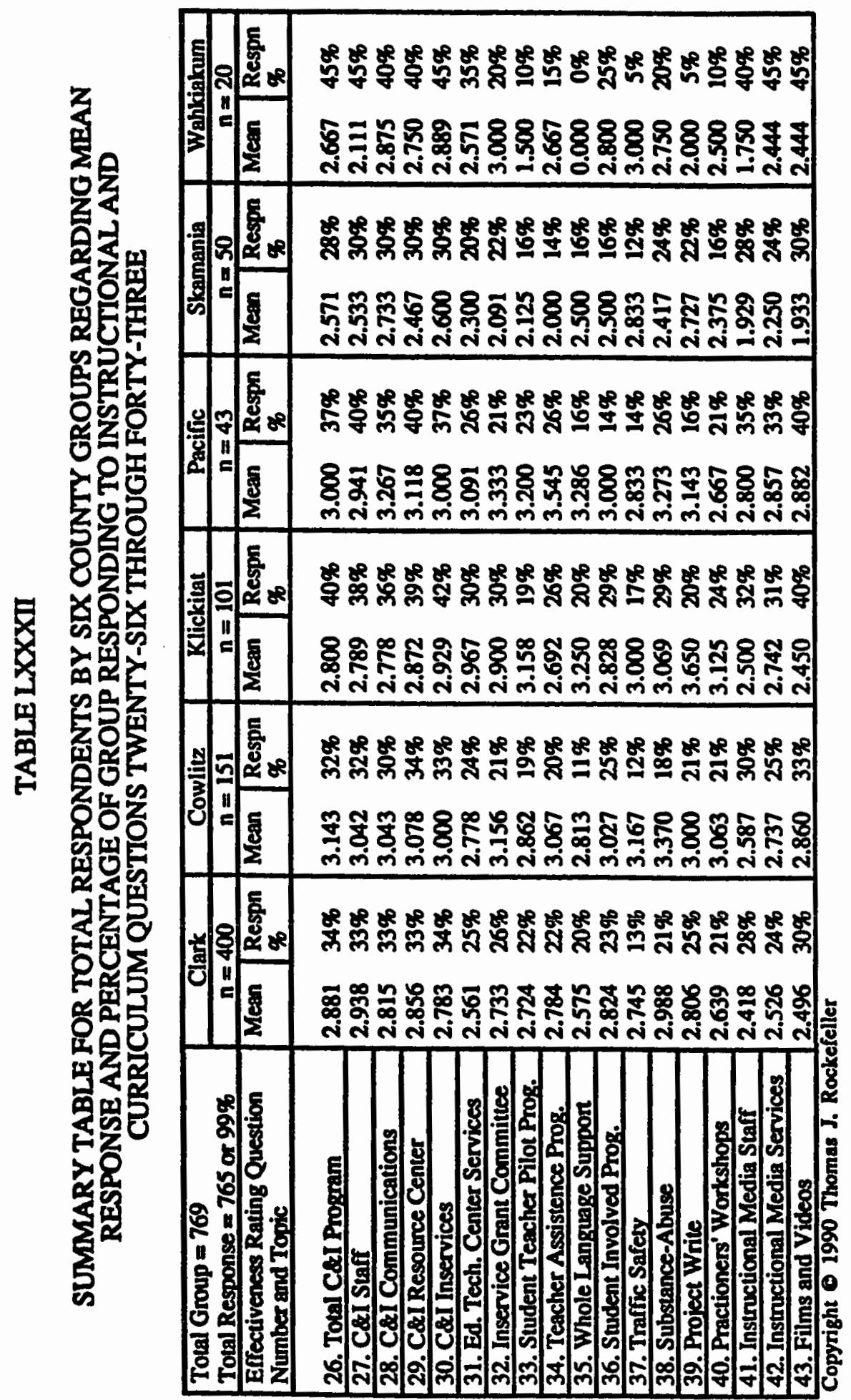




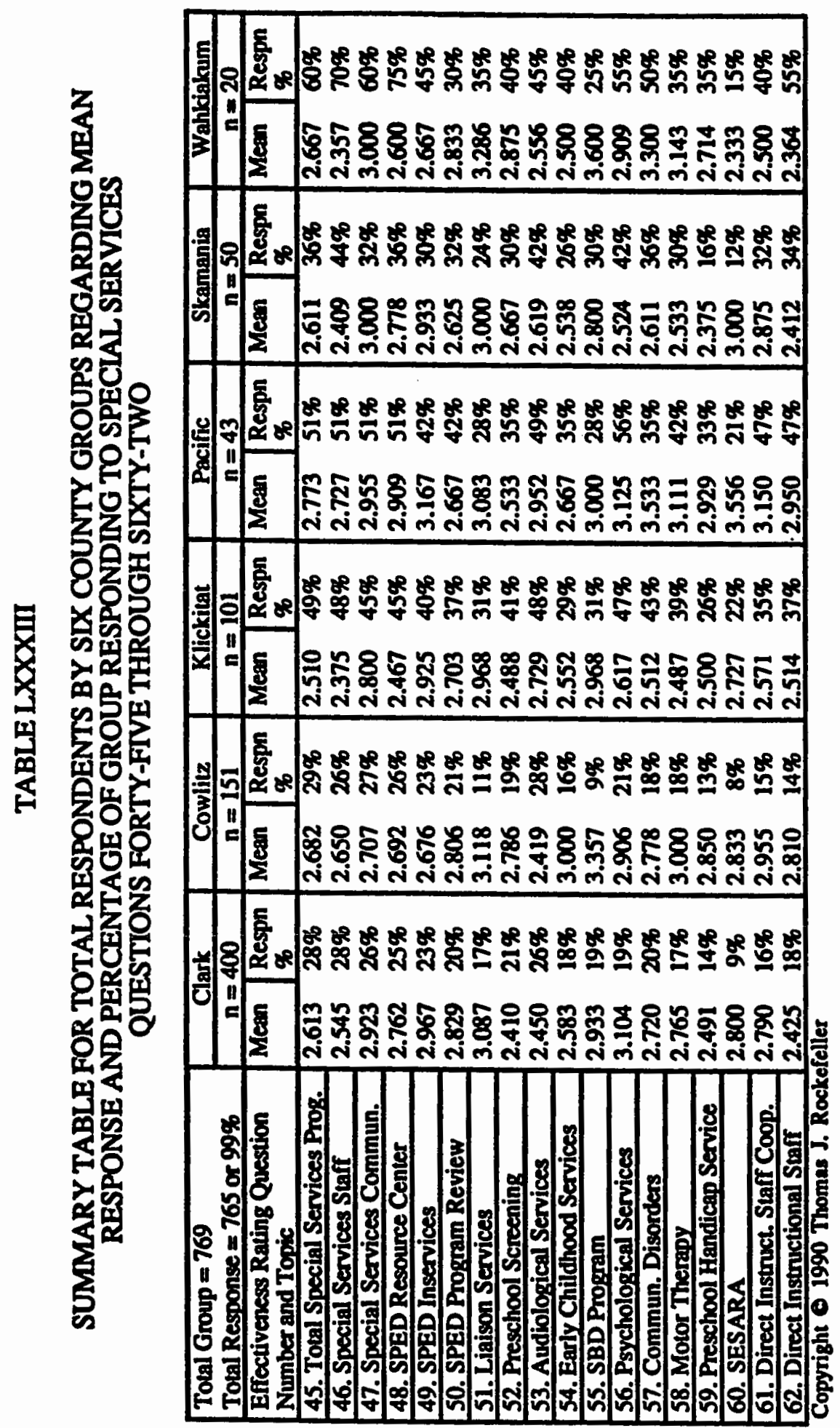




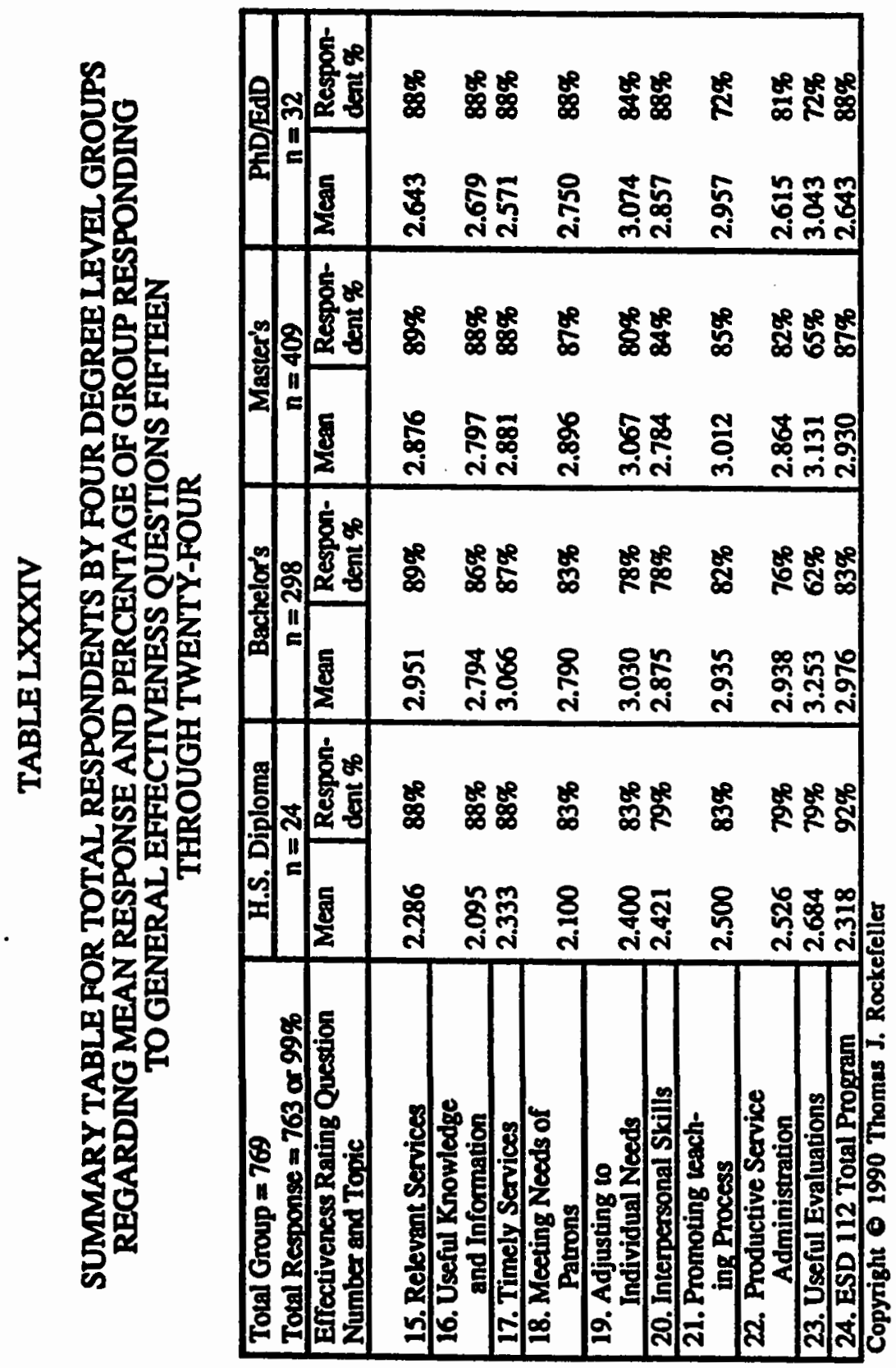




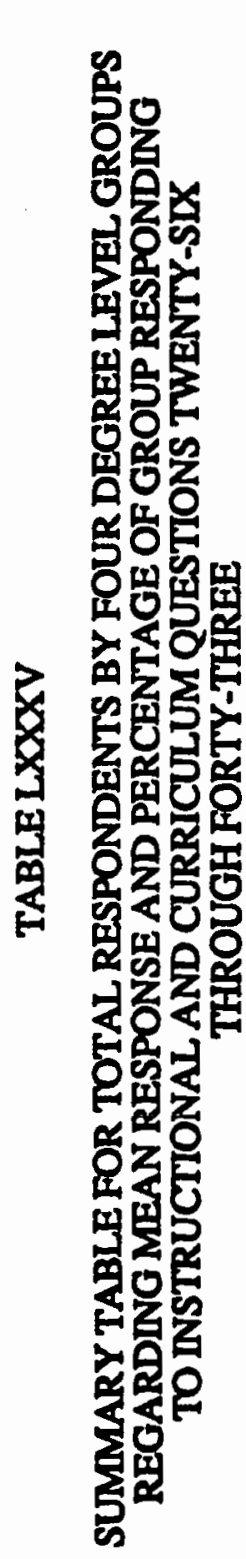

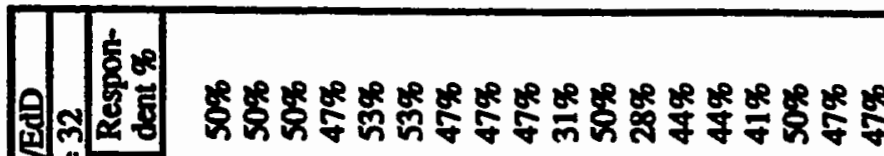

ஊッ⿻

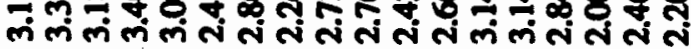

客8

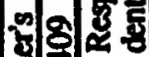

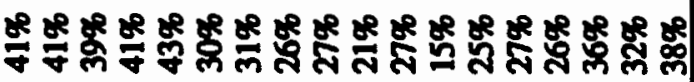

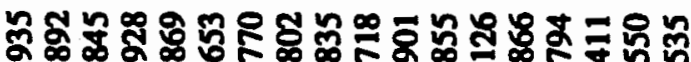

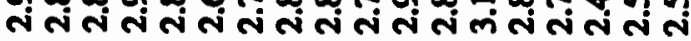

208

워용

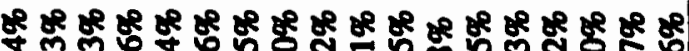

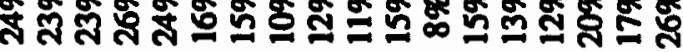

密

ร ง่ง

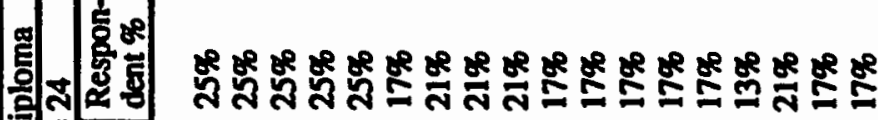

垔

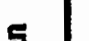

ติ๊

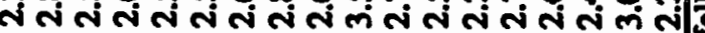

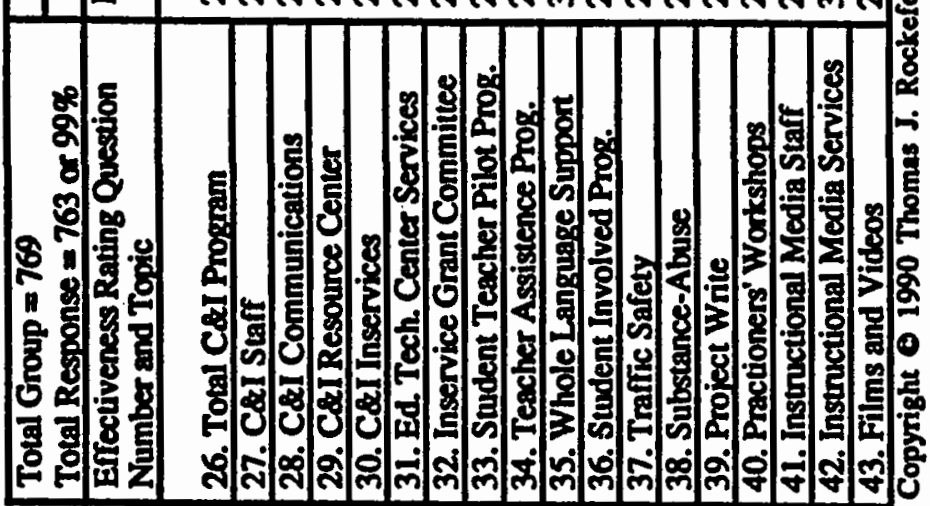




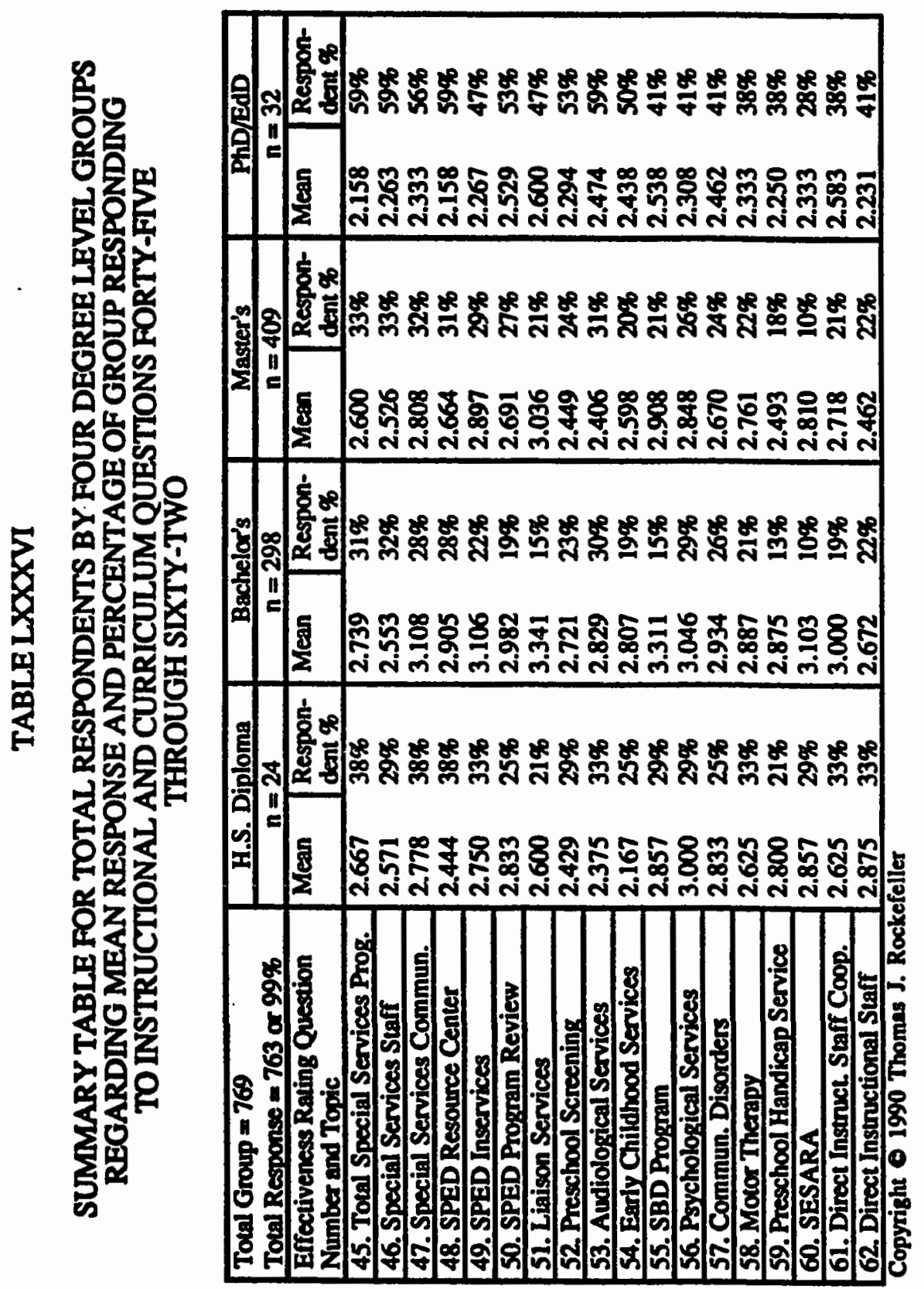


APPENDIX C

INDIVIDUAL PROGRAM AND SERVICE DESCRIPTIONS 
Individual Program and Service Descriptions

Educational Technology Center: Provides services in the area of computers and advanced technology. Training, demonstrations, and information are provided for the purpose of enhancing the knowledge and skills of teachers and administrators.

Inservice Grant Committee; Awards teacher training grants three times annually for the purpose of making advanced training sessions available to teachers who desire to expand current skills.

Student Teacher Pilot program: Provides placements of student teachers in Southwest Washington school districts. Works as liaison with universities and local school districts.

Teacher Assistance program: Assists new teachers through the use of mentors and specifically designed training sessions.

Whole Language Support Group: Coordinates activities and programs relating to language instruction in the classroom.

Student Involved programs: Coordinates student excellence programs and activities on a yearly basis. Programs such as Knowledge Bowl, History Day, and Art Shows.

Traffic Safety Cooperative: Provides certificated traffic safety instructors to participating districts to instruct all required aspects of traffic safety programs.

Substance-Abuse proprams: Coordinates and plans substance-abuse educational programs with area schools and community organizations.

Project Write: Provides student and teacher training components for middle through high school-aged students for a self-developed writing curriculum.

Practioners' Workshops: Coordinates applications and procedures to facilitate district teams' participation in the yearly Practioners' Training Session.

Instructional Media Cooperative: Provides services relating to films, videotapes, and visual media. The service also provides information on purchasing and renting audio-visual materials and equipment.

Special Education Program Review service: Special education programs are monitored for compliance with state and federal regulations.

Special Services Inservice in the area special education: Training in the area of special education is provided based on needs identified through the monitoring process, along with needs identified through individual district requests.

Preschool Screening services: Preschool children, from ages birth to five, are screened (assessed) for developmental problems and referred for further assistance if needed.

Audiological and hearing services: Provides screening, diagnosis, referral, education programming, and general follow-up for hearing impaired children. 
Regional early childhood coordination service: Provides information regarding preschool eligibility and statewide practices. Assists districts in developing preschool programs to serve students.

Seriously Behavior Program: Coordination of services for seriously behaviorally disturbed students between local districts in the ESD. Also serves as a liaison with state and regional seriously behavior committees and services.

School Psychological services: School psychologists work within the districts with special education staff to provide assessment and placement services for students in special education.

Communications Disorders services: Services which are provided to school districts to meet the needs of preschool and school-aged children with communication handicaps.

Motor Therapy services: Provides special education students with physical therapy, occupational therapy, and adaptive P.E. services.

Preschool Handicap services: Provides assessment and programs to developmentally delayed children from the ages of three to five.

Training of Special Education Support Assistants in Rural Areas: Provides training and supervision of paraprofessionals in rural districts to supplement programs in speech and language, vision and hearing, and motor skills.

Special Education Direct Instruction Staff: Special education teachers, instructional aides, and master teachers provide special education programs for specific students. 